\title{
AVALIAÇÃO DE QUALIDADE EM RADIODIAGNÓSTICO: SIMULAÇÃO COMPUTACIONAL PARA INVESTIGAÇÃO DA CAMADA SEMI-REDUTORA
}

MARCELO ANDRADE DA COSTA VIEIRA

Dissertação apresentada à Escola de Engenharia de São Carlos da Universidade de São Paulo, como parte dos requisitos para obtenção do Título de Mestre em Engenharia Elétrica.

ORIENTADOR: Prof. Dr. Homero Schiabel

São Carlos

1999 
Este trabalho teve o apoio financeiro da FAPESP

Fundação de Amparo à Pesquisa do Estado de São Paulo Processo n ${ }^{\circ}$ 97/04177-8 
Aos meus pais,

José Lúcio e Elisa Helena, com minha eterna gratidão. 


\section{AGRADECIMENTOS}

Ao Prof. Dr. Homero Schiabel, pelo apoio, dedicação e grande competência como orientador, indispensável para a idealização desse projeto.

À FAPESP, Fundação de Amparo à Pesquisa do Estado e São Paulo, pelo apoio financeiro e por acreditar na importância da realização desse trabalho.

Ao meu tio, Prof. Dr. Benedito Manoel Vieira, pelas críticas, sugestões e pela disposição em acompanhar de perto todo o desenvolvimento dessa pesquisa.

Ao Prof. Dr. Márcio Alexandre Marques, pelo apoio prestado na parte de simulação computacional e pela disposição e paciência em solucionar minhas inúmeras dúvidas.

Ao colega Henrique de Jesus Quintino, pelas importantes discussões relativas à parte teórica do projeto e por ceder-me os programas de simulação que foram fundamentais para a realização desse trabalho.

Ao Dr. Newton Sá de Miranda Curi, pela ajuda com o dispositivo eletrônico de medição, fundamental para a realização dos testes com os aparelhos radiográficos.

Ao Hospital das Clínicas de Ribeirão Preto e ao Instituto Romeu Santini de Diagnóstico de São Carlos, pela gentileza em ceder-me os aparelhos radiográficos para a realização dos testes de campo.

Ao SAPRA, Serviço de Assessoria e Proteção Radiológica S/C Ltda., pela competência na prestação dos serviços relativos aos testes práticos dessa pesquisa.

Ao Rui Bertho, técnico do Departamento de Engenharia Elétrica, pela competência e precisão na construção dos filtros de compensação para Raios-X.

Aos colegas do Laboratório de Análise e Digitalização de Imagens (LADI) e do Laboratório de Imagens Médicas (ALADIM), pela amizade e companheirismo demonstrados durante todos esses anos de convivência.

Aos meus pais, meu irmão, meus amigos e à toda minha família, pelo apoio, incentivo e compreensão nos inúmeros momentos de ausência.

À Viviane, minha namorada e psicóloga, pelo apoio, estímulo, pelas sugestões relacionadas ao meu trabalho e principalmente pelo amor demonstrado ao longo desses anos, sem o qual nada disso teria sentido.

Finalmente, a Deus, o principal responsável por tudo isso. 


\section{SUMÁRIO}

LISTA DE FIGURAS....................................................................................ii

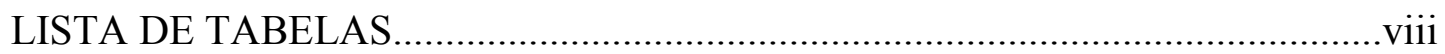

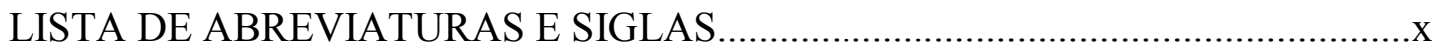

LISTA DE SÍMBOLOS.................................................................................

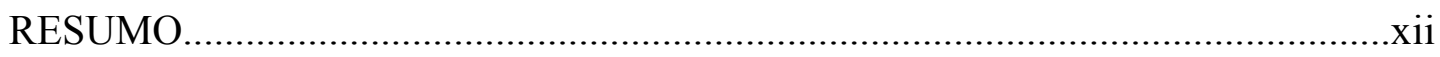

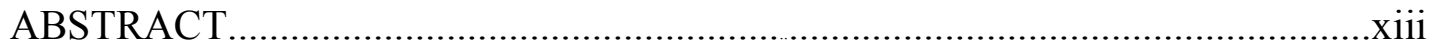

CAPÍTULO 1 - Introdução .............................................................................. 1

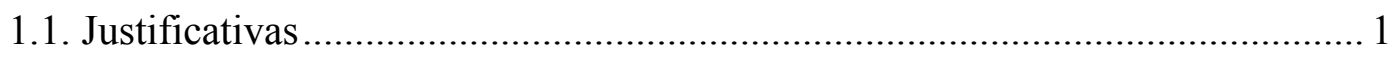

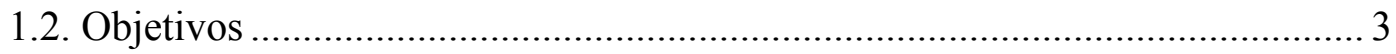

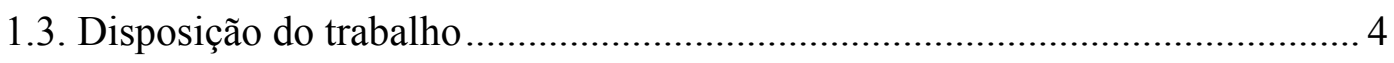

CAPÍTULO 2 - Características Operacionais dos Aparelhos de Raios-X................. 6

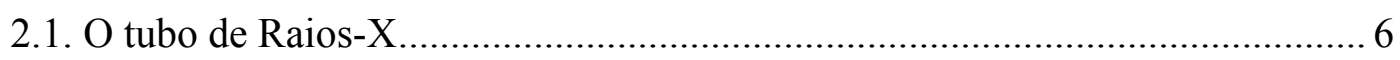

2.2. O ponto focal ........................................................................................... 7

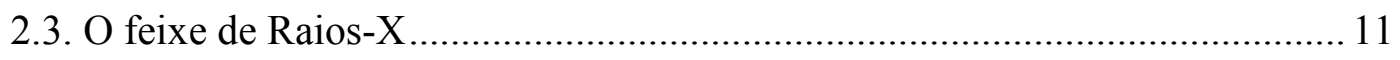

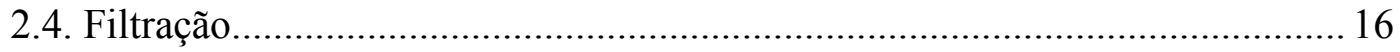

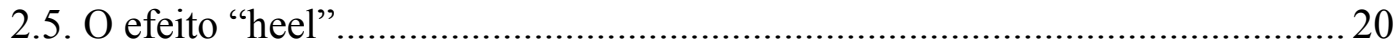

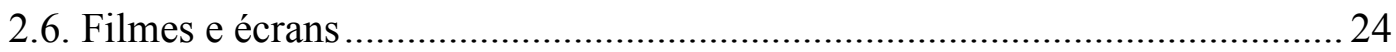

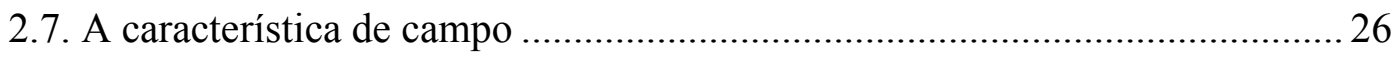

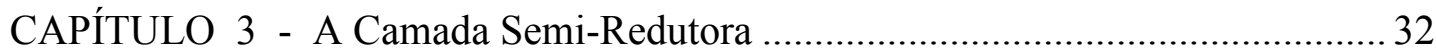

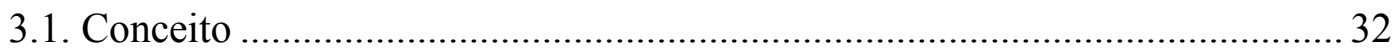

3.2. Métodos experimentais para a determinação da CSR ................................... 35

3.3. Influência da radiação espalhada nas medidas da CSR ................................ 39

3.4. Técnicas para uma medida única da CSR ................................................... 44

3.5. Fontes de erro nas medidas da CSR ................................................................ 46

3.6. A Segunda CSR e o coeficiente de homogeneidade ..................................... 48

3.7. Dispositivo eletrônico para medida experimental da CSR ............................. 51 
CAPÍTULO 4 - Técnicas Radiográficas para imagens de Estruturas Anatômicas

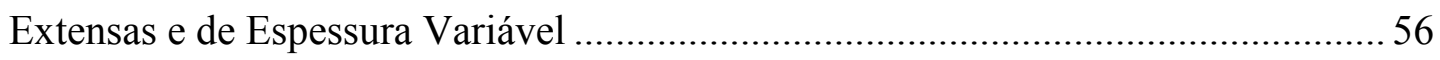

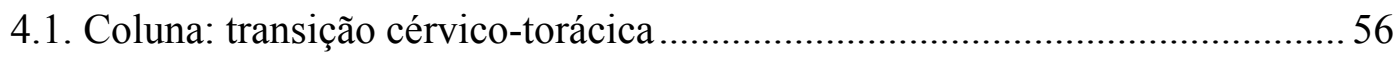

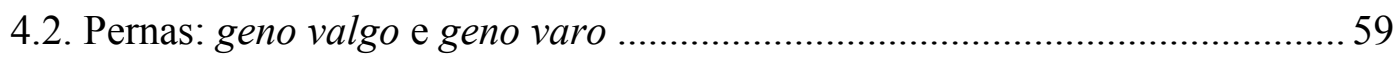

CAPÍTULO 5 - Simulação Computacional para Determinação da Camada

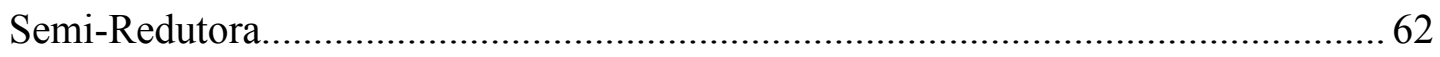

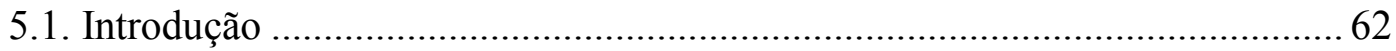

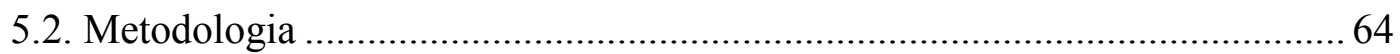

CAPÍTULO 6 - Testes Práticos com Aparelhos Radiográficos Hospitalares......... 72

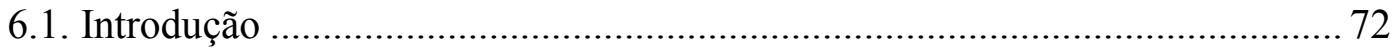

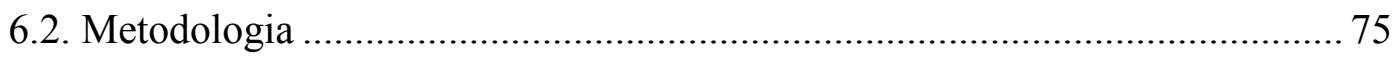

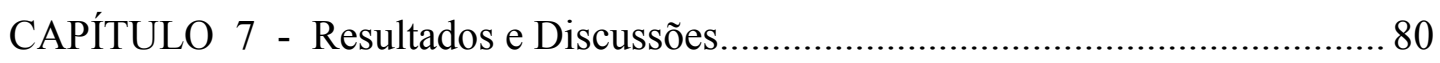

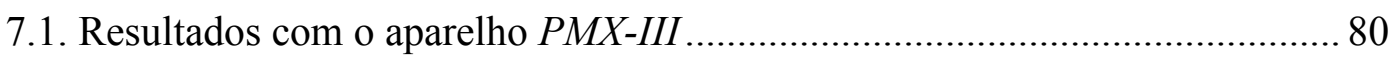

7.2. Resultados com o dispositivo eletrônico de medição ................................... 100

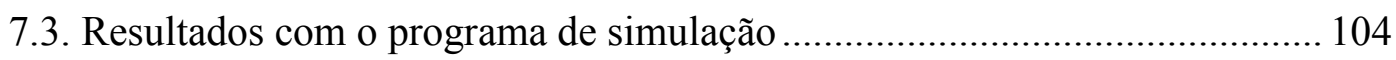

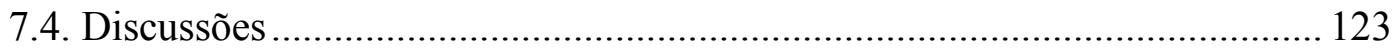

CAPÍTULO 8 - Método Computacional para Elaboração de Filtros de

Compensação para Raios-X ……............................................................................ 127

8.1. Filtros para compensação do efeito "heel" .................................................. 127

8.2. Filtros para radiografia lateral da coluna cervical ...................................... 130

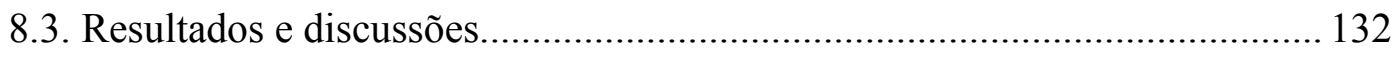

CAPÍTULO 9 - Conclusões ............................................................................. 141

9.1. Simulação computacional da camada semi-redutora ................................. 141

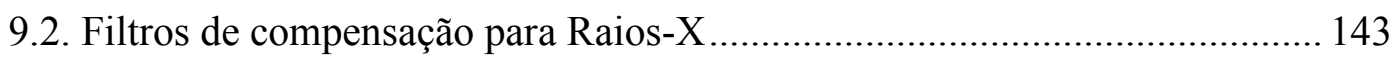

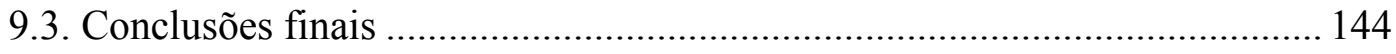

9.4. Sugestões para pesquisas futuras ............................................................. 144

CAPÍTULO 10 - Referências Bibliográficas ...................................................... 145 


\section{LISTA DE FIGURAS}

Figura 2.1. - Um tubo de Raios-X (WILKS_87).

Figura 2.2. - Efeito da inclinação do anodo no tamanho do ponto focal. .................. 9

Figura 2.3. - O anodo rotativo e o tamanho do ponto focal (JOHNS_83)............... 10

Figura 2.4. - Princípio de obtenção da imagem do ponto focal através da câmara de

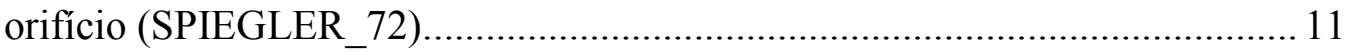

Figura 2.5. - Espectro de Raios-X produzidos por elétrons de 50 e $100 \mathrm{keV}$ (WOLBARST_93). 12

Figura 2.6. - Efeitos da filtração inerente e da radiação característica em um espectro de Raios-X (WOLBARST_93).

Figura 2.7. - Intensidade relativa da radiação em cada intervalo de energia (JOHNS_83).

Figura 2.8. - A lei do inverso do quadrado da distância (WOLBARST_93). 16

Figura 2.9. - Distribuição espectral da radiação gerada por um feixe monoenergético de elétrons de $200 \mathrm{keV}$ bombardeando um alvo de tungstênio (JOHNS_83).... 18

Figura 2.10. - Distribuição da intensidade da radiação através de um feixe de Raios-X (SCAFF_79). 20

Figura 2.11. - Esquema simplificado da ocorrência do efeito "heel"

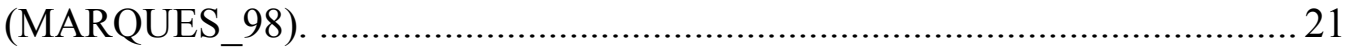

Figura 2.12. - Processo de emissão de fótons pelo anodo......................................... 23

Figura 2.13. - Diagrama ilustrando como a imagem radiológica é formada (JOHNS_83).

Figura 2.14. - Curva sensitométrica ou curva H\&D de um filme radiográfico (SILVA_97). 26

Figura 2.15. - Imagem do ponto focal de um aparelho de Raios-X obtida experimentalmente com o uso de uma matriz de orifício.

Figura 2.16. - Ponto focal no centro do campo e em uma posição arbitrária (MARQUES_96). 28

Figura 2.17. - Cálculo do lado $a^{\prime}$ do ponto focal em uma posição qualquer do eixo $x(d y=0)$ (MARQUES_98). 
Figura 3.1. - Relação entre a CSR e energia equivalente para $\mathrm{Pb}, \mathrm{Cu}$ e $\mathrm{Al}$

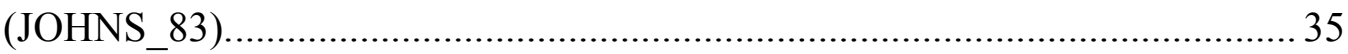

Figura 3.2. - Diagrama do método experimental para determinação da CSR

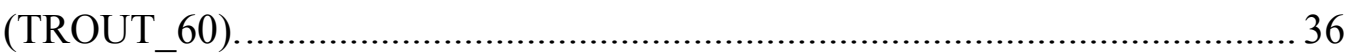

Figura 3.3. - Medida da CSR com feixe divergente (SCAFF_79) .......................... 37

Figura 3.4. - CSR para feixe colimado e para feixe divergente (SCAFF 79)......... 37

Figura 3.5. - Curva de atenuação gerada pela filtração de um feixe de Raios-X

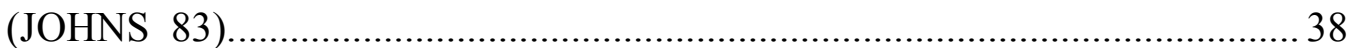

Figura 3.6. - Arranjo dos componentes para medida da CSR (JOHNS_83)............40

Figura 3.7. - Medidas da CSR obtidas para arranjos geométricos diferentes (JOHNS_83)

Figura 3.8. - Variação nas medidas da CSR em função do tamanho do campo (TROUT_60).

Figura 3.9. - Variação nas medidas da CSR em função da variação da distância foco-filtro (TROUT_60).

Figura 3.10. - Variação nas medidas da CSR em função da distância do dosímetro ao tubo (TROUT_60).

Figura 3.11. - Variação nas medidas da CSR em função do tamanho do campo (TROUT_60). 45

Figura 3.12. - Relação entre radiação espalhada e radiação primária em função da $\mathrm{kVp}$ (WOLBARST_93). 46

Figura 3.13. - Método para determinar a $1^{\mathrm{a}} \mathrm{CSR}$ e a $2^{\mathrm{a}}$ CSR (TROUT_62). 49

Figura 3.14. - Variação da $1^{\mathrm{a}} \mathrm{CSR}$ e da $2^{\mathrm{a}} \mathrm{CSR}$ como função da espessura do filtro de cobre (TROUT_62).

Figura 3.15. - Variação da $1^{\mathrm{a}}$ CSR em função da espessura do filtro de alumínio (TROUT_62). 51

Figura 3.16. - Cunha de alumínio e sensores utilizados pelo dispositivo eletrônico de medição (CURI_98). 52

Figura 3.17. - Tela de saída do software registrando o sinal proveniente do sensor durante uma exposição (CURI_98).

Figura 3.18. - Tela de saída do software com a escala de tempo convertida em escala de distância (CURI_98). 
Figura 3.19. - Dispositivo eletrônico posicionado sobre os suportes, abaixo de um tubo mamográfico para calibração. 55

Figura 4.1. - Radiografia lateral da coluna cervical. 58

Figura 4.2. - Técnica para radiografia lateral da coluna cervical (MESCHAN_75). 59

Figura 4.3. - Radiografia das pernas de um paciente com geno varo (GREENSPAN_96). 60

Figura 5.1. - Ilustração da geometria para o cálculo da CSR por simulação. 66

Figura 5.2. - Tela do programa de simulação com resultados referentes a um tubo de Raios-X convencional. .68

Figura 5.3. - Tela do segundo programa de simulação com resultados referentes a um campo de exposição de $20 \mathrm{~cm}$. 70

Figura 6.1. - PMX-III, aparelho utilizado para as medições da dose e da CSR. 73

Figura 6.2. - $R 25$, detector de estado sólido utilizado juntamente com o PMX-III para os testes práticos. 74

Figura 6.3. - Posicionamento do detector ao longo do campo de exposição. 76

Figura 6.4. - Dispositivo eletrônico posicionado no campo durante a realização dos testes no Hospital das Clínicas de Ribeirão Preto. 79

Figura 7.1. - Curva de atenuação obtida através dos dados da Tabela 7.1. 82

Figura 7.2. - Resultados da simulação da $1^{\mathrm{a}}$ CSR para o Teste 1. 105

Figura 7.3. - Resultados da simulação da $2^{\mathrm{a}}$ CSR para o Teste 1. 105

Figura 7.4. - Resultados da simulação do Coeficiente de Homogeneidade para o Teste 1. 106

Figura 7.5. - Resultados da simulação da Dose para o Teste 1............................... 107

Figura 7.6. - Resultados da simulação da CSR para o Teste 2 ................................ 108

Figura 7.7. - Resultados da simulação da Dose para o Teste 2 .............................. 108

Figura 7.8. - Resultados da simulação da CSR para o Teste 3................................ 109

Figura 7.9. - Resultados da simulação da Dose para o Teste 3............................... 110

Figura 7.10. - Resultados da simulação da CSR para o Teste 4.............................. 111

Figura 7.11. - Resultados da simulação da Dose para o Teste 4............................ 111

Figura 7.12. - Resultados da simulação da CSR para o Teste 5............................. 112

Figura 7.13. - Resultados da simulação da Dose para o Teste 5............................ 113 
Figura 7.14. - Resultados da simulação da CSR para o Teste 6.

Figura 7.15. - Resultados da simulação da Dose para o Teste 6.

Figura 7.16. - Resultados da simulação da CSR para o Teste 7.

Figura 7.17. - Resultados da simulação da Dose para o Teste 7.

Figura 7.18. - Resultados da simulação da CSR para o Teste 8.

Figura 7.19. - Resultados da simulação da Dose para o Teste 8.

Figura 7.20. - Resultados da simulação da CSR para o Teste 9.

Figura 7.21. - Resultados da simulação do sinal do sensor para o Teste 9.

Figura 7.22. - Resultados da simulação da CSR para o Teste 10

Figura 7.23. - Resultados da simulação do sinal do sensor para o Teste 10.

Figura 7.24. - Resultados da simulação da CSR para o Teste 11

Figura 7.25. - Resultados da simulação do sinal do sensor para o Teste 11.

Figura 8.1. - Ilustração da geometria para o cálculo do filtro para uniformização do efeito "heel". 128

Figura 8.2. - Tela do programa de simulação de filtros para compensação do efeito "heel".

Figura 8.3. - Ossos da região superior do corpo humano; vista frontal.

Figura 8.4. - Filtro de Lucite construído para uniformizar a intensidade da radiação no campo de exposição. 133

Figura 8.5. - Sinal proveniente do sensor em diversas posições no campo (lado do anodo), sem a utilização do filtro de compensação, mostrando a variação da intensidade do feixe causada pelo efeito "heel".

Figura 8.6. - Sinal proveniente do sensor em diversas posições no campo (lado do catodo), sem a utilização do filtro de compensação, mostrando a variação da intensidade do feixe causada pelo efeito "heel". 135

Figura 8.7. - Sinal proveniente do sensor em diversas posições no campo (lado do anodo) com o filtro de compensação posicionado sob o tubo de Raios-X. 135

Figura 8.8. - Sinal proveniente do sensor em diversas posições no campo (lado do catodo) com o filtro de compensação posicionado sob o tubo de Raios-X. .... 136

Figura 8.9. - Tela do programa de simulação do filtro de compensação para radiografia lateral da coluna cervical. 
Figura 8.10. - Filtro desenvolvido para utilização em radiografia lateral da coluna cervical. 138

Figura 8.11. - Posicionamento do filtro de cobre na janela do colimador do aparelho de Raios-X utilizado nos testes. 138

Figura 8.12. - Radiografia lateral da coluna cervical sem o filtro de compensação $(85 \mathrm{kVp}, 32 \mathrm{mAs})$ 139

Figura 8.13. - Radiografia lateral da coluna cervical com o filtro de compensação posicionado na saída do colimador do tubo de Raios-X (85kVp, 32mAs)..... 140 


\section{LISTA DE TABELAS}

Tabela 7.1. - Resultados Teste 1: centro do campo................................................... 81

Tabela 7.2. - Resultados Teste 1: lado do anodo - $2 \mathrm{~cm}$ do centro. .......................... 82

Tabela 7.3. - Resultados Teste 1: lado do anodo - $6 \mathrm{~cm}$ do centro. ........................... 83

Tabela 7.4. - Resultados Teste 1: lado do anodo - $8 \mathrm{~cm}$ do centro. .......................... 83

Tabela 7.5. - Resultados Teste 1: lado do anodo - $12 \mathrm{~cm}$ do centro. ......................... 84

Tabela 7.6. - Resultados Finais do Teste 1.................................................................. 84

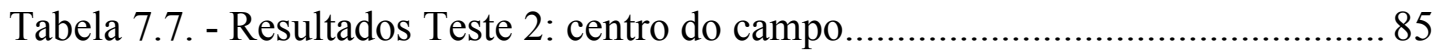

Tabela 7.8. - Resultados Teste 2: lado do anodo - $2 \mathrm{~cm}$ do centro. ......................... 85

Tabela 7.9. - Resultados Teste 2: lado do anodo - $6 \mathrm{~cm}$ do centro. ........................... 86

Tabela 7.10. - Resultados Teste 2: lado do anodo - $8 \mathrm{~cm}$ do centro. ......................... 86

Tabela 7.11. - Resultados Teste 2: lado do anodo - $12 \mathrm{~cm}$ do centro. ....................... 86

Tabela 7.12. - Resultados Finais do Teste 2 .......................................................... 87

Tabela 7.13. - Resultados Teste 3: centro do campo................................................. 87

Tabela 7.14. - Resultados Teste 3: lado do anodo - $6 \mathrm{~cm}$ do centro. ........................ 88

Tabela 7.15. - Resultados Teste 3: lado do anodo - $12 \mathrm{~cm}$ do centro. .......................8 88

Tabela 7.16. - Resultados Finais do Teste 3 ............................................................. 88

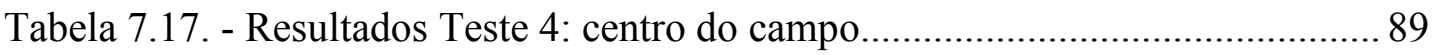

Tabela 7.18. - Resultados Teste 4: lado do catodo - $6 \mathrm{~cm}$ do centro. ........................89

Tabela 7.19. - Resultados Teste 4: lado do catodo - $10 \mathrm{~cm}$ do centro. ..................... 90

Tabela 7.20. - Resultados Teste 4: lado do catodo - $16 \mathrm{~cm}$ do centro. ..................... 90

Tabela 7.21. - Resultados Teste 4: lado do anodo - $10 \mathrm{~cm}$ do centro. ...................... 90

Tabela 7.22. - Resultados Teste 4: lado do anodo - $16 \mathrm{~cm}$ do centro. ..................... 91

Tabela 7.23. - Resultados Finais do Teste 4 ............................................................... 91

Tabela 7.24. - Resultados Teste 5: centro do campo............................................... 92

Tabela 7.25. - Resultados Teste 5: lado do catodo - $10 \mathrm{~cm}$ do centro. ...................... 92

Tabela 7.26. - Resultados Teste 5: lado do anodo - 14cm do centro. ......................93

Tabela 7.27. - Resultados Finais do Teste 5............................................................ 93

Tabela 7.28. - Resultados Teste 6: centro do campo.................................................. 94

Tabela 7.29. - Resultados Teste 6: lado do catodo - $10 \mathrm{~cm}$ do centro. ....................... 94 
Tabela 7.30. - Resultados Teste 6: lado do anodo - $14 \mathrm{~cm}$ do centro. ...................... 95

Tabela 7.31. - Resultados Finais do Teste 6............................................................ 95

Tabela 7.32. - Resultados Teste 7: centro do campo..................................................96

Tabela 7.33. - Resultados Teste 7: lado do anodo - $6 \mathrm{~cm}$ do centro. ......................... 96

Tabela 7.34. - Resultados Teste 7: lado do anodo - $10 \mathrm{~cm}$ do centro. .......................97

Tabela 7.35. - Resultados Teste 7: lado do catodo - 10cm do centro. ...................... 97

Tabela 7.36. - Resultados Finais do Teste 7............................................................. 97

Tabela 7.37. - Resultados Teste 8: centro do campo.................................................. 98

Tabela 7.38. - Resultados Teste 8: lado do anodo - 4cm do centro. ........................ 98

Tabela 7.39. - Resultados Teste 8: lado do anodo - $10 \mathrm{~cm}$ do centro. ....................... 99

Tabela 7.40. - Resultados Teste 8: lado do catodo - $10 \mathrm{~cm}$ do centro. ...................... 99

Tabela 7.41. - Resultados Finais do Teste 8............................................................. 99

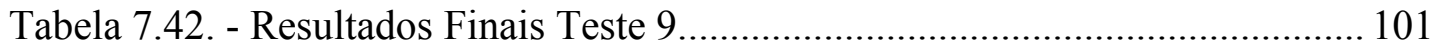

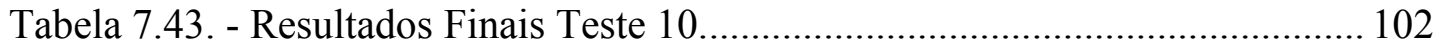

Tabela 7.44. - Resultados Finais Teste 11............................................................... 103

Tabela 7.45. - Resultados da simulação para o Teste 1 - Parte 1............................. 104

Tabela 7.46. - Resultados da simulação para o Teste 1 - Parte 2 . ............................ 106

Tabela 7.47. - Resultados da simulação para o Teste 2........................................... 107

Tabela 7.48. - Resultados da simulação para o Teste 3........................................... 109

Tabela 7.49. - Resultados da simulação para o Teste 4. ............................................ 110

Tabela 7.50. - Resultados da simulação para o Teste 5........................................... 112

Tabela 7.51. - Resultados da simulação para o Teste 6............................................. 113

Tabela 7.52. - Resultados da simulação para o Teste 7. ............................................. 115

Tabela 7.53. - Resultados da simulação para o Teste 8........................................... 116

Tabela 7.54. - Resultados da simulação para o Teste 9............................................ 118

Tabela 7.55. - Resultados da simulação para o Teste 10 .......................................... 119

Tabela 7.56. - Resultados da simulação para o Teste 11.......................................... 121

Tabela 7.57. - Desvio médio (\%) entre os valores experimentais e os valores obtidos por simulação para os testes 1 a 8 . 122

Tabela 7.58. - Desvio médio (\%) entre os valores experimentais e os valores obtidos por simulação para os testes 9 a 11 . 


\title{
LISTA DE ABREVIATURAS E SIGLAS
}

\author{
$1^{\text {a }}$ CSR - Primeira Camada Semi-Redutora \\ $2^{\text {a }}$ CSR - Segunda Camada Semi-Redutora \\ CD - Constant Depth of Production \\ CSDA - Continuous Slowing-Down Approximation \\ CSR - Camada Semi-Redutora \\ EESC / USP - Escola de Engenharia de São Carlos da Universidade de São Paulo \\ FEP - Função de Espalhamento de Ponto \\ LADI - Laboratório de Análise e Digitalização de Imagens \\ SAPRA - Serviço de Assessoria e Proteção Radiológica S/C Ltda.
}




\section{LISTA DE SÍMBOLOS}

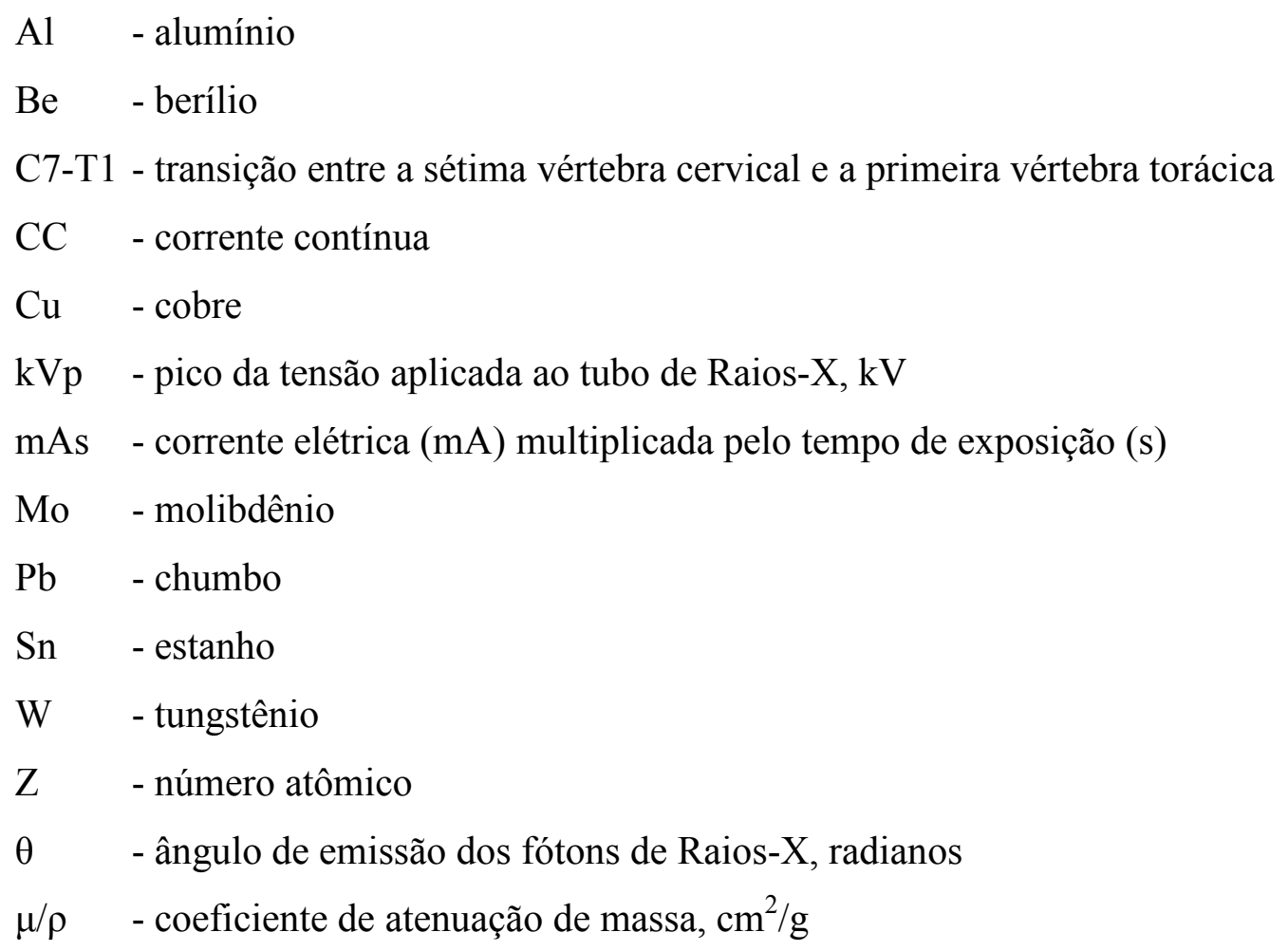




\section{RESUMO}

A camada semi-redutora (CSR), definida como a espessura de um material absorvedor que colocado sob um feixe de Raios-X reduz sua intensidade à metade, é um parâmetro que deve ser avaliado periodicamente nos programas de garantia de qualidade em radiologia médica, pois fornece informações a respeito do desempenho do feixe radiográfico produzido pelo aparelho. Todavia, sua medida é normalmente feita na região central do campo de exposição e não considera a variação da qualidade relativa do feixe ao longo de toda a sua extensão, causada essencialmente pelo efeito "heel".

Em vista disso, o presente trabalho propõe um algoritmo de simulação computacional para determinar a CSR de aparelhos radiográficos em qualquer posição no campo através de uma única medida na região central, para permitir uma avaliação mais completa da variação da qualidade do feixe em função do posicionamento do objeto no plano imagem. Além disso, a partir dos resultados obtidos, também é proposto um procedimento computacional capaz de determinar filtros de características específicas para compensar essas variações na qualidade da imagem causadas pelo efeito "heel" e também por variações na espessura do objeto radiografado.

Os resultados obtidos com os programas de simulação desenvolvidos mostraram-se coerentes com os obtidos em testes práticos realizados com aparelhos radiográficos hospitalares, comprovando a validade dos algoritmos propostos. 


\begin{abstract}
The half-value layer (HVL) is defined as the thickness of an absorbing material which placed under an X-Ray beam reduces its intensity to half. It is a parameter that should be periodically evaluated in medical radiology quality control programs because it gives information related to the radiographic system beam performance. However, its measurement is done normally at the center of the radiation field, not taking into account the beam relative quality variation along the field, caused essentially by the "heel" effect.

Bearing that in mind, the present work proposes a computer simulation algorithm to determine the radiographic systems HVL at any location on the field based on a single measurement at the central area, to allow a more complete evaluation of the beam quality variation due to the object location on the image plane. Furthermore, from these results, another computer simulation procedure is proposed to determine particular filter characteristics to compensate these image quality variations caused by the "heel" effect and also by the X-rayed object thickness variation.

The results obtained from the simulation programs are consistent with the experimental results performed in medical radiographic systems, confirming therefore the validity of the proposed algorithms.
\end{abstract}




\section{CAPÍTULO 1}

\section{Introdução}

\subsection{Justificativas}

A importância do controle de qualidade em sistemas de imagem radiológica tem sido muito reconhecida devido à necessidade de se garantir a confiabilidade do exame executado, produzindo uma imagem que apresente as características necessárias para o correto diagnóstico médico. Existem diversos métodos para efetuar essa avaliação, largamente destacados pela literatura especializada; entre eles, destaca-se o método das funções de transferência (ROSSMANN_69, RAO_69, METZ_79, SCHIABEL_93), os métodos que se utilizam de "phantoms" (MUNTZ_78, KARILA_88, CALDWELL_90) e, mais recentemente, os métodos baseados em mapas de nitidez (MARQUES_96, OLIVEIRA_96) e em simulação computacional (OLIVEIRA_95, MARQUES_98, SCHIABEL_98).

A principal finalidade da utilização de alguma forma ou técnica de controle de qualidade em radiodiagnóstico é a obtenção de imagens de alta qualidade, suficientes para um diagnóstico médico confiável, submetendo o paciente à menor quantidade de radiação possível. Nesse sentido, alguns procedimentos de controle de qualidade contribuem em maior ou menor grau para que esses objetivos sejam atingidos, dependendo da forma e freqüência com que são utilizados. 
Os procedimentos baseados em simulação computacional utilizam-se das equações características do processo de exposição radiográfica para produzir, antecipadamente, a característica da imagem que o sistema poderá apresentar. Oliveira (OLIVEIRA_95) desenvolveu um algoritmo de simulação computacional capaz de prever a variação da nitidez da imagem radiográfica em função da localização do objeto no campo de radiação, considerando a característica de campo (BURGESS_77, DOI_77). Silva (SILVA_97) apresentou um procedimento para simulação da influência de diversos tipos de filmes radiográficos e telas intensificadoras na qualidade da imagem. Marques (MARQUES_98), também por simulação computacional, desenvolveu métodos de avaliação de diversos parâmetros importantes para sistemas radiológicos, como tamanho e distribuição de intensidade do ponto focal, efeito Compton e efeito "heel". A utilização desses métodos permite avaliar os mais diferentes parâmetros operacionais de aparelhos radiográficos de forma rápida e completa, apresentando, antecipadamente, ao usuário ou ao radiologista, as características da imagem que o sistema poderá apresentar.

A intensidade da radiação produzida por um aparelho de Raios-X não é uniforme ao longo do campo devido à filtração que os fótons sofrem pelo próprio material do alvo quando são emitidos. Assim, dependendo da direção em que o fóton é emitido, sofre mais ou menos absorção, o que provoca uma variação na intensidade do feixe de aproximadamente $30 \%$ de uma extremidade à outra do campo, no eixo catodo-anodo (WOLBARST_93). Esse fenômeno é conhecido como efeito "heel".

Existem técnicas radiográficas em que torna-se necessário o uso de filmes grandes em razão da necessidade de se irradiar uma região extensa do paciente. Um exemplo disso é a investigação diagnóstica de deformidades de angulação de joelhos, em que uma visualização das articulações do joelho, do quadril e dos tornozelos numa única imagem é requerida pelo radiologista. Todavia, em razão do efeito "heel", a intensidade da radiação que irradia o paciente não é uniforme ao longo do campo. Além disso, há uma diferença de espessura entre a região do quadril e a dos tornozelos, o que pode provocar variações significativas no contraste da imagem radiográfica.

Outro exemplo é o da investigação de problemas na região da coluna vertebral correspondente à junção entre ombros e pescoço (transição cérvico- 
torácica), onde o diagnóstico médico é dificultado pela má qualidade da imagem radiográfica produzida nas imagens de perfil, pois ocorre uma diferença brusca na absorção dos fótons devido à diferença de espessura entre a cabeça e o ombro do paciente. Como o nível de intensidade do feixe numa determinada posição é único e definido pela $\mathrm{kVp}$, corrente e tempo de exposição no tubo, o contraste da imagem fica seriamente prejudicado.

\subsection{Objetivos}

Um parâmetro muito utilizado em controle de qualidade para avaliação de um feixe de Raios-X é a camada semi-redutora (CSR), definida como a espessura de um material absorvedor necessária para reduzir a intensidade de um feixe de Raios-X à metade de seu valor original; quanto mais energética ou penetrante for a radiação contida nesse feixe, maior será a espessura necessária para que um absorvedor reduza sua intensidade à metade. $\mathrm{O}$ método normalmente utilizado para a determinação experimental da CSR é o proposto por Trout, Kelley \& Lucas (TROUT_60), que estabelece a medição no centro do campo para um feixe bem colimado, o que não leva em conta as variações da qualidade desse feixe ao longo de toda a extensão do campo, causadas essencialmente pelo efeito "heel".

Embora seja importante definir a posição no campo para a medida da CSR, a maioria dos trabalhos a respeito não menciona esse aspecto. Além disso, uma única medida numa posição definida não leva em consideração a qualidade relativa do feixe em outras posições ao longo do campo. Por isso, a medida de qualidade pela CSR deveria ser feita em toda a extensão do campo e não apenas no centro.

Como a execução extensiva dessas medições não é simples, em decorrência de questões práticas, a finalidade deste trabalho é apresentar um método computacional que permita obter, por simulação, a CSR para qualquer posição do campo a partir de uma única medida efetuada no centro. Além disso, através do estudo do seu efeito prático, estabelecer as características de filtros específicos para compensar o efeito causado na qualidade da imagem radiográfica devido às variações 
na intensidade do feixe em função do efeito "heel" e da espessura da estrutura irradiada.

\subsection{Disposição do trabalho}

O trabalho aqui descrito está dividido em 10 capítulos, incluindo essa introdução. Os capítulos 2 a 4 apresentam uma revisão bibliográfica sobre o assunto, e os capítulos seguintes descrevem os algoritmos de simulação desenvolvidos e os resultados obtidos. Os assuntos são abordados da seguinte forma:

- Capítulo 2. Descrição das principais características operacionais dos aparelhos de Raios-X e de como elas influenciam nos processos de formação de imagens.

- Capítulo 3. Apresentação de forma detalhada dos conceitos relativos à camada semi-redutora (CSR), além dos métodos experimentais utilizados para sua determinação.

- Capítulo 4. Descrição das técnicas radiográficas utilizadas para a determinação de imagens de algumas estruturas anatômicas extensas e de espessura variável, além da discussão dos problemas relacionados à qualidade dessas imagens.

- Capítulo 5. Descrição da metodologia utilizada para o desenvolvimento do algoritmo de simulação para a determinação da CSR em diversas posições ao longo do campo.

- Capítulo 6. Apresentação dos procedimentos utilizados para os testes práticos realizados em hospital e em clínica radiológica. 
- Capítulo 7. Comparação dos resultados obtidos por simulação com os dados obtidos na prática, discutindo a validade do sistema desenvolvido.

- Capítulo 8. Descrição do procedimento utilizado no desenvolvimento do algoritmo de simulação dos filtros para compensação do efeito "heel" e das variações na espessura da estrutura radiografada, mostrando os resultados obtidos.

- Capítulo 9. Apresentação das conclusões desse trabalho e algumas sugestões para pesquisas futuras.

- Capítulo 10. Referências Bibliográficas. 


\title{
CAPÍTULO 2 \\ Características Operacionais dos Aparelhos de Raios-X
}

\begin{abstract}
Nesse capítulo são apresentadas as principais características operacionais dos aparelhos de Raios-X médicos, além dos conceitos básicos envolvendo os processos de formação de imagens radiográficas.
\end{abstract}

\subsection{O tubo de Raios-X}

Um tubo gerador de Raios-X é formado basicamente por dois eletrodos, o anodo e o catodo, colocados em uma ampola de vidro e submetidos à vácuo. Entre esses eletrodos é aplicada uma tensão da ordem de milhares de volts, que faz com que elétrons do catodo sejam acelerados para o anodo, gerando um feixe eletrônico. Esses elétrons são subitamente desacelerados ao colidirem com a extremidade do anodo, chamada de alvo, revestida por um metal pesado, geralmente tungstênio ou molibdênio. A energia cinética dos elétrons é então transferida ao alvo e convertida em outras formas de energia, como calor e Raios-X. Segundo Johns \& Cunningham (JOHNS_83), em um aparelho operando na faixa de energia para diagnóstico, a maior parte da energia cinética dos elétrons, na colisão com o alvo, é dissipada na forma de calor, enquanto somente $1 \%$ de toda essa energia é convertida em Raios-X. Por isso, o anodo é constituído geralmente de cobre, para que o calor 
produzido pelo bombardeamento dos elétrons seja rapidamente dissipado. CurryIII et al. (CURRYIII_90) destacam as razões da utilização do tungstênio como material do alvo: número atômico bastante alto $(Z=74)$, o que o torna mais eficiente na produção de Raios-X; alto ponto de fusão $\left(3387^{\circ} \mathrm{C}\right)$, o que o torna capaz de suportar o calor produzido pelo bombardeamento de elétrons; e excelente condutor, o que faz com que o calor produzido no alvo seja rapidamente dissipado para o anodo.

Como os Raios-X são emitidos em todas as direções, o tubo possui um revestimento de chumbo com apenas uma pequena abertura, o que faz com que a radiação produzida seja direcionada para uma região de interesse. A Figura 2.1 abaixo ilustra um esquema simplificado de um tubo de Raios-X.

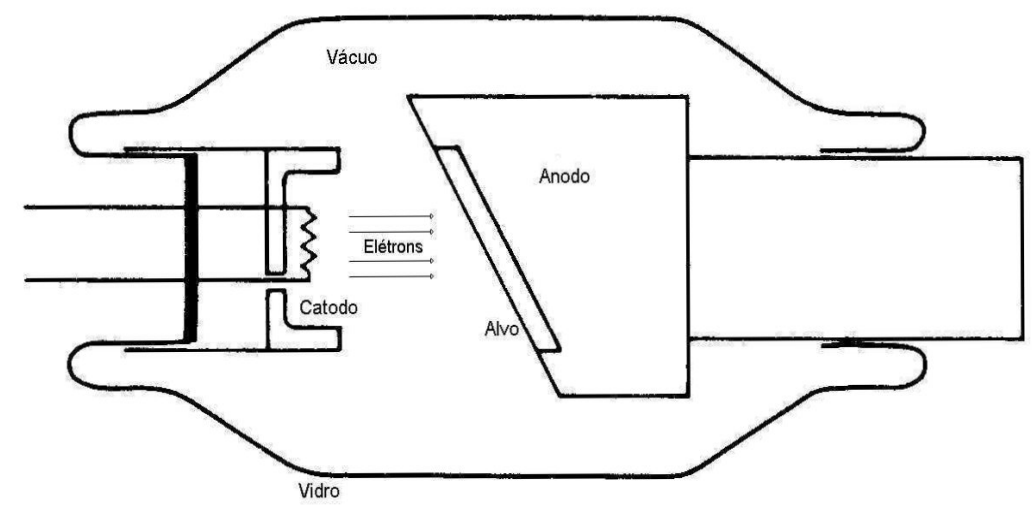

Figura 2.1. - Um tubo de Raios-X (WILKS_87).

\subsection{O ponto focal}

O ponto focal de um aparelho de Raios-X corresponde à área do alvo que é efetivamente bombardeada pelo feixe eletrônico proveniente do catodo. É nessa região que os Raios-X são produzidos e é também nessa região que o anodo é submetido a um calor elevado, sendo este um fator determinante no que diz respeito à vida útil de um tubo de Raios-X. Aparentemente, a melhor solução para esse problema seria aumentar a área de incidência dos elétrons no alvo, ou seja, aumentar ao máximo o tamanho do ponto focal. Com tal procedimento, o calor seria melhor dissipado pelo anodo e a vida útil do tubo aumentaria consideravelmente. No entanto, como o tamanho do ponto focal está diretamente ligado à nitidez da imagem 
produzida, quanto maior o seu tamanho, menor será a resolução do sistema radiográfico e pior será a qualidade da imagem.

A radiografia nada mais é do que a projeção de uma parte do corpo de um paciente em um filme radiográfico; em outras palavras, é a "sombra" de um determinado objeto criada a partir dos Raios-X. Para que a imagem projetada seja capaz de reproduzir com perfeição o objeto em questão, a fonte de radiação, ou foco, deve ser pontual. Um foco não pontual faz com que a imagem apresente uma penumbra, o que prejudica a sua nitidez.

À medida que se aumenta o tamanho do foco, aumenta-se também o tamanho da penumbra formada pelo objeto, piorando a nitidez da imagem. Quando o tamanho do ponto focal for maior do que o próprio objeto, a imagem formada não terá nitidez alguma, já que a penumbra formada neste caso será maior do que a própria imagem. Todavia, se o tamanho do objeto for muito maior do que o tamanho do foco (mais que dez vezes), a distorção apresentada na imagem será desprezível (OLIVEIRA_95). Portanto, a resolução de um aparelho radiográfico pode ser determinada através do tamanho do ponto focal que ele apresenta.

A nitidez da imagem formada por um sistema radiográfico será melhorada quanto menor for o tamanho do seu ponto focal em relação ao tamanho do objeto. Por isso os aparelhos mais modernos de Raios-X, utilizados para o radiodiagnóstico, apresentam duas particularidades que visam minimizar os efeitos do calor gerado no anodo, sem comprometer a qualidade da imagem produzida. A primeira delas é a inclinação do anodo em relação ao eixo de incidência do feixe eletrônico e a outra é a utilização de um anodo rotativo.

Com uma pequena inclinação do anodo torna-se possível que a área do alvo bombardeada pelos elétrons seja maior do que a sua projeção no filme radiográfico, ou seja, o ponto focal aparente, ou efetivo, responsável pela resolução da imagem apresentada pelo sistema torna-se menor do que o ponto focal real, correspondente à área bombardeada pelos elétrons no alvo do anodo. A construção do anodo inclinado segue o princípio do foco-linha (JOHNS_83, WILKS_87, CURRYIII_90, WOLBARST_93) e é ilustrado pela Figura 2.2. 


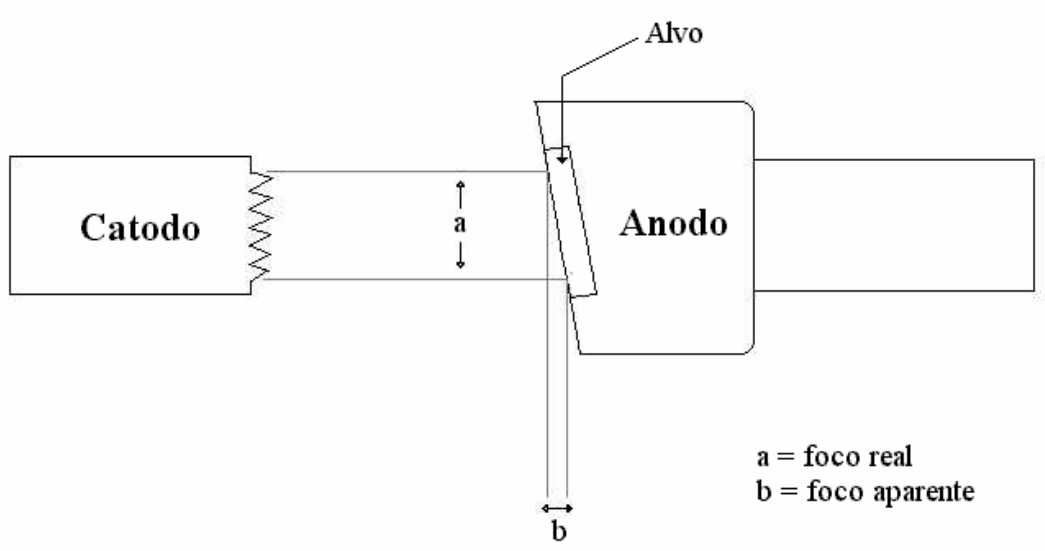

Figura 2.2. - Efeito da inclinação do anodo no tamanho do ponto focal.

O tamanho aparente do ponto focal é função do tamanho do foco e do ângulo de inclinação do anodo (JOHNS_83) e pode ser descrito pela seguinte equação:

$$
b=a \cdot \operatorname{sen} \theta
$$

onde $a$ corresponde ao tamanho real do foco, $b$ ao seu tamanho aparente e $\theta$ ao ângulo de inclinação do anodo.

Assim, quanto menor o ângulo de inclinação do anodo, menor será o tamanho aparente do ponto focal; o ângulo de inclinação utilizado varia de acordo com a aplicação pretendida. No entanto, segundo Fritz \& Livingston (FRITZ_85), não são utilizados ângulos menores do que $12^{\circ}$ para aparelhos de Raios-X de diagnóstico, pois isto limitaria demasiadamente o tamanho do campo, além de aumentar a influência do efeito "heel" no que diz respeito à distribuição de intensidade do feixe ao longo do campo, tornando-a muito heterogênea.

Nos aparelhos de Raios-X disponíveis comercialmente, o valor nominal do ponto focal fornecido pelo fabricante é seu tamanho aparente. Kemp \& Nichols (KEMP_58) ressaltam, todavia, a importância de uma avaliação periódica do tamanho do ponto focal de um sistema que se encontra em uso devido à degradação do tubo em função do tempo e, conseqüentemente, uma variação no valor nominal do tamanho do ponto focal fornecido pelo fabricante. Para isto, existem diversos 
métodos que são capazes de determinar, com certa precisão, o valor real do ponto focal, como a câmara de orifício, a câmara de fenda e o método das funções de transferência (SPIEGLER_72, KRATZAT_88, RAO_69).

Os anodos rotativos utilizados nos aparelhos de Raios-X modernos têm a finalidade de aumentar a área do alvo bombardeada pelos elétrons, possibilitando maior dissipação de calor. Rotacionando-se o anodo, o ponto focal real passa a ser um anel, como mostra a Figura 2.3, com área maior do que nos anodos fixos, promovendo uma melhora na dissipação de calor, sem com isso alterar o tamanho aparente do ponto focal e, conseqüentemente, a resolução do sistema.
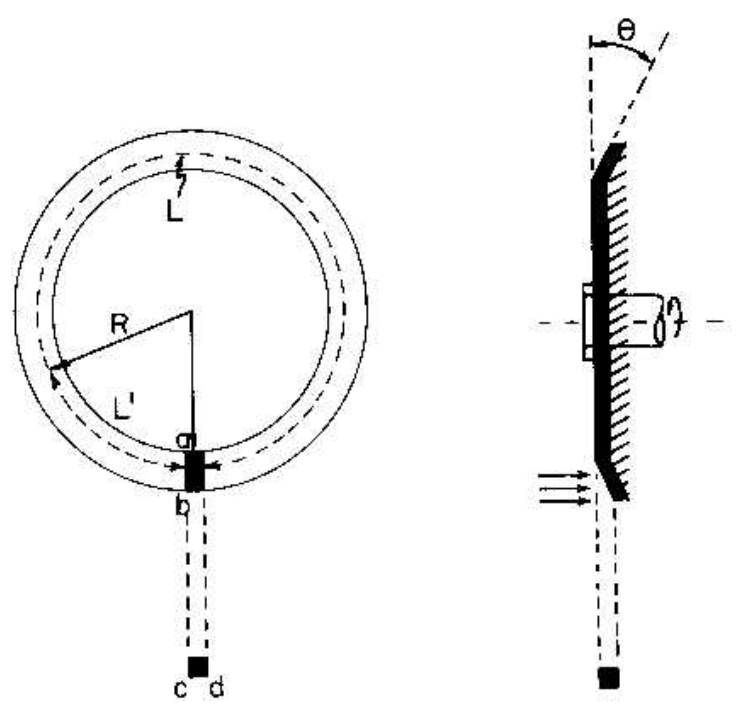

Figura 2.3. - O anodo rotativo e o tamanho do ponto focal (JOHNS_83).

A utilização do método da câmara de orifício em radiologia, segundo Kuntke (KUNTKE_57), é tão antiga como a própria radiologia. Assim, se um furo fino com diâmetro $d$ (sendo $d$ uma fração da dimensão linear do ponto focal) é colocado a uma distância $d_{1}$ da fonte e $d_{2}$ do filme, a imagem do ponto focal será aumentada pela razão $m=d_{1} / d_{2}$, como ilustra a Figura 2.4. Como essa câmara de orifício não é ideal, a imagem do ponto focal impressa no filme será acrescida de um borramento nas bordas, o que faz com que a imagem medida no filme seja maior do que o ponto focal real do aparelho. Assim, segundo Kuntke, pode-se obter o tamanho real do ponto focal através da equação (2.2): 


$$
F=(S / m)-(m+1) \cdot d / m
$$

onde $S$ é o tamanho da imagem medida no filme.

Na prática, para a medição do tamanho do ponto focal deve-se tomar cuidado em relação à posição em que a câmara de orifício é colocada no campo. Devido ao fenômeno da característica de campo (que será abordado no item 2.7), o tamanho efetivo do ponto focal pode variar em até 300\% dependendo da posição na qual ele é medido (OLIVEIRA_95). Por isso, a não observação deste fenômeno temse mostrado como uma das principais fontes de erro nessas medições.

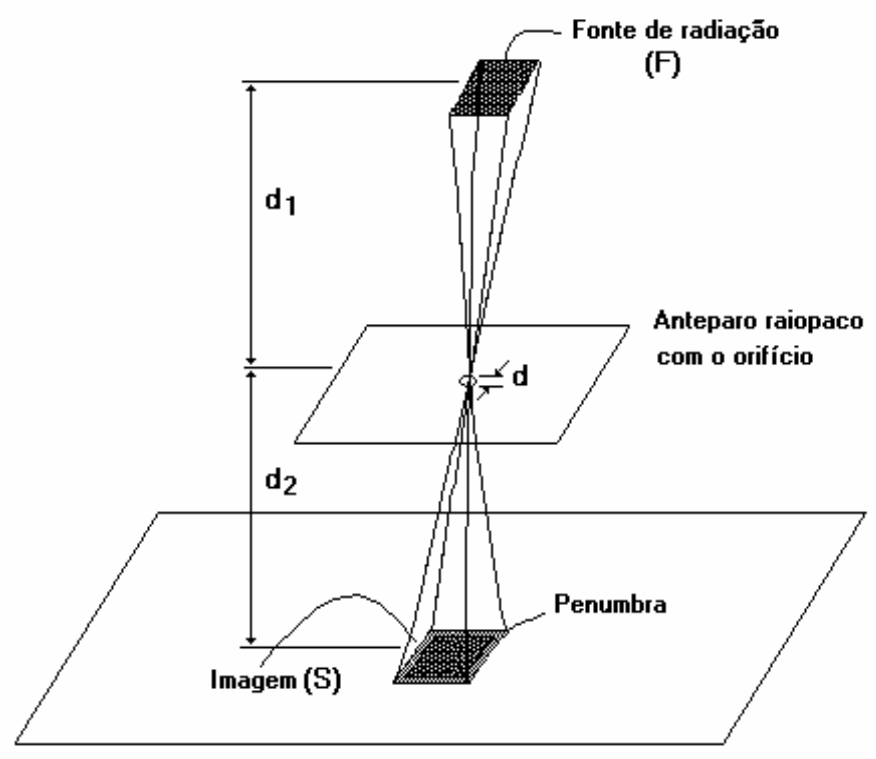

Figura 2.4. - Princípio de obtenção da imagem do ponto focal através da câmara de orifício (SPIEGLER_72).

\subsection{O feixe de Raios- $X$}

Segundo Wolbarst, (WOLBARST_93), quando os elétrons colidem com o anodo do tubo de Raios-X, sofrem uma série de diferentes tipos de interações com os átomos do material que compõe o alvo, de modo que uma parte ou toda a energia cinética desses elétrons pode ser transformada em radiação eletromagnética. 
Essa radiação produzida através dessas interações é chamada de radiação bremsstrahlung. Os fótons de Raios-X produzidos não possuem a mesma energia devido aos diferentes tipos de interações que podem ocorrer no interior do alvo, no processo aleatório de colisão. O número relativo de fótons produzidos por essas interações é, estatisticamente, inversamente proporcional a sua energia, sendo que a máxima energia possível de um fóton é igual à energia dos elétrons que colidiram com o alvo e corresponde ao pico da tensão aplicada nos eletrodos do tubo $(\mathrm{kVp})$, conforme ilustrado na Figura 2.5. A área hachurada na figura indica que a intensidade total de radiação contida no feixe de $100 \mathrm{kVp}$ (que corresponde à área sob o espectro) é quatro vezes maior do que a produzida pelo feixe de $50 \mathrm{kVp}$, mostrando que o aumento da intensidade é proporcional ao quadrado do aumento da $\mathrm{kVp}$ aplicada ao tubo. Assim, variações na $\mathrm{kVp}$ aplicada irão alterar a energia máxima dos fótons de Raios-X produzidos e, conseqüentemente, a distribuição espectral do feixe de radiação.

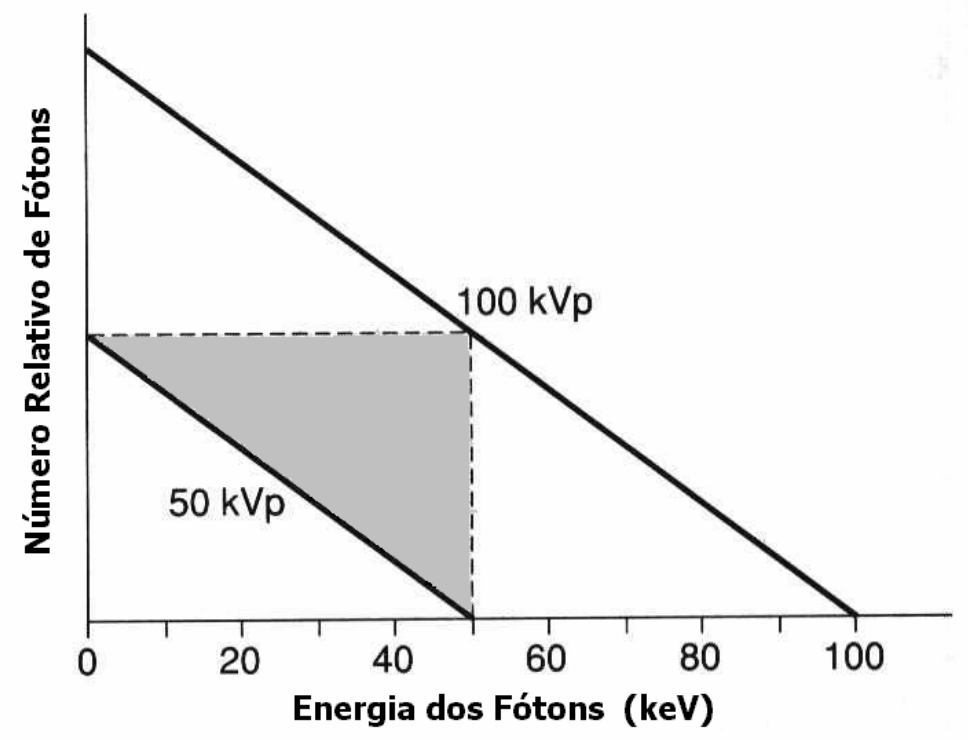

Figura 2.5. - Espectro de Raios-X produzidos por elétrons de 50 e $100 \mathrm{keV}$ (WOLBARST_93).

$\mathrm{Na}$ prática, o espectro de Raios-X que emerge de um aparelho de radiodiagnóstico não possui o mesmo aspecto do espectro ilustrado na Figura 2.5, devido à radiação característica e à filtração inerente. A radiação característica 
aparece quando a tensão aplicada ao tubo é maior do que a energia de ionização dos elétrons orbitais dos átomos do alvo. Quando os elétrons do feixe ou mesmo os fótons gerados removem elétrons das camadas internas dos átomos do alvo ocorre uma ionização e estes átomos ionizados voltam ao seu estado normal, preenchendo a vaga criada pelo elétron ejetado com elétrons de camadas mais externas. Nesse processo, ocorre a emissão de uma radiação de energia bem definida, igual à energia da camada correspondente, chamada de radiação característica.

Filtração inerente é o nome dado à filtração que os fótons de Raios-X sofrem no interior do próprio tubo quando são emitidos, resultado da interação desses fótons com o vidro da ampola, com o óleo que reveste internamente o tubo e com a janela de saída do feixe. Essa filtração retira do feixe os fótons de mais baixa energia, provocando um aumento na energia média do espectro. A Figura 2.6 mostra espectros de Raios-X gerados por um tubo com alvo de tungstênio, quando aplicada uma tensão de $100 \mathrm{kVp}$. A curva $A$ representa um feixe de radiação bremsstrahlung sem sofrer nenhum tipo de filtração; a curva $B$ inclui a radiação característica do tungstênio e a filtração inerente sofrida pelo feixe. Adicionando-se um filtro de alumínio na janela de saída do tubo, o feixe sofre uma filtração adicional, representada pela curva $C$.

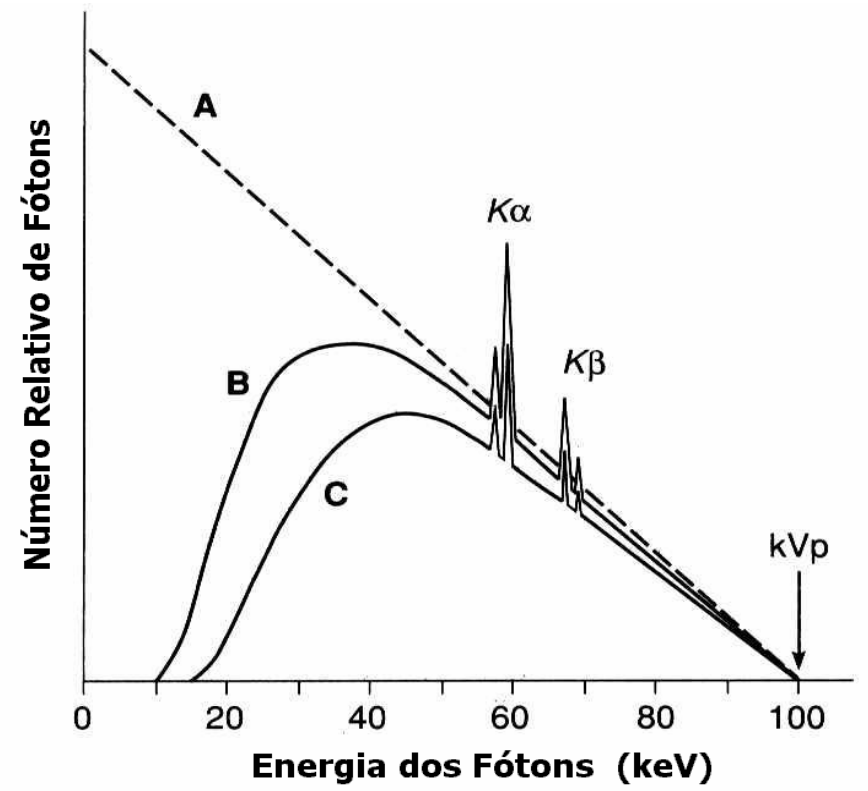

Figura 2.6. - Efeitos da filtração inerente e da radiação característica em um espectro de Raios-X (WOLBARST_93). 
Segundo Johns \& Cunningham (JOHNS_83), as diversas interações que podem ocorrer com os Raios-X produzidos antes deles emergirem do alvo são muito complexas e envolvem vários fatores, como: o caminho dos elétrons no alvo; a mudança de direção em cada interação; a probabilidade de uma perda de ionização a cada aumento de caminho; a direção da emissão da radiação e a atenuação e espalhamento do feixe ao sair do alvo. Os autores não encontraram uma solução teórica satisfatória para o estudo dessas interações; utilizam, porém, uma teoria aproximada, em que supõem a existência de dois tipos possíveis de alvo, o "fino" e o "grosso".

Em relação ao alvo "fino", considera-se que o elétron não sofre, em média, mais do que uma colisão quando passa através do alvo. Assim, quando um feixe de elétrons de energia $E_{l}$ colide com um alvo "fino", a intensidade de radiação emitida por cada fóton é constante, como mostra a curva a), na Figura 2.7. Considerando que a intensidade da radiação produzida é proporcional ao produto do número de fótons pelas suas energias, um fóton de energia $E_{1} / 2$ será produzido com o dobro de probabilidade do que um fóton de energia $E_{1}$. Portanto, fazendo um gráfico do número de fótons produzidos por intervalo de energia contra energia, obtém-se a curva representada pela Figura $a^{\prime}$ ), na mesma Figura 2.7. Essa teoria simplificada está de acordo com o que acontece na prática para elétrons de baixa energia (abaixo de $100 \mathrm{keV})$.

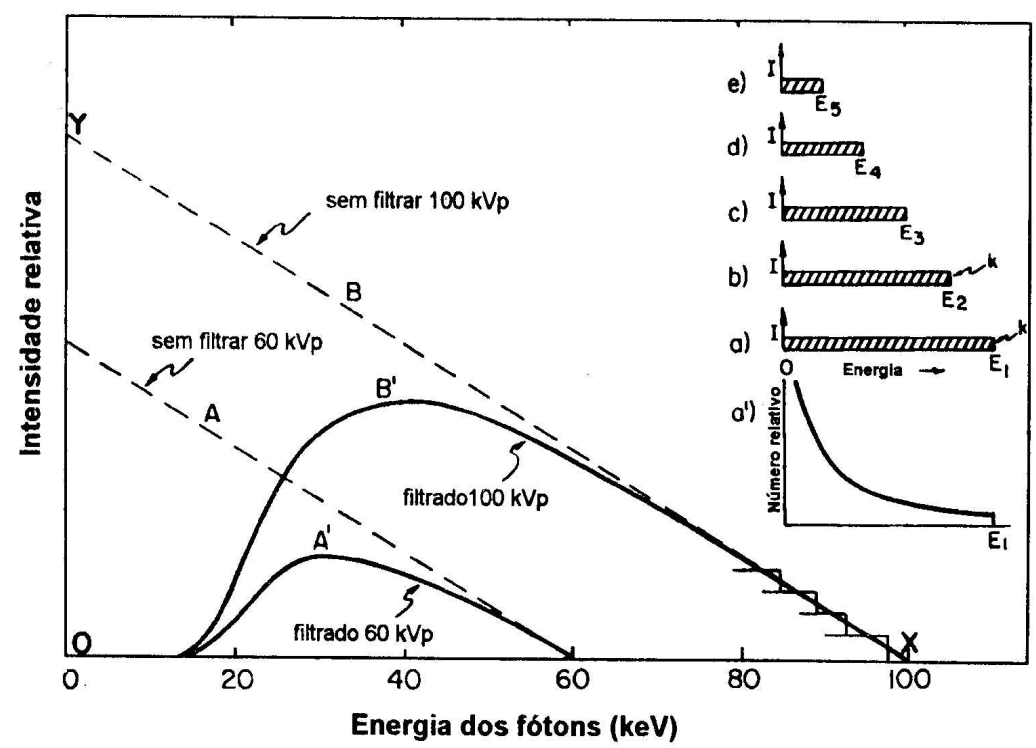

Figura 2.7. - Intensidade relativa da radiação em cada intervalo de energia (JOHNS_83). 
O alvo "grosso" pode ser considerado como uma série de alvos finos superpostos. Assim, elétrons com energia inicial $E_{1}$, após passarem pela primeira camada "fina", terão energia $E_{2}$ e após passarem pela segunda camada terão energia $E_{3}$, e assim sucessivamente, como demostrado nas curvas $a$ ), b), c), d), e), internas à Figura 2.7. O espectro total será, então, a superposição de todos os espectros de alvos "finos" de energias $E_{1}, E_{2}, E_{3}, E_{4}$, etc. Esse espectro pode ser representado pela curva $B$ (linha $X Y$ ) da Figura 2.7, descrita pela equação:

$$
I(E)=C . Z \cdot(E m a ́ x-E)
$$

onde $I$ é a intensidade da radiação de energia $E$, Emáx é a energia máxima dos fótons presentes no feixe, $Z$ é o número atômico do material do alvo e $C$ é uma constante de valor 2,76 $\mathrm{x} 10^{-6}$, calculada por Dyson $^{1}$ apud Unsworth \& Greening (UNSWORTH_70).

$\mathrm{Na}$ prática, a energia efetiva de um feixe de Raios-X, segundo CurryIII et al. (CURRYIII_90), varia de um terço à metade do valor da sua energia máxima, já que vários fótons estão na faixa de baixa energia dentro do espectro.

A área sob a linha tracejada é numericamente igual à intensidade total de radiação que foi irradiada, que é proporcional ao número atômico do material do alvo e ao quadrado da energia do feixe de elétrons, podendo ser representada, segundo Wilks (WILKS_87), pela seguinte equação:

$$
I \propto Z . E^{2}
$$

Por isso, o uso do tungstênio como material do alvo tem se mostrado muito eficiente, já que seu número atômico é bastante alto $(Z=74)$. Da mesma forma, para aparelhos de Raios- $X$ usados na radioterapia, que utilizam feixes de altas energias, a produção de fótons $\mathrm{X}$ é muito mais eficiente do que nos aparelhos de radiodiagnóstico, fazendo com que a perda de energia na forma de calor seja muito menor.

\footnotetext{
${ }^{1}$ DYSON, N. A. (1959). Proceedings of the Physical Society, v.73, p.924.
} 


\subsection{Filtração}

A qualidade de um feixe de Raios-X está relacionada ao poder de penetração de seus fótons, ou seja, a sua energia. Variações na energia dos fótons produzidos são obtidas através da variação da tensão aplicada entre os eletrodos do tubo de Raios-X; assim, a qualidade dos fótons produzidos é proporcional à $\mathrm{kVp}$. Além disso, a emissão dos Raios-X depende do número de elétrons que colidem com o alvo em um certo intervalo de tempo, ou seja, a corrente no tubo. Assim, a quantidade de Raios-X produzidos é proporcional à corrente no tubo e ao tempo de exposição, mas estes fatores não alteram a qualidade do feixe.

A intensidade do feixe de Raios-X que irradia um determinado objeto diminui à medida que este objeto é afastado da fonte de radiação. Esse efeito é conhecido como lei do inverso do quadrado da distância, já que a variação da intensidade de radiação é inversamente proporcional ao quadrado da variação da distância do objeto em relação à fonte. A ocorrência desse efeito é conseqüência unicamente da geometria, conforme ilustrado na Figura 2.8. Considerando que um número $n$ de fótons, ao atravessar uma região de $1 \mathrm{~m}^{2}$ de área gera uma intensidade de 1 unidade, a mesma quantidade de fótons, quando atravessar uma região 2 vezes mais distante da fonte, estará atravessando uma área $2^{2}$ vezes maior e, conseqüentemente, produzirá uma intensidade 4 vezes menor.

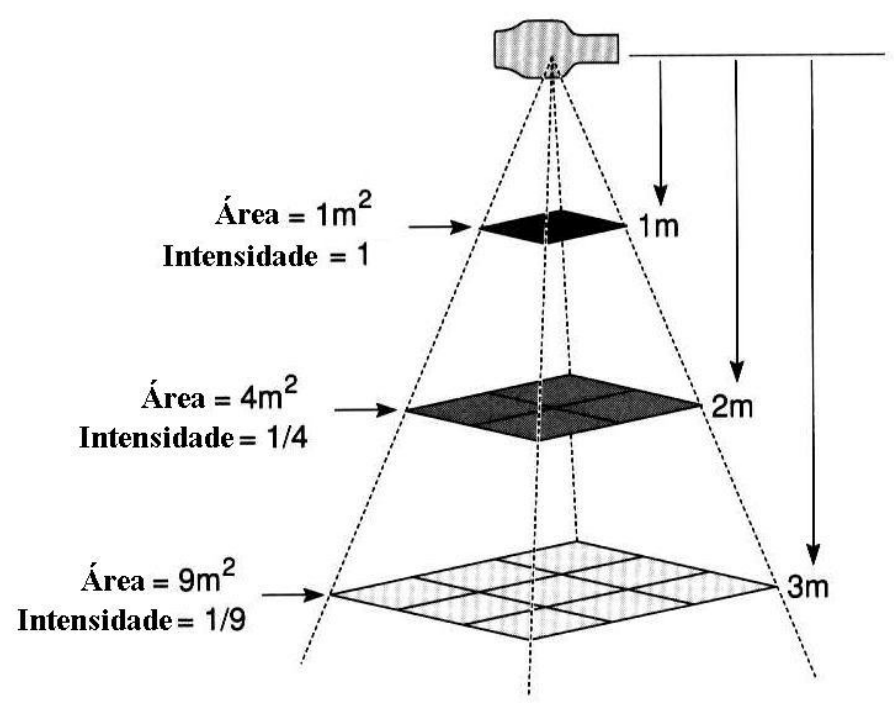

Figura 2.8. - A lei do inverso do quadrado da distância (WOLBARST_93). 
Quando os fótons de uma determinada energia ou de um determinado intervalo energético são eliminados do feixe devido à absorção por algum material tem-se um processo chamado de filtração. A intensidade da radiação transmitida por um filtro após ser bombardeado por um feixe de Raios-X pode ser expressa pela seguinte equação:

$$
I=I_{0} \cdot e^{-\mu \rho \cdot \rho \cdot x}
$$

onde $I$ é a intensidade de radiação transmitida, $I_{0}$ é a intensidade de radiação incidente, $\rho$ é a densidade do material absorvedor, $x$ é a espessura do filtro e $\mu / \rho$ é o coeficiente de atenuação de massa, que é função da energia dos fótons da radiação incidente e do material utilizado como filtro. Essa importante relação é conhecida como equação de Lambert-Beer (WOLBARST_93).

Considerando apenas a filtração inerente, o feixe produzido por um aparelho de Raios-X, segundo Johns \& Cunningham (JOHNS_83), não seria adequado, por exemplo, para radioterapia, pois os fótons de baixa energia não penetrariam no tumor, mas aumentariam a dose recebida pelo paciente. Além disso, não seria adequado para radiodiagnóstico, já que os fótons de baixa energia não conseguiriam atravessar o paciente para impressionar o filme, e também contribuiriam para o aumento da dose. No entanto, essa radiação indesejável pode ser removida do feixe através da utilização de filtros apropriados.

Quando um feixe de radiação não monocromática é filtrado, fótons de todos os comprimentos de onda poderão sofrer modificações, mas os de comprimento de onda maior, menos energéticos, sofrerão maior absorção por serem menos "penetrantes". Portanto, o espectro será modificado mais sensivelmente na região de menor energia, como mostra a Figura 2.9, resultado da experiência realizada por Johns \& Cunningham (JOHNS_83): 


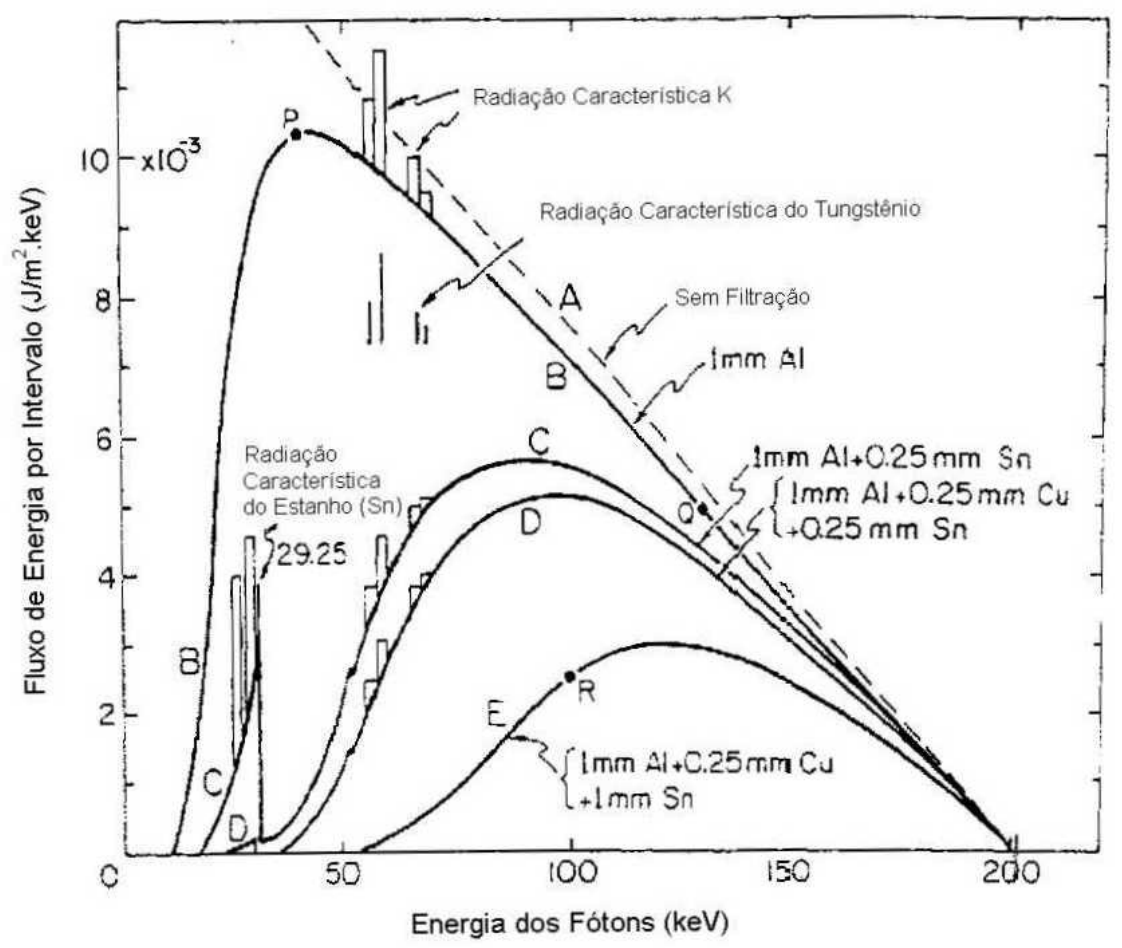

Figura 2.9. - Distribuição espectral da radiação gerada por um feixe monoenergético de elétrons de $200 \mathrm{keV}$ bombardeando um alvo de tungstênio (JOHNS_83).

A curva $A$ mostra a distribuição espectral do feixe não filtrado; a curva $B$ é conseguida filtrando-se o feixe de Raios-X com um filtro de $1,0 \mathrm{~mm}$ de alumínio (Al) e a curva $C$ é obtida adicionando-se mais uma camada de $0,25 \mathrm{~mm}$ de estanho (Sn) ao filtro. Pode-se observar que isto reduz a quantidade de fótons na região entre 30 e $40 \mathrm{keV}$ para praticamente zero, mas permite que uma faixa de radiação de exatamente $29,2 \mathrm{keV}$ passe através do filtro. Essa faixa corresponde à energia característica da camada $\mathrm{K}$ dos átomos de estanho, que pode ser filtrada colocando-se um filtro de cobre de $1,0 \mathrm{~mm}$; o resultado obtido é mostrado pela curva $D$. Do mesmo modo, segundo CurryIII et al. (CURRYIII_90), uma camada de alumínio pode ser adicionada para absorver a radiação característica do cobre. A radiação característica do alumínio é tão pequena, $1,5 \mathrm{keV}$, que é absorvida pelo próprio ar presente no espaço entre o filtro e o paciente e não causa nenhum efeito na imagem. Essa composição de filtros é chamada de filtro composto e é importante por possibilitar que os filtros sejam arranjados de maneira propícia, com os materiais de número atômico maior sendo colocados mais próximos do tubo. 
Assim, os filtros servem para retirar do feixe as radiações que não são úteis para a formação da imagem, mas aumentam a dose no paciente; além disso, esses fótons de baixa energia pioram a qualidade de um exame radiográfico, pois diminuem o contraste da imagem (CURRYIII_90). Como o feixe de Raios-X que sai do tubo é sempre heterogêneo, a utilização de filtração adequada pode torná-lo mais homogêneo e também aumentar a sua energia efetiva, aproximando-o de um feixe monoenergético.

A filtração inerente de um aparelho de Raios-X geralmente é especificada em termos de espessura equivalente ou alumínio equivalente, que nada mais é do que a espessura de alumínio necessária para produzir a mesma atenuação no feixe que a produzida pela filtração inerente do tubo. Segundo CurryIII et al. (CURRYIII_90), a filtração inerente da maioria dos aparelhos de Raios-X comerciais varia entre 0,5 e $1,0 \mathrm{~mm}$ de alumínio equivalente e o principal responsável por esta atenuação é o vidro que reveste a ampola.

Para os aparelhos de Raios-X dedicados à exames mamográficos, um feixe pouco filtrado se faz necessário e a filtração inerente passa a ser indesejável. Os mamógrafos possuem algumas características específicas que os diferenciam dos aparelhos de Raios-X convencionais. Primeiramente, a tensão utilizada nesses aparelhos varia entre 20 e $35 \mathrm{kVp}$, já que há um interesse na visualização de tecidos. Além disso, ao invés de utilizar o tungstênio como material do alvo, utiliza-se o molibdênio, por apresentar uma alta emissão de radiação característica na região do espectro entre 17,4 e $19,8 \mathrm{keV}$. Isto eleva consideravelmente o número de fótons nessa faixa energética, o que proporciona um melhor contraste para a visualização dos tecidos da mama. Em relação à filtração inerente, ela poderia retirar do espectro esses fótons de energia característica e aumentar em excesso a energia efetiva do feixe, prejudicando o contraste da imagem. Assim, a ampola do tubo de aparelhos mamográficos é geralmente revestida com berílio ao invés de vidro, pois o berílio possui número atômico baixo $(Z=4)$ e é mais transparente para as baixas energias, fazendo com que a filtração seja mínima. 


\subsection{O efeito "heel"}

A distribuição de intensidade de um feixe de Raios-X em função da sua posição no campo não é uniforme, ocorrendo uma redução significativa na radiação medida ao longo do eixo catodo-anodo, como ilustrado na Figura 2.10.

Esse fenômeno é conhecido como distribuição angular, efeito anódio ou efeito "heel" e seu estudo é de fundamental importância para o controle de qualidade de imagens radiológicas, pois provoca na imagem obtida uma variação de contraste que independe do objeto radiografado. Assim, certas regiões do filme podem ser pouco sensibilizadas ao mesmo tempo que outras podem ser sensibilizadas em excesso, prejudicando a qualidade da imagem.

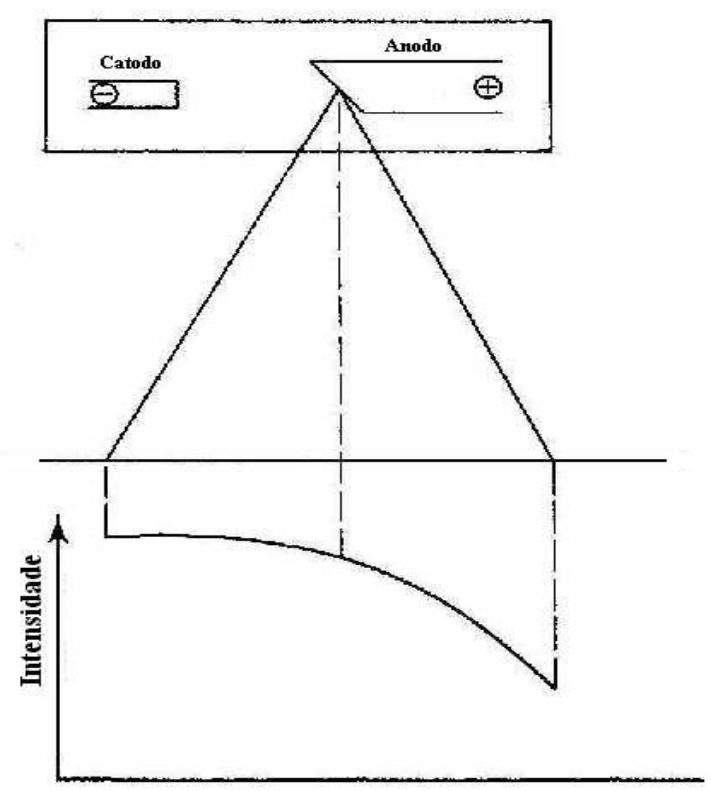

Figura 2.10. - Distribuição da intensidade da radiação através de um feixe de Raios-X (SCAFF_79).

O efeito "heel" ocorre em função da filtração que os fótons de Raios-X sofrem pelo próprio material do alvo ao serem emitidos pelo anodo. Teoricamente, toda radiação deveria ser produzida na superfície do alvo, mas isto não ocorre. Os elétrons, ao colidirem com o anodo em alta velocidade, penetram no material do alvo fazendo com que a radiação seja produzida no seu interior, e não na superfície. Assim, dependendo do caminho que o fóton percorre dentro do alvo antes 
de ser emitido, sofre mais ou menos absorção, o que provoca uma variação na intensidade do feixe, segundo Wolbarst (WOLBARST_93), de aproximadamente $30 \%$ de uma extremidade à outra do campo no eixo catodo-anodo. Segundo o mesmo autor, o efeito "heel" tem importância significativa nos exames onde se faz necessário o uso de um campo de exposição muito grande (função do tamanho da estrutura que deve ser radiografada) ou em exames onde a distância do objeto à fonte de radiação é muito pequena, como, por exemplo, em angiografia.

A Figura 2.11 ilustra de forma simplificada a ocorrência do efeito "heel”. O fóton que sofre menor absorção pelo alvo é aquele que sai perpendicular à superfície (direcionado para o lado do campo correspondente ao catodo), pois o caminho que ele percorre para ser emitido é menor. Em qualquer outro ângulo de saída menor que $90^{\circ}$ o fóton precisa percorrer um caminho cada vez maior, proporcional à diminuição deste ângulo, o que faz com que ele sofra uma maior filtração à medida que se direciona para o lado correspondente ao anodo no campo. Isso explica a ocorrência de um gradiente de intensidade da radiação no campo ao longo do eixo catodo-anodo.

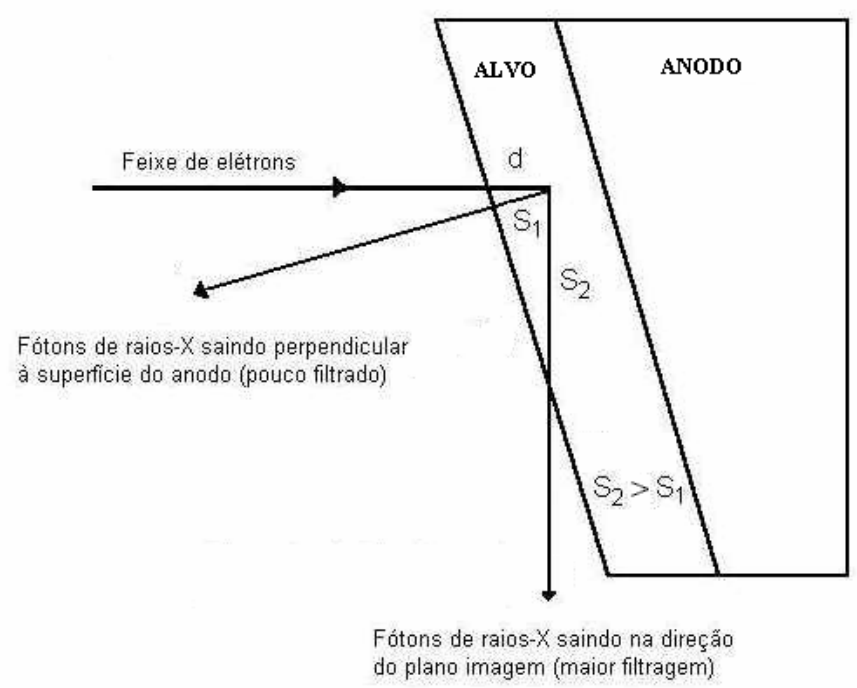

Figura 2.11. - Esquema simplificado da ocorrência do efeito "heel" (MARQUES_98).

Segundo Johns \& Cunningham (JOHNS_83), a máxima intensidade do feixe de Raios-X ocorre para ângulos entre $5^{\circ}$ e $10^{\circ}$ do lado correspondente ao 
catodo; os fótons emitidos nas direções além da linha limite da inclinação do alvo são totalmente absorvidos pelo anodo e não "escapam" do tubo. À medida que se diminui o ângulo de inclinação do alvo, o feixe de Raios-X do lado do anodo tornase cada vez mais comprimido, diminuindo-se, conseqüentemente, a área útil do feixe. $\mathrm{Na}$ prática, os tubos de Raios-X possuem colimadores que restringem ainda mais o feixe de Raios-X, mas isto não reduz de forma muito significativa a variação de intensidade no campo de um lado a outro do eixo catodo-anodo (JOHNS_83).

A teoria mais largamente utilizada no que diz respeito à produção de Raios-X é a de Kramers ${ }^{2}$ apud Fritz \& Livingston (FRITZ_82), demonstrando que, para um alvo "fino", a energia total em qualquer intervalo de energia é constante e independente da energia do fóton, como já citado no item 2.3. Para um alvo "grosso", a produção do espectro pode ser aproximada como sendo a soma de múltiplos espectros de alvos finos, cada um com energia do elétron menor do que o da camada anterior. Assim, pode-se calcular o espectro de Raios-X para alvo "grosso" através da equação:

$$
I(E)=C \cdot Z \cdot\left(E_{0}-E\right) \cdot\left(\frac{v_{0}^{2}}{c^{2}}\right)
$$

onde $E$ é a energia do fóton, $E_{0}$ é a energia máxima do espectro $(=\mathrm{kVp})$, $v_{0}$ é a velocidade inicial do elétron e $c$ é a velocidade da luz no vácuo.

Segundo Fritz \& Livingston (FRITZ_85), o comprimento do caminho que o fóton percorre no alvo é função da inclinação do anodo $\Phi$, do ângulo entre a direção perpendicular ao feixe eletrônico e a direção em que o fóton é emitido $\theta$ e da profundidade que o elétron penetra no alvo $d$, conforme ilustra a Figura 2.12.

\footnotetext{
2 KRAMERS, H. A. (1923). On the theory of X-ray absorption and the continuous X-ray spectrum. Philosophical Magazine, v.46, p.836-871.
} 


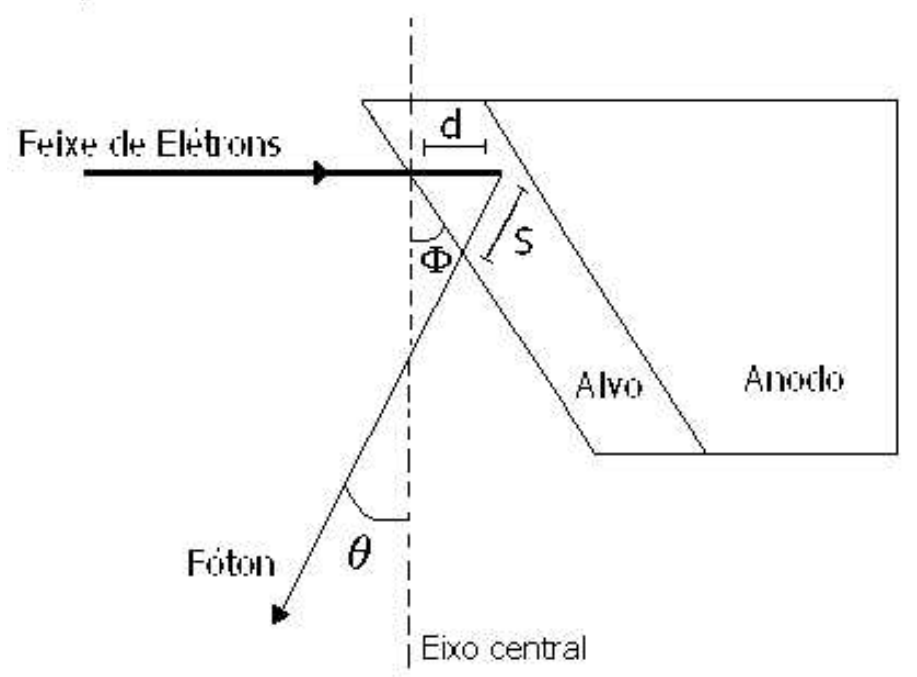

Figura 2.12. - Processo de emissão de fótons pelo anodo.

O comprimento do caminho que o fóton percorre dentro do alvo não depende do ponto no qual o elétron entra no anodo, considerando-se que as dimensões do anodo são bem maiores do que a dimensão do ponto focal. A relação entre os parâmetros descritos na figura acima, segundo Fritz \& Livingston (FRITZ_85), pode ser expressa pela equação:

$$
S(\theta)=\frac{d \cdot \cos (\Phi)}{\operatorname{sen}(\theta+\Phi)}
$$

onde $S(\theta)$ é o comprimento do caminho percorrido pelo fóton dentro do alvo, $d$ é a profundidade de penetração do elétron, $\Phi$ é o ângulo de inclinação do anodo e $\theta$ é o ângulo entre o eixo central e a direção que o fóton é emitido.

Assim, sabendo-se o comprimento do caminho percorrido pelo fóton dentro do alvo, é possível calcular a atenuação sofrida por ele através da equação:

$$
I=I_{0} \cdot e^{-\mu \rho \cdot \rho \cdot S(\theta)}
$$

que é uma variação da equação de Lambert-Beer, já apresentada no item 2.4. 


\subsection{Filmes e écrans}

Em um exame radiológico, o paciente é colocado sob o feixe de Raios-X para que os fótons possam atravessar seu corpo. Desta forma, o feixe interage com os tecidos e órgãos, sofrendo diferentes níveis de absorção. O feixe emergente, com isso, passa a possuir níveis variados de intensidade, carregando consigo informações sobre o interior do corpo do paciente necessárias para o exame radiográfico. No entanto, para uma avaliação dessas informações torna-se necessária a utilização de um meio de armazenamento adequado à visão humana. $\mathrm{O}$ filme radiográfico é o meio de armazenamento mais utilizado para registrar as informações obtidas num exame de Raios-X. A Figura 2.13 ilustra o processo de interação de um feixe de Raios-X com o corpo de um paciente.

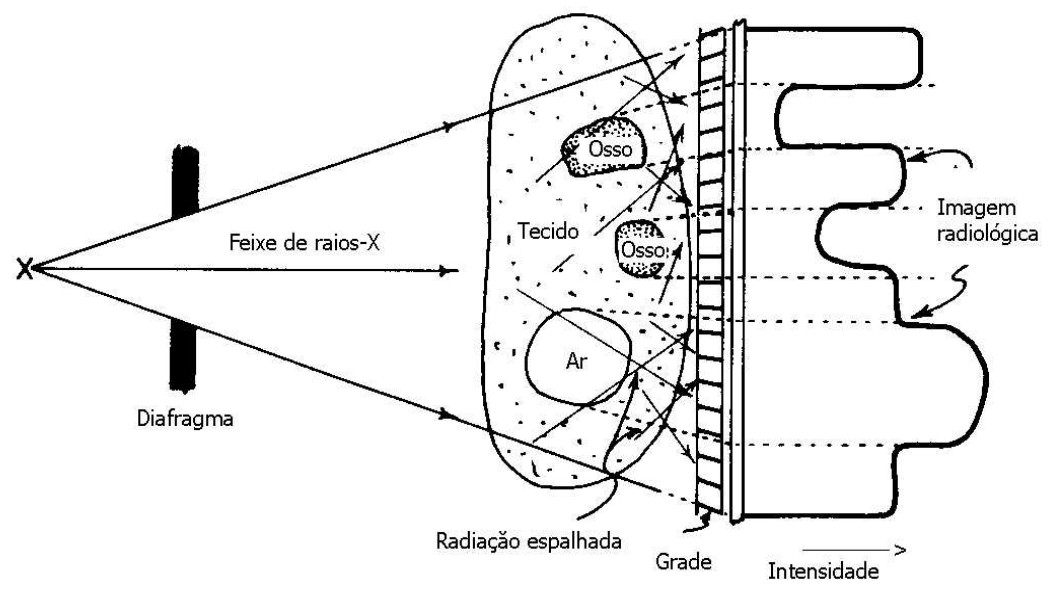

Figura 2.13. - Diagrama ilustrando como a imagem radiológica é formada (JOHNS_83).

O filme radiográfico, segundo CurryIII et al. (CURRYIII_90), é constituído basicamente por quatro camadas: a camada protetora, a base, a interface e a emulsão. A parte do filme responsável pela formação da imagem é a emulsão que, dependendo do tipo do filme, pode ser sensível à luz ou aos Raios-X. O filme sensível à luz deve ser utilizado juntamente com um écran reforçador, que tem a finalidade de transformar os fótons de Raios-X em luz, diminuindo a quantidade de radiação necessária para a formação da imagem e, conseqüentemente, a dose que o paciente recebe durante o exame radiológico. 
Existem filmes que possuem emulsão de ambos os lados da base. A finalidade da emulsão dupla é diminuir a exposição necessária para a formação de uma imagem satisfatória, diminuindo, assim, a dose de radiação no paciente.

Os écrans reforçadores, também chamados de telas intensificadoras, segundo CurryIII et al. (CURRYIII_90), têm a função de absorver os Raios-X que emergem do paciente e converter cada fóton de radiação em um jato de fótons de luz visível, os quais são absorvidos pelo filme, formando a imagem latente. Desta forma, a utilização da tela intensificadora proporciona uma diminuição significativa da dose de radiação à qual o paciente é submetido, além de diminuir o tempo de exposição durante o exame radiológico. No entanto, o uso do écran introduz um certo grau de borramento na imagem devido à difusão da luz, gerando uma diminuição da resolução do sistema e, conseqüentemente, uma degradação na qualidade da imagem.

Para descrever a resposta de um filme radiográfico ou de um sistema écran-filme à exposição utiliza-se um gráfico chamado de curva sensitométrica ou curva H\&D. A curva sensitométrica, ilustrada na Figura 2.14, relaciona densidade óptica com o logaritmo da exposição, sendo muito útil na avaliação de um filme radiográfico ou sistema écran-filme, pois dela extraem-se informações sobre o contraste (diferença de intensidade entre dois pontos ou entre duas regiões de uma imagem), sensibilidade (ou velocidade), que é determinada através da exposição necessária para produzir um determinado enegrecimento no filme e, principalmente, sobre a latitude, que corresponde à faixa de exposição que deve ser utilizada para produzir uma imagem satisfatória para o radiodiagnóstico. A eficiência do écran em converter Raios-X em luz pode ser expressa em termos de sua velocidade. Assim, quanto mais veloz é o filme, menos radiação é necessária para a formação da imagem. 


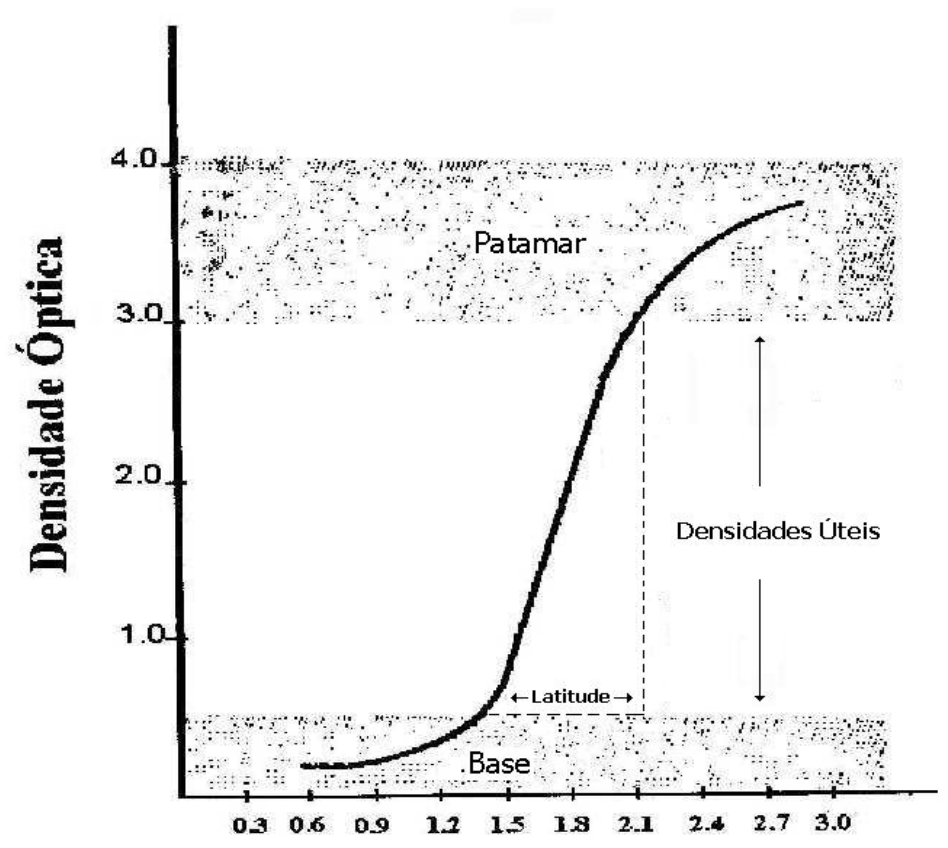

Iog Exposiçāo Relativa

Figura 2.14. - Curva sensitométrica ou curva H\&D de um filme radiográfico (SILVA_97).

Na curva $H \& D$, a faixa de exposição que produz o melhor contraste na imagem é a latitude, e corresponde à parcela linear da curva. Nas regiões de patamar e base o contraste é insatisfatório, pois grandes variações na exposição não produzem variações significativas na densidade óptica, ou por saturação (patamar) ou por subexposição (base). Em um filme radiográfico, o contraste é determinado pelo ângulo de inclinação da porção linear da sua curva característica.

\subsection{A característica de campo}

Dependendo da posição em que um objeto é colocado no campo de radiação, a imagem produzida por ele pode sofrer diferentes tipos de deformações. Essas deformações são tão significativas que é possível que um determinado objeto de interesse clínico seja visualizado em uma determinada região no campo e em outras não, ou seja, a magnitude da não-nitidez geométrica da imagem depende da posição sob o feixe de Raios-X na qual o objeto é colocado. Segundo Doi (DOI_77), 
o fenômeno que causa tais deformações geométricas na imagem é chamado de característica de campo.

A ocorrência da característica de campo se deve à inclinação do anodo, que faz com que o ponto focal apresente diferentes tamanhos e formas quando observado de diferentes posições no feixe de Raios-X, como mostra a Figura 2.15.

Para o estudo da característica de campo é importante o conhecimento dos princípios utilizados para a análise de sistemas de imagem através do método das funções de transferência. Este método é utilizado para descrever o desempenho de um sistema de imagem através da análise da relação entre a entrada e a saída produzida por ele.

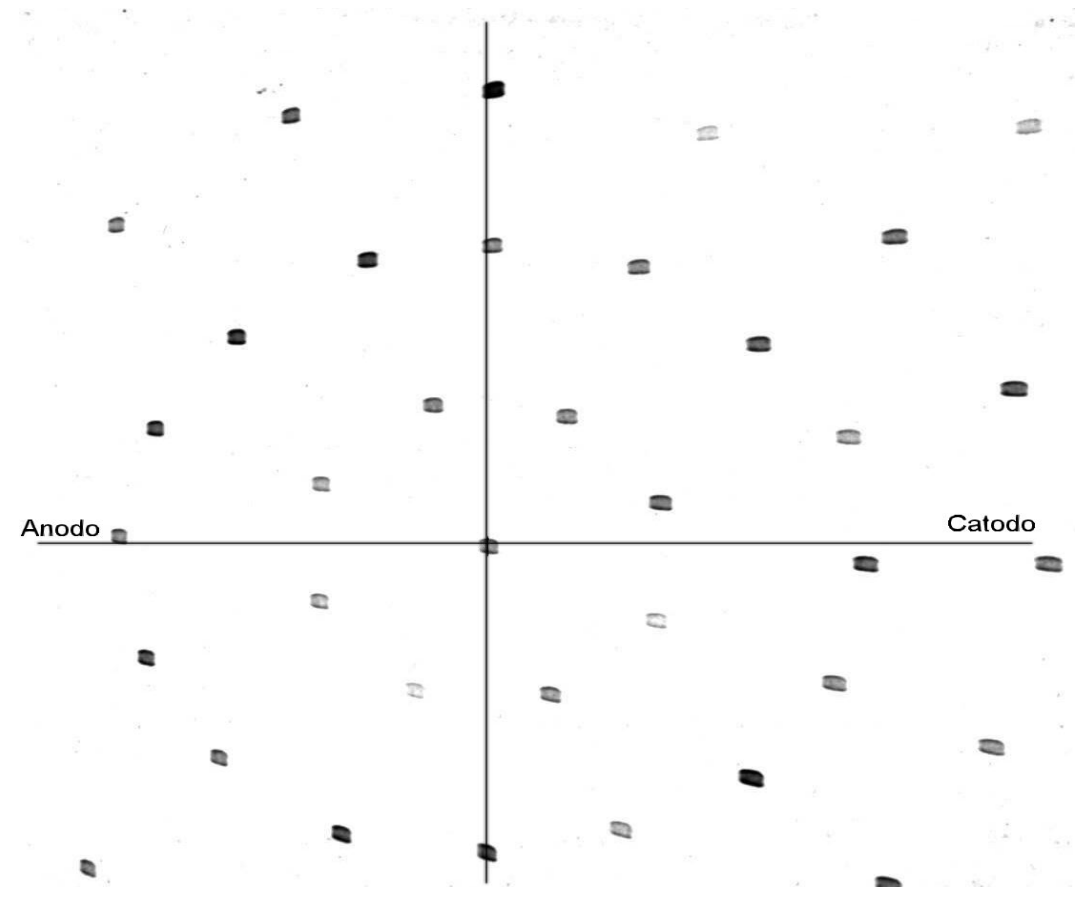

Figura 2.15. - Imagem do ponto focal de um aparelho de Raios-X obtida experimentalmente com o uso de uma matriz de orifício.

Uma função de transferência muito utilizada para avaliação de sistemas radiológicos é a Função de Espalhamento de Ponto (FEP). A FEP pode ser definida como a distribuição de intensidade de radiação na imagem de uma abertura 
infinitamente pequena com irradiação de intensidade unitária. $\mathrm{Na}$ prática, pode corresponder à projeção da imagem do ponto focal num filme radiográfico.

Doi (DOI_77) elaborou um estudo sobre a característica de campo baseado na deformação geométrica da FEP. Como a maioria dos tubos de Raios-X tem anodo rotativo o alvo é, na realidade, uma parte de uma superfície de um cone; no entanto, como a área do alvo onde os elétrons colidem é muito pequena, o ponto focal pode ser considerado como um plano. Sendo assim, um enfoque mais prático em relação ao efeito da característica de campo sobre a imagem do ponto focal foi proposto por Marques et al. (MARQUES_96) e proporcionou o cálculo de seus tamanhos efetivos ao longo do campo por simulação.

Considerando o ponto focal no centro do campo como sendo um retângulo de lados $a$ e $b$, os novos valores $a^{\prime}$ e $b^{\prime}$ desses lados em uma posição arbitrária, a uma distância $d$ da origem, podem ser determinados conforme Figura 2.16.

\section{Direção do eixo}

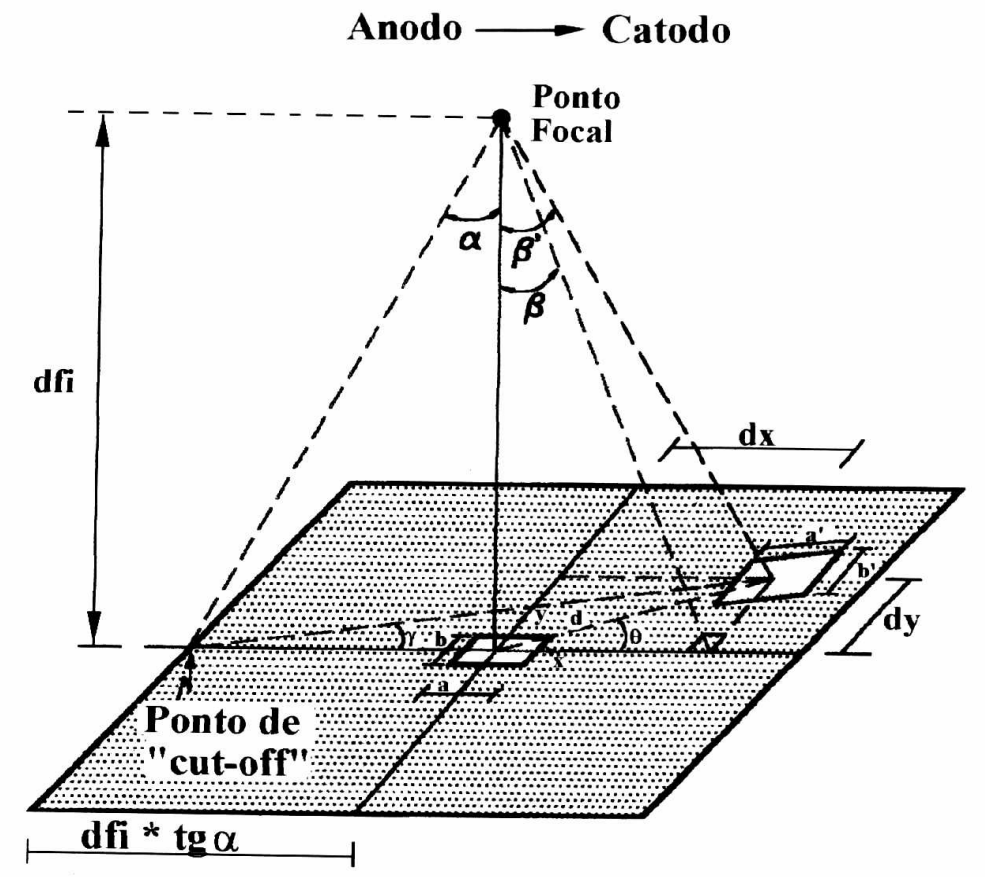

Figura 2.16. - Ponto focal no centro do campo e em uma posição arbitrária (MARQUES_96). 
Primeiro, deve-se calcular o novo valor do lado $a$ do ponto focal em uma posição que dista $d x$ do centro do feixe $(d y=0)$, conforme ilustra a Figura 2.17.

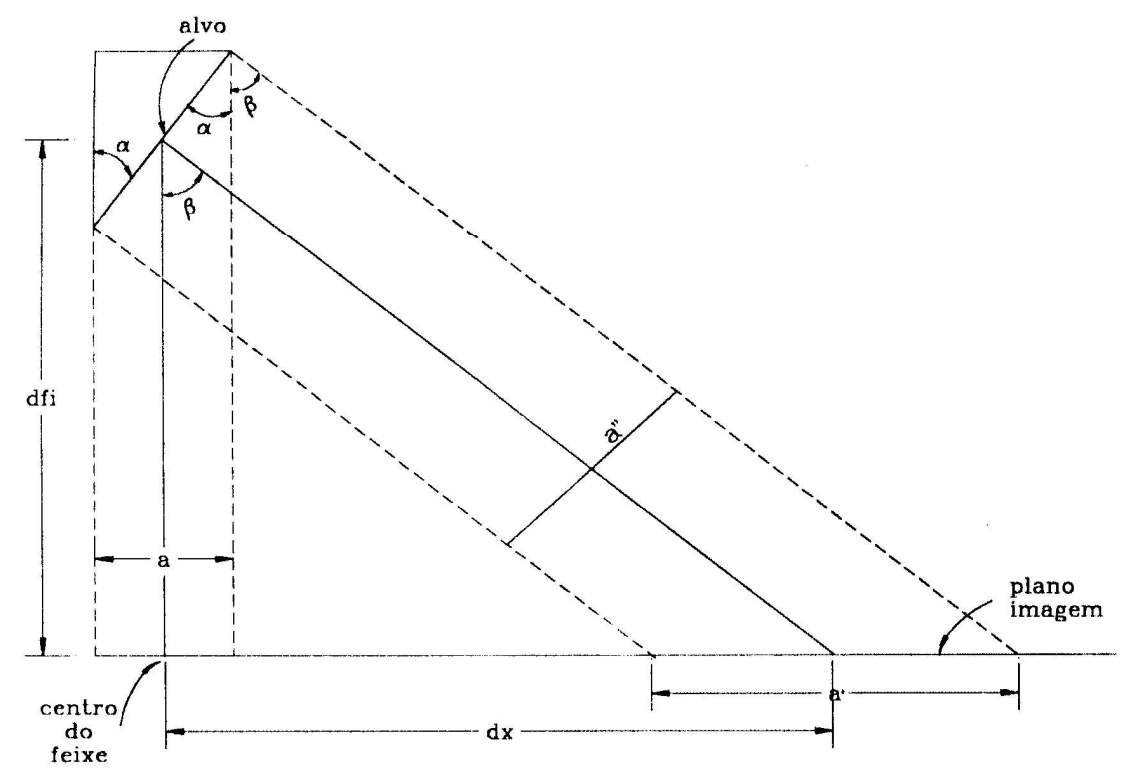

Figura 2.17. - Cálculo do lado $a^{\prime}$ do ponto focal em uma posição qualquer do eixo $x(d y=0)$ (MARQUES_98).

Sendo $a$ " o tamanho do lado do ponto focal na direção perpendicular aos Raios-X, tem-se:

$$
a^{\prime \prime}=\operatorname{alvo} * \operatorname{sen}(\alpha+\beta)
$$

onde,

$$
\text { alvo }=a / \operatorname{sen}(\alpha)
$$

$$
\beta=\arctan (d x / d f i)
$$

Substituindo a equação (2.10) na equação (2.9), obtém-se:

$$
a^{\prime \prime}=(a / \operatorname{sen}(\alpha)) \cdot \operatorname{sen}(\alpha+\beta)
$$


Assim, o valor de um lado do ponto focal no plano imagem fica:

$$
a^{\prime}=a^{\prime \prime} / \cos (\beta)
$$

Como o lado $b$ do ponto focal está num plano paralelo aos planos imagem e objeto, ele não muda de tamanho ao longo do campo, ou seja:

$$
b^{\prime}=b
$$

Portanto, para uma posição qualquer do campo, o tamanho $a$ do ponto focal pode ser determinado através das seguintes equações (MARQUES_96):

$$
a^{\prime}=\frac{a^{\prime \prime}}{\cos (\beta) \cdot \cos (\gamma)}
$$

sendo,

$$
\gamma=\arctan \left(\frac{d y}{d f i \cdot \tan (\alpha)+d x}\right)
$$

onde os valores de $\beta$ e $a$ " são determinados através das equações (2.11) e (2.12) respectivamente.

Levando em conta o fenômeno da característica de campo, Oliveira et al. (OLIVEIRA_96) desenvolveram um algoritmo de simulação capaz de apresentar a imagem do ponto focal de um aparelho de Raios-X em quaisquer posições do campo e, a partir dos parâmetros encontrados, obter imagens simuladas de objetos colocados sob o feixe de Raios-X naquelas posições. A partir deste algoritmo, Schiabel et al. (SCHIABEL_98) apresentaram uma proposta capaz de avaliar adicionalmente a influência do sistema de registro na nitidez da imagem radiográfica, obtendo como resultado imagens diferentes em função dos diversos tipos de filmes ou combinações écran-filme usadas durante a exposição. 
A finalidade desses trabalhos é fornecer uma imagem semelhante à que seria obtida em um aparelho convencional de Raios-X para as condições consideradas, permitindo ao radiologista prever a variação da nitidez da imagem gerada em função da localização do objeto no campo e do sistema de registro utilizado. 


\section{CAPÍTULO 3}

\section{A Camada Semi-Redutora}

Nesse capítulo são apresentados os conceitos envolvendo a camada semi-redutora como parâmetro de avaliação da qualidade de sistemas radiográficos, além das noções fundamentais a respeito da metodologia de obtenção experimental de seu valor.

\subsection{Conceito}

Scaff (SCAFF_79) aponta dois aspectos físicos fundamentais e distintos que caracterizam um feixe de Raios-X: intensidade e energia. A intensidade está relacionada à quantidade de radiação contida no feixe e a energia está associada ao "poder de penetração" dos seus fótons, o que expressa a qualidade dessa radiação. A utilização de algum parâmetro que descreva o tipo de radiação contida em um feixe de Raios-X parece bastante conveniente, pois determina, na verdade, sua qualidade e, por conseqüência, traduz uma estimativa da qualidade da imagem que poderá ser produzida.

Segundo Johns \& Cunningham (JOHNS_83), é importante descrever a natureza do feixe de Raios-X em termos de sua capacidade de penetrar em algum material de composição conhecida. Essa "capacidade" ou "qualidade" pode ser expressa em termos de um parâmetro conhecido como camada semi-redutora, CSR, 
que é definida como a espessura de algum material absorvedor necessária para reduzir a intensidade de um feixe à metade do seu valor original.

Para um feixe de radiação monocromática, onde todos os fótons possuem a mesma energia, a CSR pode ser facilmente determinada através da equação de Lambert-Beer (equação 2.5), substituindo-se o valor da intensidade de radiação transmitida, $I$, por $I_{0} / 2$, já que a espessura do absorvedor deve reduzir essa intensidade à metade do seu valor inicial. Assim, a equação fica da seguinte forma:

$$
\frac{I_{0} / 2}{I_{0}}=e^{-\frac{\mu}{\rho} \cdot \rho \cdot x}
$$

sendo que o valor da espessura $x$, encontrada nessas condições, corresponde à camada semi-redutora do feixe. Portanto,

$$
\operatorname{CSR}=\ln 2 / \mu \approx 0,693 / \mu
$$

onde $\mu$ é o coeficiente de atenuação linear obtido da multiplicação de $\mu / \rho$ pela densidade $\rho$.

Nota-se, através da equação (3.2), que o valor da CSR de um feixe de Raios-X não depende da sua intensidade. Portanto, a CSR de um aparelho radiográfico não é função nem da corrente, nem do tempo de exposição aplicado ao tubo. Dessa forma, para um feixe monoenergético, a CSR depende exclusivamente do valor do coeficiente de atenuação linear, que é função da energia do feixe e do material utilizado como filtro (CURRYIII_90).

$\mathrm{Na}$ prática, o feixe de Raios-X que é utilizado nos exames radiográficos não é monoenergético, possuindo fótons de várias energias; para o cálculo da CSR, a equação (3.2) não pode ser utilizada. Nesse caso, a CSR depende não só da energia dos fótons contidos no feixe, mas também da distribuição espectral desse feixe. Por exemplo, se a maioria dos fótons que compõe o feixe é de baixa energia, apresentará um valor de CSR mais baixo do que um feixe que contém, preferencialmente, fótons de maior energia, mesmo que este feixe possua menor intensidade. Por isso, a camada semi-redutora é considerada um parâmetro muito 
importante para avaliação da qualidade dos Raios-X. Ela é capaz de especificar, de maneira conveniente, a "qualidade" da radiação contida num feixe, pois, quanto mais energético ou "penetrante" for este feixe, maior será a espessura necessária para que o absorvedor reduza sua intensidade à metade.

Normas internacionais ${ }^{3}$ apud Wagner et al. (WAGNER_90) estabelecem valores mínimos da CSR que devem ser encontrados para cada tipo de aparelho com a finalidade de se manter um padrão de qualidade nas imagens radiográficas. Por exemplo, a CSR mínima exigida para aparelhos mamográficos operando com $30 \mathrm{kVp}$ é de $0,3 \mathrm{mmAl}$.

Segundo Wolbarst (WOLBARST_93), uma outra maneira de expressar a qualidade de um feixe de Raios-X é através de sua energia equivalente, definida como a energia dos fótons de um feixe de radiação monocromática que seria atenuado da mesma forma que um feixe de Raios-X não monoenergético. Como, para um feixe de radiação monocromática o valor da CSR é função apenas da energia de seus fótons (para um determinado material absorvedor), a energia equivalente de um determinado feixe de Raios-X pode ser calculada a partir do conhecimento da sua CSR. Determina-se a relação entre a energia equivalente e a CSR a partir do conhecimento do coeficiente de atenuação linear, $\mu$, do material absorvedor, utilizando-se a equação (3.2). A Figura 3.1 a seguir mostra a relação entre a CSR e a energia equivalente para o chumbo, cobre e alumínio obtida por Johns \& Cunningham (JOHNS_83).

\footnotetext{
3 "Regulations for the Administration and Enforcement of the Radiation Control for Health and Safety Act of 1968." Section 1020.30, Diagnostic X-ray Systems and Their Major Components, U. S. Department of Health, Education, and Welfare, Center for Devices and Radiological Health, Rockville, Maryland.
} 


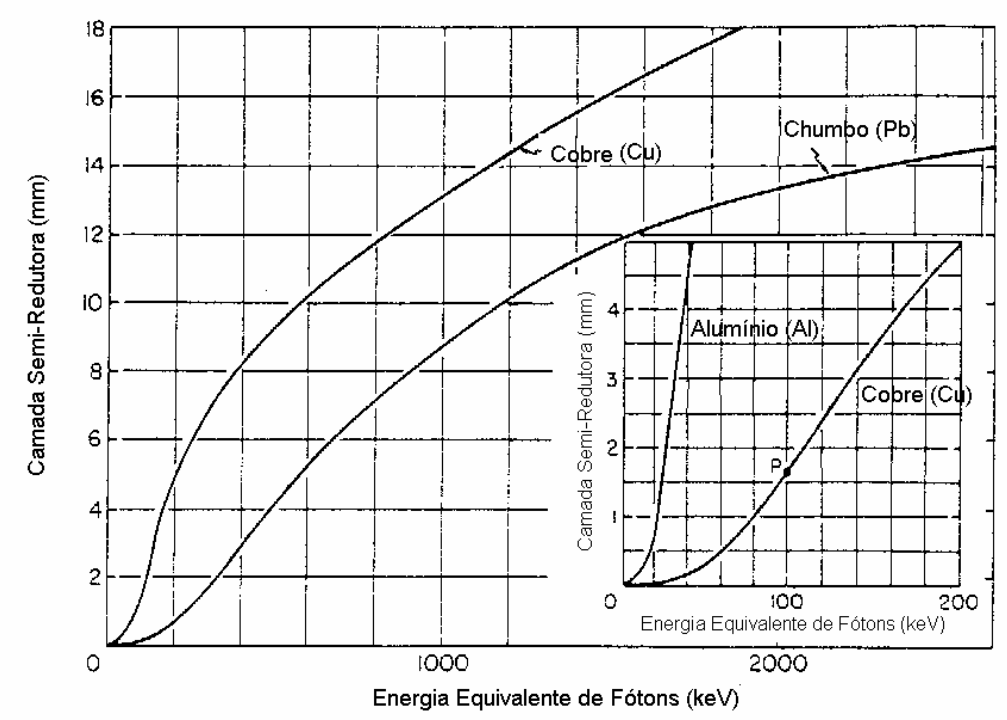

Figura 3.1. - Relação entre a CSR e energia equivalente para Pb, Cu e Al (JOHNS_83).

\subsection{Métodos experimentais para a determinação da CSR}

O método mais freqüentemente utilizado para a determinação da camada semi-redutora de aparelhos de Raios-X para radiodiagnóstico é o proposto por Trout, Kelley \& Lucas (TROUT_60). Apesar de os autores descreverem o método para aparelhos que operam na faixa de 100 a $300 \mathrm{kVp}$ utilizados em radioterapia, os procedimentos e os resultados obtidos podem ser estendidos para outros valores de tensão. O método descrito consistia em colocar um dosímetro, do tipo câmara de ionização, a uma distância de $50 \mathrm{~cm}$ do tubo de Raios-X no centro do campo de radiação. O feixe era colimado por um diafragma de chumbo de $7 \mathrm{~mm}$ de espessura e com abertura circular que podia variar de 1,5 a $10 \mathrm{~cm}$ de diâmetro. Junto a esse diafragma foram colocados vários atenuadores, de cobre ou de alumínio, de espessura conhecida, para que o feixe de Raios-X fosse filtrado por eles. $\mathrm{O}$ arranjo dos componentes utilizados para essa determinação estão ilustrados na Figura 3.2. 


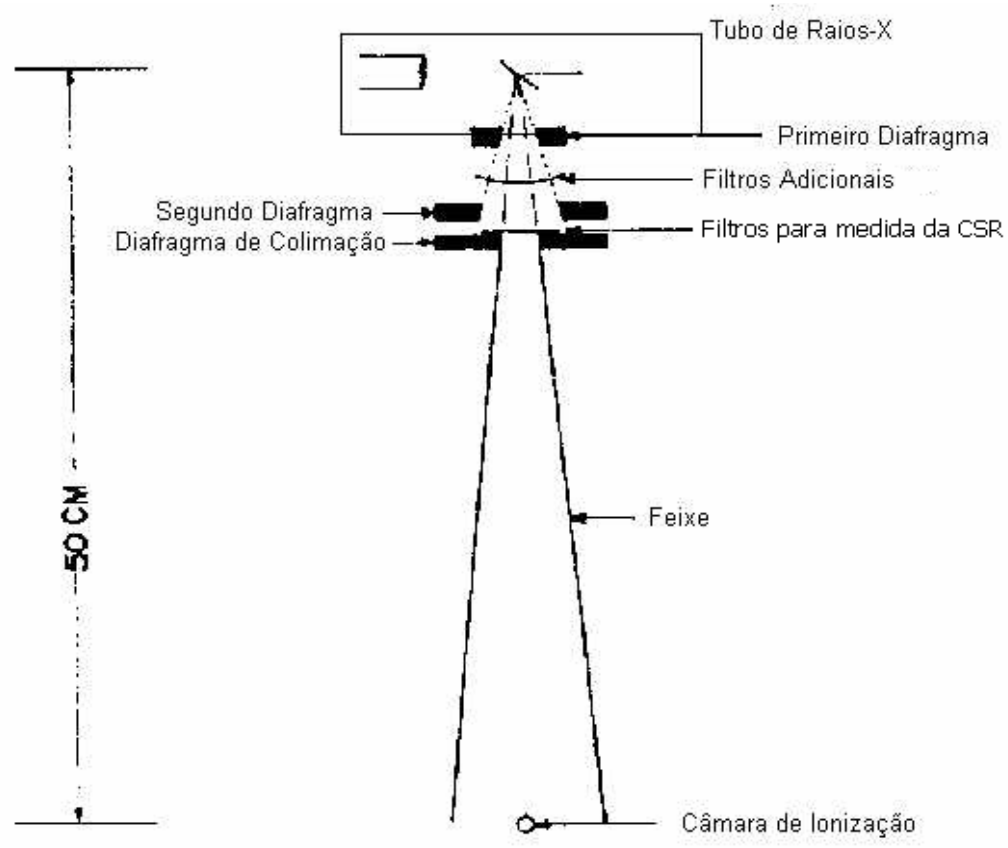

Figura 3.2. - Diagrama do método experimental para determinação da CSR (TROUT_60).

Assim, media-se a dose de radiação recebida pelo dosímetro para uma determinada $\mathrm{kVp}$ e corrente em função da espessura dos atenuadores que eram colocados junto ao diafragma de chumbo. A medida inicial era feita sem a colocação de nenhum absorvedor sob o feixe. A partir disso, várias medidas eram efetuadas para o mesmo valor de $\mathrm{kVp}$ e corrente, aumentando gradativamente a espessura das lâminas de alumínio ou cobre que eram colocadas sob o feixe a uma certa distância da fonte de Raios-X.

A partir desses dados construiu-se um gráfico relacionando os valores da dose de radiação medidos com a espessura do absorvedor utilizado (curva de atenuação). A camada semi-redutora para uma determinada $\mathrm{kVp}$ e corrente era obtida através da leitura, no gráfico, do valor correspondente à espessura que reduzia a dose inicial à metade.

Os autores notaram que os valores medidos para a CSR não eram sempre os mesmos, apresentando variações significativas à medida que era modificada a posição do filtro no feixe, o tamanho da abertura do diafragma e a distância em que o dosímetro era colocado. Essas variações, teoricamente, não deveriam ocorrer, pois a CSR deve ser função apenas da energia efetiva do feixe (equação 3.2). Desse modo, concluiu-se que as diferenças nos valores medidos eram 
conseqüência da radiação espalhada, gerada essencialmente da interação dos fótons com o filtro, que também era captada pelo dosímetro.

O mesmo problema foi apontado por outros autores (SCAFF_79, JOHNS_83, CURRYIII_90, WOLBARST_93). É necessário, portanto, que se use um feixe bem colimado para as medidas da CSR, pois, com feixes divergentes, aparecerão radiações secundárias nos absorvedores que contribuirão para aumentar a dose medida pelo detector, como mostra a Figura 3.3. Com isso, o valor da CSR medida para um feixe divergente será maior do que o valor obtido para um feixe colimado, como mostra a Figura 3.4.

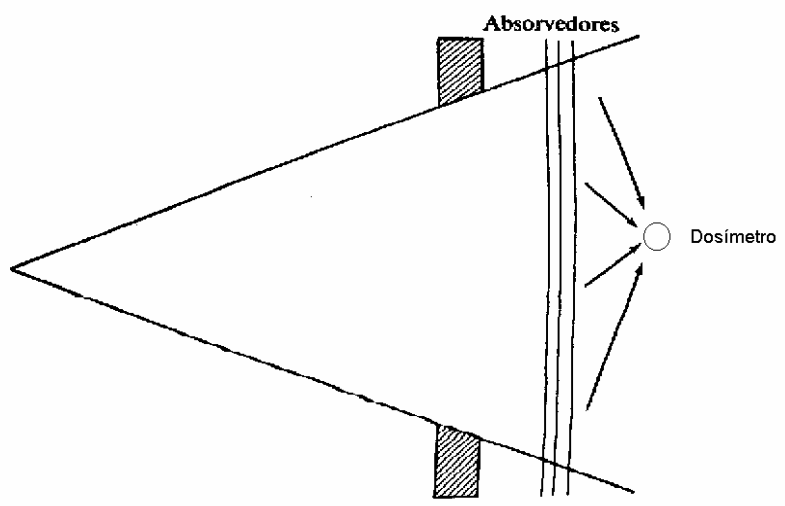

Figura 3.3. - Medida da CSR com feixe divergente (SCAFF_79).

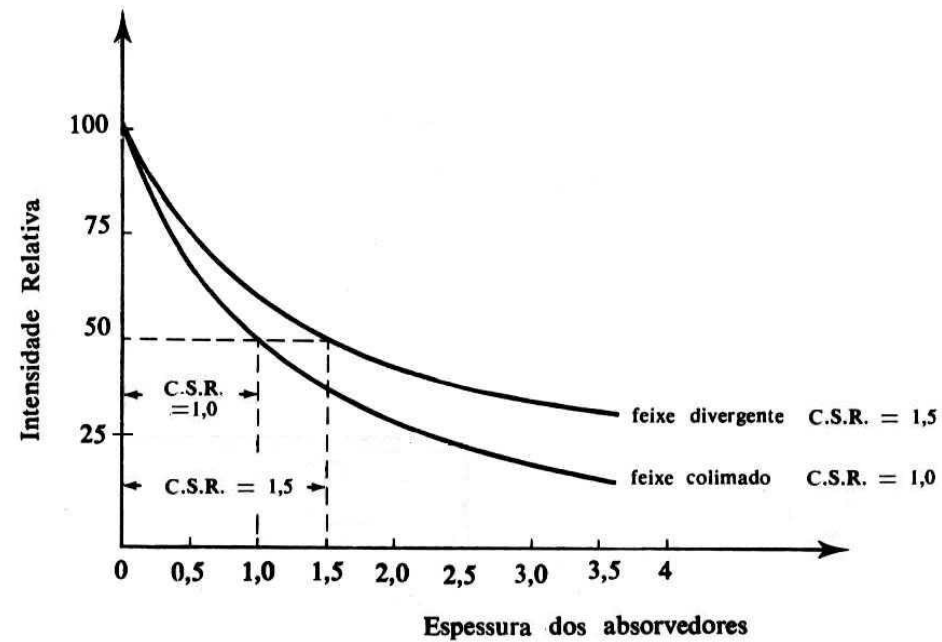

Figura 3.4. - CSR para feixe colimado e para feixe divergente (SCAFF_79). 
Segundo Wolbarst (WOLBARST_93), para um feixe de radiação monocromática, a curva de atenuação mostrada na Figura 3.4 apresentaria um comportamento perfeitamente exponencial, seguindo a equação de Lambert-Beer (equação 2.5). Como, na prática, os feixes de Raios-X não são monoenergéticos, a curva de atenuação gerada nas medidas da CSR, apesar de apresentarem a forma de uma exponencial, não seguem exatamente essa relação. As diversas camadas geradas pelos atenuadores retiram do feixe os fótons de mais baixa energia, comportando-se como os filtros descritos no item 2.4, que modificam, progressivamente, a qualidade do feixe.

Johns \& Cunningham (JOHNS_83) realizaram experiências que comprovaram esse comportamento. Empregando a mesma metodologia descrita por Trout et al. (TROUT_60), obtiveram a curva de atenuação mostrada na Figura 3.5 para um aparelho de radioterapia operando com $200 \mathrm{kVp}$. Com isso, determinaram a camada semi-redutora encontrando o ponto na curva onde a taxa de exposição se reduz à metade. Nesse caso, a taxa de exposição encontrada sem filtração foi $68(\mathrm{C} / \mathrm{Kg}) / \mathrm{min}$; portanto, a CSR do feixe não filtrado é $0,35 \mathrm{mmCu}(0,35 \mathrm{~mm}$ de cobre reduziu a taxa de exposição de $68(\mathrm{C} / \mathrm{Kg}) / \mathrm{min}$ para $34(\mathrm{C} / \mathrm{Kg}) / \mathrm{min})$. Quando um atenuador de 1,0mm de cobre foi utilizado como filtro adicional, a CSR aumentou para $1,30 \mathrm{mmCu}$.

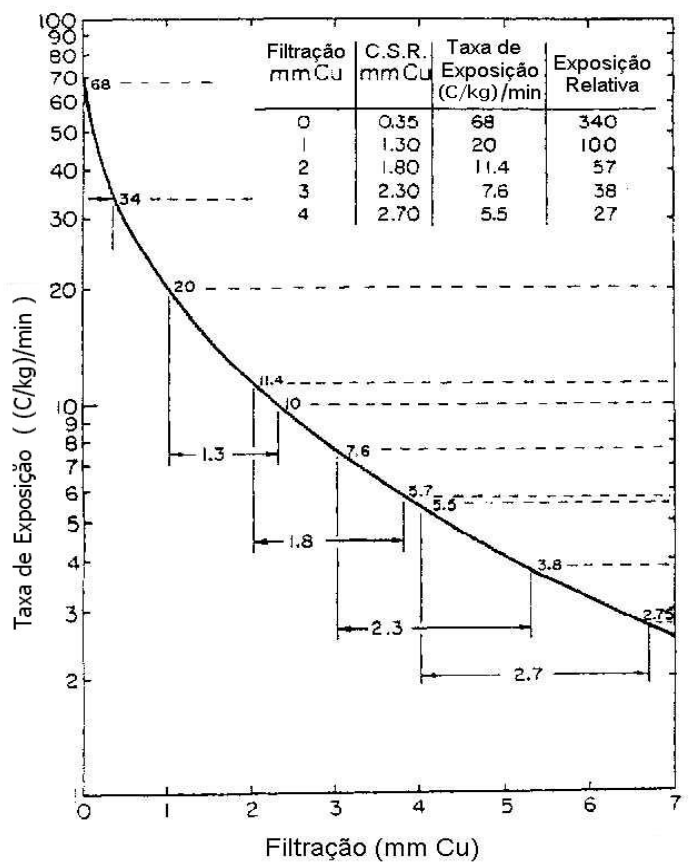

Figura 3.5. - Curva de atenuação gerada pela filtração de um feixe de Raios-X (JOHNS_83). 
Com isso, os autores observaram que, à medida que adicionavam filtros sob o feixe, a camada semi-redutora aumentava e a taxa de exposição relativa diminuía. Isto mostra que, com a adição de filtros, a energia efetiva do feixe aumenta, pois os fótons de baixa energia são absorvidos e, ao mesmo tempo, a dose de radiação diminui, já que a filtração diminui a quantidade de radiação contida no feixe. Assim, utilizando-se uma filtração adicional mais "pesada", os fótons menos energéticos do feixe seriam quase que totalmente removidos e o feixe gerado se aproximaria cada vez mais de um feixe monoenergético, fazendo com que a curva de atenuação se aproximasse de uma exponencial.

\subsection{Influência da radiação espalhada nas medidas da CSR}

Fótons do feixe de Raios-X provenientes do tubo, ao atravessarem os filtros colocados para medir a camada semi-redutora, podem sofrer um desvio na sua trajetória devido à colisão com os átomos do material do filtro. Esses fótons desviados são responsáveis por uma radiação secundária, chamada de radiação espalhada. Portanto, nas medidas da CSR procura-se minimizar a influência desta radiação, pois, ao atingir o dosímetro, ela provocará uma falsa medida da CSR, que apresentará um valor maior que o valor real.

Johns \& Cunningham (JOHNS_83) notaram que os valores obtidos para a CSR quando eram colocados filtros na posição $A$ do arranjo apresentado na Figura 3.6 eram diferentes de quando eles eram colocados na posição $B$. Além disso, usando campo de exposição maior, o valor medido da CSR também aumentava. 


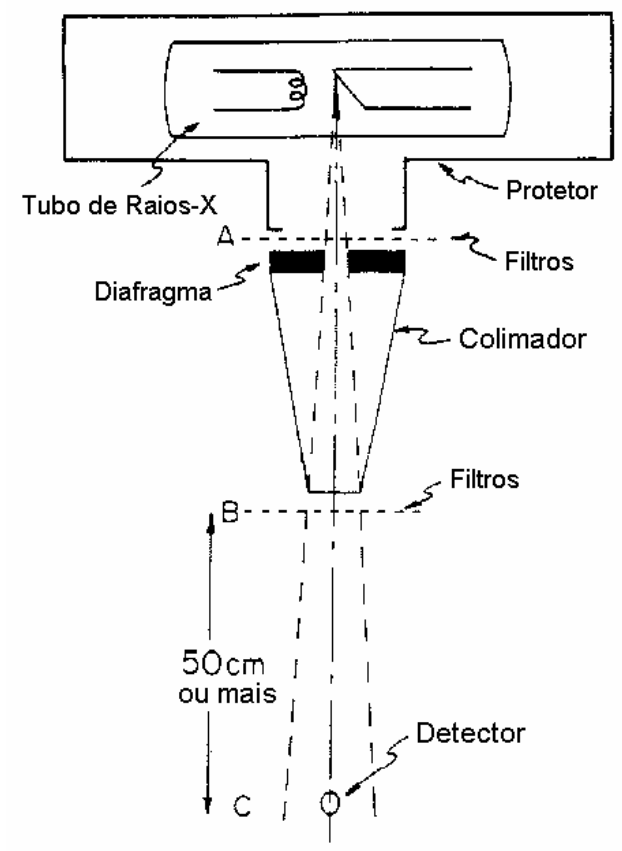

Figura 3.6. - Arranjo dos componentes para medida da CSR (JOHNS_83).

Para ilustrar esse efeito, os autores fizeram uma experiência utilizando um feixe de $250 \mathrm{kVp}$ para um campo de $5 \times 5 \mathrm{~cm}$, com um dosímetro sendo colocado a uma distância de $100 \mathrm{~cm}$ da fonte, no centro do campo. Os resultados são apresentados no gráfico da Figura 3.7.

A CSR foi medida utilizando-se primeiramente o filtro na posição $A$ do arranjo (curva $A_{l}$ ) e depois utilizando-se o filtro mais próximo ao detector, na posição $B$ (curva $B_{l}$ ). Aparentemente, o feixe medido para a posição $B$ é mais penetrante do que o medido em $A$. Quando o filtro é colocado mais próximo do detector (posição $B$ ), o dosímetro recebe mais radiação espalhada gerada pelo filtro, e o valor obtido para a CSR tende a ser maior.

Alterando-se o tamanho do campo de radiação de $5 \times 5 \mathrm{~cm}$ para 10x10cm, as medidas da CSR também variaram, como ilustram as curvas $A_{2}$ e $B_{2}$ da Figura 3.7. Assim, para o campo de exposição com maior extensão, o valor da CSR medida também aumentava devido ao aumento no espalhamento da radiação. 


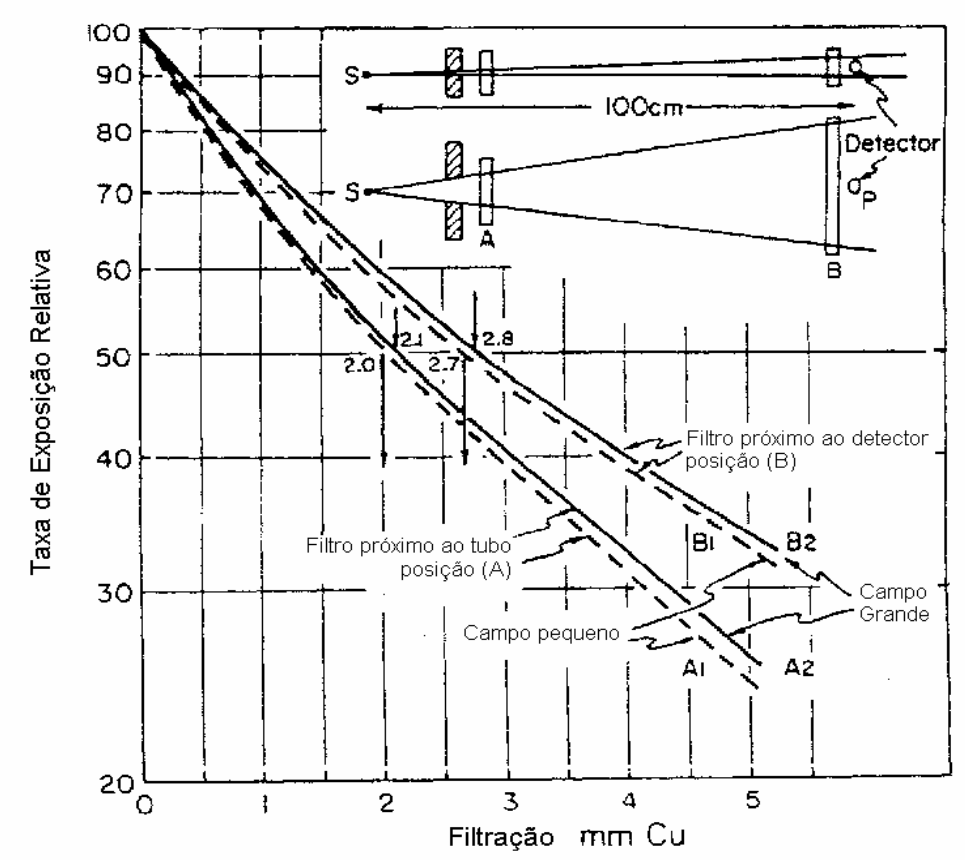

Figura 3.7. - Medidas da CSR obtidas para arranjos geométricos diferentes (JOHNS_83).

Trout et al. (TROUT_60) já haviam notado diferenças nas medidas da CSR em função do arranjo geométrico utilizado: distância do filtro e do dosímetro em relação à fonte, e tamanho e forma geométrica do campo que irradiava o filtro. Assim, elaboraram experiências para comprovar e quantificar a influência da radiação espalhada nas medidas da CSR.

Primeiramente, variaram o tamanho do campo que irradiava o filtro. Para a colimação, foi utilizado um diafragma circular cuja abertura podia ser variada. Os resultados obtidos são apresentados na Figura 3.8. Nota-se que, à medida que se aumenta o campo de radiação, a quantidade de radiação espalhada produzida também aumenta e, conseqüentemente, o valor da CSR também. 


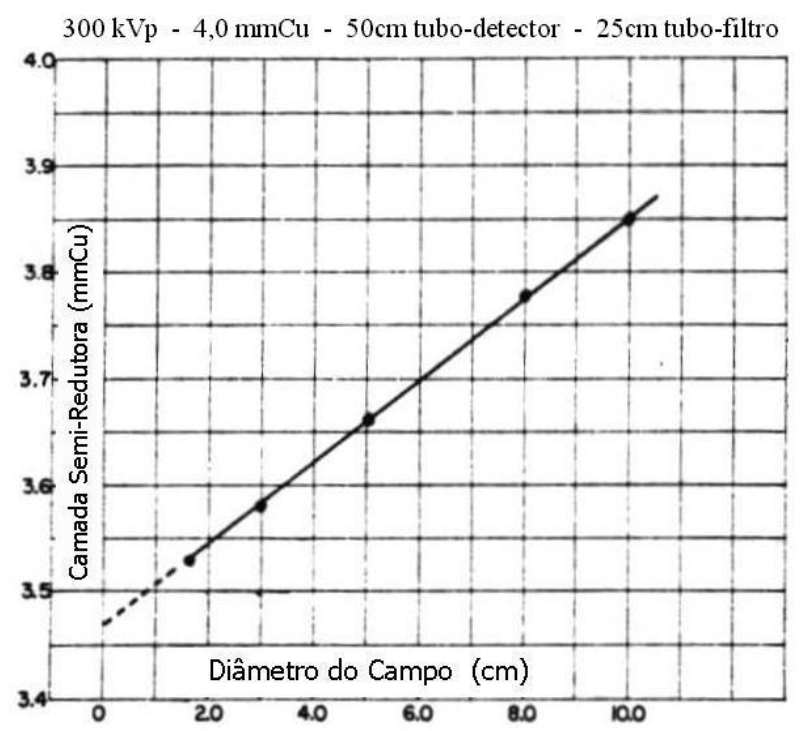

Figura 3.8. - Variação nas medidas da CSR em função do tamanho do campo (TROUT_60).

Depois, utilizando-se um tamanho fixo para o campo, mediu-se a variação das medidas da CSR em função da variação da distância do filtro ao tubo de Raios-X. A distância entre o dosímetro e o tubo foi mantida constante $(100 \mathrm{~cm})$, variando-se apenas a posição do filtro no feixe, desde bem próximo ao dosímetro até bem próximo ao tubo. Os resultados obtidos são apresentados na Figura 3.9.

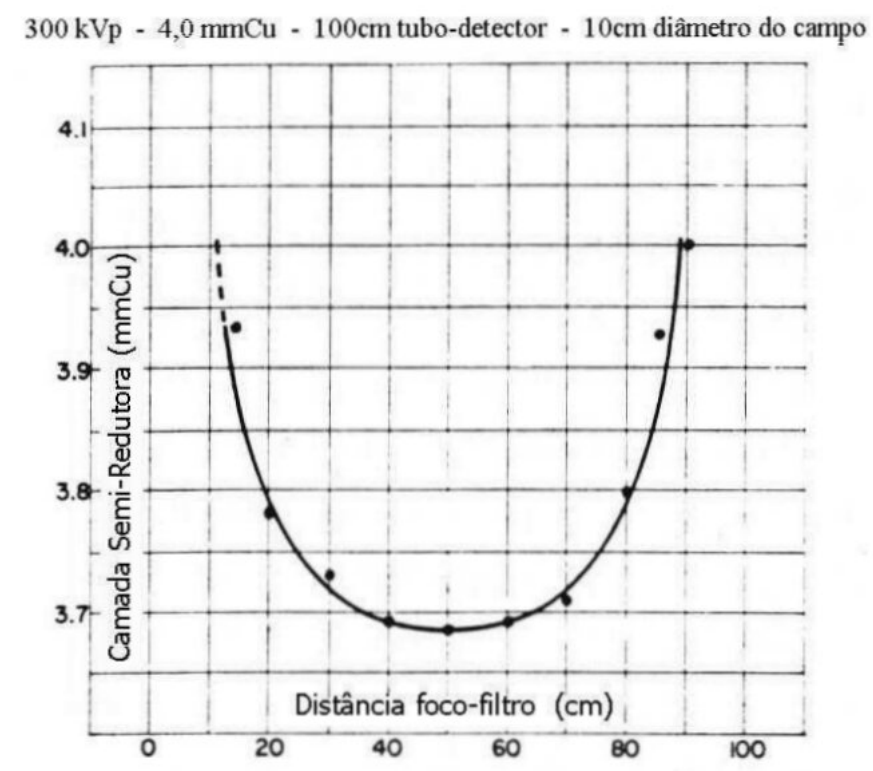

Figura 3.9. - Variação nas medidas da CSR em função da variação da distância foco-filtro (TROUT_60). 
O valor encontrado para a CSR medida foi menor quando o filtro foi colocado à metade da distância entre o tubo de Raios-X e o dosímetro, concluindo-se que este é o local onde as medidas da CSR sofrem menos o efeito do espalhamento. Assim, mantendo-se o filtro sempre na metade do valor da distância entre o tubo de Raios-X e o dosímetro, verificou-se a variação nas medidas da CSR em função da distância entre o dosímetro e o tubo. Os resultados obtidos estão apresentados na Figura 3.10.

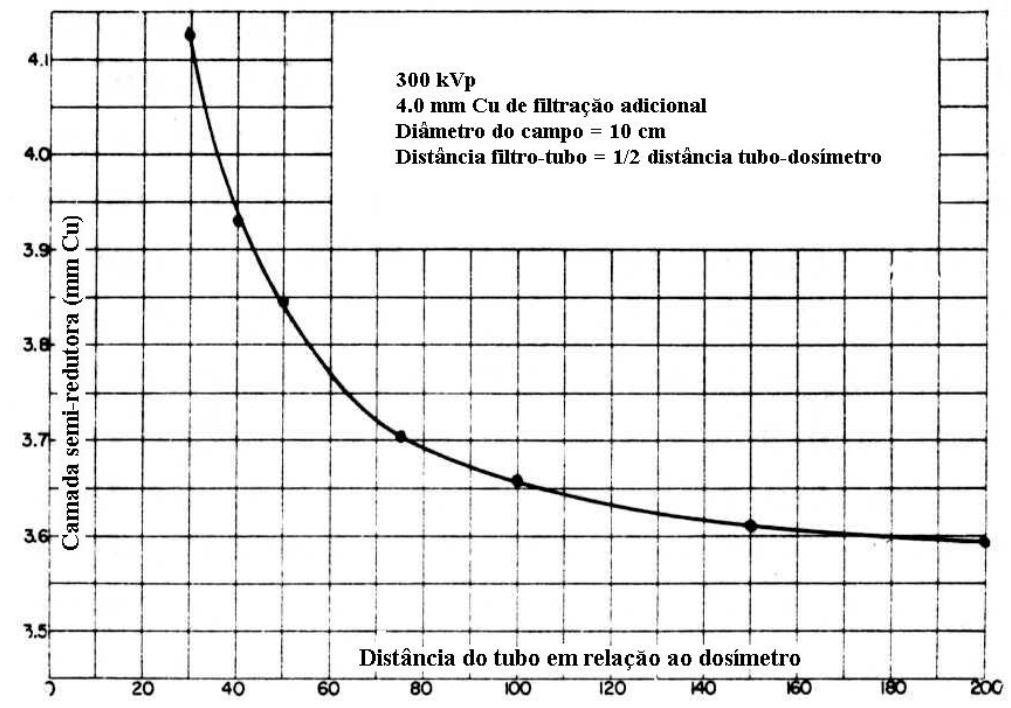

Figura 3.10. - Variação nas medidas da CSR em função da distância do dosímetro ao tubo (TROUT_60).

Com isso, observou-se que o valor medido para a CSR diminui à medida que afasta-se o dosímetro do tubo de Raios-X, estabilizando para distâncias mais longas. Isto ocorre pois, para longas distâncias, somente parte da radiação espalhada gerada pelo filtro consegue atingir o dosímetro.

Devido a essa diferença nos valores da CSR observada na prática, estabeleceu-se um padrão de medida para que a CSR de um determinado aparelho radiográfico seja única e independente da geometria utilizada na medição. 


\subsection{Técnicas para uma medida única da CSR}

A radiação espalhada gerada pelo filtro faz com que a medida da camada semi-redutora de um único aparelho, operando sob condições específicas, possa apresentar variações de até $10 \%$ em função da geometria utilizada em sua determinação. Esse parâmetro só poderia expressar realmente a qualidade de um feixe de radiação se ele fosse independente da geometria e da técnica de medição utilizada em sua determinação. Assim, Trout et al. (TROUT_60), apresentaram soluções para reduzir a influência da radiação espalhada nas medidas da CSR.

A primeira solução apresentada foi em relação à geometria a ser utilizada. O dosímetro utilizado deve possuir área de irradiação bem pequena, para que seja possível a utilização de um feixe bastante colimado, devendo ser colocado a uma distância mínima de $100 \mathrm{~cm}$ do tubo. Utilizando essa configuração, a variação nas medidas da CSR para um feixe de $300 \mathrm{kVp}$ foi reduzida a $1 \%$.

Quanto menor o campo irradiado no filtro, menor será a radiação espalhada produzida; assim, uma outra solução apresentada foi a de extrapolar os valores obtidos num experimento onde se varia o tamanho do campo (como o apresentado na Figura 3.8) para um valor onde esse tamanho é zero. A vantagem desse método é que, na prática, a maioria dos aparelhos de Raios-X comerciais possuem colimadores ajustáveis e, portanto, variar o tamanho do campo de exposição é bastante simples. Os resultados obtidos são apresentados na Figura 3.11. 


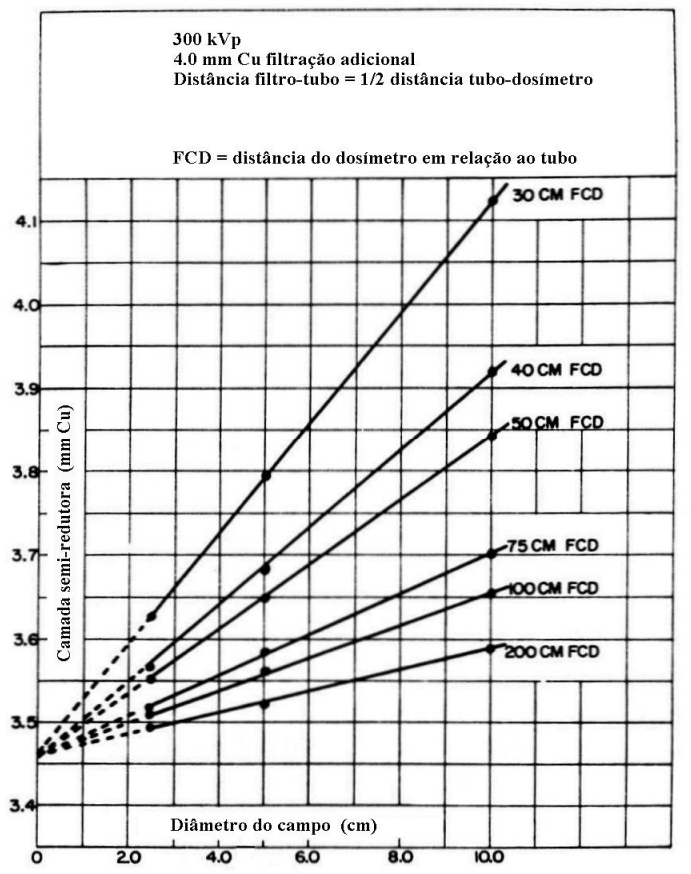

Figura 3.11. - Variação nas medidas da CSR em função do tamanho do campo (TROUT_60).

Nota-se que a variação da CSR em função do diâmetro do filtro é linear e, portanto, a extrapolação proposta por Trout et al. (TROUT_60) resulta em um único valor para a CSR. Isto mostra também que, se o campo pudesse ser reduzido a zero, a CSR medida seria sempre a mesma, independente da geometria utilizada, pois, neste caso, não existiria radiação espalhada.

Nas experiências de Trout et al. (TROUT_60) foram utilizados aparelhos operando com valores elevados de tensão, entre 100 e $300 \mathrm{kVp}$, além de filtros de cobre para a atenuação do feixe. Segundo Wolbarst (WOLBARST_93), a intensidade de radiação espalhada produzida tende a ser maior com o aumento da energia dos fótons e com o aumento da densidade do absorvedor, conforme Figura 3.12. Assim, para aparelhos de Raios-X convencionais e mamográficos, onde a tensão utilizada varia entre 20 e $120 \mathrm{kVp}$ na maioria dos casos, o espalhamento produzido é bem menor, o que provoca uma variação bem menos significativa nos valores medidos para a CSR em função da geometria utilizada. 


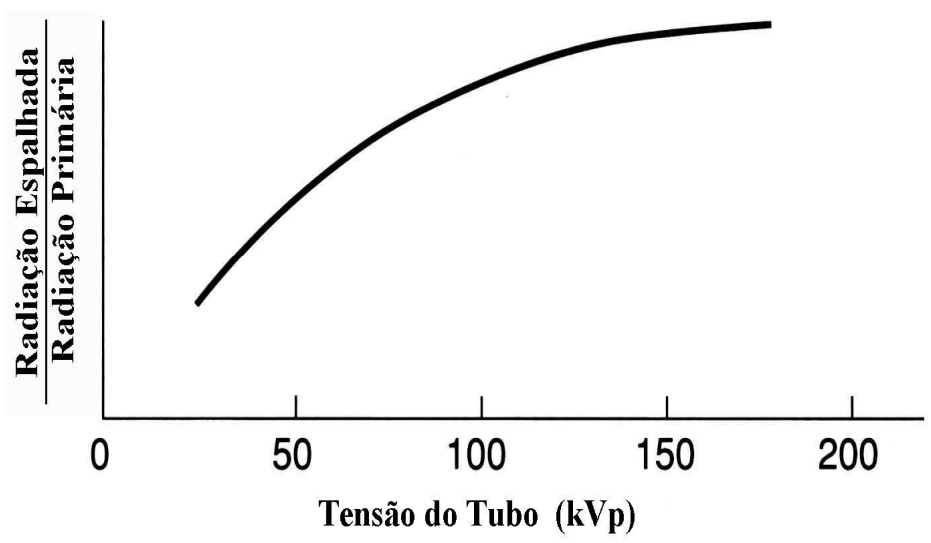

Figura 3.12. - Relação entre radiação espalhada e radiação primária em função da $k V p$ (WOLBARST_93).

\subsection{Fontes de erro nas medidas da CSR}

Apesar de todos os cuidados e técnicas de procedimento apontados por Trout et al. (TROUT_60) para uma medida de maior precisão da camada semiredutora, existem ainda outros fatores que não foram observados por eles e que constituem fontes de erros nessas medidas, podendo comprometer a utilização do parâmetro CSR como indicador de qualidade de feixes de Raios-X. Num estudo elaborado por Wagner, Archer \& Cerra (WAGNER_90), foram apontados erros maiores que $10 \%$ nas medidas da CSR em equipamentos mamográficos devidos à utilização de técnicas e equipamentos não apropriados, o que não significa, no entanto, variações causadas pelo baixo desempenho do aparelho. Os erros apontados foram creditados aos seguintes fatores:

- não adequação dos dosímetros à faixa de energia utilizada;

- impureza do material utilizado como filtro;

- imprecisão nas medidas de espessura do filtro;

- posicionamento incorreto do dosímetro no campo de exposição.

Nas experiências realizadas por Wagner et al. (WAGNER_90), foram utilizados oito dosímetros diferentes para as medidas da camada semi-redutora. Os 
valores encontrados apresentaram diferenças de até 17\%, para medidas feitas num único aparelho sob as mesmas condições. Os dosímetros, de modo geral, são projetados para operar numa faixa de energia limitada ou apresentam curvas de calibração para a utilização em outros intervalos. A não-observação desses limites é a responsável pelo erros encontrados pelos autores. Portanto, recomenda-se a utilização de um dosímetro adequado para cada faixa de energia, sendo, portanto, independente das variações ocorridas dentro desse intervalo.

Em relação aos filtros, foram utilizados filtros de alumínio com diferentes índices de pureza para verificar a variação nos valores de CSR medidos. Utilizando-se atenuadores do tipo "1100 aluminum alloy", de diversas espessuras e com $99 \%$ de pureza, foram observadas diferenças de até 7\% nas medidas da CSR em função das diferentes combinações de espessura feitas com estes atenuadores. Utilizando filtros do tipo "high purity aluminum", com mais de 99,9\% de pureza, em 36 combinações diferentes, a máxima variação encontrada entre as medidas foi da ordem de 1,4\%. Assim, para uma medida com maior precisão da CSR de um determinado aparelho devemos utilizar atenuadores com índice de pureza bastante elevado, da ordem de 99,9\%, como já afirmavam Stanton et al. (STANTON_84).

Quanto aos métodos de verificação da espessura dos atenuadores utilizados na determinação da CSR, foram encontrados erros da ordem de 5\% nos atenuadores comerciais em relação às medidas especificadas pelo fabricante. Medidas realizadas com quatro micrômetros diferentes, para o mesmo atenuador, apresentaram diferenças da ordem de $4 \%$ entre elas. A sugestão é que se utilizem vários micrômetros nas medidas de espessura do filtro e que se considere apenas a média dos valores obtidos entre estas medidas.

A posição do dosímetro no campo de radiação também é um fator importante no que diz respeito à determinação da camada semi-redutora. Wagner et al. (WAGNER_90) colocaram os dosímetros em diversas posições no campo e os resultados obtidos mostraram que a camada semi-redutora medida no lado correspondente ao anodo do tubo era cerca de $5 \%$ maior do que a medida do lado do catodo. Essa variação não pode ser considerada como "erro", pois está coerente com o efeito "heel"; o feixe tende a ser mais penetrante do lado do anodo, já que os fótons de menor energia sofrem maior absorção. Por isso, deve-se estipular um local exato 
dentro do campo para a medida da CSR. A maioria dos autores definem que a camada semi-redutora deve ser medida sempre no centro do campo para fins de comparação (TROUT_60, JOHNS_83, CURRYIII_90, WOLBARST_93).

Considerando-se todos estes fatores, a propagação de erros pode resultar em variações de até $20 \%$ na determinação da CSR. Dessa forma, certos cuidados devem ser levados em conta nas medidas experimentais da camada semiredutora, para uma avaliação mais precisa dos feixes de Raios-X.

\subsection{A Segunda CSR e o coeficiente de homogeneidade}

Embora a camada semi-redutora seja um bom parâmetro para especificar a qualidade dos feixes de Raios-X, uma mesma CSR pode ser obtida para feixes que possuam características espectrais distintas. Trout, Kelley \& Lucas (TROUT_60) apontaram este problema quando mediram a CSR para um feixe de $200 \mathrm{kVp}, 0,5 \mathrm{mmCu}$ e para outro feixe de $250 \mathrm{kVp}, 0,3 \mathrm{mmCu}$ e obtiveram o mesmo valor para a camada semi-redutora; $\mathrm{CSR}=1,0 \mathrm{mmCu}$. Assim, esses mesmos autores, em trabalho posterior (TROUT_62), sugeriram a medida de uma segunda camada semi-redutora ( $2^{\text {a }}$ CSR) como um melhor especificador da qualidade de um feixe de Raios-X.

A $2^{\mathrm{a}}$ CSR corresponde à espessura de um material absorvedor que reduz a intensidade de radiação de um feixe de Raios-X de $50 \%$ para $25 \%$ do seu valor original. Além disso, os autores definiram um coeficiente de homogeneidade obtido através da divisão entre o valor da $1^{\mathrm{a}} \mathrm{CSR}$ com o da $2^{\mathrm{a}} \mathrm{CSR}$.

Segundo Wolbarst (WOLBARST_93), a primeira camada semiredutora "endurece" o feixe, tornando-o mais penetrante. Portanto, para feixes de radiação não monocromática, a $2^{\mathrm{a}} \mathrm{CSR}$ será sempre maior que a primeira e o valor do coeficiente de homogeneidade será sempre menor do que 1. Quanto mais heterogêneo for o feixe, maior será o valor da $2^{\mathrm{a}} \mathrm{CSR}$ em relação à $1^{\mathrm{a}} \mathrm{CSR}$ e, portanto, menor será o coeficiente de homogeneidade. Para feixes monoenergéticos, os valores da $1^{\mathrm{a}} \mathrm{CSR}$ e da $2^{\mathrm{a}} \mathrm{CSR}$ serão os mesmos, e o coeficiente de homogeneidade será igual a 1 . 
O método para se medir a $2^{\mathrm{a}}$ CSR é o mesmo apresentado no item 3.2, ou seja, através da curva de atenuação produzida por filtros colocados sob o feixe, determina-se, por interpolação, a espessura do filtro necessária para reduzir a dose de $100 \%$ para $50 \%\left(1^{\mathrm{a}} \mathrm{CSR}\right)$ e de $50 \%$ para $25 \%$ (2 $\left.\mathrm{CSR}\right)$. A Figura 3.13 ilustra tal procedimento. Neste experimento, realizado por Trout et al. (TROUT_62), o valor da $1^{\mathrm{a}} \mathrm{CSR}$ é $0,65 \mathrm{mmCu}$ e o da $2^{\mathrm{a}} \mathrm{CSR}$ é $1,25 \mathrm{mmCu}$, resultando em um coeficiente de homogeneidade igual a 0,52 .

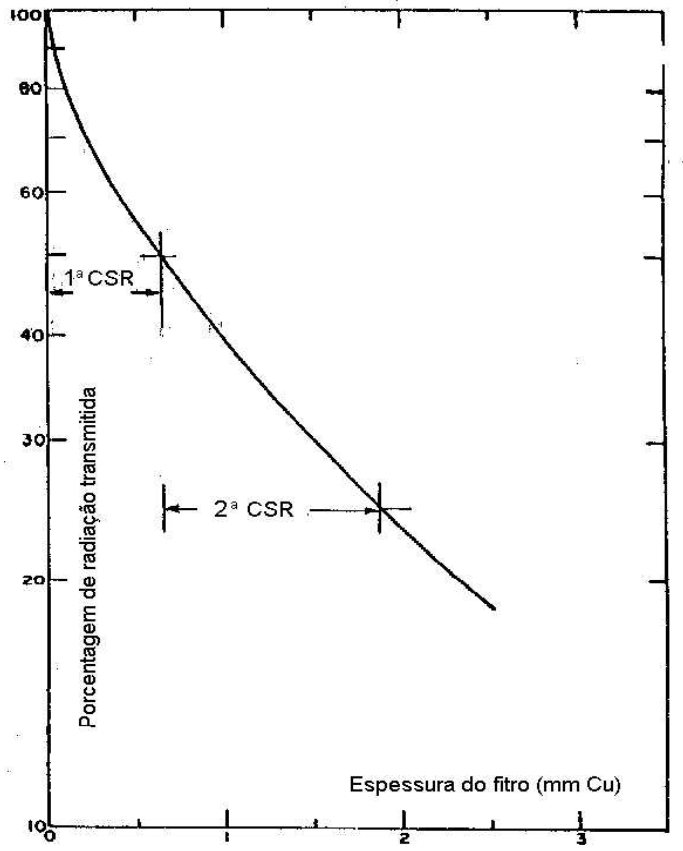

Figura 3.13. - Método para determinar a $1^{\mathrm{a}} \mathrm{CSR}$ e a $2^{\mathrm{a}}$ CSR (TROUT_62).

Além disso, os autores realizaram uma experiência onde se media a variação da $1^{\mathrm{a}}$ CSR e da $2^{\mathrm{a}} \mathrm{CSR}$ em função da espessura de um filtro adicional que era colocado sob um feixe de Raios-X. A Figura 3.14 mostra os resultados obtidos. Nota-se que a $2^{\text {a }}$ CSR é sempre maior do que a $1^{\text {a }}$ CSR e que os valores das duas convergem para um mesmo ponto quando o valor da filtração adicional aumenta. Este fato está coerente com o que foi apresentado no item 2.4 , onde, à medida que aumenta-se a filtração de um feixe de Raios-X, os fótons menos energéticos são retirados do espectro, tornando-o mais homogêneo e portanto mais próximo de um feixe monoenergético. Assim, aumentando-se a filtração, a diferença entre a $1^{\mathrm{a}} \mathrm{CSR}$ 
e a $2^{\text {a }}$ CSR diminui, aumentando, conseqüentemente, o valor do coeficiente de homogeneidade.

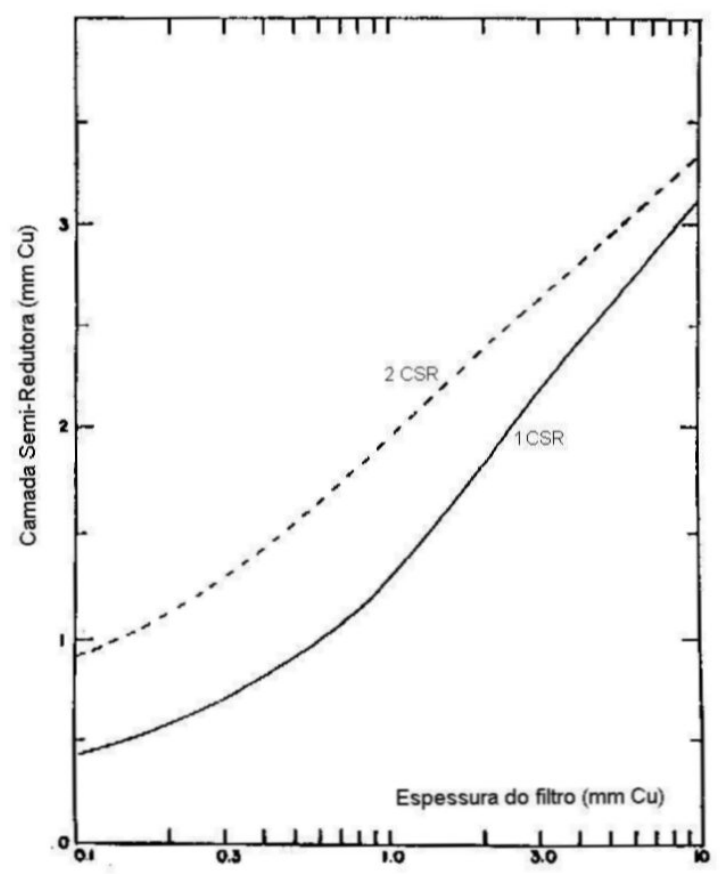

Figura 3.14. - Variação da $1^{\mathrm{a}} \mathrm{CSR}$ e da $2^{\mathrm{a}} \mathrm{CSR}$ como função da espessura do filtro de cobre (TROUT_62).

A Figura 3.15 mostra a variação da $1^{\mathrm{a}} \mathrm{CSR}$ em função da espessura do filtro de alumínio para diversos valores de tensão. $\mathrm{O}$ valor da $1^{\mathrm{a}} \mathrm{CSR}$ aumenta com o aumento da $\mathrm{kVp}$, pois o feixe torna-se mais energético; também aumenta à medida que aumenta-se a filtração adicional, pois o feixe torna-se mais penetrante e homogêneo. 


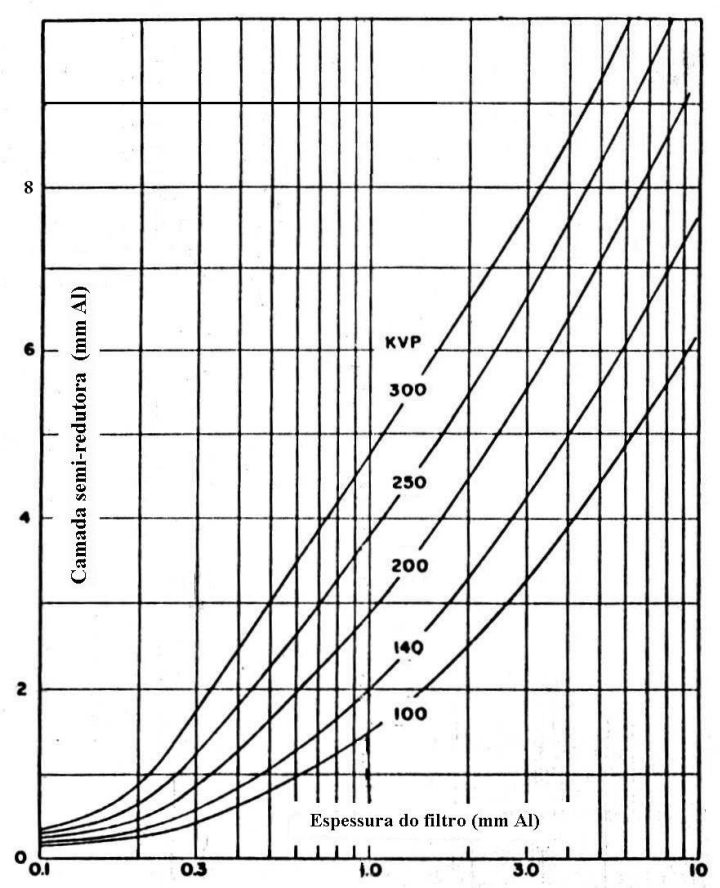

Figura 3.15. - Variação da $1^{\mathrm{a}} \mathrm{CSR}$ em função da espessura do filtro de alumínio (TROUT_62).

Assim, a indicação apenas da $1^{\text {a }}$ CSR não é suficiente para descrever por completo a qualidade ou a distribuição espectral de um feixe de radiação. Esta especificação de qualidade fica mais completa quando utilizadas, como indicadores, a $1^{\text {a }}$ CSR e a $2^{\text {a }}$ CSR (além do coeficiente de homogeneidade).

\subsection{Dispositivo eletrônico para medida experimental da CSR}

Um método alternativo para a determinação da camada semi-redutora de aparelhos de Raios-X médicos foi desenvolvido no Laboratório de Análise e Digitalização de Imagens (LADI) do Departamento de Engenharia Elétrica da EESC / USP em São Carlos. Para tanto, partiu-se de um dispositivo eletrônico de medição desenvolvido anteriormente (SCHIABEL_97a) e que era dedicado, à princípio, à medições de $\mathrm{kVp}$, corrente, intensidade e tempo de exposição. Esse dispositivo efetua as medições através de um sensor à base de silício semicondutor, capaz de converter os níveis de radiação recebidos em níveis de tensão. Esse sensor é pequeno (área de $1,0 \mathrm{~mm}^{2}$ ) e pode ser posicionado em qualquer localização no 
campo. Com a utilização conjunta de um circuito eletrônico de tratamento, tornou-se possível a medida de diversos parâmetros operacionais dos aparelhos radiográficos através do sinal gerado por esse sensor.

Em pesquisa mais recente (CURI_98), foi desenvolvido um sistema digital de aquisição de dados que opera juntamente com um dispositivo sensor, elaborado a partir daquele primeiro, permitindo que os dados sejam processados via software utilizando-se um microcomputador portátil acoplado. A operação com esse aparelho é relativamente simples e os resultados obtidos em avaliações prévias foram muito satisfatórios.

Com a implementação dessa parte computacional e a correspondente adaptação do sistema de sensoriamento do feixe, o sistema desenvolvido é capaz de medir não só os parâmetros citados anteriormente, como também a camada semiredutora de aparelhos radiográficos. Isto é feito com a utilização de uma cunha contínua de alumínio que é posicionada imediatamente acima de um dos sensores de silício. Essa cunha tem 5,35mm de espessura máxima, 0,5mm de espessura mínima, $2,0 \mathrm{~cm}$ de largura (da rampa) e 11,49cm de comprimento, e está acoplada a um mecanismo capaz de se movimentar no sentido de crescimento da sua espessura, dirigido por um motor CC, conforme Figura 3.16. Os sensores são capazes de fornecer, ao mesmo tempo, tanto um sinal livre de filtração, chamado de referência, como um sinal atenuado pela cunha de alumínio durante uma mesma exposição.

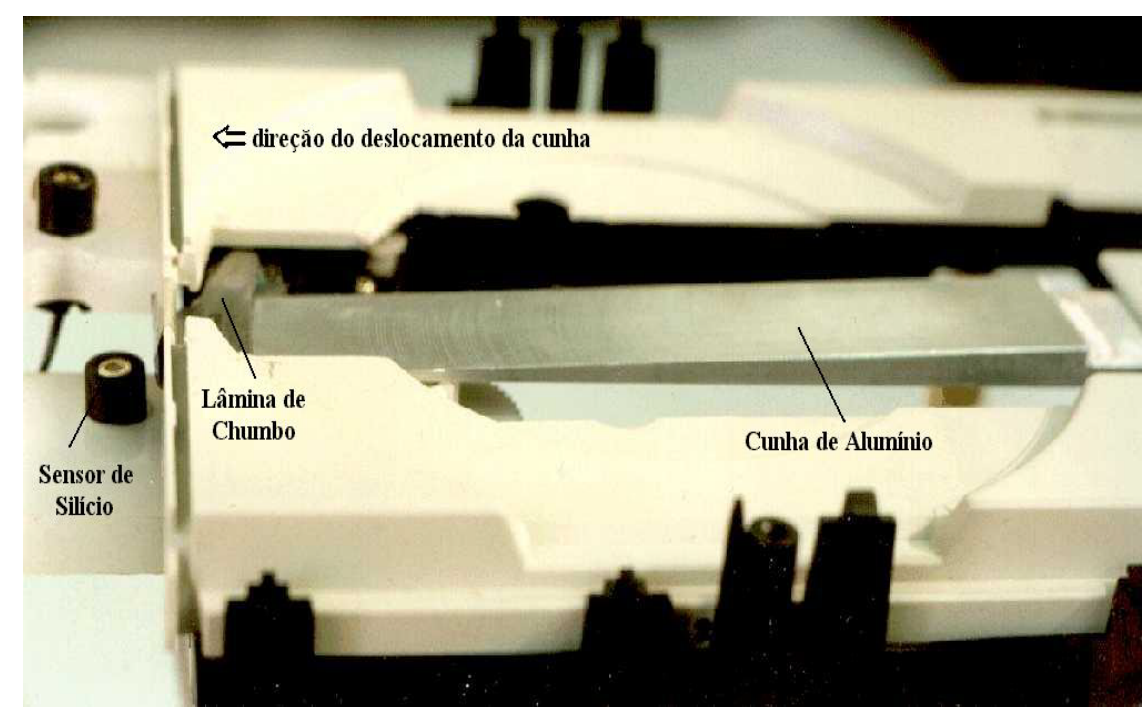

Figura 3.16. - Cunha de alumínio e sensores utilizados pelo dispositivo eletrônico de medição (CURI_98). 
O procedimento de operação desse sistema é o seguinte: durante a exposição de Raios-X, o software registra o sinal proveniente do sensor; ao mesmo tempo, o mecanismo de movimentação da cunha, sincronizado com o disparo da radiação, desloca-a por sobre o sensor. Desse modo, o sinal registrado tem um valor referencial constante, fornecido por um sensor livre da cunha, e outro que decresce até o nível de ruído à medida que a cunha avança sobre o sensor principal até atingir sua espessura máxima, conforme Figura 3.17.

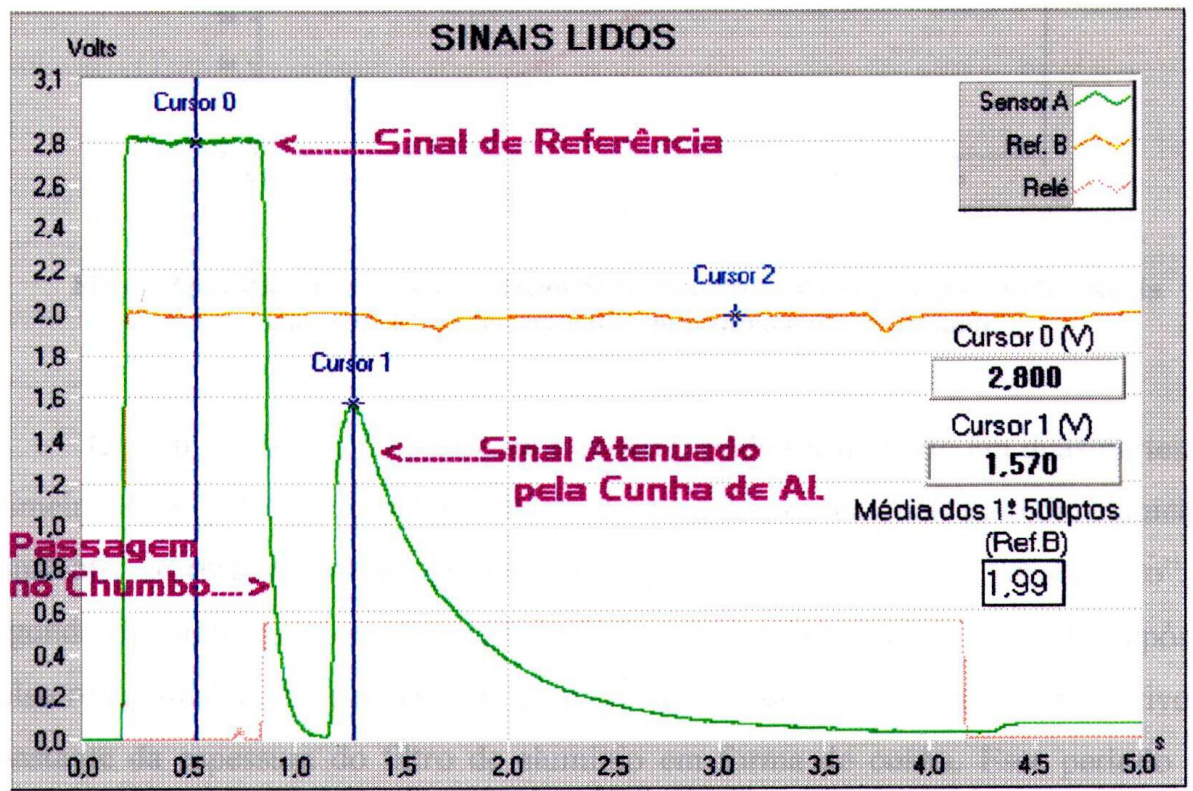

Figura 3.17. - Tela de saída do software registrando o sinal proveniente do sensor durante uma exposição (CURI_98).

A partir da determinação do sinal proveniente do sensor posicionado sob a cunha de alumínio, pode-se correr com o cursor pela onda decrescente na tela do microcomputador portátil até ser encontrada a amplitude correspondente exatamente à metade do sinal de referência. Como o programa converte, numa outra tela, a escala de tempo em distância (Figura 3.18), é possível determinar exatamente a distância percorrida desde o pico máximo até o ponto em que o sinal é atenuado à metade desse valor. Conhecidas as dimensões da cunha de alumínio, a CSR corresponde ao valor da espessura de alumínio que atenuou a intensidade do feixe naquele ponto. 


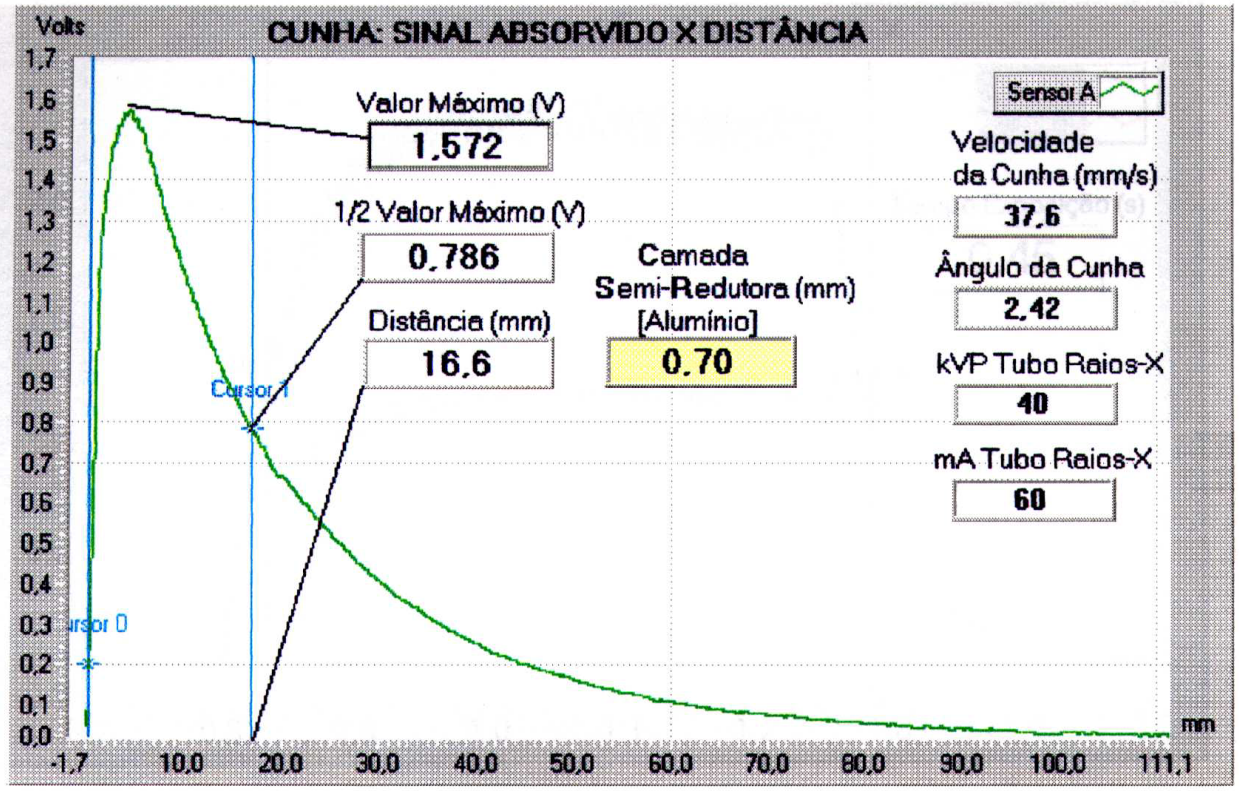

Figura 3.18. - Tela de saída do software com a escala de tempo convertida em escala de distância (CURI_98).

No exemplo da Figura 3.18, pode-se observar que os cursores registraram uma variação de $16,6 \mathrm{~mm}$ entre os sinais correspondentes a $\mathrm{V}$ e a V/2. Como o aumento de espessura da cunha é linear desde 0,5 até $5,35 \mathrm{~mm}$, conhecendo-se a distância entre os sinais é possível determinar a espessura de alumínio da CSR diretamente.

A Figura 3.19 mostra o dispositivo eletrônico descrito posicionado sob um mamógrafo durante a realização de algumas medidas experimentais para os testes de desenvolvimento e calibração do sistema. 


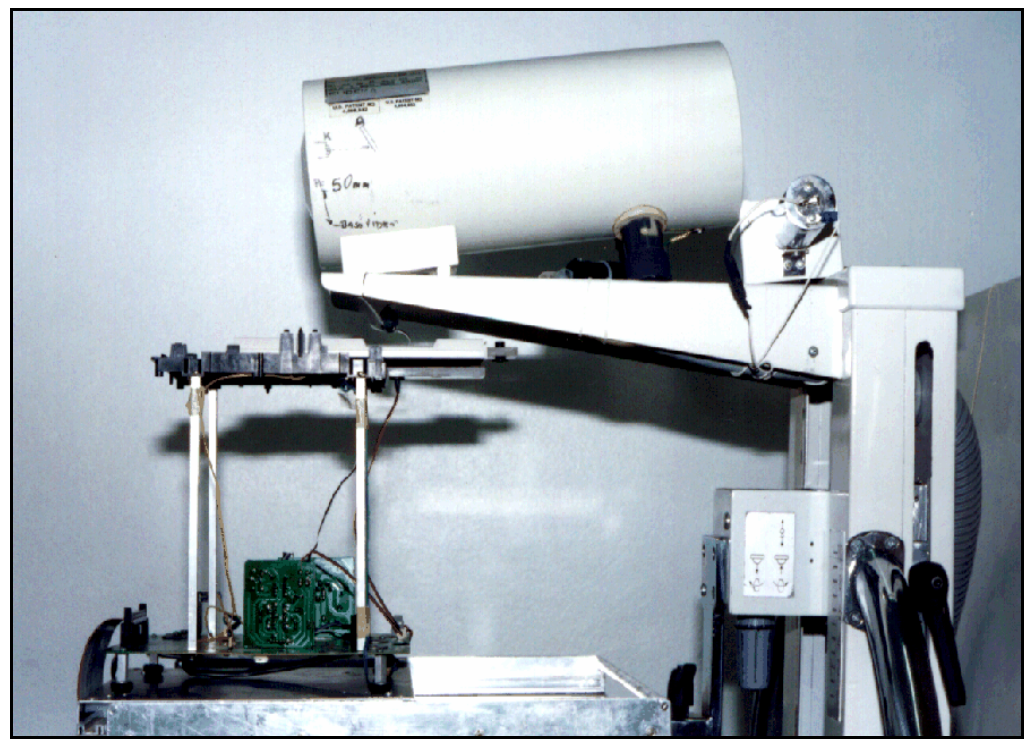

Figura 3.19. - Dispositivo eletrônico posicionado sobre os suportes, abaixo de um tubo mamográfico para calibração.

O dispositivo desenvolvido obtém valores confiáveis dos parâmetros avaliados (CURI_98), proporcionando ao usuário uma metodologia muito mais prática para medição da camada semi-redutora do que aquela descrita no item 3.2, onde se faz necessário cerca de cinco ou mais exposições para uma única medida da CSR devido ao aumento gradual que deve ser feito na filtração a cada exposição. Com este sistema eletrônico, é necessária apenas uma exposição para a determinação da CSR, evitando uma possível sobrecarga no aparelho e tornando a avaliação mais rápida, sem a necessidade da utilização de câmaras de ionização ou similares. 


\section{CAPÍTULO 4 \\ Técnicas Radiográficas para imagens de Estruturas Anatômicas Extensas e de Espessura Variável}

Este capítulo descreve basicamente as diferentes técnicas utilizadas para exames radiográficos de estruturas anatômicas extensas e de espessura variável, discutindo os problemas existentes na qualidade dessas imagens em razão de uma absorção não uniforme de Raios-X.

\subsection{Coluna: transição cérvico-torácica}

A coluna cervical é mais comumente radiografada nas posições ântero-posterior e lateral, embora as posições oblíquas possam ser utilizadas quando requisitadas pelo radiologista. Na posição ântero-posterior, a parte frontal do corpo do paciente fica de frente para o tubo de Raios-X e na posição lateral, um dos lados do corpo do paciente fica praticamente em contato com o filme.

Segundo Nascimento (NASCIMENTO_84), para as radiografias da posição ântero-posterior utiliza-se, normalmente, um filme de $18 \times 24 \mathrm{~cm}$, embora, às vezes, seja utilizado um filme de $24 \times 30 \mathrm{~cm}$ para que seja possível visualizar os arcos costais superiores e verificar a presença ou não de lesões ou de alterações congênitas. Nesta posição, somente as vértebras inferiores à terceira vértebra cervical (C-3) podem ser visualizadas, a não ser que a visualização seja obtida com a boca do 
paciente aberta (MESCHAN_75). Se a incidência for realizada com a boca do paciente aberta para a primeira à terceira vértebras cervicais, a linha básica radiográfica deve ser usada como uma linha de referência para a angulação do tubo. Quando isso não é possível, pode-se corrigir a posição do tubo através da flexão ou extensão da cabeça e do pescoço. Os parâmetros operacionais que devem ser utilizados para este exame são: $80 \mathrm{kVp}, 40 \mathrm{mAs}$ e distância foco-filme de $100 \mathrm{~cm}$. Aconselha-se também, segundo Kreel (KREEL_82), a utilização de filmes rápidos com telas intensificadoras (écran).

No exame na posição lateral, o paciente fica em pé ou sentado, com a cabeça voltada para frente e a mandíbula levemente elevada. Os ombros devem ficar abaixados para que sua densidade seja projetada abaixo do nível da sétima vértebra cervical (C-7). Quando um exame é realizado com o paciente na posição vertical, com a superfície lateral do ombro contra um apoio, o chassis fica a uma considerável distância das vértebras. Nesse caso, como a distância maior entre o objeto e o filme resulta em uma perda de definição, é necessário que se aumente a distância focofilme para um mínimo de $150 \mathrm{~cm}$. Para este exame, os seguintes parâmetros devem ser utilizados: $65 \mathrm{kVp}, 40 \mathrm{mAs}$ e $\mathrm{DFF}=180 \mathrm{~cm}$, além de filmes rápidos com écran (KREEL_82).

Um problema comumente encontrado na radiografia em posição lateral da coluna cervical diz respeito à vértebra $\mathrm{C}-7$, onde se situa a transição cérvico-torácica. Kreel (KREEL_82) já apontava dificuldades para visualizar essa região da coluna na posição lateral, já que ela fica mascarada pela densidade dos ombros. Nessa transição, há uma variação abrupta entre a espessura de absorção do pescoço e a da região dos ombros e tórax, sendo que um determinado ajuste da tensão e corrente no tubo $(\mathrm{kVp}$ e $\mathrm{mAs})$ pode ser suficiente para produzir uma imagem de contraste satisfatório para uma parte da estrutura, e insuficiente ou excessiva para outras regiões, podendo causar uma saturação no filme na região correspondente à da estrutura de menor espessura. A Figura 4.1 mostra um exemplo de radiografia lateral da coluna cervical, onde o ajuste da $\mathrm{kVp}$ e mAs foi suficiente para a visualização da região superior da coluna cervical, mas insuficiente para a visualização da região inferior (transição cérvico-torácica), devido à maior absorção 
provocada pelo aumento da densidade nos ombros, causando uma sub-exposição no filme.

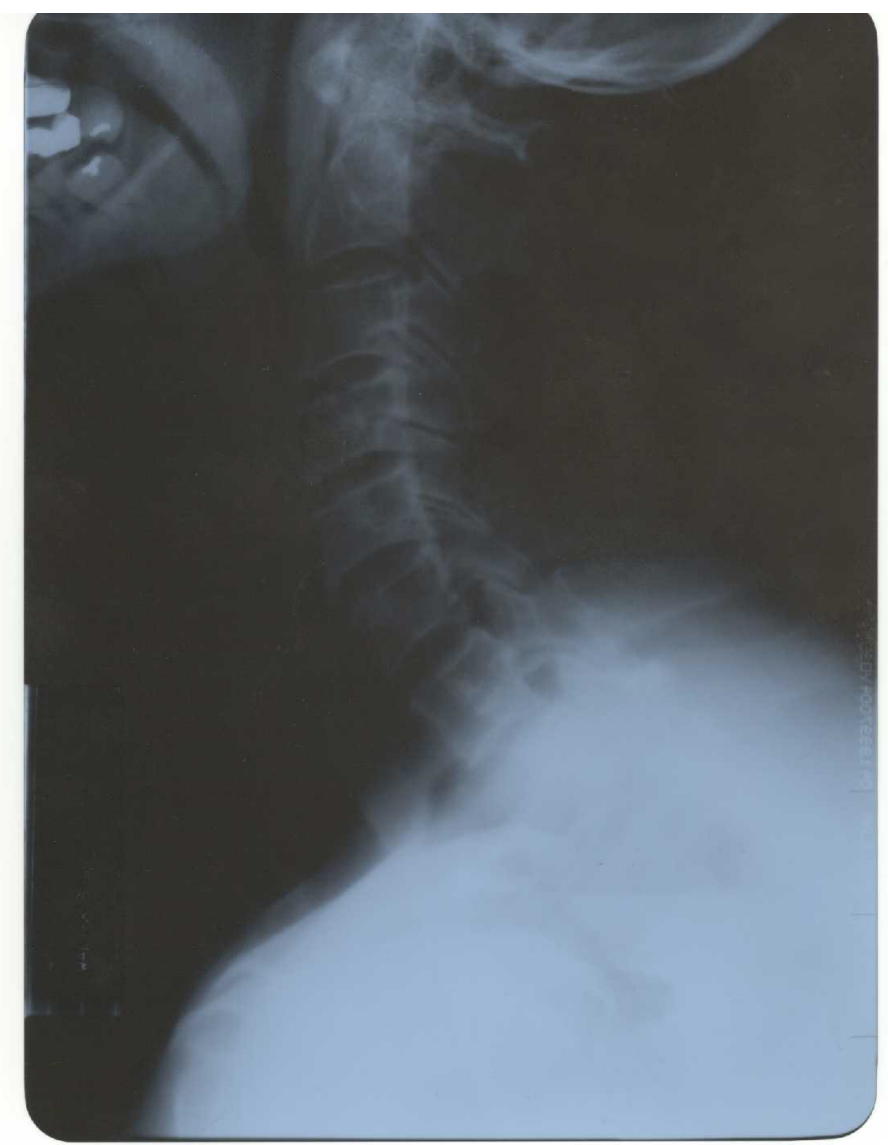

Figura 4.1. - Radiografia lateral da coluna cervical. ${ }^{4}$

Segundo Meschan (MESCHAN_75), uma melhor visualização da C-7 pode ser obtida através de uma técnica onde o paciente fica sentado, mantendo o seu pescoço perfeitamente perpendicular aos seus ombros, segurando em suas mãos um objeto pesado a fim de manter seus ombros abaixados o máximo possível, conforme Figura 4.2. Nessa posição, a coluna cervical acaba ficando a uma distância considerável do filme (aproximadamente $20 \mathrm{~cm}$ ), provocando distorção devido à magnificação da imagem. Deste modo, procura-se aumentar a distância foco-filme para diminuir esse efeito.

\footnotetext{
${ }^{4}$ Cedida pelo Hospital das Clínicas da Faculdade de Medicina de Ribeirão Preto.
} 


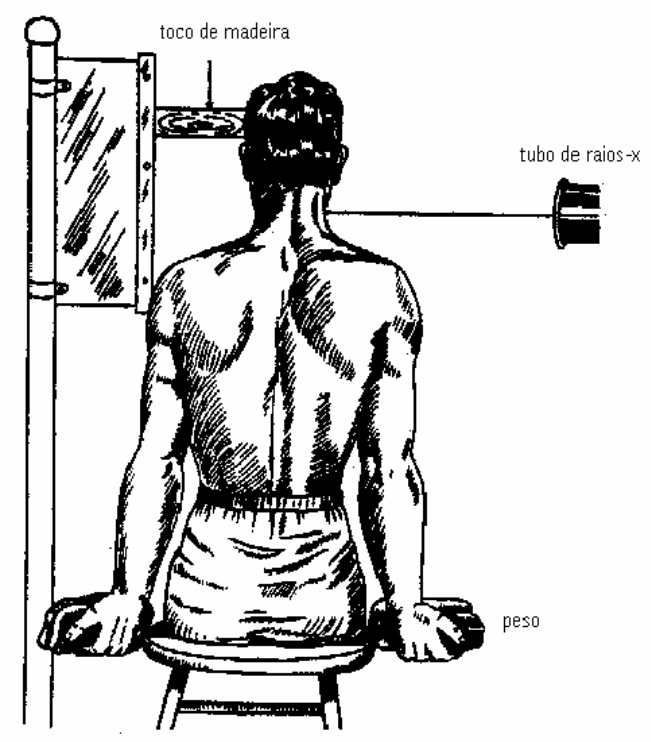

Figura 4.2. - Técnica para radiografia lateral da coluna cervical (MESCHAN_75).

\subsection{Pernas: geno valgo e geno varo}

A radiografia das pernas é realizada, segundo Kreel (KREEL_82), nas posições ântero-posterior e lateral. Na posição ântero-posterior, o paciente deve ficar deitado de bruços com os joelhos levemente voltados para dentro; na posição lateral o paciente é posicionado de maneira que a região de interesse fique virada para o lado do tubo.

Para a investigação de deformidades de angulação dos joelhos, em que a região a ser radiografada é extensa, há a necessidade de utilizar-se filmes grandes. Os tipos mais comuns de deformidades na angulação dos joelhos são o geno valgo e o geno varo, onde há uma alteração na angulação do joelho em relação ao fêmur e à tíbia. No geno valgo, esta angulação faz com que os joelhos fiquem juntos e as pernas fiquem encurvadas para fora, enquanto no geno varo acontece o oposto, fazendo com que os joelhos e pernas fiquem dispostos em forma de arco (TUREK_91).

Uma técnica cirúrgica empregada para a correção dessas deformidades é a Osteotomia Óssea, através da qual se procura remover uma parte do osso da 
região dos joelhos com o intuito de diminuir ou corrigir sua angulação. Segundo Resnick e Niwayama (RESNICK_88), para uma medição correta do grau de deformidade dessa angulação com vistas a uma posterior intervenção cirúrgica, é necessário um exame onde as articulações do joelho, do quadril e dos tornozelos possam ser vistas simultaneamente, em uma única imagem.

Devido à existência de uma diferença entre a espessura da região dos quadris e a da região dos tornozelos, o mesmo problema apontado por Kreel (KREEL_82) nas radiografias laterais da coluna cervical (item 4.1) ocorre. Se um ajuste nos parâmetros operacionais do aparelho de Raios-X é suficiente para produzir uma imagem de boa qualidade para uma determinada região das pernas, pode ser insuficiente ou excessivo para outras regiões, podendo causar uma sub-exposição ou saturação na imagem, dependendo do caso. A Figura 4.3 mostra uma radiografia na posição ântero-posterior de um paciente com geno varo, onde os parâmetros utilizados foram adequados para a visualização dos tornozelos, mas insuficientes para produzir um contraste satisfatório na região dos quadris.

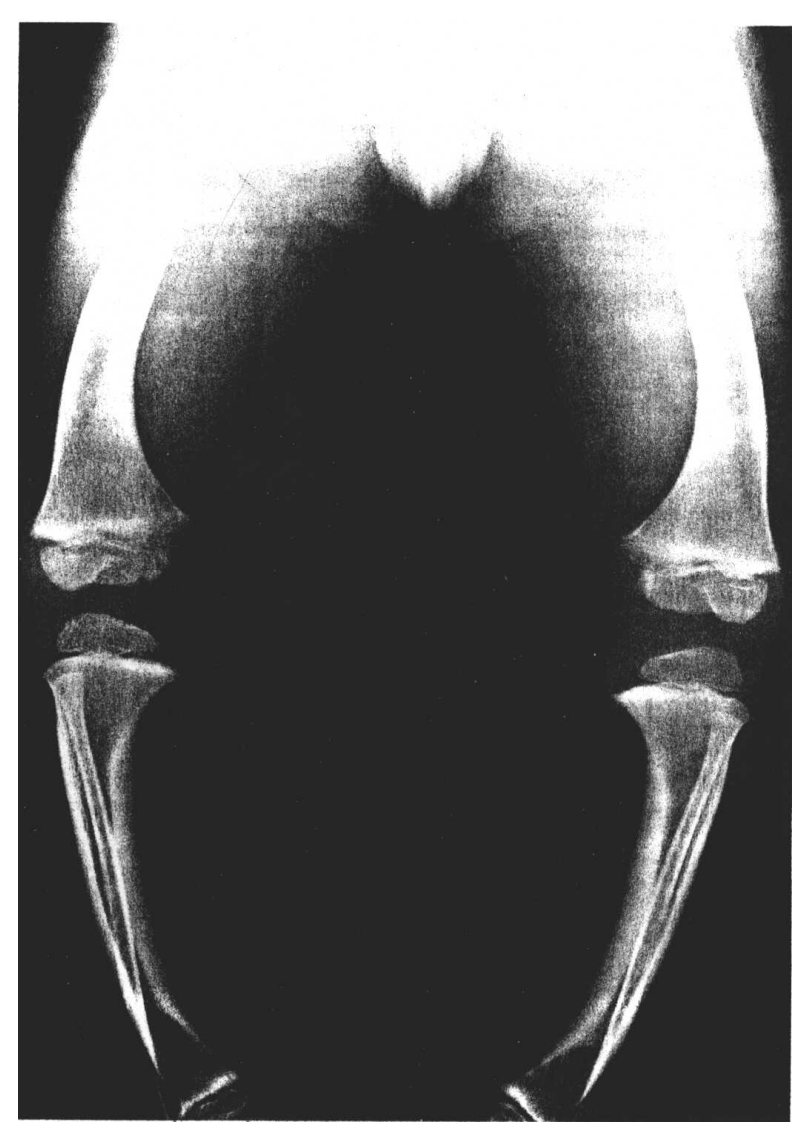

Figura 4.3. - Radiografia das pernas de um paciente com geno varo (GREENSPAN_96). 
Segundo Wolbarst (WOLBARST_93), o efeito "heel” tem influência significativa para imagens de objetos extensos devido à grande variação de intensidade entre um lado e outro do campo de exposição. Mesmo sendo possível a elaboração de um filtro para que essa variação de intensidade fosse eliminada, isso raramente é feito. Além disso, algumas vezes o efeito "heel" é acentuado, colocandose a parte mais espessa do objeto na região do campo correspondente ao lado do anodo do tubo, onde a intensidade é menor (Figura 2.10).

Portanto, através das imagens radiográficas ilustradas nas Figuras 4.1 e 4.3, percebe-se a dificuldade existente para a visualização de estruturas onde há uma variação considerável de espessura entre uma região e outra. Um único ajuste dos parâmetros operacionais do aparelho não é suficiente para provocar um nível de escurecimento satisfatório em toda a extensão da imagem, ocorrendo, dependendo do caso, saturação ou sub-exposição em certas regiões. 


\section{CAPÍTULO 5 \\ Simulação Computacional para Determinação da Camada Semi-Redutora}

A camada semi-redutora é usualmente medida no centro do campo de exposição para fins de avaliação da qualidade do feixe de Raios-X. Em vista disso, esse capítulo propõe um método computacional capaz de determinar, por simulação, a CSR de equipamentos radiográficos em toda a extensão do campo, a partir de uma única medida obtida no seu centro.

\subsection{Introdução}

A camada semi-redutora é um parâmetro que deve ser avaliado periodicamente nos aparelhos radiográficos utilizados em hospitais, pois fornece informações à respeito da qualidade do feixe de Raios-X gerado pelo aparelho. Além disso, existem normas internacionais (citadas no Capítulo 3) que estabelecem um valor mínimo para a CSR requerida para cada tipo de aparelho, de acordo com sua aplicação, para que se mantenha um padrão de qualidade nos exames radiográficos.

No Programa de Garantia de Qualidade em radiologia médica, que deve ser implantado por todos os serviços radiológicos em operação no estado de São Paulo, é obrigatório que se faça a medida da CSR dos aparelhos radiográficos que estão sendo utilizados nos exames de rotina, segundo a Resolução SS-625 de 1994 da 
Secretaria de Vigilância Sanitária do Estado de São Paulo ${ }^{5}$. Além disso, a partir de 01 de junho de 1998, através da portaria 453, a obrigatoriedade da realização desse programa foi ampliada para todo o território nacional. Nesses casos, a medida da CSR é normalmente feita no centro do campo de exposição, para um feixe bem colimado, o que não leva em conta a qualidade relativa desse feixe em outras posições.

O cálculo do valor exato, por simulação, da CSR de um aparelho radiográfico a partir apenas das informações técnicas fornecidas pelo fabricante é possível, seguindo-se os procedimentos propostos (conforme será discutido mais adiante), mas não parece ser conveniente na prática. Existe um grande número de fatores que influenciam no valor da CSR de um aparelho radiográfico, sendo que muitos deles não são fornecidos normalmente pelo fabricante. Isto ocorre, talvez, por serem informações consideradas irrelevantes para a prática radiológica, já que são características internas do aparelho, resultado da forma com que ele foi construído, dos materiais utilizados, da posição do ponto focal no alvo, da distância dele à janela do tubo, da posição exata em que o tubo foi colocado no interior do aparelho, do tempo de uso, entre outros. Sendo assim, a medição desses fatores em avaliações periódicas de aparelhos radiográficos parece ser mais complexa do que efetivamente realizar uma medição única do valor da CSR na posição central do campo, mesmo porque essa medida central já deve fazer parte dos programas de controle de qualidade realizados atualmente, pelos motivos já expostos.

Desse modo, o algoritmo de simulação desenvolvido calcula a variação nos valores da CSR e da intensidade da radiação em função da distância relativa ao centro do campo percorrida na direção perpendicular ao feixe de Raios-X. Assim, a partir de uma única medida experimental na posição central do campo de exposição é possível, através da simulação, a determinação do valor da CSR e da intensidade em qualquer outra posição no plano imagem.

\footnotetext{
${ }^{5}$ Resolução SS-625/94 - Secretaria de Estado da Saúde de São Paulo - item 6.6.3 i).
} 


\subsection{Metodologia}

O algoritmo de simulação computacional foi desenvolvido para o cálculo da camada semi-redutora de sistemas radiográficos em qualquer posição no campo de exposição. Baseia-se no método proposto por Fritz \& Livingston (FRITZ_82), posteriormente implementado por Marques (MARQUES_98), de acordo com o qual é calculada a intensidade do feixe de radiação, por simulação computacional, em qualquer posição do campo, considerando os diferentes níveis de absorção do feixe em função do ângulo de emissão causado pelo efeito "heel".

O efeito "heel" provoca uma variação na intensidade da radiação, quando medida ao longo do campo, em razão da filtração que os fótons de Raios-X sofrem pelo próprio material do alvo ao serem emitidos pelo anodo (conforme descrito no Capítulo 2). O cálculo dessa filtração é feito a partir do conhecimento do comprimento do caminho $S(\theta)$ percorrido pelos fótons dentro do alvo quando são emitidos. Quanto maior o comprimento desse caminho, maior será a absorção sofrida pelo feixe e, conseqüentemente, menor será sua intensidade. O valor de $S(\theta)$ é calculado a partir da equação (2.7) e a intensidade resultante, devido à filtração pelo alvo, é calculada através da equação (2.8).

Para o cálculo do espectro dos Raios-X emitidos pelo anodo para qualquer ângulo de emissão, Fritz \& Livingston (FRITZ_82) propuseram dois métodos computacionais: o método da aproximação com diminuição constante da velocidade (continuous slowing-down approximation ou csda) e o método da profundidade única de produção de fótons (constant depth of production ou $c d$ ).

O primeiro método considera o espectro total gerado pelo alvo "grosso" como uma série de espectros de alvos "finos", cada um gerado em uma determinada camada dentro do alvo. Esse método é usado para determinar a energia do elétron em cada profundidade. $\mathrm{O}$ outro método considera que o espectro produzido pelo alvo "grosso", descrito pela equação (2.6), é produzido em uma única camada dentro do alvo. Assim, no método $c s d a$, o alcance $d$ do elétron dentro do alvo utilizado para o cálculo da equação (2.7) varia de acordo com sua energia $E$, enquanto que no método $c d$, o alcance $d$ é constante e corresponde a uma fração obtida empiricamente através de uma aproximação dos dados observados do efeito 
"heel" do alcance máximo dos elétrons dentro do alvo. Os valores para esse alcance máximo dos elétrons em função da $\mathrm{kVp}$, para diversos materiais, foram calculados por Berger \& Seltzer (BERGER_64).

Marques (MARQUES_98), utilizando ambos os métodos, desenvolveu um programa de simulação para o cálculo do efeito "heel", através do qual é possível obter a intensidade da radiação em qualquer ponto do campo de exposição no eixo catodo/anodo. A metodologia proposta pelo autor foi a seguinte: para cada energia $E$ do espectro do alvo "grosso" dado pela equação (2.6), calcula-se a filtração total sofrida pelos fótons em função do seu ângulo de emissão, levando-se em consideração a absorção pelo material do alvo (devida ao caminho $S$ ) e a filtração inerente sofrida dentro do tubo. Assim, o espectro deve ser integrado sobre $E$ para se obter a intensidade total do feixe de ângulo $\theta$.

O algoritmo de simulação, desenvolvido nessa pesquisa para a determinação da camada semi-redutora, baseia-se nessa metodologia implementada por Marques (MARQUES_98) e tem os seguintes parâmetros de entrada:

- $\mathrm{kVp}$, corrente e tempo de exposição;

- material (W ou Mo) e ângulo de inclinação do anodo;

- filtração inerente e adicional;

- distância do tubo ao campo;

- área da região onde a CSR e a intensidade do feixe devem ser calculadas;

- posição (x) no campo de exposição, no eixo catodo/anodo, onde o cálculo deve ser efetuado.

Com base nesse dados, o espectro da radiação de intensidade $I_{0}(E)$, produzida no interior do alvo, é obtido através da equação (5.1) para um tubo convencional (alvo de tungstênio) e da equação (5.2) para um tubo mamográfico (alvo de molibdênio), conforme proposto por Unsworth \& Greening (UNSWORTH_70):

$$
I_{0}(E)=1,02 \times 10^{11}\left(E_{0}-E\right) \quad[\mathrm{keV} / \mathrm{mA} . \mathrm{s} . \mathrm{Sr} . \text { intervalo] }
$$




$$
I_{0}(E)=0,579 \times 10^{11}\left(E_{0}-E\right) \quad[\mathrm{keV} / \mathrm{mA} . \mathrm{s} . \mathrm{Sr} . \text { intervalo] }
$$

onde $E_{0}$ é a energia máxima dos fótons, $E$ a energia dos fótons onde a intensidade deve ser calculada, $m A$ a corrente no tubo, $s$ o tempo de exposição, $S r$ o ângulo sólido da emissão do feixe de Raios-X (em estereorradianos), que é função da área no campo em que a medida deve ser feita, e intervalo (em $\mathrm{keV}$ ) o intervalo entre as energias $E$ que foi considerado.

A Figura 5.1 apresenta um esquema ilustrativo da metodologia utilizada na simulação.

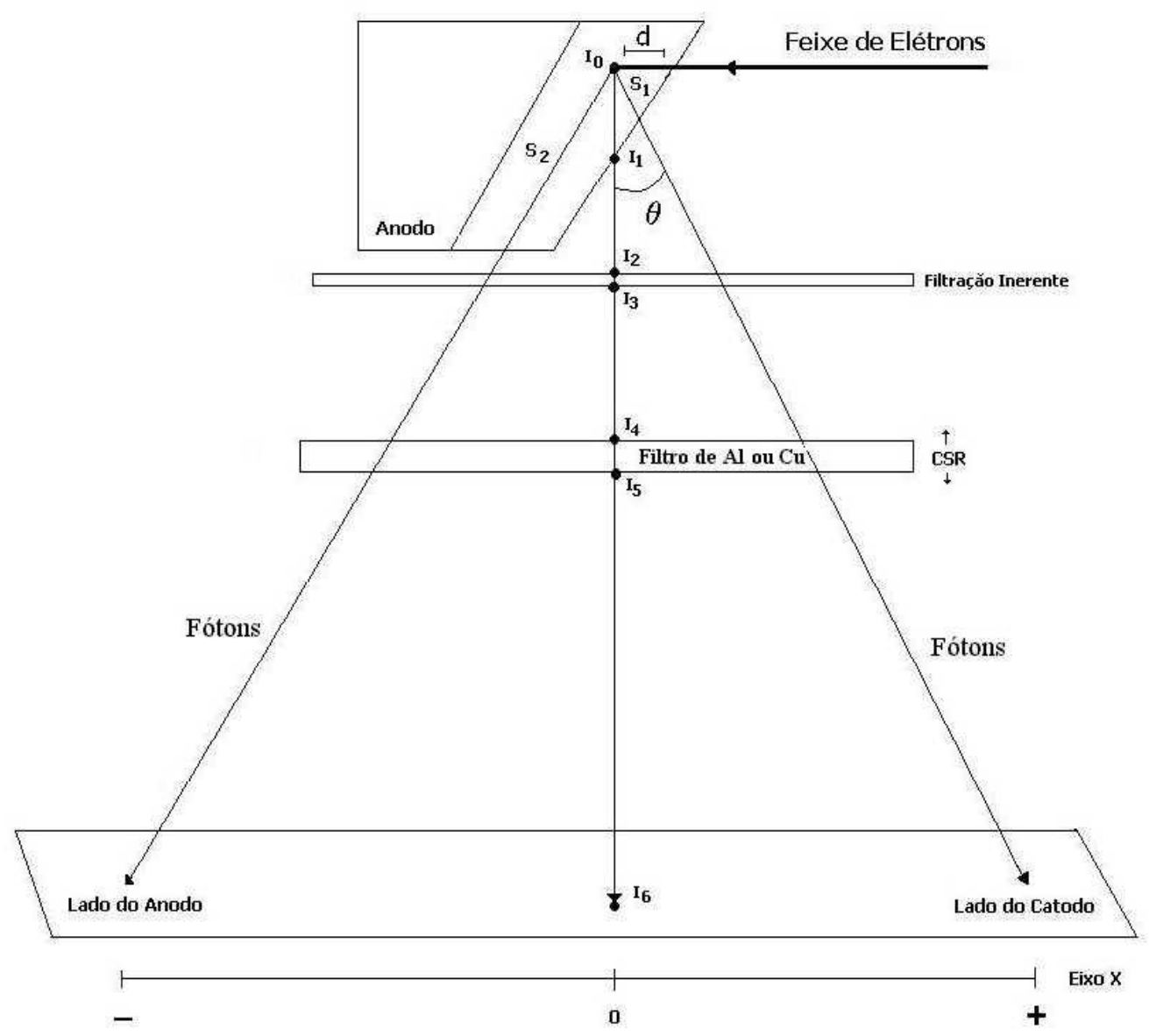

Figura 5.1. - Ilustração da geometria para o cálculo da CSR por simulação.

Sabendo-se a posição $(x)$ no campo onde se deseja obter a CSR, obtém-se matematicamente o valor do ângulo $\theta$ de emissão dos fótons. Com isso, calcula-se o comprimento do caminho percorrido pelo fóton dentro do alvo, $S(\theta)$, 
através da equação (2.7), pelos métodos $c d$ e $c s d a$ propostos por Fritz \& Livingston (FRITZ_82). O valor da intensidade do feixe $\left(I_{1}\right)$, após ser atenuado pelo material do alvo, é obtido através da equação (2.8), efetuando-se os cálculos separadamente para cada intervalo de energia do espectro, já que os valores dos coeficientes de atenuação de massa $(\mu / \rho)$ dependem da energia dos fótons. O mesmo procedimento deve ser utilizado para calcular a atenuação causada pela filtração inerente $\left(I_{3}\right)$ considerando, nesse caso, a equação de Lambert-Beer (equação 2.5).

Os valores utilizados para os coeficientes de atenuação de massa dos materiais considerados na simulação para o cálculo da equação (2.8) e das outras atenuações propostas no algoritmo foram os calculados por Boone \& Chavez (BOONE_96). Assim, foram utilizados os valores de $\mu / \rho$ em função da energia dos fótons para intervalos de $0,5 \mathrm{keV}$, entre 1 e $120 \mathrm{keV}$, para todos os materiais considerados no algoritmo.

Considerando-se, primeiramente, que nenhum filtro adicional é colocado sob o feixe de Raios-X, calcula-se a intensidade final $\left(I_{6}\right)$ para uma área específica em qualquer posição no campo, utilizando-se apenas a correção pela lei do inverso do quadrado da distância.

Para a determinação da CSR simula-se um filtro de espessura variável (alumínio ou cobre) sob esse feixe de radiação. O valor inicial da espessura do filtro é zero. Aumentando-se gradativamente a espessura desse filtro, calcula-se o valor da intensidade final resultante (área total sob o espectro de radiação do feixe) a cada incremento de espessura, comparando-se o valor encontrado com a intensidade $I_{6}$. Quando o valor encontrado para a intensidade final for igual a $I_{6} / 2$, ou seja, metade da intensidade inicial, a espessura utilizada para este filtro corresponde à primeira CSR naquele ponto. Do mesmo modo, quando a espessura deste filtro for suficiente para reduzir a intensidade inicial $\left(I_{6}\right)$ à um quarto do seu valor, obtém-se a segunda CSR subtraindo-se o valor encontrado para essa espessura pela primeira CSR já calculada.

Utilizou-se a plataforma Delphi 3.0 para a construção do programa de simulação em razão da clareza e da rapidez com que ela apresenta os resultados na tela do microcomputador. A Figura 5.2 mostra a tela do programa de simulação implementado. 


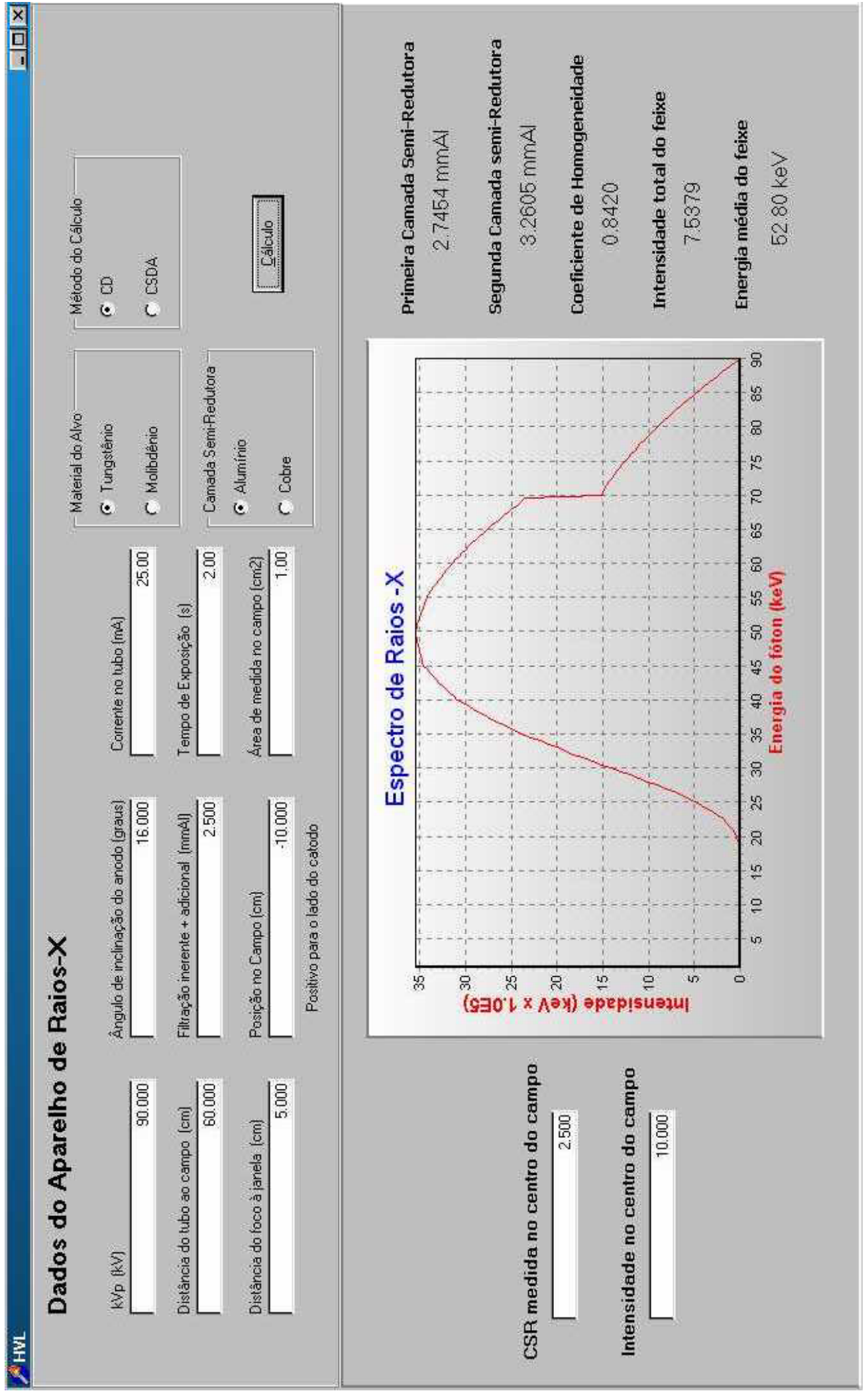

Figura 5.2. - Tela do programa de simulação com resultados referentes a um tubo de Raios-X convencional. 
Para a utilização do programa de simulação, o usuário deve preencher todos os campos relativos aos dados operacionais do aparelho de raios- $\mathrm{X}$ avaliado (campos com fundo branco da figura 5.2), selecionar o material que foi utilizado para a medida central da CSR (alumínio ou cobre), o método que deve ser considerado para os cálculos ( $c d$ ou $c s d a$ ), a posição no campo em que se deseja saber o valor da CSR e pressionar o botão "Cálculo". Dessa forma, o programa efetuará os cálculos dos valores da $1^{\text {a }} \mathrm{CSR}$, da $2^{\mathrm{a}} \mathrm{CSR}$, do coeficiente de homogeneidade, da intensidade da radiação e da energia média do feixe na posição desejada, além de apresentar um esboço de como deve ser o espectro de Raios-X nessa região. Com isso, torna-se possível prever a variação que a CSR e os outros parâmetros calculados apresentam em função da distância relativa ao centro do campo percorrida na direção perpendicular ao feixe de Raios-X no plano imagem. Essa variação é transformada em dados percentuais que são aplicados aos valores experimentais medidos para o centro do campo, determinando, assim, o valores da CSR e da intensidade do feixe para esse aparelho em qualquer outra posição desejada. A fim de tornar possível a utilização dessa simulação não só para aparelhos de Raios-X convencionais, mas também para aparelhos mamográficos, o programa pode efetuar os cálculos tanto para tubo de tungstênio (convencional) como para tubos de molibdênio (mamógrafo) para tensões de até $120 \mathrm{kVp}$.

Desenvolveu-se também outro programa para que fosse possível prever, de imediato, a variação da CSR e da intensidade do feixe ao longo de todo o campo em função dos parâmetros descritos anteriormente. Neste caso, o usuário deve fornecer ao programa o tamanho do campo que será utilizado ao invés de especificar uma única posição, como no programa anterior. São calculados, então, os valores da $1^{\text {a }}$ CSR, da $2^{\text {a }}$ CSR, do coeficiente de homogeneidade, da intensidade da radiação e da energia média do feixe em todas as posições definidas pelo usuário ao longo do eixo catodo-anodo, com espaços regulares entre elas. Os gráficos representativos das variações ocorridas são imediatamente apresentados na tela do microcomputador. A Figura 5.3 a seguir mostra a tela do segundo programa de simulação desenvolvido com os resultados simulados para um campo de exposição de $20 \mathrm{~cm}$ de comprimento. 


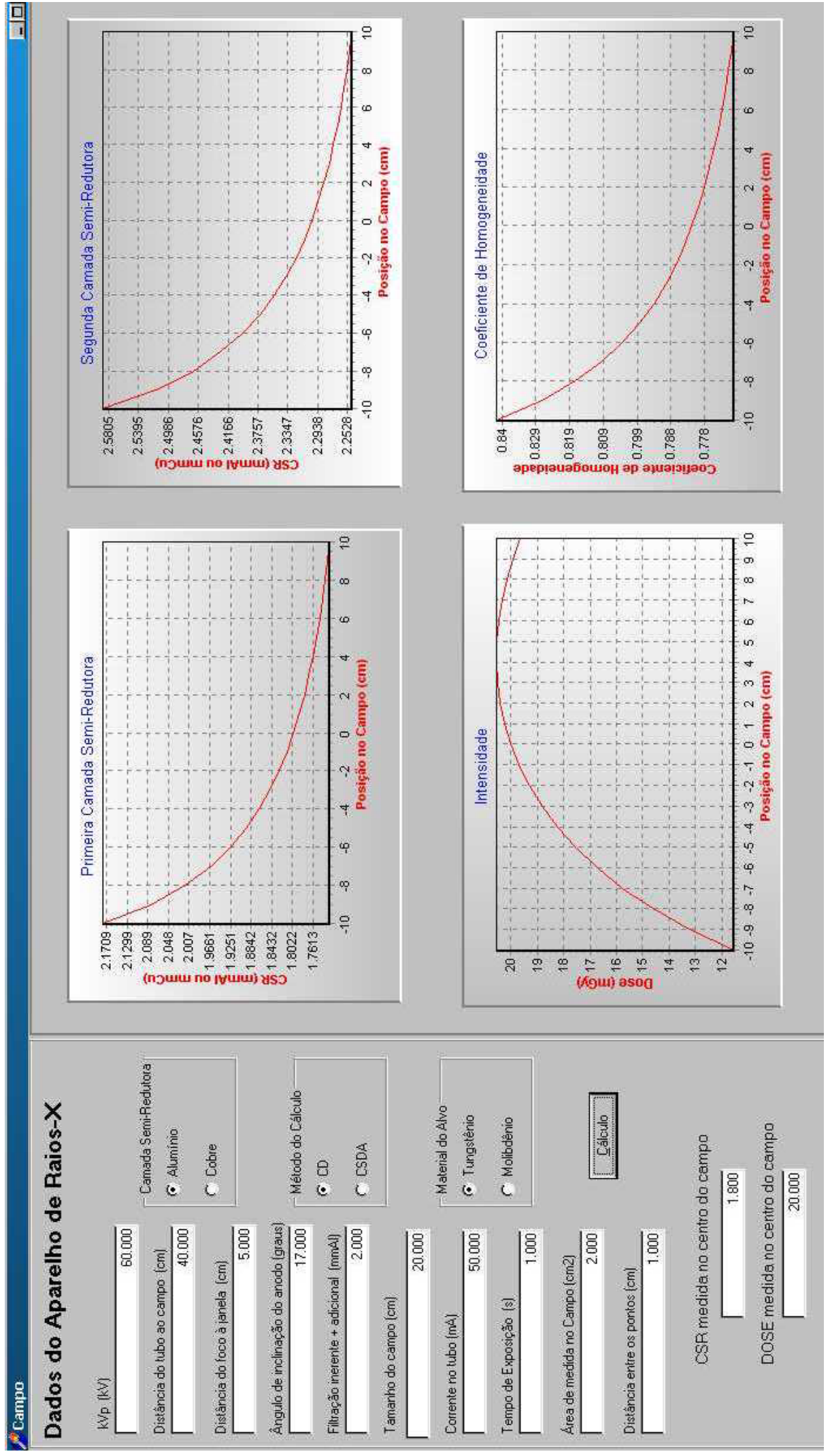

Figura 5.3. - Tela do segundo programa de simulação com resultados referentes a um campo de exposição de $20 \mathrm{~cm}$. 
Os resultados apresentados pela simulação estão bastante coerentes com os encontrados na literatura especializada (JOHNS_83, WAGNER_90, WOLBARST_93) e que posteriormente foram encontrados na prática (Capítulo 7): maior valor para a CSR e menor valor para a intensidade no lado correspondente ao anodo do tubo devido à filtração provocada pelo efeito 'heel', que torna mais energético e menos intenso o feixe que atinge este lado do campo. O coeficiente de homogeneidade também aumenta à medida que a região de interesse no campo é deslocada para a região correspondente ao anodo, já que o feixe torna-se mais homogêneo com o aumento da filtração (conforme descrito no item 3.6). 


\section{CAPÍTULO 6 \\ Testes Práticos com Aparelhos Radiográficos Hospitalares}

Esse capítulo descreve a metodologia utilizada para a realização das medidas experimentais da camada semi-redutora de aparelhos radiográficos para comprovação da validade do programa de simulação desenvolvido.

\subsection{Introdução}

Para a comprovação da validade do programa de simulação proposto, foram realizadas medidas experimentais da CSR e da dose de radiação em diversas posições no campo de exposição de aparelhos radiográficos hospitalares (convencional e mamográfico). Os testes foram efetuados em aparelhos do Hospital das Clínicas da Faculdade de Medicina de Ribeirão Preto, do Instituto Romeu Santini de Diagnóstico (em São Carlos) e do Laboratório de Raios-X do Departamento de Engenharia Elétrica da EESC / USP de São Carlos.

As medidas da CSR foram efetuadas considerando-se as duas metodologias descritas no Capítulo 3, ou seja, com a utilização de um dosímetro comercial juntamente com atenuadores de alumínio e utilizando-se o dispositivo eletrônico de medição desenvolvido em nosso laboratório (previamente descrito no item 3.7). 
O medidor comercial utilizado nos testes é da marca RTI Electronics modelo PMX-III, de origem sueca, um dos mais modernos e completos aparelhos comerciais de avaliação radiológica da atualidade, capaz de obter medidas de $\mathrm{kVp}$, dose, taxa de dose, tempo de exposição e CSR. Esse aparelho é utilizado nos programas de Controle de Qualidade da Imagem de equipamentos radiográficos realizados pelo SAPRA, Serviço de Assessoria e Proteção Radiológica S/C Ltda., uma empresa especializada em proteção radiológica, dosimetria pessoal e controle de qualidade de imagem em radiodiagnóstico.

A utilização desse aparelho foi necessária devido ao fato das câmaras de ionização comerciais geralmente possuírem uma área de absorção aos Raios-X muito ampla, em torno de $50 \mathrm{~cm}^{2}$, o que inviabilizaria uma análise da variação de intensidade ao longo do campo, já que a câmara tomaria quase toda a sua extensão. $O$ $P M X$-III possui um acessório, o $R 25$, que é um detector de estado sólido com área de absorção de apenas $1 \mathrm{~cm}^{2}$, tornando possível uma análise da variação da intensidade da radiação e do valor da CSR em várias posições do campo. Além disso, o PMX-III tem como acessório uma série de atenuadores de alumínio do tipo 1100 aluminum alloy (99\% de pureza) com espessuras que variam de 0,1 a 3,0mm, podendo ser acoplados para as medidas da CSR. As Figuras 6.1 e 6.2 a seguir mostram o $P M X-I I I$, o microcomputador portátil e o detector $R 25$ utilizados nos testes.

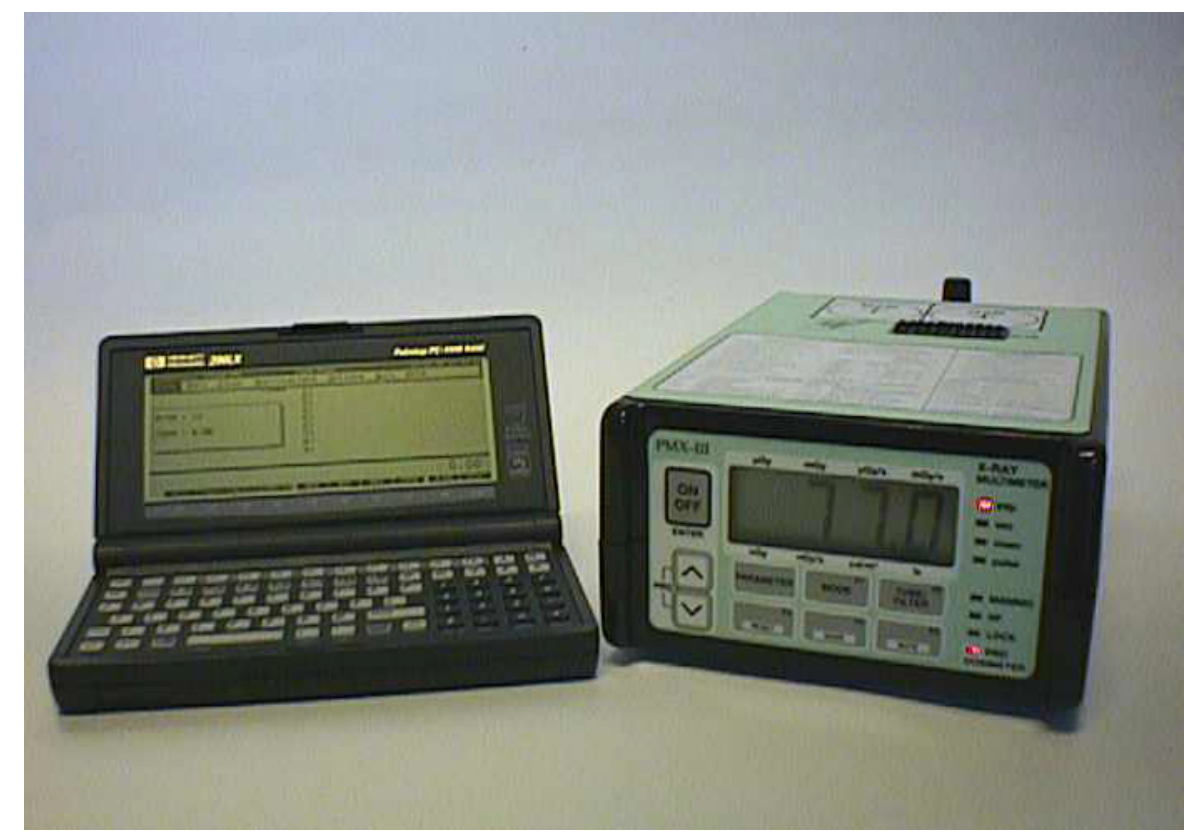

Figura 6.1. - PMX-III, aparelho utilizado para as medições da dose e da CSR. 


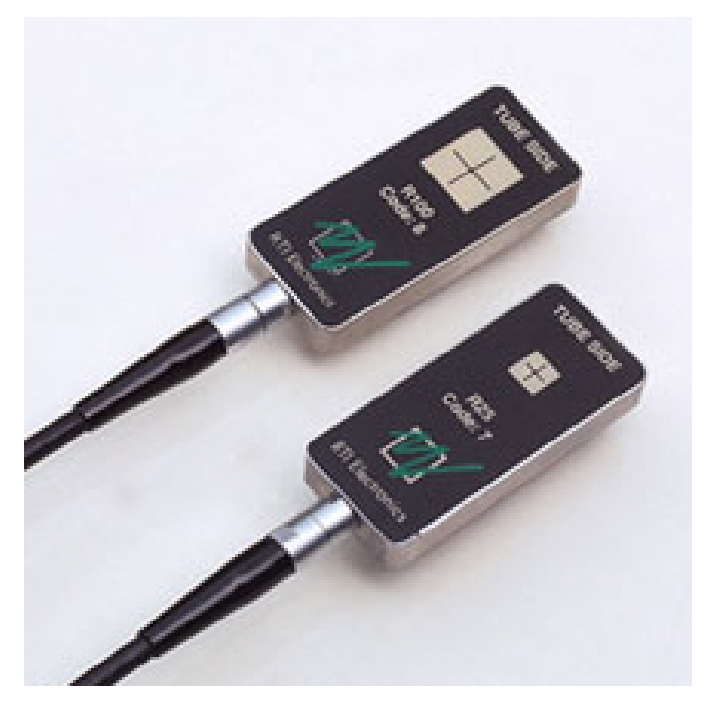

Figura 6.2. - $R 25$, detector de estado sólido utilizado juntamente com o PMX-III para os testes práticos.

As medidas foram realizadas para diferentes valores de $\mathrm{kVp}$, corrente e tempo de exposição em quatro aparelhos diferentes, cujas especificações, fornecidas pelo fabricante, estão descritas a seguir:

\section{Mamógrafo A}

- Local: Instituto Romeu Santini de Diagnóstico - São Carlos;

- Marca: GE - CGR;

- Modelo: Senographe 600 T;

- Tensão máxima: $36 \mathrm{kVp}$;

- Corrente máxima: 400mA;

- Tempo de exposição máximo: 3,0s;

- Filtração inerente: $0,8 \mathrm{mmBe}+0,03 \mathrm{mmMo}$.

\section{Mamógrafo B}

- Local: Laboratório de Raios-X do Departamento de Engenharia Elétrica da EESC / USP - São Carlos

- Marca: GE - CGR;

- Modelo: Senographe 500 T; 
- Tensão máxima: $40 \mathrm{kVp}$;

- Corrente máxima: $8 \mathrm{~mA}$;

- Tempo de exposição máximo: 10,0s;

- Filtração inerente: $0,5 \mathrm{mmAl}$.

\section{Convencional A}

- Local : Instituto Romeu Santini de Diagnóstico - São Carlos;

- Marca: SHIMADZU;

- Modelo: 500;

- Tensão máxima: $125 \mathrm{kVp}$;

- Corrente máxima: 500mA;

- Tempo de exposição máximo: 10,0s;

- Filtração inerente: $2,5 \mathrm{mmAl}$.

\section{Convencional B}

- Local: Hospital das Clínicas da Faculdade de Medicina de Ribeirão Preto;

- Marca: PHILIPS;

- Modelo: ROTALIX 350;

- Tensão máxima: $120 \mathrm{kVp}$;

- Corrente máxima: 500mA;

- Tempo de exposição máximo: 10,0s;

- Filtração inerente: $2,5 \mathrm{mmAl}$.

\subsection{Metodologia}

A metodologia utilizada nas medições com o $P M X$-III é a mesma proposta por Trout et al. (TROUT_60), já descrita no Capítulo 3. Primeiramente, obtém-se a medida da dose, numa certa posição do campo, sem a utilização de nenhum atenuador; em seguida, coloca-se sob o feixe de radiação um dos atenuadores de alumínio, de espessura conhecida, e mede-se novamente a dose. Essa 
filtração é aumentada gradativamente com a adição dos atenuadores sob o feixe, até que a dose lida pelo detector seja menor do que a metade da dose inicial medida (sem filtração). Essas medidas são tomadas em várias posições do campo, ao longo do eixo catodo-anodo. A partir desses dados, obtém-se os gráficos que representam a variação da dose recebida pelo detector em cada posição em função da filtração que foi adicionada ao feixe; estas curvas são chamadas de curvas de atenuação e têm uma forma exponencial decrescente. O valor da CSR do aparelho, em determinada posição, corresponde ao ponto do gráfico onde a espessura do filtro de alumínio reduziu a dose inicial medida à metade de seu valor. O $P M X$-III possui um programa contendo um protocolo de medida onde é calculado automaticamente o valor da CSR a partir do valores da dose obtidos com a adição dos filtros.

Para que as medidas da CSR fossem efetuadas em diferentes posições no plano imagem, o detector foi deslocado na direção perpendicular ao feixe de radiação (sobre o eixo catodo/anodo) em ambos os sentidos. Foi colocado um papel milimetrado sobre o campo de exposição dos aparelhos a fim de medir, com precisão, a que distância do centro do campo o detector era colocado. A Figura 6.3 abaixo ilustra as diferentes posições no campo, ao longo do eixo catodo-anodo, em que o detector foi colocado para a realização das medidas.

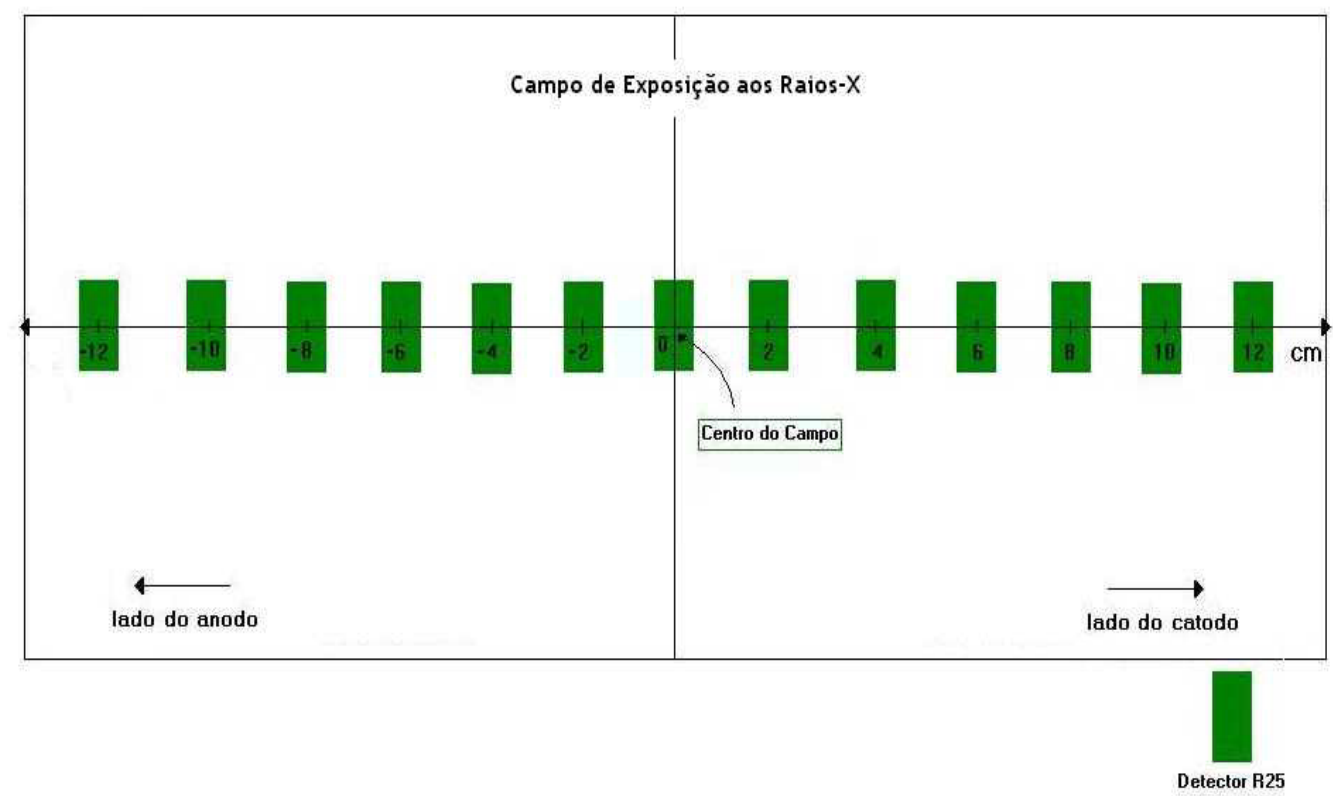

Figura 6.3. - Posicionamento do detector ao longo do campo de exposição. 
Os mamógrafos, em geral, possuem seu campo de radiação "cortado" quase ao meio. A utilização de um colimador de chumbo posicionado na janela do tubo faz com que a maior parte da região do campo correspondente ao lado do catodo seja descartada; isto é feito para diminuir a dose de radiação absorvida pela paciente durante o exame mamográfico, já que a região do campo correspondente ao lado do catodo é a região onde fica o tórax da paciente e não a mama, que fica posicionada na outra metade do campo. Por isso, nos testes com o aparelho mamográfico do Instituto Romeu Santini de Diagnóstico (Mamógrafo A), só foi possível deslocar o detector em direção ao lado do anodo. No mamógrafo do Laboratório de Raios-X do Departamento de Engenharia da EESC / USP (Mamógrafo B) foi possível efetuar algumas medidas na região correspondente ao lado do catodo do tubo, retirando-se o colimador para a realização dos testes.

Trout et al. (TROUT_62) propuseram também a medida da $2^{\mathrm{a}}$ CSR e do coeficiente de homogeneidade para uma completa avaliação da qualidade de um feixe de Raios-X, conforme apresentado no item 3.6. Desta forma, em alguns testes práticos foram medidos também a $2^{\mathrm{a}} \mathrm{CSR}$ e o coeficiente de homogeneidade para posterior comparação com os resultados apresentados pelo programa de simulação.

Apesar da recomendação encontrada na bibliografia especializada para que se utilize um feixe bem colimado nas medidas da CSR, a fim de minimizar a influência da radiação espalhada nos valores medidos (conforme discutido no Capítulo 3), foram utilizados nos testes feixes bastante divergentes, com o mínimo de colimação possível, em razão da necessidade de se irradiar toda a extensão do campo para a realização das medidas nas diversas posições distantes do centro. Esse procedimento, apesar de aparentemente inadequado, não invalida os testes realizados, pois o algoritmo de simulação proposto calcula a variação nos valores da CSR em função da posição no campo, e não seu valor absoluto. O desvio nos valores medidos, devido à influência da radiação espalhada, é bem menor do que o desvio encontrado nas experiências de Trout et al. (TROUT_60), descritas no item 3.3, onde a tensão utilizada foi da ordem de $300 \mathrm{kVp}$. Nas experiências realizadas no âmbito dessa pesquisa, a tensão máxima utilizada foi de $90 \mathrm{kVp}$, o que diminui significativamente o espalhamento da radiação (conforme discutido no item 3.4). Além disso, a influência da radiação espalhada nos testes realizados é estendida a 
todos os valores medidos, em todas as posições, já que a geometria de exposição em cada caso foi mantida; portanto, para efeito de comparação, os resultados encontrados são válidos. Por outro lado, o programa desenvolvido tem como parâmetro de entrada a CSR medida no centro do campo para o aparelho em questão. Se essa medida na região central for efetuada com precisão utilizando os procedimentos recomendados (item 3.4 e 3.5), os demais resultados fornecidos pela simulação também estarão corretos, uma vez comprovada a validade do algoritmo.

Os experimentos com o dispositivo eletrônico de medição (CURI_98) foram realizados posteriormente aos testes com o PMX-III para os aparelhos Mamógrafo B e Convencional B, onde foram efetuadas as medidas de intensidade e da CSR para diversas posições do campo pelo método descrito no item 3.7. Nos testes realizados com esse dispositivo considerou-se uma filtração adicional de 0,5mm de alumínio, para que os resultados fossem suscetíveis de comparação com outros que eventualmente fossem obtidos através de outro método de medida. Isto se fez necessário porque a espessura mínima da cunha de alumínio que opera junto ao dispositivo é de $0,5 \mathrm{~mm}$; portanto, o valor inicial da intensidade da radiação considerado como referência para o cálculo da CSR, quando a cunha se desloca por cima do sensor, já é um sinal atenuado se comparado com o sinal recebido antes do início desse deslocamento (livre de filtração). Assim, para que o valor medido para a CSR, quando utilizado o dispositivo eletrônico de medição, seja coerente com os protocolos de medida utilizados na prática, considera-se que o feixe de radiação avaliado possui filtração adicional de $0,5 \mathrm{~mm}$ de alumínio.

Para que fosse possível o posicionamento desse dispositivo em diversas regiões no campo de exposição, utilizou-se uma mesa especial desenvolvida em nosso laboratório para operar juntamente com um sistema eletrônico de alinhamento (SCHIABEL_97b). Colocando-se o dispositivo eletrônico de medição (CURI_98) sobre essa mesa foi possível seu deslocamento de um lado a outro do campo, no eixo catodo/anodo. A Figura 6.4, a seguir, mostra esse dispositivo e a mesa de alinhamento posicionados sob o aparelho de Raios-X (Convencional B) durante os testes realizados no Hospital das Clínicas de Ribeirão Preto. 


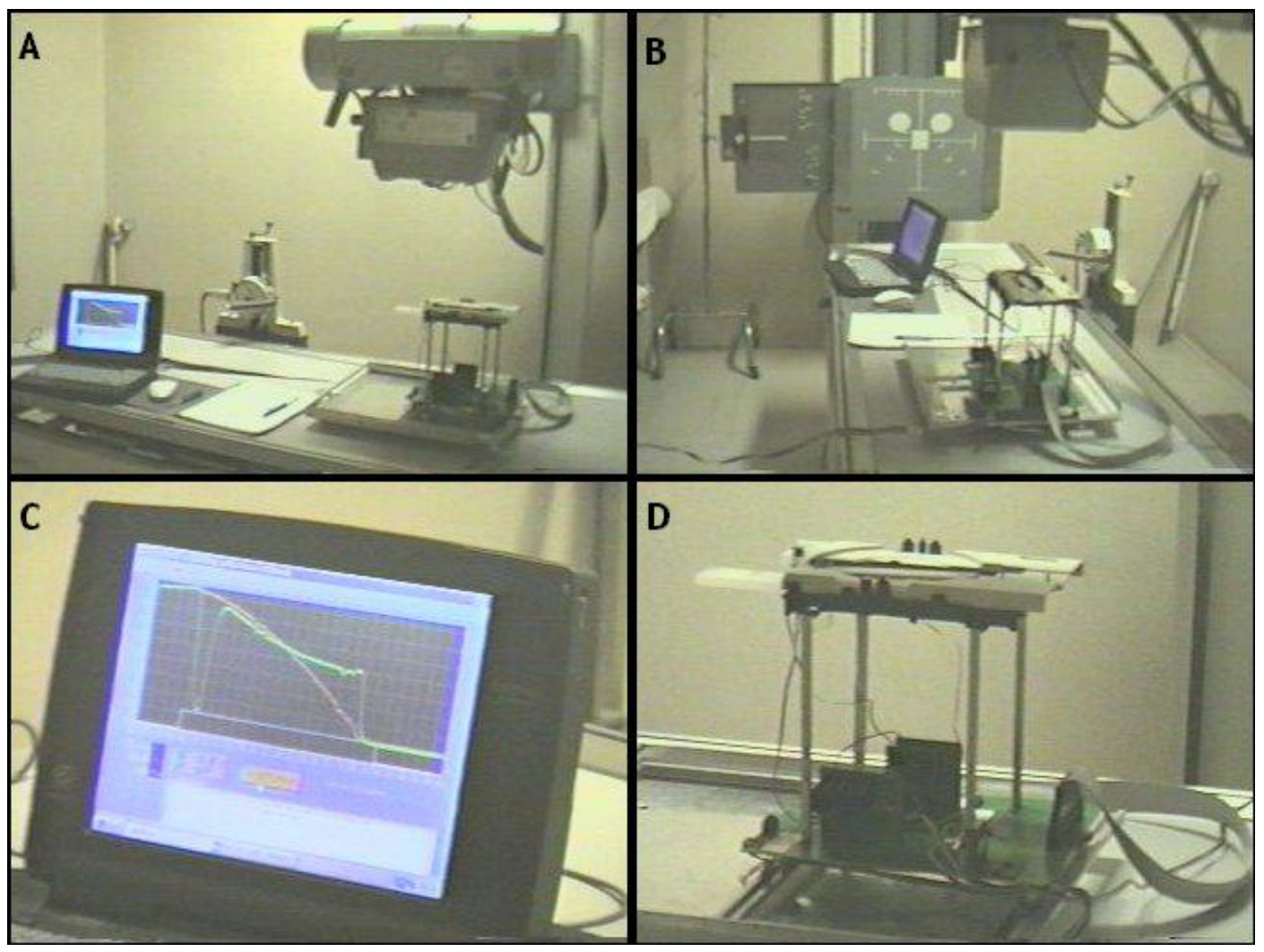

Figura 6.4. - Dispositivo eletrônico posicionado no campo durante a realização dos testes no Hospital das Clínicas de Ribeirão Preto. 


\section{CAPÍTULO 7 Resultados e Discussões}

Neste capítulo são apresentados os resultados experimentais obtidos com o medidor comercial, com o dispositivo eletrônico de medição (CURI_98) e com o programa de simulação para os valores da CSR e da dose de aparelhos radiográficos hospitalares.

\subsection{Resultados com o aparelho $P M X-I I I$}

São apresentados a seguir os resultados obtidos em oito testes realizados em aparelhos radiográficos hospitalares. Os testes foram realizados para diferentes valores de $\mathrm{kVp}$, corrente e tempo de exposição. As tabelas a seguir mostram os valores da dose de radiação recebida pelo medidor em função da espessura do filtro de alumínio que foi colocado sob o feixe de Raios-X, próximo à janela do tubo. Assim, obteve-se o valor da dose de radiação recebida (em mGy), livre de filtração, em várias posições no campo para avaliação do efeito "heel”, além dos valores da CSR em todas as posições onde foram feitas as medidas. 


\section{TESTE 1}

Local: Instituto Romeu Santini de Diagnóstico - São Carlos;

Aparelho: Mamógrafo A (especificado no Capítulo 6);

Tensão: $26 \mathrm{kVp}$;

Corrente: $100 \mathrm{~mA}$;

Tempo de exposição: 1,0s;

Distância do tubo ao campo: $50 \mathrm{~cm}$.

Tabela 7.1. - Resultados Teste 1: centro do campo.

\begin{tabular}{|c|c|}
\hline Espessura (mmAl) & Dose (mGy) \\
\hline 0,0 & 11,10 \\
\hline 0,1 & 8,77 \\
\hline 0,2 & 7,18 \\
\hline 0,3 & 5,94 \\
\hline 0,4 & 5,07 \\
\hline 0,5 & 4,27 \\
\hline 0,8 & 2,87 \\
\hline 0,9 & 2,36 \\
\hline
\end{tabular}

A partir dos dados da Tabela 7.1 determina-se a curva de atenuação gerada pela adição dos filtros sob o feixe de Raios-X e, através dela, obtém-se o valor da CSR do aparelho utilizando-se a metodologia descrita no item 3.2. À título de ilustração, a Figura 7.1 mostra a curva de atenuação obtida com os dados da Tabela 7.1, juntamente com a metodologia utilizada para a determinação dos valores da $1^{\text {a }} \mathrm{CSR}$, da $2^{\mathrm{a}} \mathrm{CSR}$ e do coeficiente de homogeneidade $(\mathrm{H})$. 


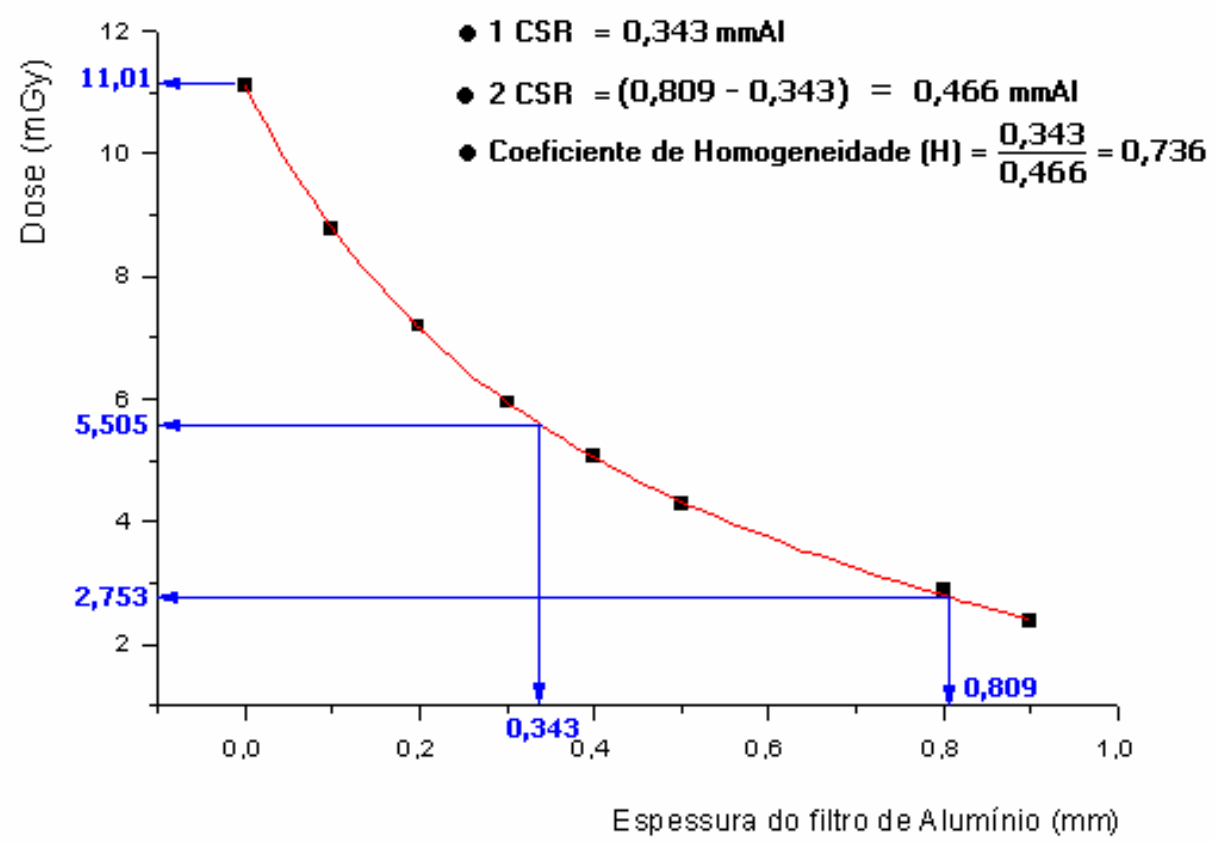

Figura 7.1. - Curva de atenuação obtida através dos dados da Tabela 7.1.

Assim, os valores obtidos com os dados da Tabela 7.1 são listados a seguir:

$$
\begin{aligned}
& 1^{\mathrm{a}} \mathrm{CSR}=0,343 \mathrm{mmAl} \\
& 2^{\mathrm{a}} \mathrm{CSR}=0,466 \mathrm{mmAl} \\
& \text { Dose }=11,01 \mathrm{mGy} \\
& \mathrm{H}=0,736
\end{aligned}
$$

Tabela 7.2. - Resultados Teste 1: lado do anodo - $2 \mathrm{~cm}$ do centro.

\begin{tabular}{|c|c|}
\hline Espessura (mmAl) & Dose (mGy) \\
\hline 0,0 & 10,98 \\
\hline 0,1 & 8,70 \\
\hline 0,2 & 7,11 \\
\hline 0,3 & 5,90 \\
\hline 0,4 & 5,01 \\
\hline 0,5 & 4,23 \\
\hline 0,8 & 2,79 \\
\hline 0,9 & 2,36 \\
\hline
\end{tabular}




$$
\begin{aligned}
& 1^{\mathrm{a}} \mathrm{CSR}=0,344 \mathrm{mmAl} \\
& 2^{\mathrm{a}} \mathrm{CSR}=0,461 \mathrm{mmAl} \\
& \text { Dose }=10,90 \mathrm{mGy} \\
& \mathrm{H}=0,746
\end{aligned}
$$

Tabela 7.3. - Resultados Teste 1: lado do anodo - $6 \mathrm{~cm}$ do centro.

\begin{tabular}{|c|c|}
\hline Espessura (mmAl) & Dose (mGy) \\
\hline 0,0 & 9,95 \\
\hline 0,1 & 7,92 \\
\hline 0,2 & 6,49 \\
\hline 0,3 & 5,39 \\
\hline 0,4 & 4,60 \\
\hline 0,5 & 3,87 \\
\hline 0,8 & 2,49 \\
\hline 0,9 & 2,15 \\
\hline
\end{tabular}

$1^{\mathrm{a}} \mathrm{CSR}=0,349 \mathrm{mmAl}$

$2^{\mathrm{a}} \mathrm{CSR}=0,455 \mathrm{mmAl}$

Dose $=9,88 \mathrm{mGy}$

$\mathrm{H}=0,767$

Tabela 7.4. - Resultados Teste 1: lado do anodo - $8 \mathrm{~cm}$ do centro.

\begin{tabular}{|c|c|}
\hline Espessura (mmAl) & Dose (mGy) \\
\hline 0,0 & 8,77 \\
\hline 0,1 & 7,08 \\
\hline 0,2 & 5,79 \\
\hline 0,3 & 4,80 \\
\hline 0,4 & 4,09 \\
\hline 0,5 & 3,44 \\
\hline 0,8 & 2,22 \\
\hline 0,9 & 1,91 \\
\hline
\end{tabular}

$1^{\mathrm{a}} \mathrm{CSR}=0,355 \mathrm{mmAl}$

$2^{\mathrm{a}} \mathrm{CSR}=0,452 \mathrm{mmAl}$

Dose $=8,73 \mathrm{mGy}$

$\mathrm{H}=0,785$ 
Tabela 7.5. - Resultados Teste 1: lado do anodo - $12 \mathrm{~cm}$ do centro.

\begin{tabular}{|c|c|}
\hline Espessura (mmAl) & Dose (mGy) \\
\hline 0,0 & 6,04 \\
\hline 0,1 & 4,78 \\
\hline 0,2 & 4,00 \\
\hline 0,3 & 3,32 \\
\hline 0,4 & 2,83 \\
\hline 0,5 & 2,38 \\
\hline 0,8 & 1,53 \\
\hline 0,9 & 1,32 \\
\hline
\end{tabular}

$1^{\text {a }} \mathrm{CSR}=0,358 \mathrm{mmAl}$

$2^{\mathrm{a}} \mathrm{CSR}=0,451 \mathrm{mmAl}$

Dose $=6,01 \mathrm{mGy}$

$\mathrm{H}=0,794$

Tabela 7.6. - Resultados Finais do Teste 1.

\begin{tabular}{|c|c|c|c|c|}
\hline Posição $^{\mathbf{6}}$ (cm) & 1 $^{\text {a }}$ CSR (mmAl) & 2 $^{\mathbf{a}}$ CSR (mmAl) & H & Dose (mGy) \\
\hline 0 & 0,343 & 0,466 & 0,736 & 11,01 \\
\hline-2 & 0,344 & 0,461 & 0,746 & 10,90 \\
\hline-6 & 0,349 & 0,455 & 0,767 & 9,88 \\
\hline-8 & 0,355 & 0,452 & 0,785 & 8,73 \\
\hline-12 & 0,358 & 0,451 & 0,794 & 6,01 \\
\hline
\end{tabular}

Variação nos valores medidos na extremidade do campo em relação ao valor central ${ }^{7}$ :

- $1^{\mathrm{a}} \mathrm{CSR}: \quad+4,37 \%$

- $2^{\mathrm{a}} \mathrm{CSR}: \quad-3,22 \%$

- $\mathrm{H}: \quad+7,88 \%$

- Dose: - $45,41 \%$

${ }^{6}$ O sinal negativo indica que o deslocamento do detector foi em direção ao lado do campo correspondente ao anodo do tubo. Sinal positivo indicaria deslocamento para o lado do catodo.

${ }^{7} \mathrm{O}$ sinal colocado antes do valor obtido para a variação indica se o valor medido na extremidade do campo de radiação aumentou $(+)$ ou diminuiu $(-)$ em relação ao valor medido no centro. 


\section{TESTE 2}

Local: Instituto Romeu Santini de Diagnóstico - São Carlos;

Aparelho: Mamógrafo A;

Tensão: $30 \mathrm{kVp}$;

Corrente: $80 \mathrm{~mA}$;

Tempo de exposição: 1,0s;

Distância do tubo ao campo: $60 \mathrm{~cm}$.

Tabela 7.7. - Resultados Teste 2: centro do campo.

\begin{tabular}{|c|c|}
\hline Espessura (mmAl) & Dose (mGy) \\
\hline 0,0 & 14,73 \\
\hline 0,1 & 11,90 \\
\hline 0,2 & 9,94 \\
\hline 0,3 & 8,37 \\
\hline 0,4 & 7,24 \\
\hline 0,5 & 6,19 \\
\hline
\end{tabular}

$$
\begin{aligned}
& \mathrm{CSR}=0,382 \mathrm{mmAl} \\
& \text { Dose }=14,69 \mathrm{mGy}
\end{aligned}
$$

Tabela 7.8. - Resultados Teste 2: lado do anodo - $2 \mathrm{~cm}$ do centro.

\begin{tabular}{|c|c|}
\hline Espessura (mmAl) & Dose (mGy) \\
\hline 0,0 & 14,50 \\
\hline 0,1 & 11,89 \\
\hline 0,2 & 9,92 \\
\hline 0,3 & 8,31 \\
\hline 0,4 & 7,02 \\
\hline 0,5 & 6,12 \\
\hline
\end{tabular}

$\mathrm{CSR}=0,383 \mathrm{mmAl}$

Dose $=14,50 \mathrm{mGy}$ 
Tabela 7.9. - Resultados Teste 2: lado do anodo - $6 \mathrm{~cm}$ do centro.

\begin{tabular}{|c|c|}
\hline Espessura (mmAl) & Dose (mGy) \\
\hline 0,0 & 13,34 \\
\hline 0,1 & 10,97 \\
\hline 0,2 & 9,12 \\
\hline 0,3 & 7,65 \\
\hline 0,4 & 6,58 \\
\hline 0,5 & 5,61 \\
\hline
\end{tabular}

$$
\begin{aligned}
& \mathrm{CSR}=0,386 \mathrm{mmAl} \\
& \text { Dose }=13,34 \mathrm{mGy}
\end{aligned}
$$

Tabela 7.10. - Resultados Teste 2: lado do anodo - $8 \mathrm{~cm}$ do centro.

\begin{tabular}{|c|c|}
\hline Espessura (mmAl) & Dose (mGy) \\
\hline 0,0 & 12,12 \\
\hline 0,1 & 9,96 \\
\hline 0,2 & 8,30 \\
\hline 0,3 & 6,96 \\
\hline 0,4 & 5,99 \\
\hline 0,5 & 5,11 \\
\hline
\end{tabular}

$$
\begin{aligned}
& \mathrm{CSR}=0,388 \mathrm{mmAl} \\
& \text { Dose }=12,11 \mathrm{mGy}
\end{aligned}
$$

Tabela 7.11. - Resultados Teste 2: lado do anodo - $12 \mathrm{~cm}$ do centro.

\begin{tabular}{|c|c|}
\hline Espessura (mmAl) & Dose (mGy) \\
\hline 0,0 & 10,30 \\
\hline 0,1 & 8,48 \\
\hline 0,2 & 7,10 \\
\hline 0,3 & 5,98 \\
\hline 0,4 & 5,16 \\
\hline 0,5 & 4,40 \\
\hline
\end{tabular}

$$
\begin{aligned}
& \mathrm{CSR}=0,395 \mathrm{mmAl} \\
& \text { Dose }=10,29 \mathrm{mGy}
\end{aligned}
$$


Tabela 7.12. - Resultados Finais do Teste 2.

\begin{tabular}{|c|c|c|}
\hline Posição (cm) & CSR (mmAl) & Dose (mGy) \\
\hline 0 & 0,382 & 14,69 \\
\hline-2 & 0,383 & 14,50 \\
\hline-6 & 0,386 & 13,34 \\
\hline-8 & 0,388 & 12,11 \\
\hline-12 & 0,395 & 10,29 \\
\hline
\end{tabular}

Variação nos valores medidos na extremidade do campo em relação ao valor central:

- CSR: $+3,40 \%$

- Dose: - 29,95\%

\section{$\underline{T E S T E} 3$}

Local: Instituto Romeu Santini de Diagnóstico - São Carlos;

Aparelho: Mamógrafo A;

Tensão: $34 \mathrm{kVp}$;

Corrente: $50 \mathrm{~mA}$;

Tempo de exposição: 1,0s;

Distância do tubo ao campo: $60 \mathrm{~cm}$.

Tabela 7.13. - Resultados Teste 3: centro do campo.

\begin{tabular}{|c|c|}
\hline Espessura (mmAI) & Dose (mGy) \\
\hline 0,0 & 13,42 \\
\hline 0,1 & 11,13 \\
\hline 0,2 & 9,36 \\
\hline 0,3 & 7,98 \\
\hline 0,4 & 6,94 \\
\hline 0,5 & 5,98 \\
\hline 0,8 & 4,09 \\
\hline
\end{tabular}

$$
\begin{aligned}
& \mathrm{CSR}=0,416 \mathrm{mmAl} \\
& \text { Dose }=13,37 \mathrm{mGy}
\end{aligned}
$$


Tabela 7.14. - Resultados Teste 3: lado do anodo - $6 \mathrm{~cm}$ do centro.

\begin{tabular}{|c|c|}
\hline Espessura (mmAl) & Dose (mGy) \\
\hline 0,0 & 12,18 \\
\hline 0,1 & 10,11 \\
\hline 0,2 & 8,53 \\
\hline 0,3 & 7,26 \\
\hline 0,4 & 6,32 \\
\hline 0,5 & 5,46 \\
\hline 0,8 & 3,74 \\
\hline
\end{tabular}

$$
\begin{aligned}
& \mathrm{CSR}=0,420 \mathrm{mmAl} \\
& \text { Dose }=12,14 \mathrm{mGy}
\end{aligned}
$$

Tabela 7.15. - Resultados Teste 3: lado do anodo - $12 \mathrm{~cm}$ do centro.

\begin{tabular}{|c|c|}
\hline Espessura (mmAl) & Dose (mGy) \\
\hline 0,0 & 8,93 \\
\hline 0,1 & 7,44 \\
\hline 0,2 & 6,32 \\
\hline 0,3 & 5,40 \\
\hline 0,4 & 4,70 \\
\hline 0,5 & 4,05 \\
\hline 0,8 & 2,78 \\
\hline
\end{tabular}

$$
\begin{aligned}
\mathrm{CSR} & =0,430 \mathrm{~mm} \mathrm{Al} \\
\text { Dose } & =8,90 \mathrm{mGy}
\end{aligned}
$$

Tabela 7.16. - Resultados Finais do Teste 3.

\begin{tabular}{|c|c|c|}
\hline Posição (cm) & CSR (mmAl) & Dose (mGy) \\
\hline 0 & 0,416 & 13,37 \\
\hline-6 & 0,420 & 12,14 \\
\hline-12 & 0,430 & 8,90 \\
\hline
\end{tabular}

Variação nos valores medidos na extremidade do campo em relação ao valor central:

- CSR: $+3,37 \%$

- Dose: - $33,43 \%$ 


\section{$\underline{\text { TESTE } 4}$}

Local: Instituto Romeu Santini de Diagnóstico - São Carlos;

Aparelho: Convencional A;

Tensão: 90kVp;

Corrente: $50 \mathrm{~mA}$;

Tempo de exposição: $0,25 \mathrm{~s}$;

Distância do tubo ao campo: $90 \mathrm{~cm}$.

Tabela 7.17. - Resultados Teste 4: centro do campo.

\begin{tabular}{|c|c|}
\hline Espessura (mmAl) & Dose (mGy) \\
\hline 0,0 & 1,981 \\
\hline 0,5 & 1,783 \\
\hline 1,0 & 1,557 \\
\hline 1,5 & 1,439 \\
\hline 2,0 & 1,282 \\
\hline 2,5 & 1,173 \\
\hline 3,0 & 1,071 \\
\hline 3,5 & 0,967 \\
\hline
\end{tabular}

$$
\begin{aligned}
& \mathrm{CSR}=3,41 \mathrm{mmAl} \\
& \text { Dose }=1,98 \mathrm{mGy}
\end{aligned}
$$

Tabela 7.18. - Resultados Teste 4: lado do catodo - $6 \mathrm{~cm}$ do centro.

\begin{tabular}{|c|c|}
\hline Espessura (mmAl) & Dose (mGy) \\
\hline 0,0 & 2,093 \\
\hline 0,5 & 1,879 \\
\hline 1,0 & 1,704 \\
\hline 1,5 & 1,529 \\
\hline 2,0 & 1,425 \\
\hline 2,5 & 1,197 \\
\hline 3,0 & 1,099 \\
\hline 3,5 & 0,999 \\
\hline
\end{tabular}

$$
\begin{aligned}
& \mathrm{CSR}=3,32 \mathrm{mmAl} \\
& \text { Dose }=2,09 \mathrm{mGy}
\end{aligned}
$$


Tabela 7.19. - Resultados Teste 4: lado do catodo - $10 \mathrm{~cm}$ do centro.

\begin{tabular}{|c|c|}
\hline Espessura (mmAl) & Dose (mGy) \\
\hline 0,0 & 1,965 \\
\hline 0,5 & 1,726 \\
\hline 1,0 & 1,566 \\
\hline 1,5 & 1,368 \\
\hline 2,0 & 1,264 \\
\hline 2,5 & 1,146 \\
\hline 3,0 & 1,041 \\
\hline 3,5 & 0,948 \\
\hline
\end{tabular}

$$
\begin{aligned}
& \mathrm{CSR}=3,34 \mathrm{mmAl} \\
& \text { Dose }=1,96 \mathrm{mGy}
\end{aligned}
$$

Tabela 7.20. - Resultados Teste 4: lado do catodo - $16 \mathrm{~cm}$ do centro.

\begin{tabular}{|c|c|}
\hline Espessura (mmAl) & Dose (mGy) \\
\hline 0,0 & 1,921 \\
\hline 0,5 & 1,737 \\
\hline 1,0 & 1,566 \\
\hline 1,5 & 1,367 \\
\hline 2,0 & 1,228 \\
\hline 2,5 & 1,115 \\
\hline 3,0 & 1,031 \\
\hline 3,5 & 0,953 \\
\hline
\end{tabular}

$$
\begin{aligned}
\mathrm{CSR} & =3,33 \mathrm{mmAl} \\
\text { Dose } & =1,94 \mathrm{mGy}
\end{aligned}
$$

Tabela 7.21. - Resultados Teste 4: lado do anodo - $10 \mathrm{~cm}$ do centro.

\begin{tabular}{|c|c|}
\hline Espessura (mmAl) & Dose (mGy) \\
\hline 0,0 & 1,705 \\
\hline 0,5 & 1,543 \\
\hline 1,0 & 1,388 \\
\hline 1,5 & 1,276 \\
\hline 2,0 & 1,182 \\
\hline 2,5 & 1,075 \\
\hline 3,0 & 0,993 \\
\hline 3,5 & 0,898 \\
\hline 4,5 & 0,752 \\
\hline
\end{tabular}




$$
\begin{aligned}
\mathrm{CSR} & =3,83 \mathrm{mmAl} \\
\text { Dose } & =1,70 \mathrm{mGy}
\end{aligned}
$$

Tabela 7.22. - Resultados Teste 4: lado do anodo - $16 \mathrm{~cm}$ do centro.

\begin{tabular}{|c|c|}
\hline Espessura (mmAl) & Dose (mGy) \\
\hline 0,0 & 1,347 \\
\hline 0,5 & 1,242 \\
\hline 1,0 & 1,126 \\
\hline 1,5 & 1,031 \\
\hline 2,0 & 0,933 \\
\hline 2,5 & 0,854 \\
\hline 3,0 & 0,791 \\
\hline 3,5 & 0,738 \\
\hline 4,0 & 0,686 \\
\hline 4,5 & 0,631 \\
\hline
\end{tabular}

$$
\begin{aligned}
& \mathrm{CSR}=4,00 \mathrm{mmAl} \\
& \text { Dose }=1,36 \mathrm{mGy}
\end{aligned}
$$

Tabela 7.23. - Resultados Finais do Teste 4.

\begin{tabular}{|c|c|c|}
\hline Posição (cm) & CSR (mmAl) & Dose (mGy) \\
\hline+16 & 3,33 & 1,94 \\
\hline+10 & 3,34 & 1,96 \\
\hline+6 & 3,32 & 2,09 \\
\hline 0 & 3,41 & 1,98 \\
\hline-10 & 3,83 & 1,70 \\
\hline-16 & 4,00 & 1,36 \\
\hline
\end{tabular}

Variação nos valores medidos na extremidade do campo, no lado correspondente ao catodo, em relação ao valor central:

- CSR: $-2,35 \%$

- Dose: $-2,02 \%$

Variação nos valores medidos na extremidade do campo, no lado correspondente ao anodo, em relação ao valor central:

- CSR: $+17,30 \%$

- Dose: - 31,31\%

Variação nos valores medidos de um extremo a outro no campo: 
- CSR: 20,12\%

- Dose: $29,89 \%$

\section{TESTE 5}

Local: Instituto Romeu Santini de Diagnóstico - São Carlos;

Aparelho: Convencional A;

Tensão: $80 \mathrm{kVp}$;

Corrente: $50 \mathrm{~mA}$;

Tempo de exposição: $0,5 \mathrm{~s}$;

Distância do tubo ao campo: $90 \mathrm{~cm}$.

Tabela 7.24. - Resultados Teste 5: centro do campo.

\begin{tabular}{|c|c|}
\hline Espessura (mmAl) & Dose (mGy) \\
\hline 0,0 & 1,907 \\
\hline 0,5 & 1,640 \\
\hline 1,0 & 1,464 \\
\hline 1,5 & 1,306 \\
\hline 2,0 & 1,185 \\
\hline 2,5 & 1,074 \\
\hline 3,0 & 0,939 \\
\hline 3,5 & 0,869 \\
\hline
\end{tabular}

$$
\begin{aligned}
& \mathrm{CSR}=3,06 \mathrm{mmAl} \\
& \text { Dose }=1,89 \mathrm{mGy}
\end{aligned}
$$

Tabela 7.25. - Resultados Teste 5: lado do catodo - $10 \mathrm{~cm}$ do centro.

\begin{tabular}{|c|c|}
\hline Espessura (mmAl) & Dose (mGy) \\
\hline 0,0 & 2,034 \\
\hline 0,5 & 1,708 \\
\hline 1,0 & 1,540 \\
\hline 1,5 & 1,385 \\
\hline 2,0 & 1,252 \\
\hline 2,5 & 1,118 \\
\hline 3,0 & 1,013 \\
\hline 3,5 & 0,927 \\
\hline
\end{tabular}




$$
\begin{aligned}
\mathrm{CSR} & =3,07 \mathrm{mmAl} \\
\text { Dose } & =2,01 \mathrm{mGy}
\end{aligned}
$$

Tabela 7.26. - Resultados Teste 5: lado do anodo - $14 \mathrm{~cm}$ do centro.

\begin{tabular}{|c|c|}
\hline Espessura (mmAl) & Dose (mGy) \\
\hline 0,0 & 1,354 \\
\hline 0,5 & 1,212 \\
\hline 1,0 & 1,106 \\
\hline 1,5 & 0,984 \\
\hline 2,0 & 0,908 \\
\hline 2,5 & 0,823 \\
\hline 3,0 & 0,733 \\
\hline 3,5 & 0,630 \\
\hline
\end{tabular}

$$
\begin{aligned}
& \mathrm{CSR}=3,32 \mathrm{mmAl} \\
& \text { Dose }=1,34 \mathrm{mGy}
\end{aligned}
$$

Tabela 7.27. - Resultados Finais do Teste 5.

\begin{tabular}{|c|c|c|}
\hline Posição (cm) & CSR (mmAl) & Dose (mGy) \\
\hline+10 & 3,07 & 2,01 \\
\hline 0 & 3,06 & 1,89 \\
\hline-14 & 3,32 & 1,34 \\
\hline
\end{tabular}

Variação nos valores medidos na extremidade do campo, no lado correspondente ao catodo, em relação ao valor central:

- CSR: +0,33\%

- Dose: $+6,35 \%$

Variação nos valores medidos na extremidade do campo, no lado correspondente ao anodo, em relação ao valor central:

- CSR: $+8,50 \%$

- Dose: - 29,10\%

Variação nos valores medidos de um extremo a outro no campo:

- CSR: $8,14 \%$

- Dose: $33,33 \%$ 


\section{TESTE 6}

Local: Instituto Romeu Santini de Diagnóstico - São Carlos;

Aparelho: Convencional A;

Tensão: 60kVp;

Corrente: $50 \mathrm{~mA}$;

Tempo de exposição: $0,5 \mathrm{~s}$;

Distância do tubo ao campo: $90 \mathrm{~cm}$.

Tabela 7.28. - Resultados Teste 6: centro do campo.

\begin{tabular}{|c|c|}
\hline Espessura (mmAl) & Dose (mGy) \\
\hline 0,0 & 0,929 \\
\hline 0,5 & 0,804 \\
\hline 1,0 & 0,693 \\
\hline 1,5 & 0,595 \\
\hline 2,0 & 0,533 \\
\hline 2,5 & 0,473 \\
\hline 3,0 & 0,422 \\
\hline 3,5 & 0,367 \\
\hline
\end{tabular}

$$
\begin{aligned}
& \mathrm{CSR}=2,53 \mathrm{mmAl} \\
& \text { Dose }=0,929 \mathrm{mGy}
\end{aligned}
$$

Tabela 7.29. - Resultados Teste 6: lado do catodo - $10 \mathrm{~cm}$ do centro.

\begin{tabular}{|c|c|}
\hline Espessura (mmAl) & Dose (mGy) \\
\hline 0,0 & 0,980 \\
\hline 0,5 & 0,846 \\
\hline 1,0 & 0,737 \\
\hline 1,5 & 0,628 \\
\hline 2,0 & 0,555 \\
\hline 2,5 & 0,487 \\
\hline 3,0 & 0,440 \\
\hline
\end{tabular}

$$
\begin{aligned}
& \mathrm{CSR}=2,49 \mathrm{mmAl} \\
& \text { Dose }=0,982 \mathrm{mGy}
\end{aligned}
$$


Tabela 7.30. - Resultados Teste 6: lado do anodo - $14 \mathrm{~cm}$ do centro.

\begin{tabular}{|c|c|}
\hline Espessura (mmAI) & Dose (mGy) \\
\hline 0,0 & 0,678 \\
\hline 0,5 & 0,584 \\
\hline 1,0 & 0,524 \\
\hline 1,5 & 0,445 \\
\hline 2,0 & 0,402 \\
\hline 2,5 & 0,356 \\
\hline 3,0 & 0,318 \\
\hline
\end{tabular}

$$
\begin{aligned}
& \mathrm{CSR}=2,72 \mathrm{mmAl} \\
& \text { Dose }=0,677 \mathrm{mGy}
\end{aligned}
$$

Tabela 7.31. - Resultados Finais do Teste 6.

\begin{tabular}{|c|c|c|}
\hline Posição (cm) & CSR (mmAl) & Dose (mGy) \\
\hline+10 & 2,49 & 0,982 \\
\hline 0 & 2,53 & 0,929 \\
\hline-14 & 2,72 & 0,677 \\
\hline
\end{tabular}

Variação nos valores medidos na extremidade do campo, no lado correspondente ao catodo, em relação ao valor central:

- CSR: $-1,58 \%$

- Dose: $+5,71 \%$

Variação nos valores medidos na extremidade do campo, no lado correspondente ao anodo, em relação ao valor central:

- CSR: $+7,51 \%$

- Dose: $-27,13 \%$

Variação nos valores medidos de um extremo a outro no campo:

- CSR: $9,24 \%$

- Dose: 31,06\% 


\section{TESTE 7}

Local: Laboratório de Raios-X - Departamento de Engenharia Elétrica - EESC / USP Aparelho: Mamógrafo B;

Tensão: 26kVp;

Corrente: $8 \mathrm{~mA}$;

Tempo de exposição: 2,0s;

Distância do tubo ao campo: $45 \mathrm{~cm}$.

Tabela 7.32. - Resultados Teste 7: centro do campo.

\begin{tabular}{|c|c|}
\hline Espessura (mmAI) & Dose (mGy) \\
\hline 0,0 & 3,94 \\
\hline 0,1 & 2,82 \\
\hline 0,2 & 2,13 \\
\hline 0,3 & 1,66 \\
\hline 0,4 & 1,33 \\
\hline
\end{tabular}

$$
\begin{aligned}
& \mathrm{CSR}=0,228 \mathrm{mmAl} \\
& \text { Dose }=3,93 \mathrm{mGy}
\end{aligned}
$$

Tabela 7.33. - Resultados Teste 7: lado do anodo - $6 \mathrm{~cm}$ do centro.

\begin{tabular}{|c|c|}
\hline Espessura (mmAl) & Dose (mGy) \\
\hline 0,0 & 3,38 \\
\hline 0,1 & 2,43 \\
\hline 0,2 & 1,83 \\
\hline 0,3 & 1,38 \\
\hline 0,4 & 1,06 \\
\hline
\end{tabular}

$$
\begin{aligned}
& \mathrm{CSR}=0,225 \mathrm{mmAl} \\
& \text { Dose }=3,37 \mathrm{mGy}
\end{aligned}
$$


Tabela 7.34. - Resultados Teste 7: lado do anodo - 10cm do centro.

\begin{tabular}{|c|c|}
\hline Espessura (mmAI) & Dose (mGy) \\
\hline 0,0 & 2,55 \\
\hline 0,1 & 1,77 \\
\hline 0,2 & 1,34 \\
\hline 0,3 & 1,13 \\
\hline 0,4 & 0,91 \\
\hline
\end{tabular}

$$
\begin{aligned}
& \mathrm{CSR}=0,224 \mathrm{mmAl} \\
& \text { Dose }=2,54 \mathrm{mGy}
\end{aligned}
$$

Tabela 7.35. - Resultados Teste 7: lado do catodo $-10 \mathrm{~cm}$ do centro.

\begin{tabular}{|c|c|}
\hline Espessura (mmAI) & Dose (mGy) \\
\hline 0,0 & 3,75 \\
\hline 0,1 & 2,77 \\
\hline 0,2 & 2,08 \\
\hline 0,3 & 1,61 \\
\hline 0,4 & 1,29 \\
\hline
\end{tabular}

$$
\begin{aligned}
& \mathrm{CSR}=0,240 \mathrm{mmAl} \\
& \text { Dose }=3,75 \mathrm{mGy}
\end{aligned}
$$

Tabela 7.36. - Resultados Finais do Teste 7.

\begin{tabular}{|c|c|c|}
\hline Posição (cm) & CSR (mmAl) & Dose (mGy) \\
\hline+10 & 0,240 & 3,75 \\
\hline 0 & 0,228 & 3,93 \\
\hline-6 & 0,225 & 3,37 \\
\hline-10 & 0,224 & 2,54 \\
\hline
\end{tabular}

Variação nos valores medidos na extremidade do campo, no lado correspondente ao catodo, em relação ao valor central:

- CSR: $+5,26 \%$

- Dose: - 4,58\%

Variação nos valores medidos na extremidade do campo, no lado correspondente ao anodo, em relação ao valor central: 
- CSR: - 1,75\%

- Dose: $-35,37 \%$

Variação nos valores medidos de um extremo a outro no campo:

- CSR: $7,14 \%$

- Dose: $32,26 \%$

\section{$\underline{T E S T E ~} 8$}

Local: Laboratório de Raios-X - Departamento de Engenharia Elétrica - EESC / USP Aparelho: Mamógrafo B;

Tensão: $30 \mathrm{kVp}$;

Corrente: $5 \mathrm{~mA}$;

Tempo de exposição: 2,0s;

Distância do tubo ao campo: $45 \mathrm{~cm}$.

Tabela 7.37. - Resultados Teste 8: centro do campo.

\begin{tabular}{|c|c|}
\hline Espessura (mmAl) & Dose (mGy) \\
\hline 0,0 & 3,29 \\
\hline 0,1 & 2,60 \\
\hline 0,2 & 2,08 \\
\hline 0,3 & 1,69 \\
\hline 0,4 & 1,53 \\
\hline
\end{tabular}

$$
\begin{aligned}
& \mathrm{CSR}=0,333 \mathrm{mmAl} \\
& \text { Dose }=3,30 \mathrm{mGy}
\end{aligned}
$$

Tabela 7.38. - Resultados Teste 8: lado do anodo - $4 \mathrm{~cm}$ do centro.

\begin{tabular}{|c|c|}
\hline Espessura (mmAl) & Dose (mGy) \\
\hline 0,0 & 3,09 \\
\hline 0,1 & 2,43 \\
\hline 0,2 & 1,94 \\
\hline 0,3 & 1,62 \\
\hline 0,4 & 1,43 \\
\hline
\end{tabular}




$$
\begin{aligned}
& \mathrm{CSR}=0,334 \mathrm{mmAl} \\
& \text { Dose }=3,10 \mathrm{mGy}
\end{aligned}
$$

Tabela 7.39. - Resultados Teste 8: lado do anodo - $10 \mathrm{~cm}$ do centro.

\begin{tabular}{|c|c|}
\hline Espessura (mmAl) & Dose (mGy) \\
\hline 0,0 & 1,94 \\
\hline 0,1 & 1,52 \\
\hline 0,2 & 1,21 \\
\hline 0,3 & 1,03 \\
\hline 0,4 & 0,89 \\
\hline 0,5 & 0,74 \\
\hline
\end{tabular}

$$
\begin{aligned}
& \mathrm{CSR}=0,328 \mathrm{mmAl} \\
& \text { Dose }=1,94 \mathrm{mGy}
\end{aligned}
$$

Tabela 7.40. - Resultados Teste 8: lado do catodo - $10 \mathrm{~cm}$ do centro.

\begin{tabular}{|c|c|}
\hline Espessura (mmAI) & Dose (mGy) \\
\hline 0,0 & 3,10 \\
\hline 0,1 & 2,56 \\
\hline 0,2 & 2,07 \\
\hline 0,3 & 1,68 \\
\hline 0,4 & 1,44 \\
\hline
\end{tabular}

$$
\begin{aligned}
& \mathrm{CSR}=0,351 \mathrm{mmAl} \\
& \text { Dose }=3,11 \mathrm{mGy}
\end{aligned}
$$

Tabela 7.41. - Resultados Finais do Teste 8.

\begin{tabular}{|c|c|c|}
\hline Posição (cm) & CSR (mmAl) & Dose (mGy) \\
\hline+10 & 0,351 & 3,11 \\
\hline 0 & 0,333 & 3,30 \\
\hline-4 & 0,334 & 3,10 \\
\hline-10 & 0,328 & 1,94 \\
\hline
\end{tabular}

Variação nos valores medidos na extremidade do campo, no lado correspondente ao catodo, em relação ao valor central:

- CSR: $+5,41 \%$

- Dose: - 5,76\% 
Variação nos valores medidos na extremidade do campo, no lado correspondente ao anodo, em relação ao valor central:

- CSR: $-1,51 \%$

- Dose: - $41,21 \%$

Variação nos valores medidos de um extremo a outro no campo:

- CSR: 7,01\%

- Dose: $37,62 \%$

\subsection{Resultados com o dispositivo eletrônico de medição}

A seguir são apresentados os resultados obtidos em três testes realizados com o dispositivo eletrônico descrito no item 3.7 (CURI_98). O método utilizado para as medidas da CSR e da intensidade de radiação através desse dispositivo já foi descrito no Capítulo 6. As tabelas a seguir mostram os resultados finais obtidos para CSR e intensidade em função do posicionamento do sensor no campo de exposição.

\section{TESTE 9}

Local: Laboratório de Raios-X - Departamento de Engenharia Elétrica - EESC / USP Aparelho: Mamógrafo B;

Tensão: 40kVp;

Corrente: $8 \mathrm{~mA}$;

Tempo de exposição: 4,0s;

Distância do tubo ao campo: $50 \mathrm{~cm}$;

Filtração adicional: $0,5 \mathrm{mmAl}^{8}$.

\footnotetext{
${ }^{8}$ Pelos motivos expostos no capítulo 6 .
} 
Tabela 7.42. - Resultados Finais Teste 9.

\begin{tabular}{|c|c|c|}
\hline Posição (cm) & CSR (mmAl) & Sinal do Sensor $(\mathbf{V})^{\mathbf{9}}$ \\
\hline+6 & 0,501 & 2,50 \\
\hline+4 & 0,508 & 2,51 \\
\hline 0 & 0,495 & 2,49 \\
\hline-4 & 0,495 & 2,21 \\
\hline-6 & 0,490 & 2,09 \\
\hline-8 & 0,491 & 1,72 \\
\hline
\end{tabular}

Variação nos valores medidos na extremidade do campo, no lado correspondente ao catodo, em relação ao valor central:

- CSR: $+1,21 \%$

- Intensidade ${ }^{10}:+0,40 \%$

Variação nos valores medidos na extremidade do campo, no lado correspondente ao anodo, em relação ao valor central:

- CSR: $-0,81 \%$

- Intensidade: - 30,92\%

Variação nos valores medidos de um extremo a outro no campo:

- CSR: $2,04 \%$

- Intensidade: $31,20 \%$

${ }^{9}$ O dispositivo eletrônico tem como sinal de saída um valor de tensão (em volts) proporcional à intensidade da radiação recebida pelo sensor, diferente dos dosímetros, que fornecem valores relativos à dose de radiação absorvida pela câmara de ionização.

${ }^{10} \mathrm{O}$ sinal proveniente do sensor de silício do dispositivo eletrônico de medição varia linearmente com a variação da intensidade da radiação no campo (CURI_98). 


\section{TESTE 10}

Local: Hospital das Clínicas da Faculdade de Medicina de Ribeirão Preto Aparelho: Convencional B;

Tensão: $65 \mathrm{kVp}$;

Corrente: $25 \mathrm{~mA}$;

Tempo de exposição: 4,0s;

Distância do tubo ao campo: $57 \mathrm{~cm}$;

Filtração adicional: 0,5mmAl.

Tabela 7.43. - Resultados Finais Teste 10.

\begin{tabular}{|c|c|c|}
\hline Posição (cm) & CSR (mmAl) & Sinal do Sensor (V) \\
\hline+6 & 3,97 & 3,83 \\
\hline 0 & 3,99 & 3,64 \\
\hline-4 & 4,06 & 3,37 \\
\hline-8 & 4,18 & 3,08 \\
\hline-10 & 4,25 & 2,70 \\
\hline-12 & 4,44 & 2,22 \\
\hline-14 & 4,57 & 1,55 \\
\hline
\end{tabular}

Variação nos valores medidos na extremidade do campo, no lado correspondente ao catodo, em relação ao valor central:

- CSR: $-0,50 \%$

- Intensidade: $+5,22 \%$

Variação nos valores medidos na extremidade do campo, no lado correspondente ao anodo, em relação ao valor central:

- CSR: $+14,54 \%$

- Intensidade: - $57,42 \%$

Variação nos valores medidos de um extremo a outro no campo:

- CSR: $15,11 \%$

- Intensidade: $59,53 \%$ 


\section{TESTE 11}

Local: Hospital das Clínicas da Faculdade de Medicina de Ribeirão Preto Aparelho: Convencional B;

Tensão: $45 \mathrm{kVp}$;

Corrente: 156,25mA;

Tempo de exposição: 4,0s;

Distância do tubo ao campo: $98 \mathrm{~cm}$;

Filtração adicional: 0,5mmAl.

Tabela 7.44. - Resultados Finais Teste 11.

\begin{tabular}{|c|c|c|}
\hline Posição (cm) & CSR (mmAl) & Sinal do Sensor (V) \\
\hline+16 & 1,52 & 3,34 \\
\hline+8 & 1,56 & 3,40 \\
\hline 0 & 1,58 & 3,21 \\
\hline-4 & 1,62 & 3,11 \\
\hline-10 & 1,62 & 2,97 \\
\hline-12 & 1,66 & 2,78 \\
\hline-14 & 1,67 & 2,54 \\
\hline
\end{tabular}

Variação nos valores medidos na extremidade do campo, no lado correspondente ao catodo, em relação ao valor central:

- CSR: $-3,80 \%$

- Intensidade: $+4,05 \%$

Variação nos valores medidos na extremidade do campo, no lado correspondente ao anodo, em relação ao valor central:

- CSR: $+5,70 \%$

- Intensidade: - 20,87\%

Variação nos valores medidos de um extremo a outro no campo:

- CSR: $9,87 \%$

- Intensidade: $23,95 \%$ 


\subsection{Resultados com o programa de simulação}

Realizados os testes práticos, efetuou-se a simulação computacional da CSR para as diversas posições no campo a partir da medida obtida no centro, sob as mesmas condições dos experimentos. Para a simulação dos testes com os aparelhos mamográficos (testes 1, 2, 3, 7, 8 e 9) foi utilizado o método $c d$ (descrito no Capítulo 5) e para os testes com os aparelhos convencionais (testes 4, 5, 6, 10 e 11) o método csda. As tabelas a seguir mostram os resultados obtidos com a simulação dos testes práticos realizados, juntamente com os dados obtidos experimentalmente, para comparação.

Além disso, calculou-se o desvio entre os valores obtidos na prática e por meio da simulação; o sinal colocado antes do desvio calculado indica se o valor simulado foi maior (+) ou menor (-) que o obtido nos experimentos. A numeração dos testes é a mesma utilizada nos itens 7.1 e 7.2.

\section{TESTE 1}

Tabela 7.45. - Resultados da simulação para o Teste 1 - Parte 1.

\begin{tabular}{|c|c|c|c|c|c|c|}
\hline & \multicolumn{3}{|c|}{$1^{\text {a }}$ CSR (mmAI) } & \multicolumn{3}{c|}{$2^{\text {a }}$ CSR (mmAl) } \\
\hline Posição(cm) & Medida & Simulada & Desvio (\%) & Medida & Simulada & Desvio (\%) \\
\hline 0 & 0,343 & 0,343 & -- & 0,466 & 0,461 & $-1,07$ \\
\hline-2 & 0,344 & 0,344 & 0 & 0,461 & 0,461 & 0 \\
\hline-6 & 0,349 & 0,346 & $-0,86$ & 0,455 & 0,458 & $+0,66$ \\
\hline-8 & 0,355 & 0,350 & $-1,41$ & 0,452 & 0,451 & $-0,22$ \\
\hline-12 & 0,358 & 0,357 & $-0,28$ & 0,451 & 0,443 & $-1,77$ \\
\hline
\end{tabular}




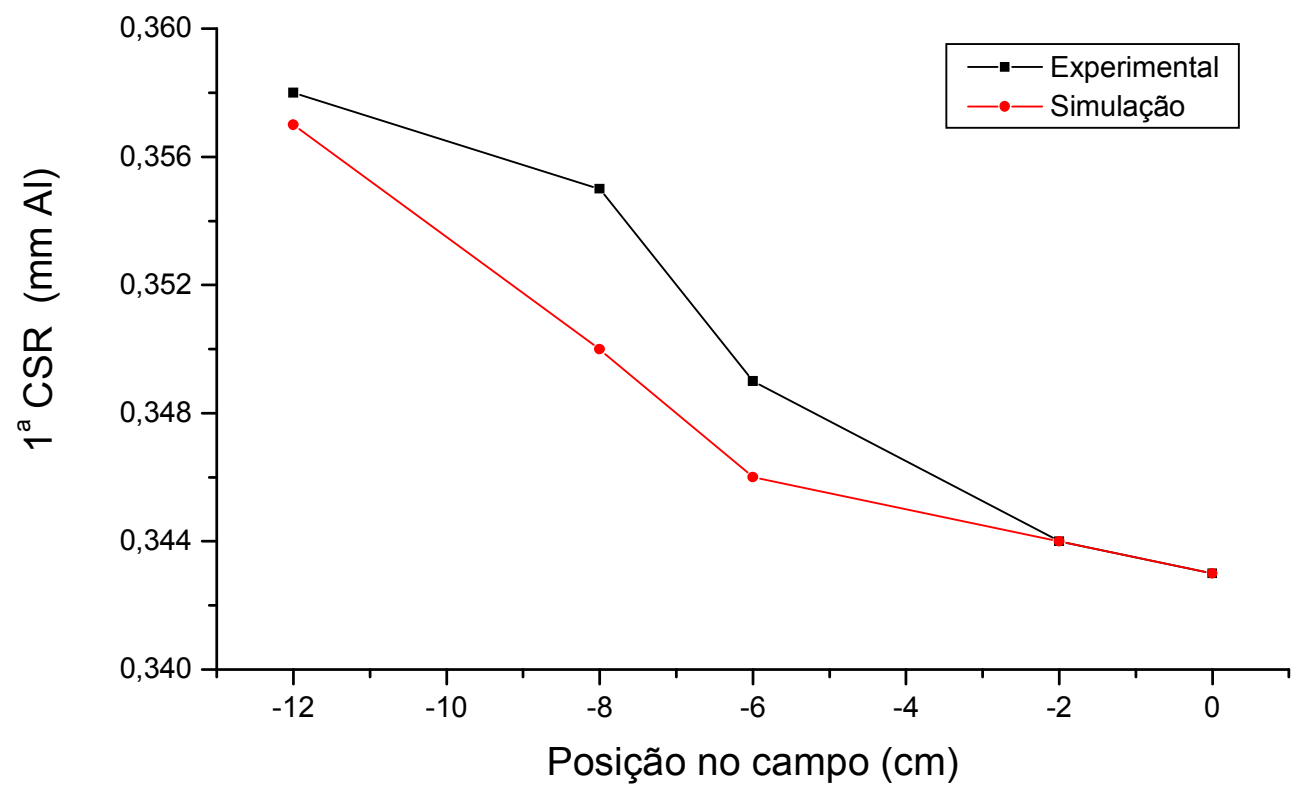

Figura 7.2. - Resultados da simulação da $1^{\mathrm{a}}$ CSR para o Teste 1.

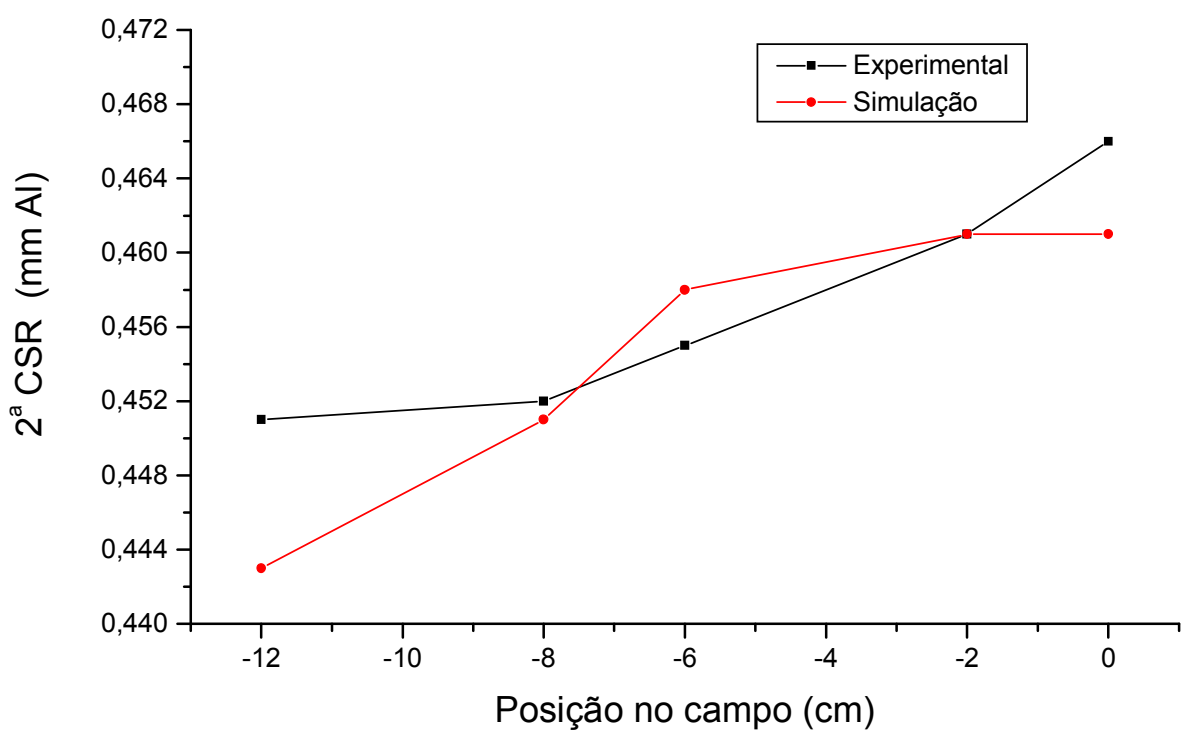

Figura 7.3. - Resultados da simulação da $2^{\mathrm{a}}$ CSR para o Teste 1. 
Tabela 7.46. - Resultados da simulação para o Teste 1 - Parte 2.

\begin{tabular}{|c|c|c|c|c|c|c|}
\hline & \multicolumn{3}{|c|}{ Coeficiente de Homogeneidade } & \multicolumn{3}{c|}{ Dose (mGy) } \\
\hline Posição(cm) & Medido & Simulado & Desvio (\%) & Medida & Simulada & Desvio (\%) \\
\hline 0 & 0,736 & 0,743 & $+0,95$ & 11,01 & 11,01 & -- \\
\hline-2 & 0,746 & 0,746 & 0 & 10,90 & 10,76 & $-1,28$ \\
\hline-6 & 0,767 & 0,755 & $-1,56$ & 9,88 & 9,85 & $-0,30$ \\
\hline-8 & 0,785 & 0,793 & $+1,02$ & 8,73 & 7,93 & $-9,16$ \\
\hline-12 & 0,794 & 0,806 & $+1,51$ & 6,01 & 5,95 & $-1,00$ \\
\hline
\end{tabular}

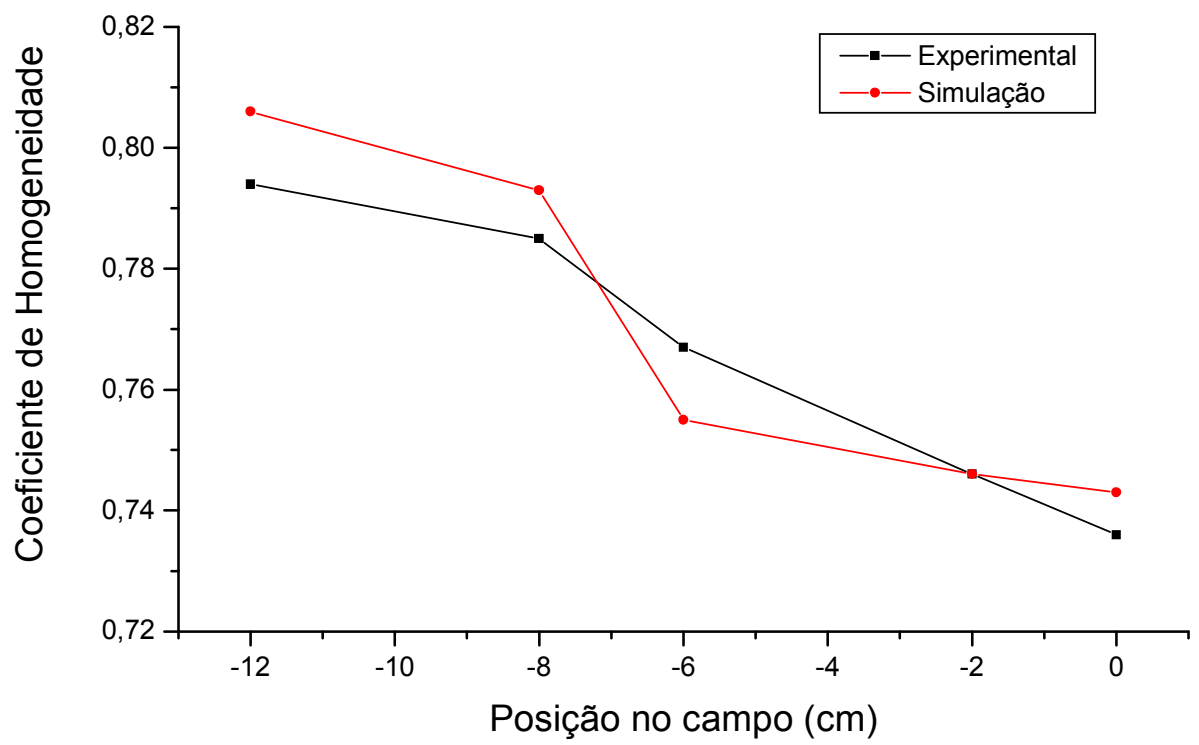

Figura 7.4. - Resultados da simulação do Coeficiente de Homogeneidade para o Teste 1. 


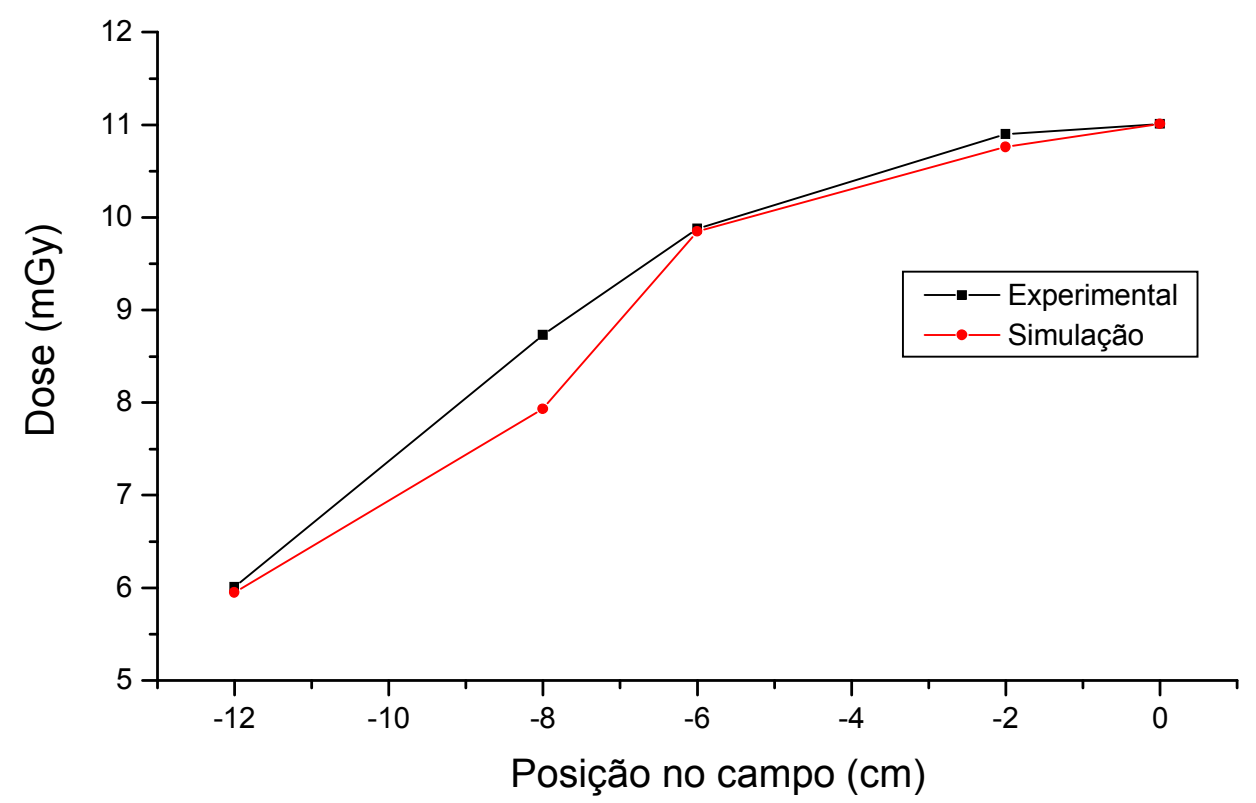

Figura 7.5. - Resultados da simulação da Dose para o Teste 1.

\section{TESTE 2}

Tabela 7.47. - Resultados da simulação para o Teste 2.

\begin{tabular}{|c|c|c|c|c|c|c|}
\hline & \multicolumn{3}{|c|}{ CSR (mmAl) } & \multicolumn{3}{c|}{ Dose (mGy) } \\
\hline Posição(cm) & Medida & Simulada & Desvio (\%) & Medida & Simulada & Desvio (\%) \\
\hline 0 & 0,382 & 0,382 & -- & 14,69 & 14,69 & -- \\
\hline-2 & 0,383 & 0,383 & 0 & 14,50 & 14,34 & $-1,10$ \\
\hline-6 & 0,386 & 0,386 & 0 & 13,34 & 13,21 & $-0,97$ \\
\hline-8 & 0,388 & 0,387 & $-0,26$ & 12,11 & 12,34 & $+1,90$ \\
\hline-12 & 0,395 & 0,394 & $-0,25$ & 10,29 & 9,54 & $-7,29$ \\
\hline
\end{tabular}




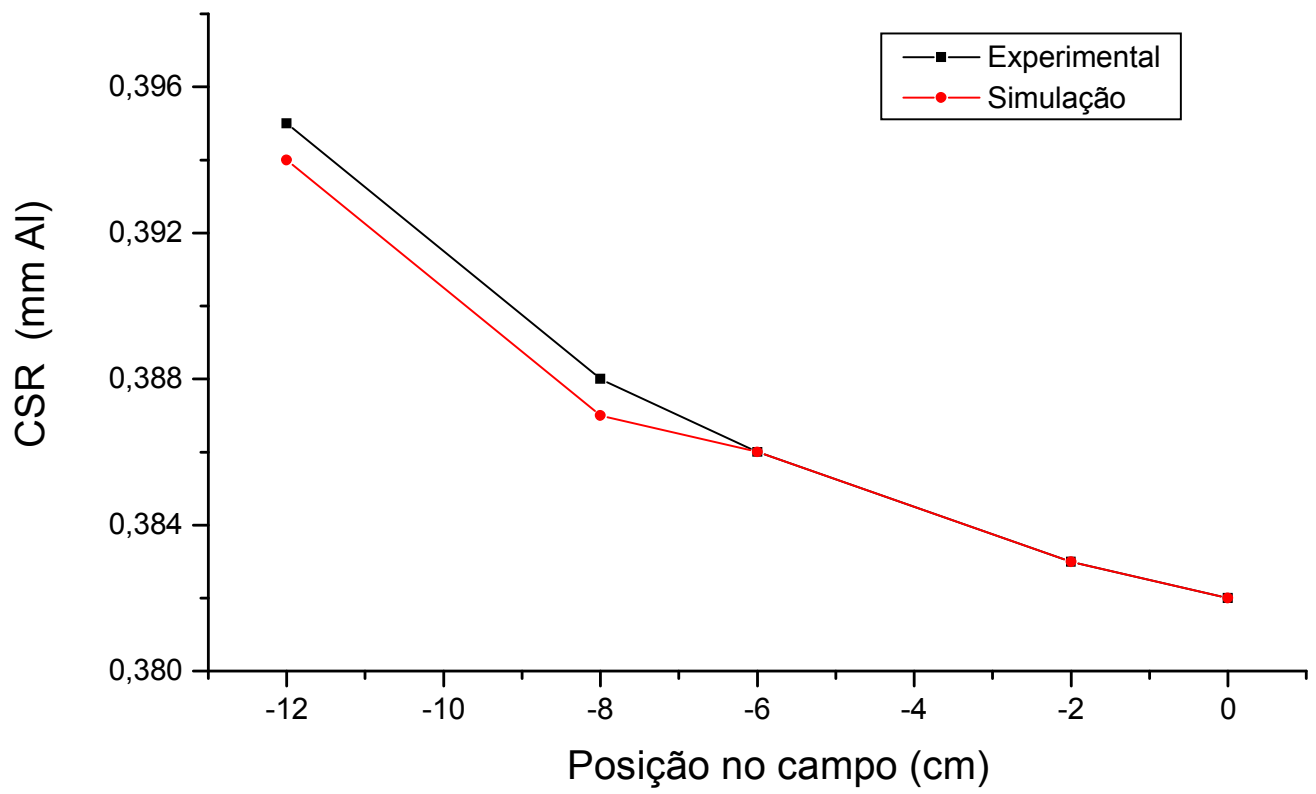

Figura 7.6. - Resultados da simulação da CSR para o Teste 2.

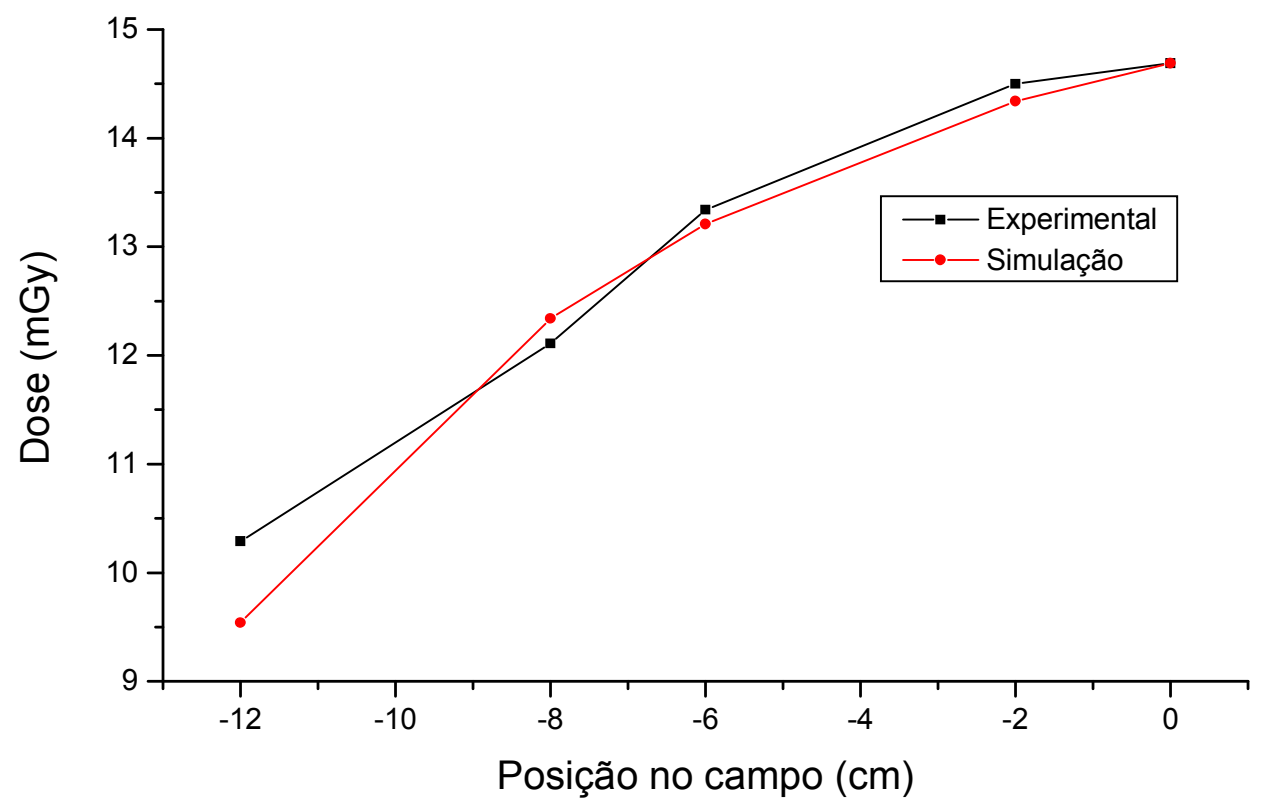

Figura 7.7. - Resultados da simulação da Dose para o Teste 2. 


\section{TESTE 3}

Tabela 7.48. - Resultados da simulação para o Teste 3.

\begin{tabular}{|c|c|c|c|c|c|c|}
\hline & \multicolumn{3}{|c|}{ CSR (mmAI) } & \multicolumn{3}{c|}{ Dose (mGy) } \\
\hline Posição(cm) & Medida & Simulada & Desvio (\%) & Medida & Simulada & Desvio (\%) \\
\hline 0 & 0,416 & 0,416 & -- & 13,37 & 13,37 & -- \\
\hline-6 & 0,420 & 0,420 & 0 & 12,14 & 11,83 & $-2,55$ \\
\hline-12 & 0,430 & 0,428 & $-0,47$ & 8,90 & 8,15 & $-8,43$ \\
\hline
\end{tabular}

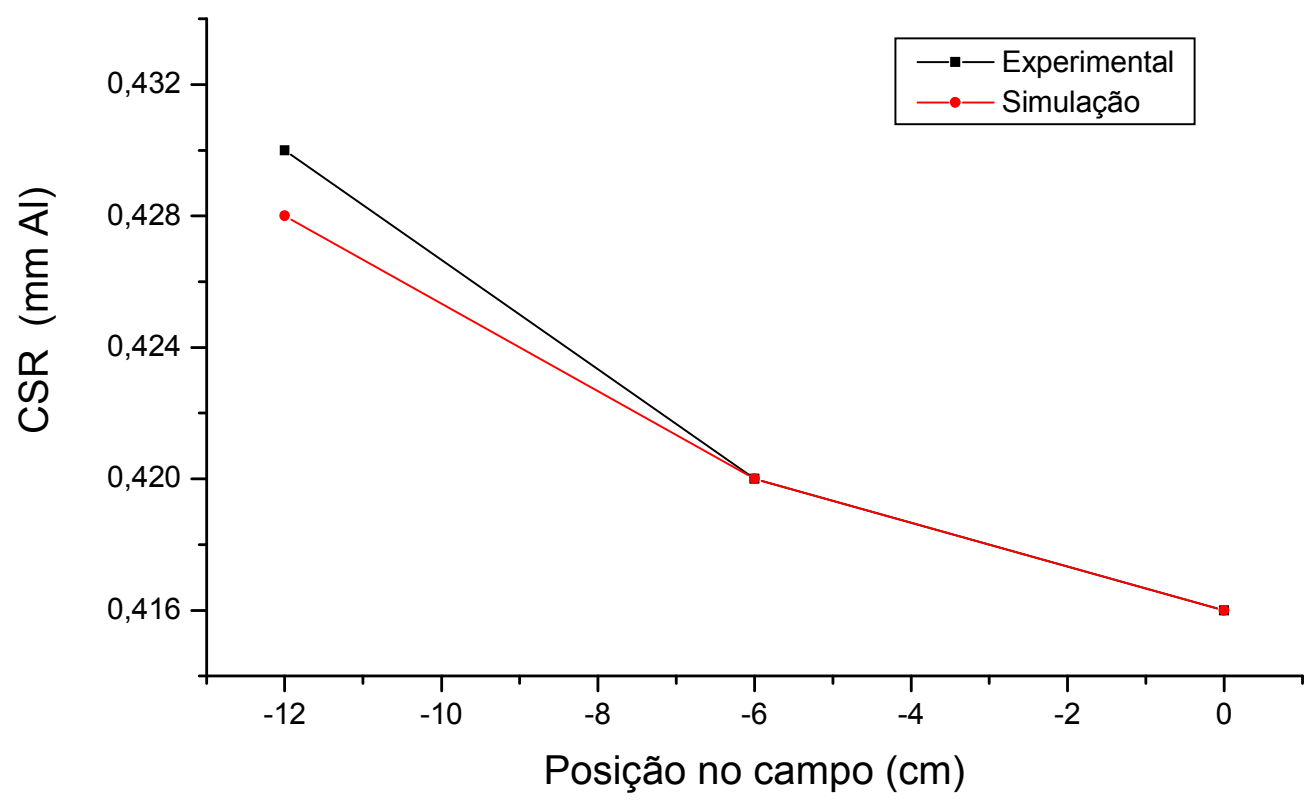

Figura 7.8. - Resultados da simulação da CSR para o Teste 3. 


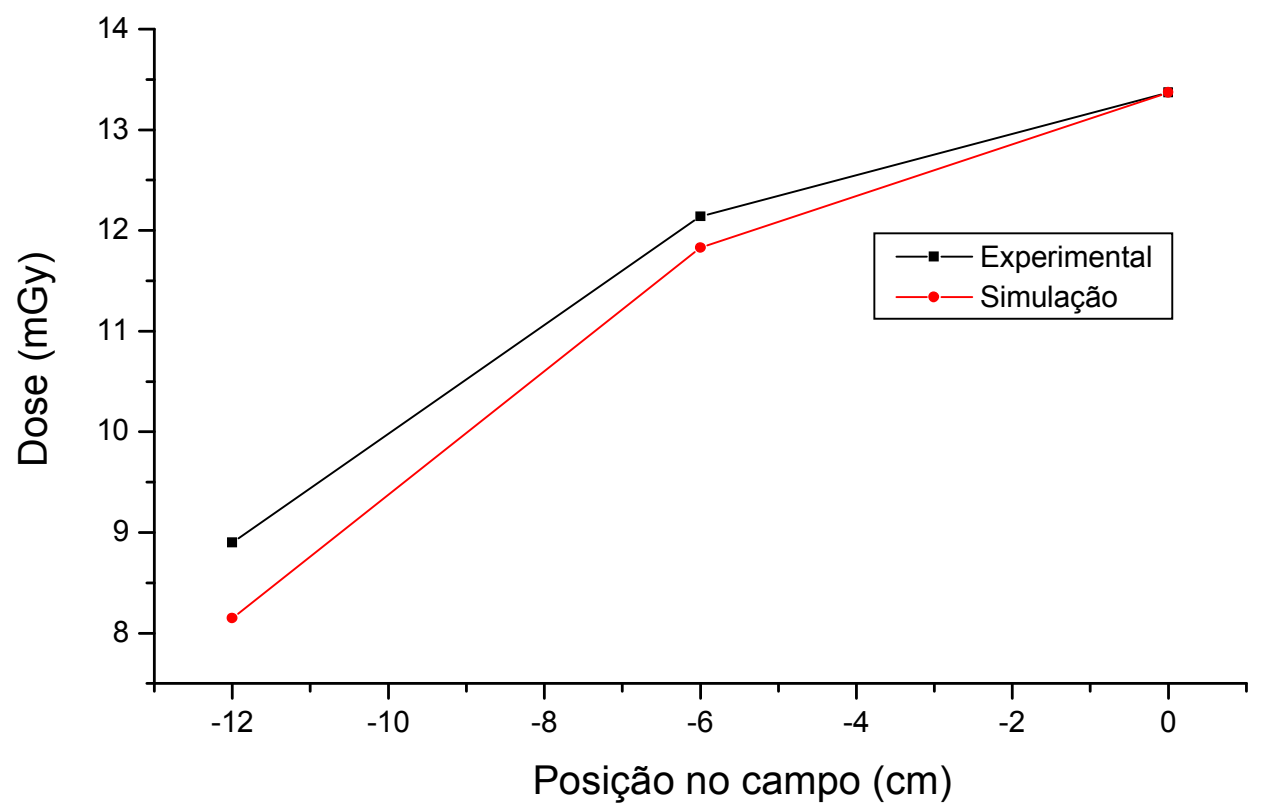

Figura 7.9. - Resultados da simulação da Dose para o Teste 3.

\section{TESTE 4}

Tabela 7.49. - Resultados da simulação para o Teste 4.

\begin{tabular}{|c|c|c|c|c|c|c|}
\hline & \multicolumn{3}{|c|}{ CSR (mmAl) } & \multicolumn{3}{c|}{ Dose (mGy) } \\
\hline Posição(cm) & Medida & Simulada & Desvio (\%) & Medida & Simulada & Desvio (\%) \\
\hline+16 & 3,33 & 3,27 & $-1,80$ & 1,94 & 2,05 & $+5,67$ \\
\hline+10 & 3,34 & 3,31 & $-0,90$ & 1,96 & 2,07 & $+5,61$ \\
\hline+6 & 3,32 & 3,34 & $+0,60$ & 2,09 & 2,05 & $-1,91$ \\
\hline 0 & 3,41 & 3,41 & -- & 1,98 & 1,98 & -- \\
\hline-10 & 3,83 & 3,62 & $-5,48$ & 1,70 & 1,68 & $-1,18$ \\
\hline-16 & 4,00 & 3,88 & $-3,00$ & 1,36 & 1,32 & $-2,94$ \\
\hline
\end{tabular}




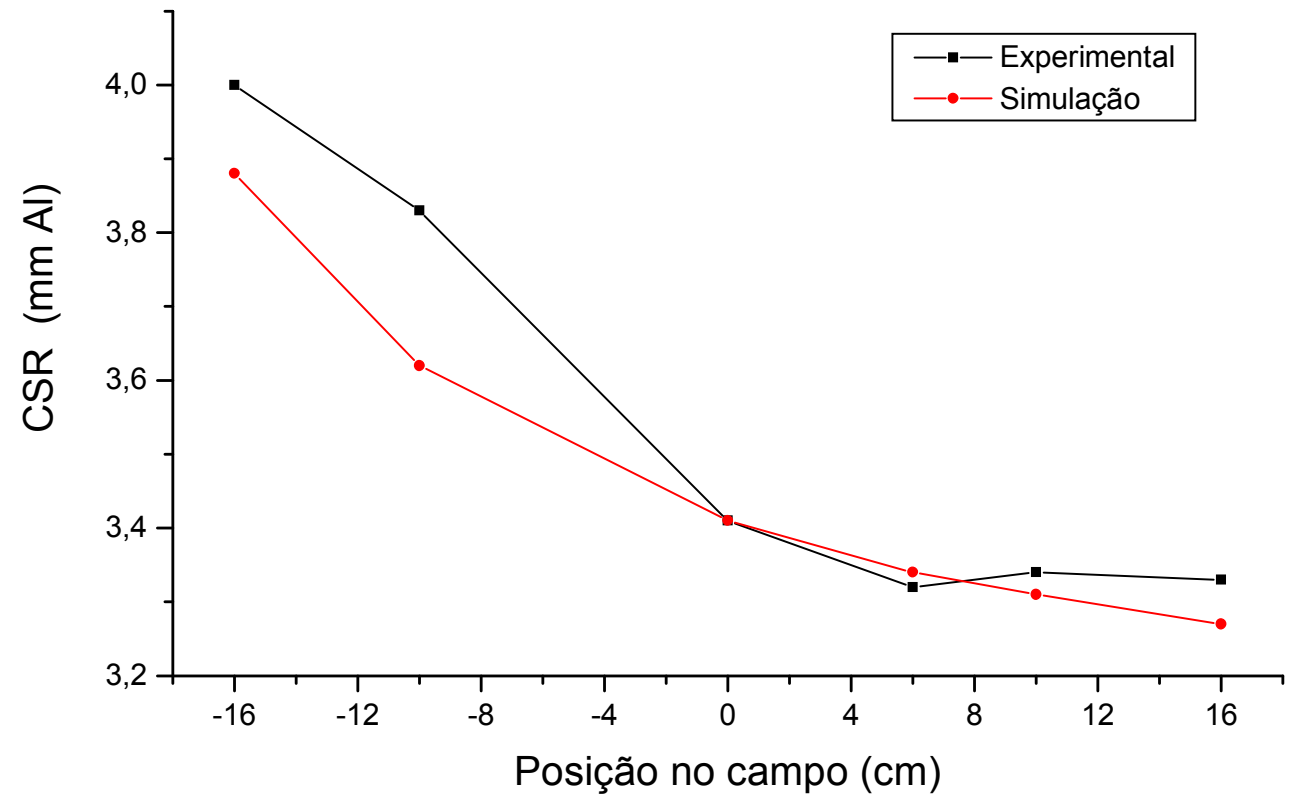

Figura 7.10. - Resultados da simulação da CSR para o Teste 4.

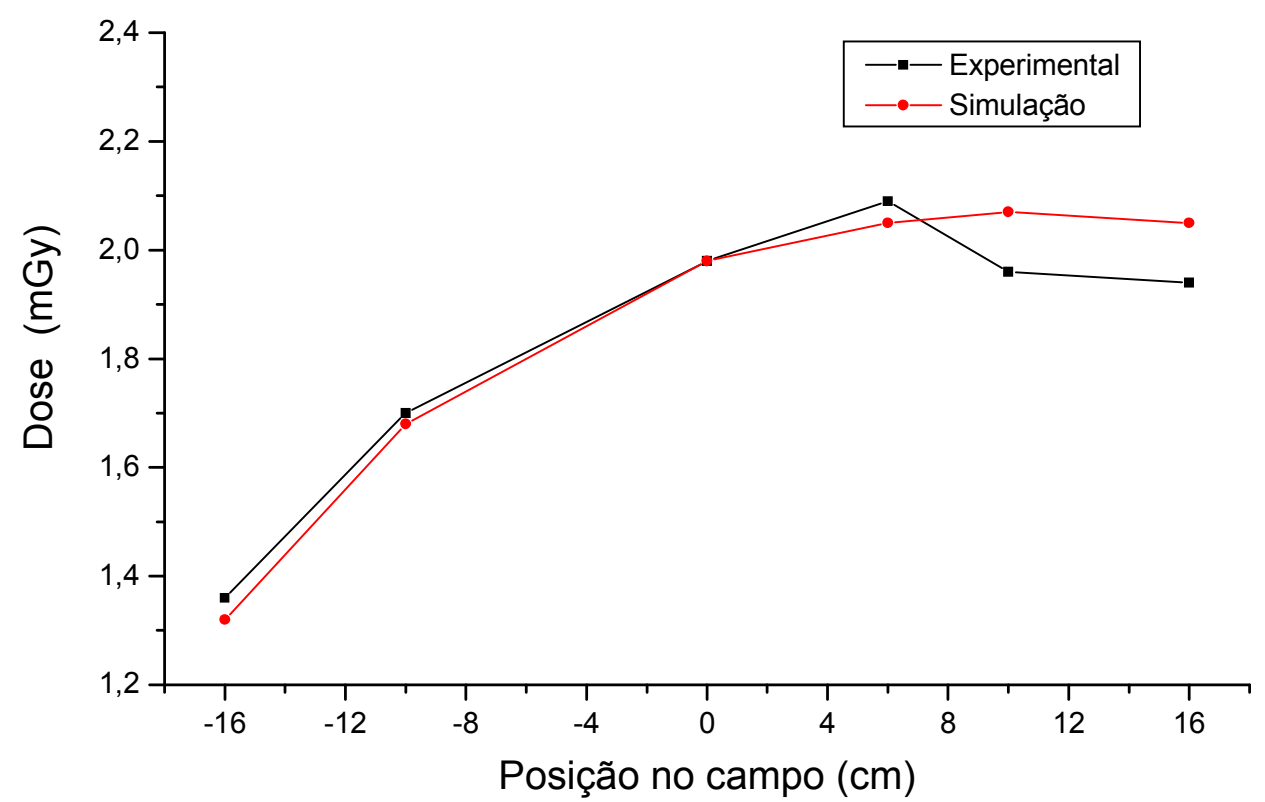

Figura 7.11. - Resultados da simulação da Dose para o Teste 4. 


\section{TESTE 5}

Tabela 7.50. - Resultados da simulação para o Teste 5.

\begin{tabular}{|c|c|c|c|c|c|c|}
\hline & \multicolumn{3}{|c|}{ CSR (mmAI) } & \multicolumn{3}{c|}{ Dose (mGy) } \\
\hline Posição(cm) & Medida & Simulada & Desvio (\%) & Medida & Simulada & Desvio (\%) \\
\hline+10 & 3,07 & 2,97 & $-3,26$ & 2,01 & 1,96 & $-2,49$ \\
\hline 0 & 3,06 & 3,06 & -- & 1,89 & 1,89 & -- \\
\hline-14 & 3,32 & 3,40 & $+2,41$ & 1,34 & 1,42 & $+5,97$ \\
\hline
\end{tabular}

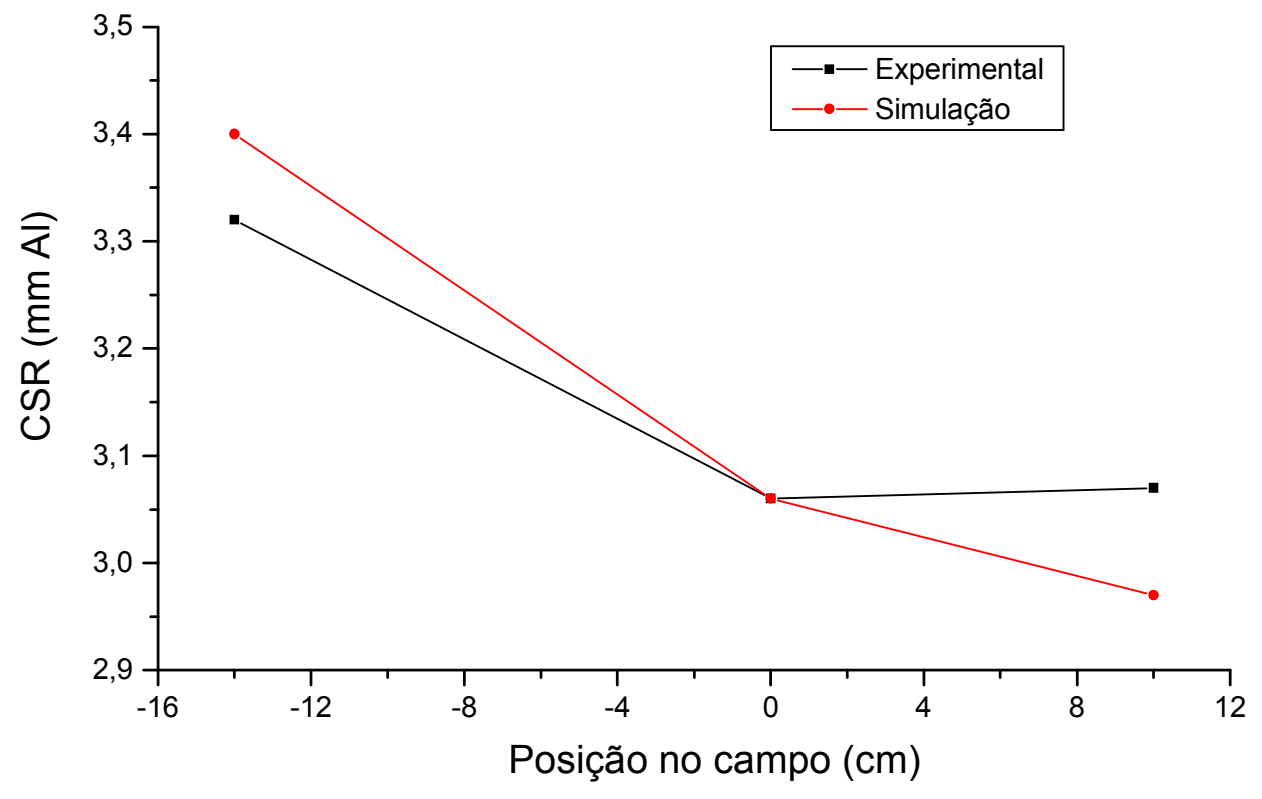

Figura 7.12. - Resultados da simulação da CSR para o Teste 5. 


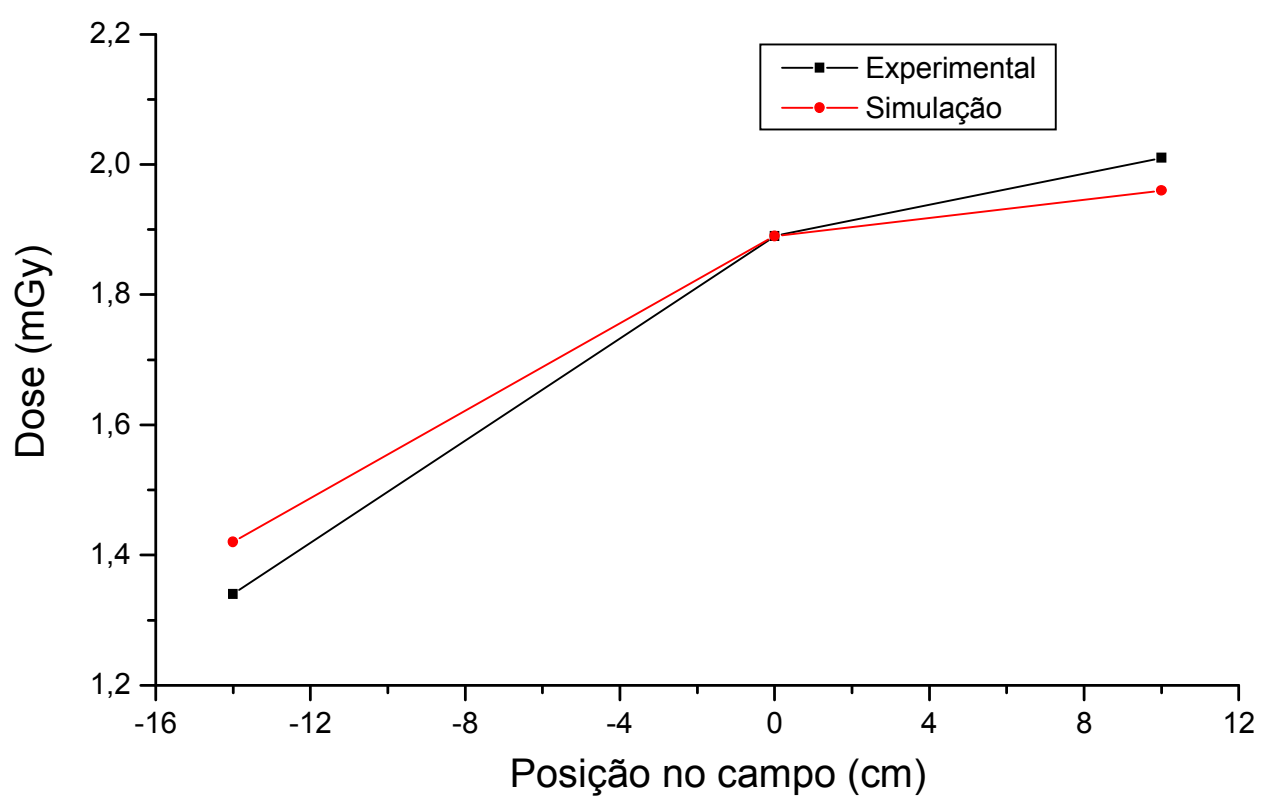

Figura 7.13. - Resultados da simulação da Dose para o Teste 5.

\section{TESTE 6}

Tabela 7.51. - Resultados da simulação para o Teste 6.

\begin{tabular}{|c|c|c|c|c|c|c|}
\hline & \multicolumn{3}{|c|}{ CSR (mmAI) } & \multicolumn{3}{c|}{ Dose (mGy) } \\
\hline Posição(cm) & Medida & Simulada & Desvio (\%) & Medida & Simulada & Desvio (\%) \\
\hline+10 & 2,49 & 2,47 & $-0,80$ & 0,982 & 0,961 & $-2,14$ \\
\hline 0 & 2,53 & 2,53 & -- & 0,929 & 0,929 & -- \\
\hline-14 & 2,72 & 2,78 & $+2,21$ & 0,677 & 0,707 & $+4,43$ \\
\hline
\end{tabular}




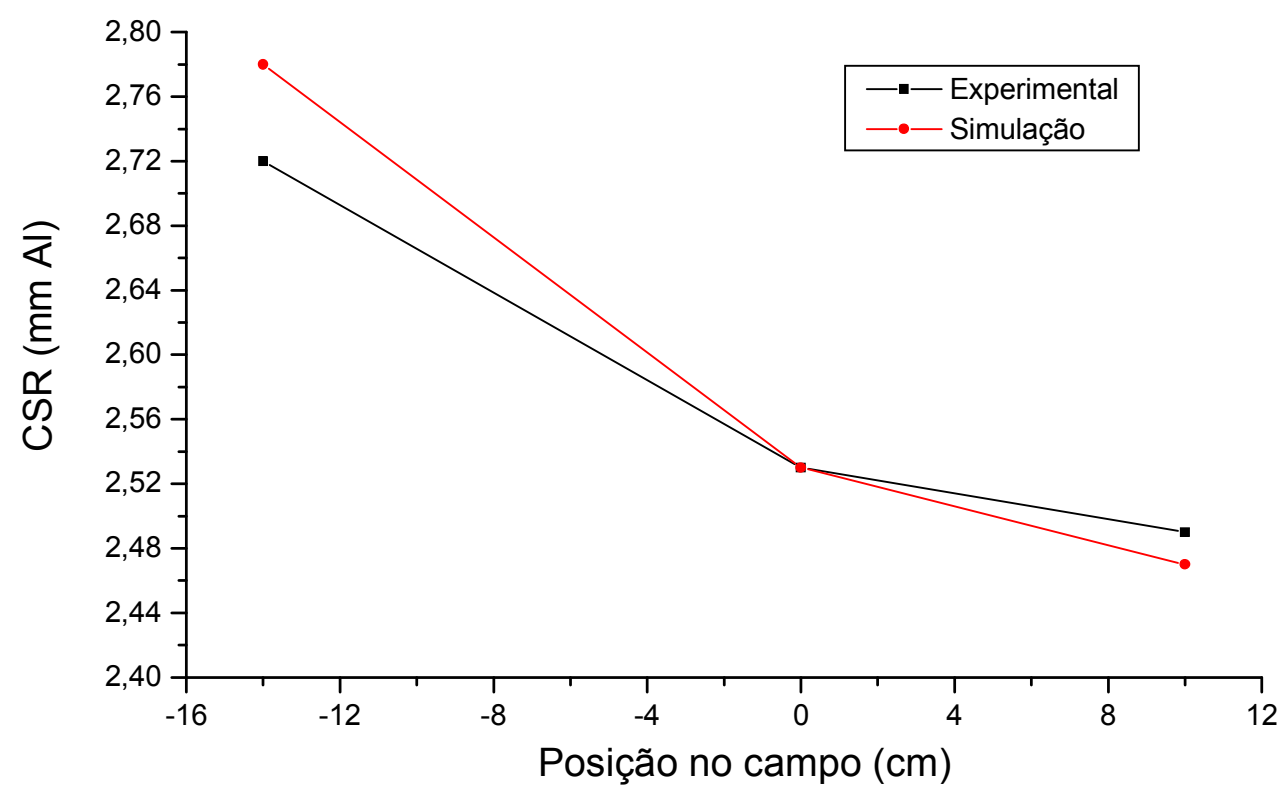

Figura 7.14. - Resultados da simulação da CSR para o Teste 6.

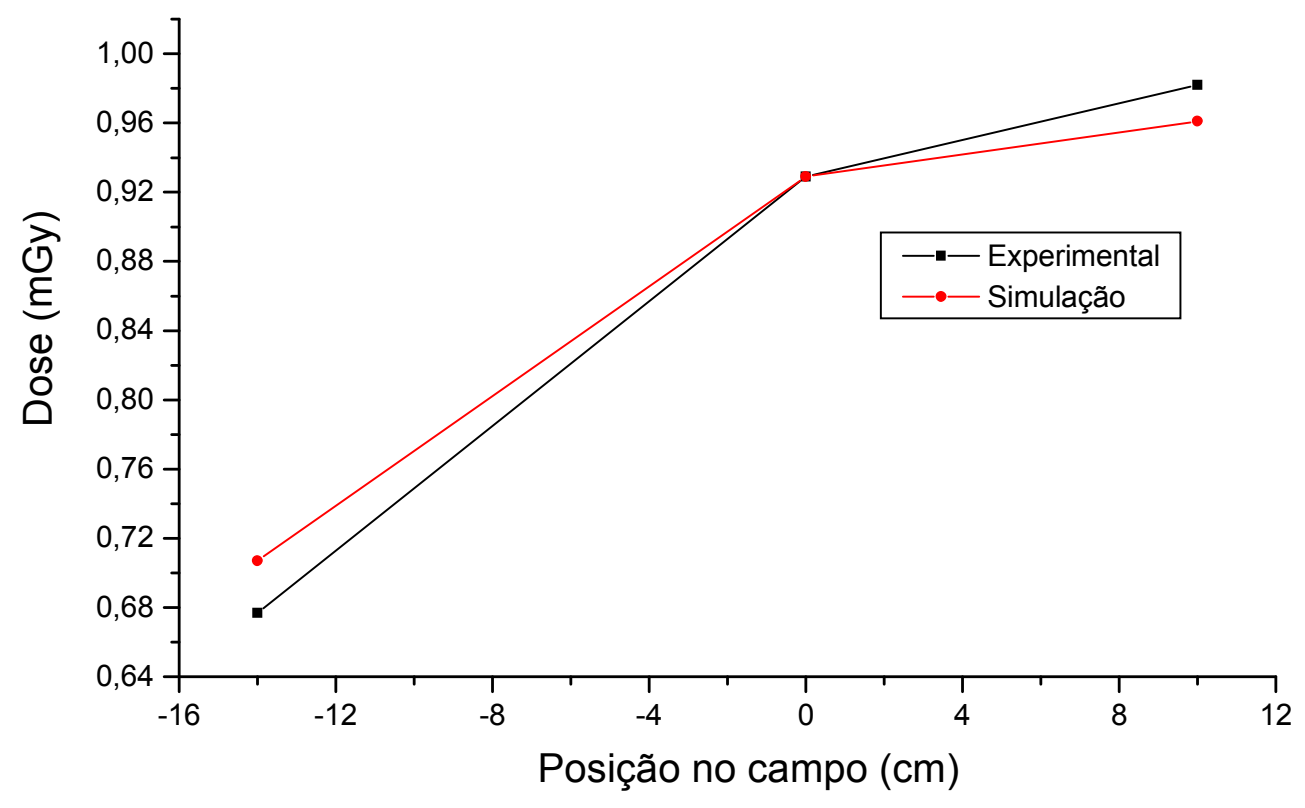

Figura 7.15. - Resultados da simulação da Dose para o Teste 6. 


\section{TESTE 7}

Tabela 7.52. - Resultados da simulação para o Teste 7.

\begin{tabular}{|c|c|c|c|c|c|c|}
\hline & \multicolumn{3}{|c|}{ CSR (mmAI) } & \multicolumn{3}{c|}{ Dose (mGy) } \\
\hline Posição(cm) & Medida & Simulada & Desvio (\%) & Medida & Simulada & Desvio (\%) \\
\hline+10 & 0,240 & 0,229 & $-4,58$ & 3,75 & 3,82 & $+1,87$ \\
\hline 0 & 0,228 & 0,228 & -- & 3.93 & 3,93 & -- \\
\hline-6 & 0,225 & 0,227 & $+0,89$ & 3,37 & 3,46 & $+2,67$ \\
\hline-10 & 0,224 & 0,224 & 0 & 2,54 & 2,57 & $+1,18$ \\
\hline
\end{tabular}

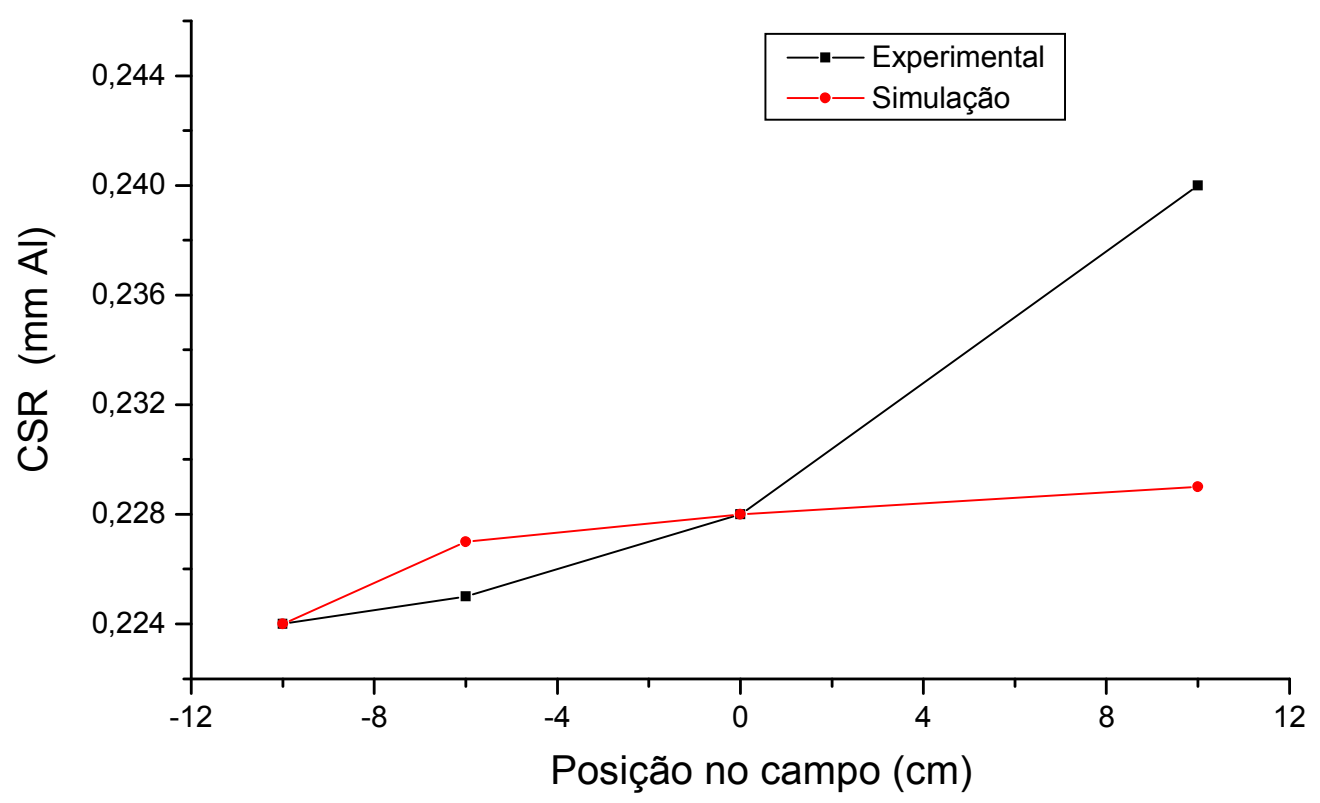

Figura 7.16. - Resultados da simulação da CSR para o Teste 7. 


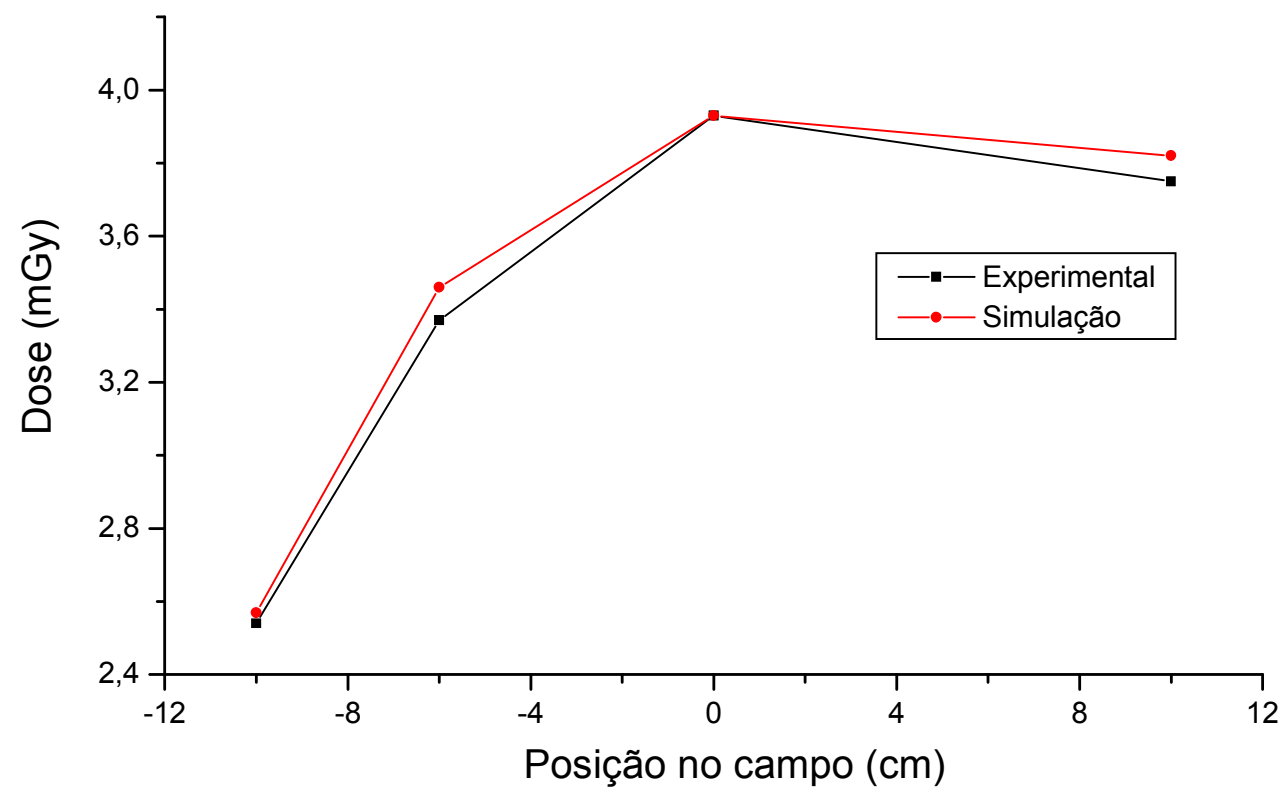

Figura 7.17. - Resultados da simulação da Dose para o Teste 7.

\section{$\underline{\text { TESTE } 8}$}

Tabela 7.53. - Resultados da simulação para o Teste 8.

\begin{tabular}{|c|c|c|c|c|c|c|}
\hline & \multicolumn{3}{|c|}{ CSR (mmAI) } & \multicolumn{3}{c|}{ Dose (mGy) } \\
\hline Posição(cm) & Medida & Simulada & Desvio (\%) & Medida & Simulada & Desvio (\%) \\
\hline+10 & 0,351 & 0,335 & $-4,56$ & 3,11 & 3,26 & $+4,82$ \\
\hline 0 & 0,333 & 0,333 & -- & 3,30 & 3,30 & -- \\
\hline-4 & 0,334 & 0,331 & $-0,90$ & 3,10 & 3,04 & $-1,94$ \\
\hline-10 & 0,328 & 0,319 & $-2,74$ & 1,94 & 1,95 & $+0,52$ \\
\hline
\end{tabular}




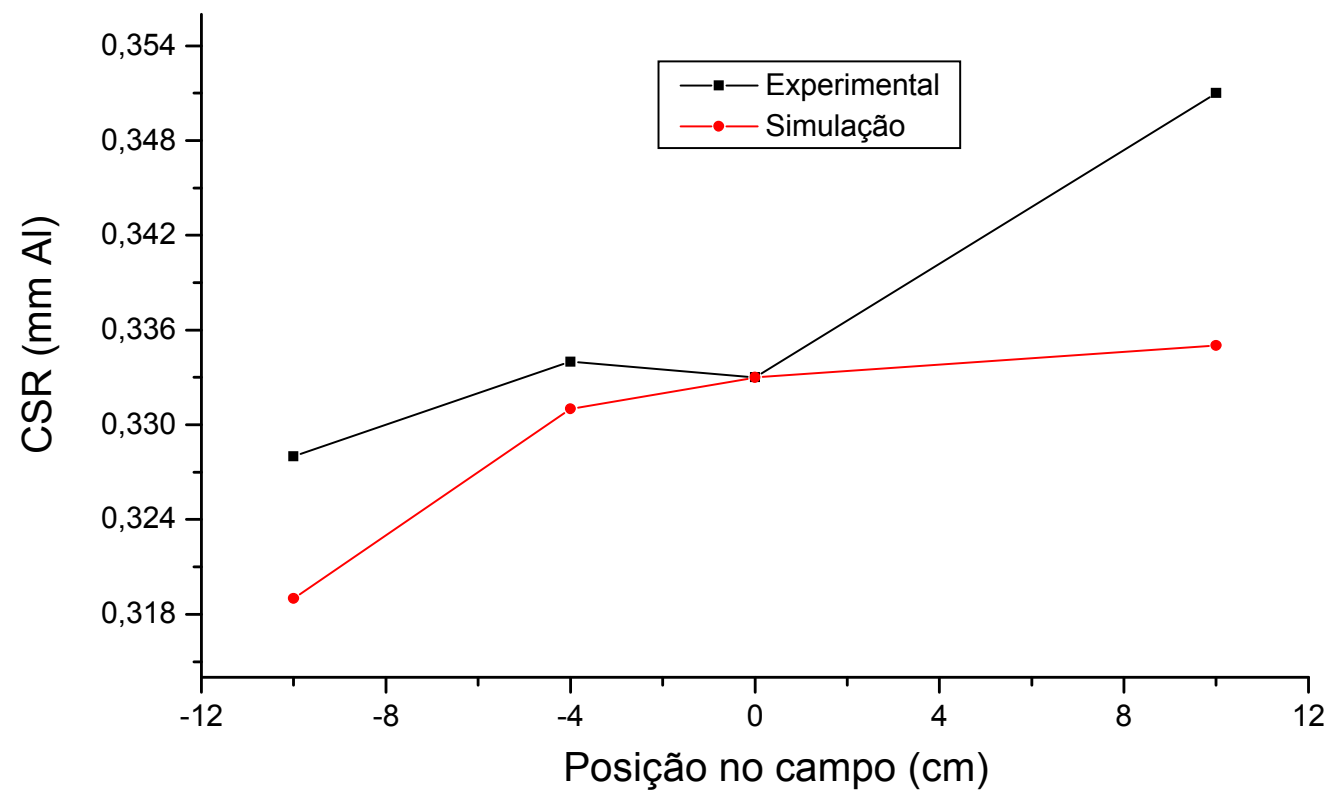

Figura 7.18. - Resultados da simulação da CSR para o Teste 8.

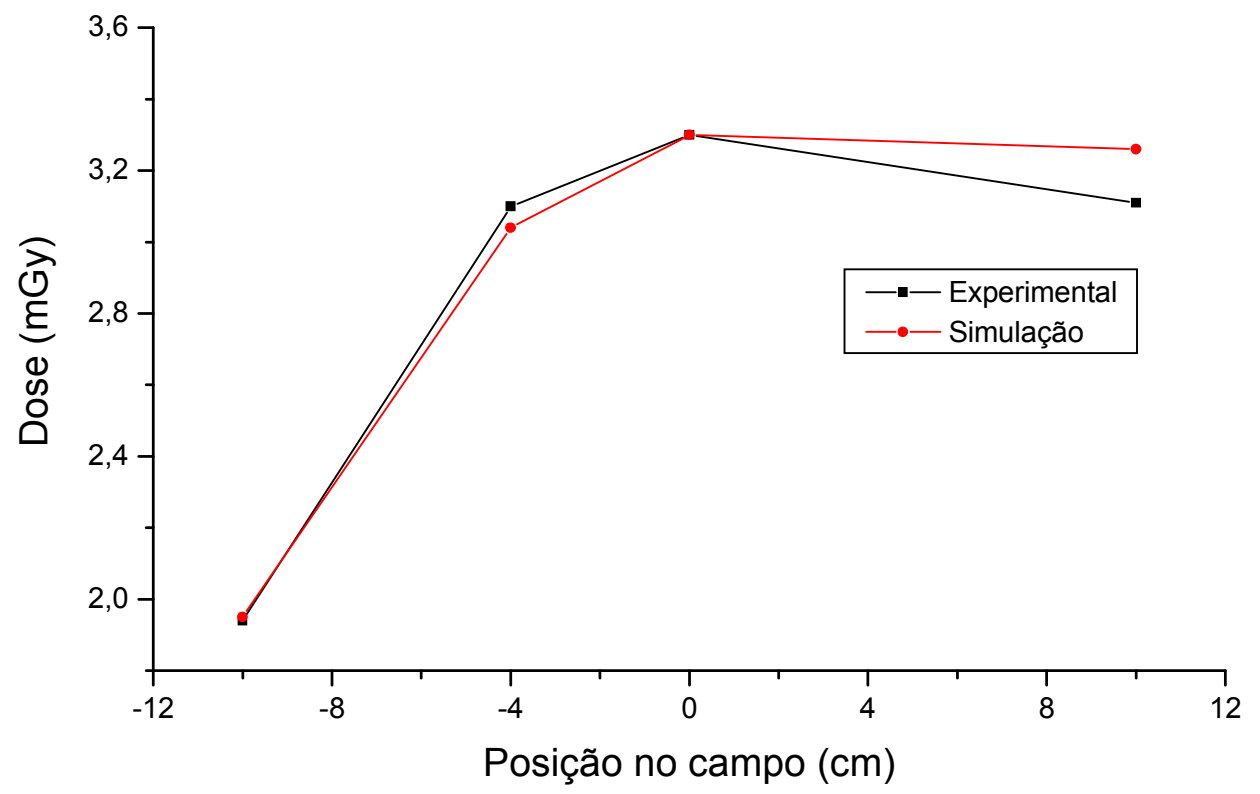

Figura 7.19. - Resultados da simulação da Dose para o Teste 8. 


\section{TESTE 9}

Tabela 7.54. - Resultados da simulação para o Teste 9.

\begin{tabular}{|c|c|c|c|c|c|c|}
\hline & \multicolumn{3}{|c|}{ CSR (mmAI) } & \multicolumn{3}{c|}{ Sinal do Sensor (V) } \\
\hline Posição(cm) & Medida & Simulada & Desvio (\%) & Medida & Simulada & Desvio (\%) \\
\hline+6 & 0,501 & 0,501 & 0 & 2,50 & 2,64 & $+5,60$ \\
\hline+4 & 0,508 & 0,500 & $-1,57$ & 2,51 & 2,62 & $+4,38$ \\
\hline 0 & 0,495 & 0,495 & -- & 2,49 & 2,49 & -- \\
\hline-4 & 0,495 & 0,486 & $-1,82$ & 2,21 & 2,21 & 0 \\
\hline-6 & 0,490 & 0,478 & $-2,45$ & 2,09 & 1,99 & $-4,78$ \\
\hline-8 & 0,491 & 0,464 & $-5,50$ & 1,72 & 1,70 & $-1,16$ \\
\hline
\end{tabular}

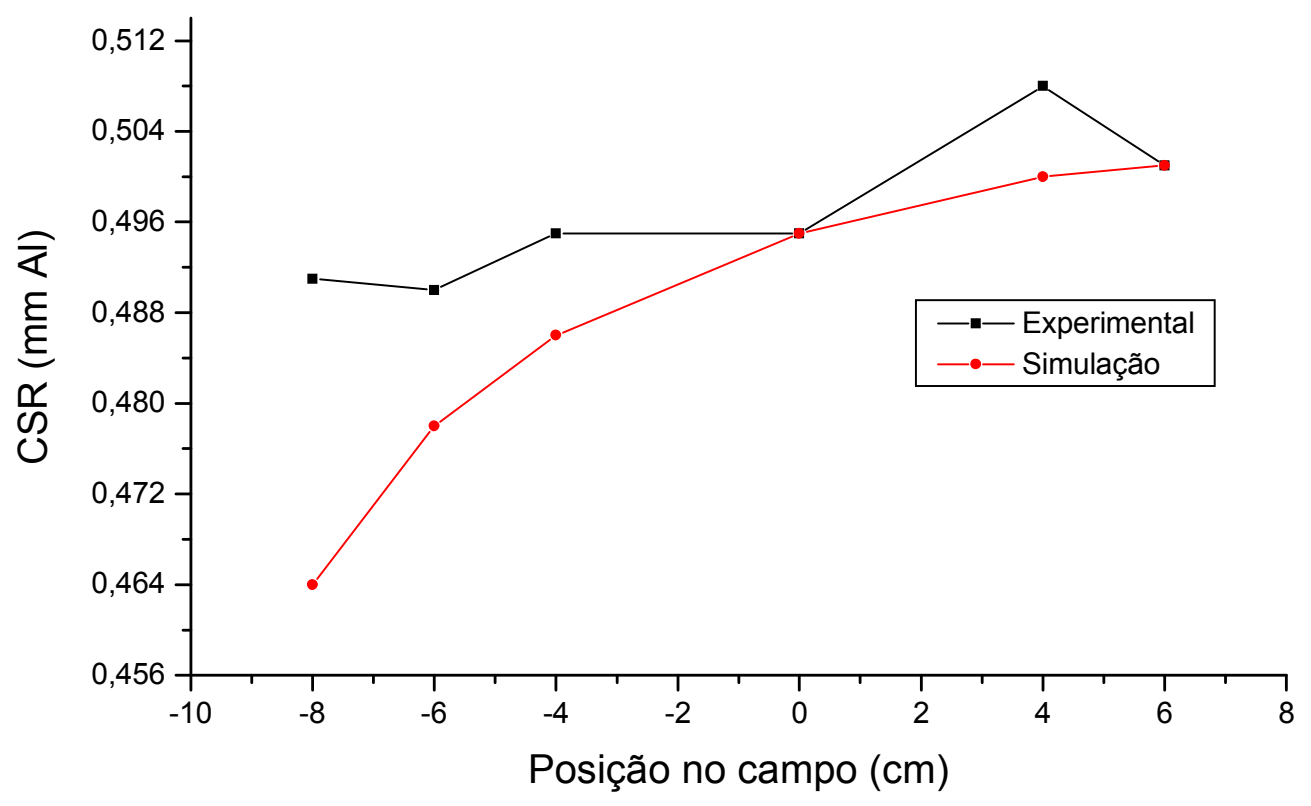

Figura 7.20. - Resultados da simulação da CSR para o Teste 9. 


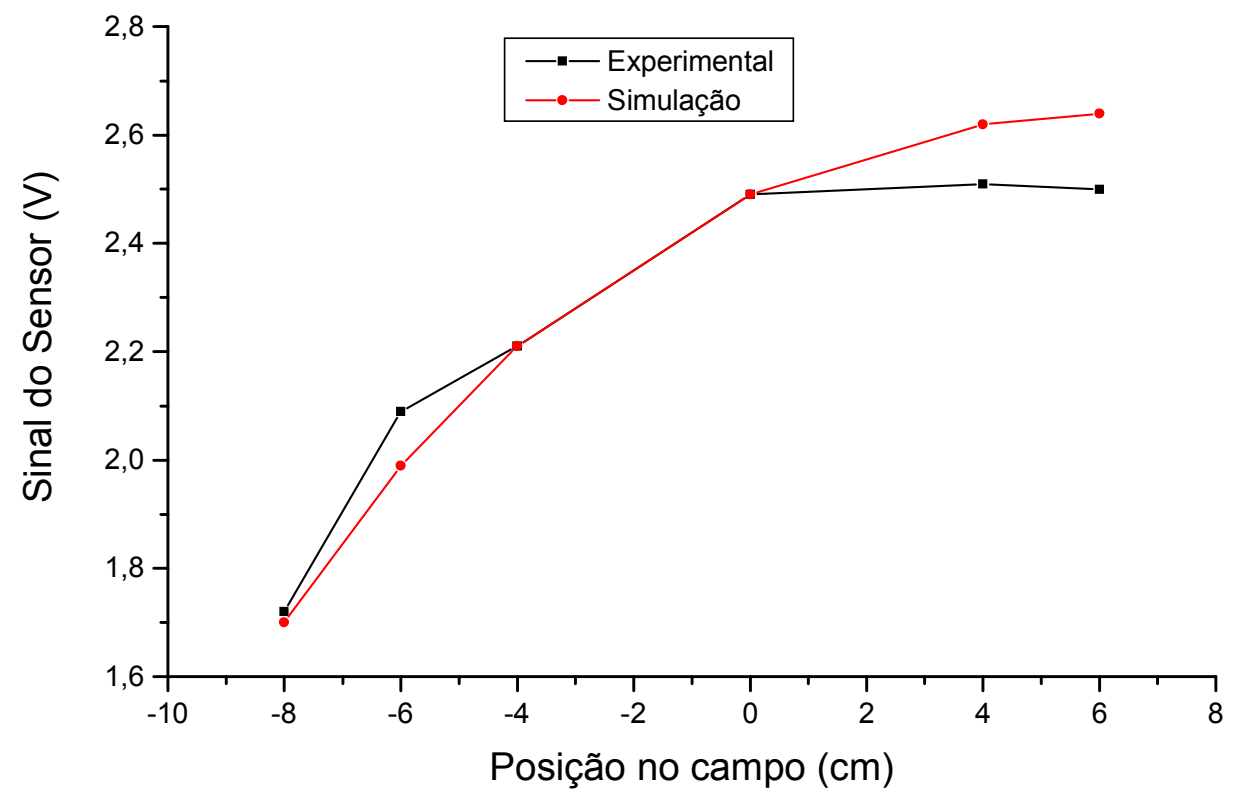

Figura 7.21. - Resultados da simulação do sinal do sensor para o Teste 9.

\section{TESTE 10}

Tabela 7.55. - Resultados da simulação para o Teste 10.

\begin{tabular}{|c|c|c|c|c|c|c|}
\hline & \multicolumn{3}{|c|}{ CSR (mmAI) } & \multicolumn{3}{c|}{ Sinal do Sensor (V) } \\
\hline Posição(cm) & Medida & Simulada & Desvio (\%) & Medida & Simulada & Desvio (\%) \\
\hline+6 & 3,97 & 3,95 & $-0,50$ & 3,83 & 3,76 & $-1,83$ \\
\hline 0 & 3,99 & 3,99 & -- & 3,64 & 3,64 & -- \\
\hline-4 & 4,06 & 4,03 & $-0,74$ & 3,37 & 3,40 & $+0,89$ \\
\hline-8 & 4,18 & 4,11 & $-1,67$ & 3,08 & 2,98 & $-3,25$ \\
\hline-10 & 4,25 & 4,18 & $-1,65$ & 2,70 & 2,65 & $-1,85$ \\
\hline-12 & 4,44 & 4,31 & $-2,93$ & 2,22 & 2,18 & $-1,80$ \\
\hline-14 & 4,57 & 4,56 & $-0,22$ & 1,55 & 1,48 & $-4,52$ \\
\hline
\end{tabular}




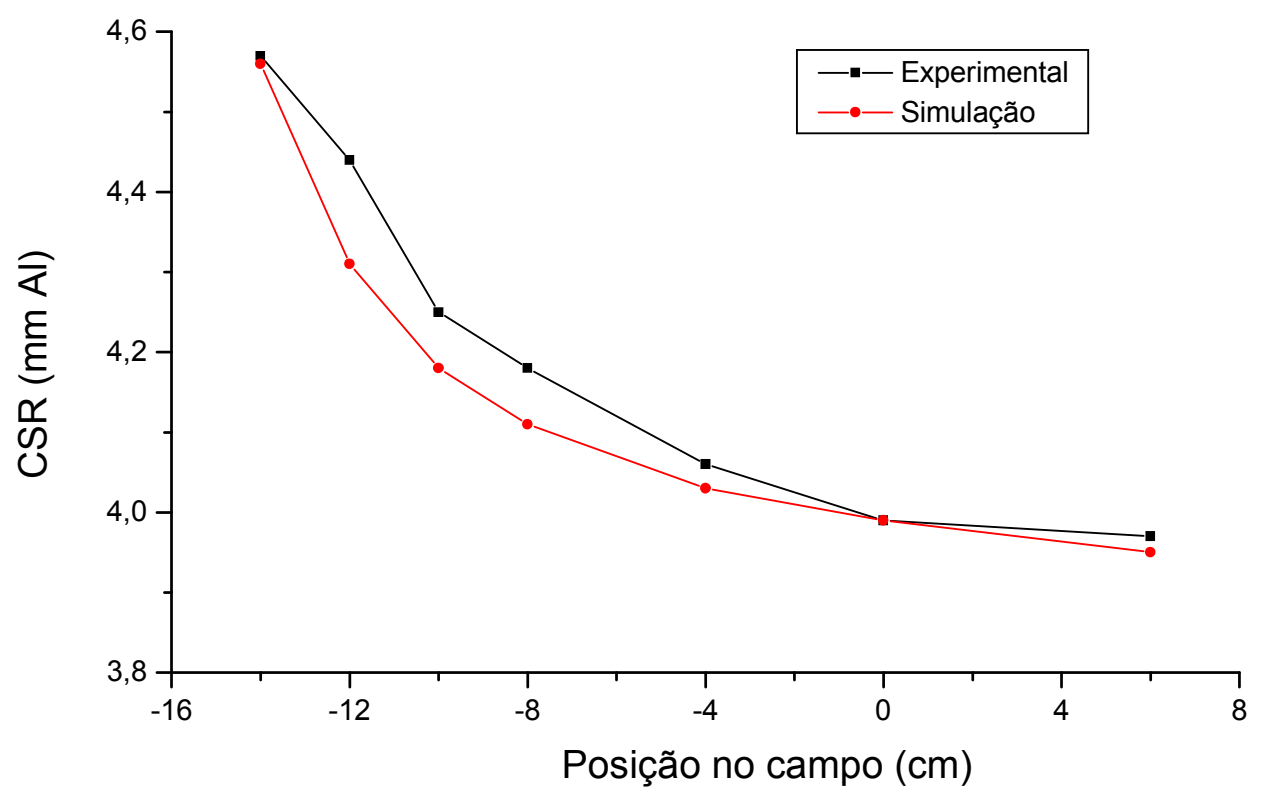

Figura 7.22. - Resultados da simulação da CSR para o Teste 10.

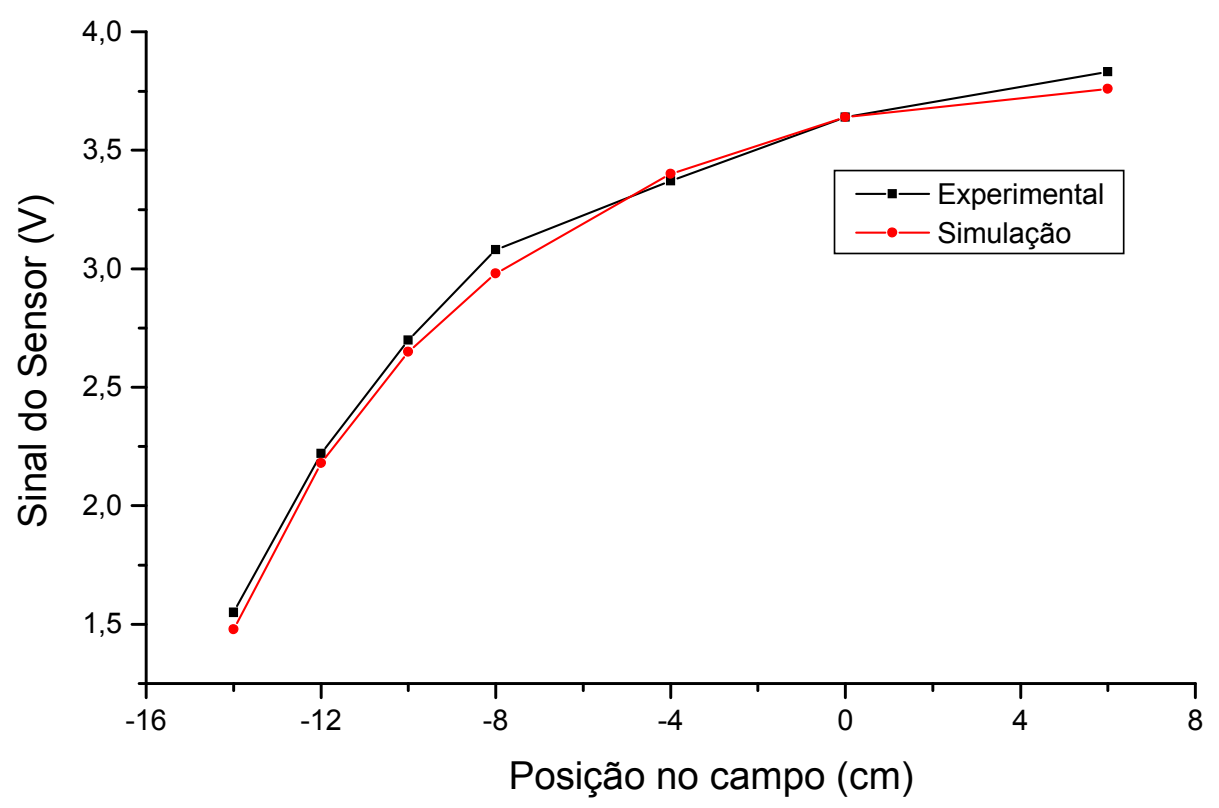

Figura 7.23. - Resultados da simulação do sinal do sensor para o Teste 10. 


\section{TESTE 11}

Tabela 7.56. - Resultados da simulação para o Teste 11.

\begin{tabular}{|c|c|c|c|c|c|c|}
\hline & \multicolumn{3}{|c|}{ CSR (mmAI) } & \multicolumn{3}{c|}{ Sinal do Sensor (V) } \\
\hline Posição(cm) & Medida & Simulada & Desvio (\%) & Medida & Simulada & Desvio (\%) \\
\hline+16 & 1,52 & 1,55 & $+1,97$ & 3,34 & 3,27 & $-2,10$ \\
\hline+8 & 1,56 & 1,56 & 0 & 3,40 & 3,30 & $-2,94$ \\
\hline 0 & 1,58 & 1,58 & -- & 3,21 & 3,21 & -- \\
\hline-4 & 1,62 & 1,59 & $-1,85$ & 3,11 & 3,11 & 0 \\
\hline-10 & 1,62 & 1,62 & 0 & 2,97 & 2,86 & $-3,70$ \\
\hline-12 & 1,66 & 1,64 & $-1,20$ & 2,78 & 2,75 & $-1,08$ \\
\hline-14 & 1,67 & 1,66 & $-0,60$ & 2,54 & 2,61 & $+2,76$ \\
\hline
\end{tabular}

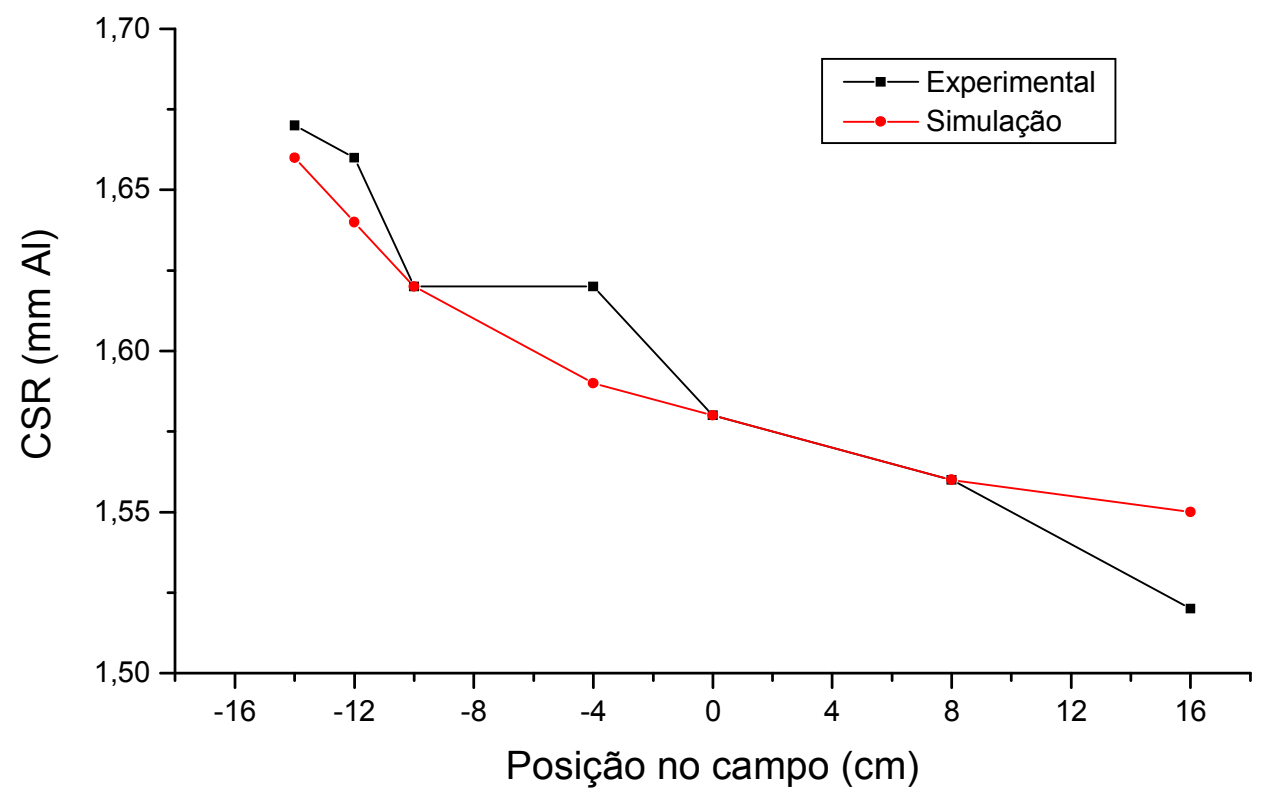

Figura 7.24. - Resultados da simulação da CSR para o Teste 11. 


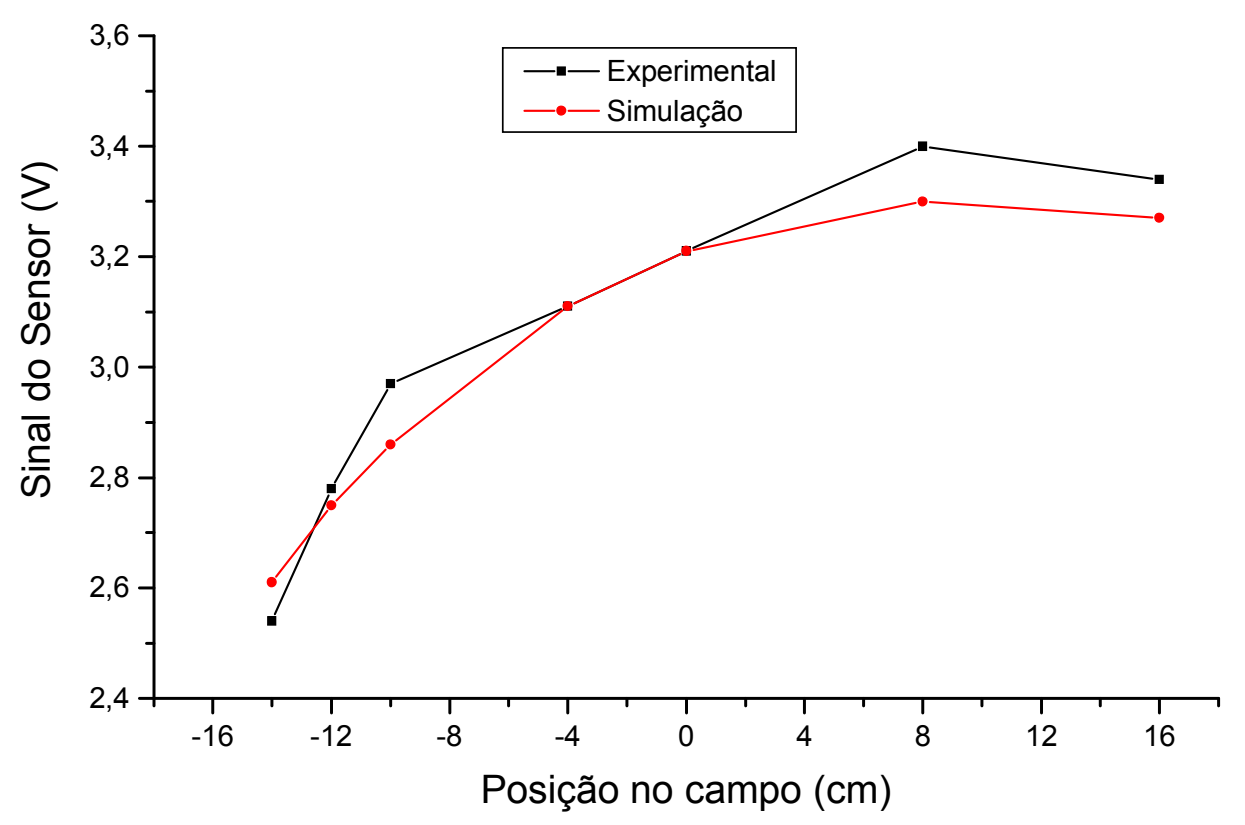

Figura 7.25. - Resultados da simulação do sinal do sensor para o Teste 11.

As tabelas a seguir apresentam os desvios médios observados entre os valores experimentais e os valores obtidos com o programa de simulação para todos os testes realizados.

Tabela 7.57. - Desvio médio (\%) entre os valores experimentais e os valores obtidos por simulação para os testes 1 a 8 .

\begin{tabular}{|c|c|c|c|c|}
\hline & $\mathbf{1}^{\text {a }}$ CSR & Dose & $\mathbf{2}^{\text {a }}$ CSR & H \\
\hline Teste 1 & 0,64 & 2,94 & 0,74 & 1,01 \\
\hline Teste 2 & 0,19 & 2,82 & -- & -- \\
\hline Teste 3 & 0,24 & 5,49 & -- & -- \\
\hline Teste 4 & 2,36 & 3,46 & -- & -- \\
\hline Teste 5 & 2,84 & 4,23 & -- & -- \\
\hline Teste 6 & 1,51 & 3,29 & -- & -- \\
\hline Teste 7 & 1,82 & 1,91 & -- & -- \\
\hline Teste 8 & 2,73 & 2,43 & -- & -- \\
\hline
\end{tabular}


Tabela 7.58. - Desvio médio (\%) entre os valores experimentais e os valores obtidos por simulação para os testes 9 a 11.

\begin{tabular}{|c|c|c|}
\hline & CSR & Intensidade \\
\hline Teste 9 & 2,27 & 3,98 \\
\hline Teste 10 & 1,29 & 2,36 \\
\hline Teste 11 & 0,94 & 2,10 \\
\hline
\end{tabular}

\subsection{Discussões}

Realizou-se uma série de testes práticos para a verificação da coerência entre os valores obtidos com o programa de simulação e os obtidos na prática para aparelhos de radiodiagnóstico. Nesses experimentos foram utilizados quatro aparelhos distintos, dois mamográficos e dois convencionais, operando com diferentes valores de tensão e corrente, com a finalidade de estender ao máximo os resultados obtidos. Além disso, as medidas foram realizadas por meio de duas metodologias distintas: com um medidor comercial e filtros de alumínio e com o dispositivo eletrônico de medição desenvolvido em pesquisa prévia no nosso grupo.

O efeito "heel" provoca uma filtração maior pelo material do anodo nos fótons que emergem em direção a este lado no campo, diminuindo a intensidade da radiação que chega nesta região. No entanto, como essa filtração acaba removendo em maior quantidade os fótons menos energéticos do espectro de Raios-X, ela provoca, conseqüentemente, o aumento na energia efetiva desse feixe. Assim, ao mesmo tempo que a intensidade da radiação medida no campo no lado correspondente ao catodo é maior do que a do lado do anodo devido ao efeito "heel", a CSR do feixe que irradia o lado do anodo é maior devido à filtração sofrida.

Essa variação foi observada em praticamente todos os testes efetuados, com exceção dos testes realizados com o Mamógrafo B (testes 7, 8 e 9) do Laboratório de Raios-X do Departamento de Engenharia Elétrica da EESC / USP. Esse aparelho apresentou problemas operacionais relacionados à quantidade de radiação produzida durante a realização dos testes. Uma análise mais minuciosa 
apontou uma diferença muito significativa entre a corrente efetiva aplicada ao tubo e o valor fornecido pelo painel de controle do mamógrafo, da ordem de 1/10. Dessa forma, como a corrente máxima fornecida pelo aparelho, segundo especificações do fabricante, é $80 \mathrm{~mA}$, na verdade, o valor máximo atingido durante os experimentos foi de $8 \mathrm{~mA}$, inaplicável a qualquer tipo de exame mamográfico real. Portanto, os valores da CSR medidos para esse aparelho, mesmo através do programa de simulação, são diferentes dos valores normalmente encontrados em aparelhos mamográficos hospitalares, conforme observado nos testes 1, 2 e 3 realizados com outro mamógrafo, que apresentou valores compatíveis com os encontrados na bibliografia especializada.

Por outro lado, as medidas realizadas com o Mamógrafo B tornaram-se muito mais suscetíveis à erros do que as outras, pois ambos os medidores utilizados nas aferições foram projetados para operar com uma dose maior de radiação do que a observada nos testes com esse mamógrafo. Além disso, nas medidas da CSR, os filtros de alumínio que foram colocados sob o feixe de Raios-X diminuíram ainda mais a intensidade da radiação que atingia os medidores, dificultando a leitura do sinal pelos sistemas de aquisição correspondentes.

Outro problema observado nos experimentos em que foi utilizado esse aparelho ocorreu especificamente para o Teste 9, realizado com o dispositivo eletrônico de medição. O valor máximo da CSR deste mamógrafo, medida previamente com o PMX-III (Teste 7 e Teste 8) foi 0,351mmAl. Como a cunha de alumínio que opera junto ao dispositivo eletrônico possui espessura mínima de $0,5 \mathrm{~mm}$, conforme descrito no Capítulo 6 , o valor inicial da intensidade de radiação obtido pelo aparelho, quando a cunha começava a se deslocar por cima do sensor, já correspondia a um valor menor do que $50 \%$ da intensidade inicial livre de filtração; em outras palavras, a espessura inicial da cunha de alumínio $(0,5 \mathrm{~mm})$ corresponde a um valor maior do que a própria camada semi-redutora do aparelho. Considerando-se uma filtração adicional de $0,5 \mathrm{~mm}$ de alumínio, conforme proposto no Capítulo 6 , os resultados obtidos com o programa de simulação tornaram-se coerentes com os resultados obtidos experimentalmente (valores menores da CSR à medida que o detector era deslocado em direção ao lado correspondente ao anodo), mas diferentes dos registrados em sistemas mamográficos hospitalares, já que nenhum exame 
mamográfico utiliza filtração adicional de $0,5 \mathrm{~mm}$ de alumínio, considerada muito alta pelos motivos já expostos no item 2.4.

Em relação aos métodos utilizados na simulação para o cálculo do espectro de Raios-X, propostos por Fritz \& Livingston (FRITZ_82), melhores resultados foram obtidos quando utilizou-se o método $c d$ na simulação dos testes com os aparelhos mamográficos e o método csda para os testes com os aparelhos convencionais.

Outro aspecto observado nos testes diz respeito à variação da intensidade no campo devido ao efeito "heel". A dose de radiação medida apresentou índices muito maiores de variação, comparadas ao valor no centro do campo, quando o detector era deslocado para o lado correspondente ao anodo do que quando era deslocado para o lado do catodo. Enquanto a dose medida do lado do catodo, comparada com o valor medido no centro do campo, apresentou variações de aproximadamente $5 \%$, no lado do anodo, observaram-se variações em torno de $30 \%$ (máxima variação de 57\% no Teste 10).

Dessa forma, o efeito "heel" deve influenciar mais significativamente as imagens de objetos posicionados no lado do campo correspondente ao anodo do que quando colocados no lado do catodo. Isto ocorre porque, em relação ao feixe central, a variação na filtração sofrida pelos fótons no interior do alvo é muito mais significativa para o feixe direcionado para o lado correspondente ao anodo no campo do que para o lado do catodo, conforme pode ser observado pelo desenho da Figura 2.12.

Além disso, à medida que o detector é afastado do centro do campo em qualquer direção no plano imagem, sua distância em relação ao ponto focal do tubo aumenta, diminuindo a intensidade da radiação recebida por ele como conseqüência da lei do inverso do quadrado da distância. Esse fenômeno acaba intensificando a variação de intensidade causada pela filtração no interior do alvo para o feixe que é direcionado no campo para o lado correspondente ao anodo, que apresenta menor valor de intensidade devido à maior filtração e à maior distância da fonte. $\mathrm{O}$ inverso ocorre com o feixe que é direcionado para o lado do catodo, que sofre menor filtração do que o feixe central (provocando o aumento na sua intensidade), mas atinge uma região mais distante no campo (provocando, em 
contrapartida, uma diminuição nessa intensidade). $\mathrm{O}$ fenômeno geralmente predominante (principalmente para posições não muito distantes do centro do campo) é a variação da filtração no interior do alvo, o que faz com que o feixe apresente maior intensidade no lado correspondente ao catodo do que o feixe central, conforme observado nos testes 5, 6 e 10. Por outro lado, para posições muito distantes do centro do campo, a lei do inverso do quadrado da distância passa a ser o fenômeno predominante, fazendo com que a intensidade do feixe do lado do catodo seja menor do que a intensidade no centro (testes 4, 7, 8 e 11).

Os valores obtidos com o algoritmo de simulação para a primeira e a segunda camadas semi-redutoras e também para o coeficiente de homogeneidade mostraram-se muito próximos aos valores obtidos experimentalmente, sendo que o maior desvio médio observado foi de $2,84 \%$ entre todos os testes realizados. Esse desvio pode ser considerado dentro do normal, levando-se em conta os erros inerentes ao procedimento de medida da CSR e que podem estar relacionados a uma série de fatores envolvidos nesse processo, conforme descrito no Capítulo 3.

Em relação aos valores obtidos com a simulação da dose de radiação em diferentes posições no campo, foram encontrados desvios um pouco maiores, principalmente nas regiões muito afastadas do centro do campo, devido à influência da radiação espalhada. Para os testes com os aparelhos mamográficos, os valores experimentais obtidos foram maiores do que os obtidos por simulação porque a radiação espalhada que o detector recebe à medida que é afastado do centro do campo em direção ao anodo é maior devido ao espalhamento provocado pelo suporte do tubo de Raios-X, posicionado a cerca de $15 \mathrm{~cm}$ do centro do campo nos mamógrafos utilizados nos testes. Para os experimentos com os aparelhos convencionais de Raios-X, os resultados experimentais obtidos apresentaram valores menores do que os obtidos por simulação, pois nesse caso a radiação espalhada recebida pelo detector nas extremidades do campo é menor do que a recebida no centro devido ao aumento da distância (lei do inverso do quadrado da distância). Mesmo assim, o máximo desvio médio registrado foi de 5,49\%.

Portanto, de modo geral, o programa apresentou resultados coerentes com os fenômenos observados na prática, podendo ser utilizado como indicador das variações da qualidade do feixe ao longo do campo. 


\section{CAPÍTULO 8 \\ Método Computacional para Elaboração de Filtros de Compensação para Raios-X}

Nesse capítulo é descrita a metodologia utilizada para a simulação dos filtros de compensação para o efeito "heel" e para variações de espessura do objeto radiografado, juntamente com os resultados obtidos em testes experimentais.

\subsection{Filtros para compensação do efeito "heel"}

Nos testes realizados com os aparelhos radiográficos constatou-se que a variação na intensidade no campo de radiação é bastante significativa, com variação de até $59 \%$ entre um extremo e outro no campo. Considerando-se os exames radiográficos de estruturas anatômicas grandes, em que é necessária a utilização de campos de exposição muito extensos, o efeito "heel" tende a ser proporcionalmente maior, influenciando negativamente a qualidade da imagem radiográfica, a qual apresentará uma variação de contraste que não é meramente conseqüência de variações no objeto radiografado.

Levando-se em conta esses fatos, desenvolveu-se um programa de simulação computacional para projetar um filtro de características particulares capaz de uniformizar a dose de radiação que irradia o campo em toda sua extensão e 
eliminando, portanto, as variações de contraste que degradam a imagem radiográfica de estruturas extensas que não apresentam variações significativas em sua espessura.

O programa de simulação dos filtros baseia-se no algoritmo desenvolvido para a determinação da camada semi-redutora em toda a extensão do campo, descrito no Capítulo 5. Este algoritmo é capaz de determinar as variações na intensidade e na energia do feixe em função da posição do objeto no campo, através dos procedimentos já enumerados. Assim, para o cálculo do filtro de uniformização, algumas pequenas modificações foram introduzidas ao programa de simulação da CSR. A Figura 8.1, a seguir, apresenta um esquema da geometria utilizada para a aplicação do algoritmo desenvolvido.

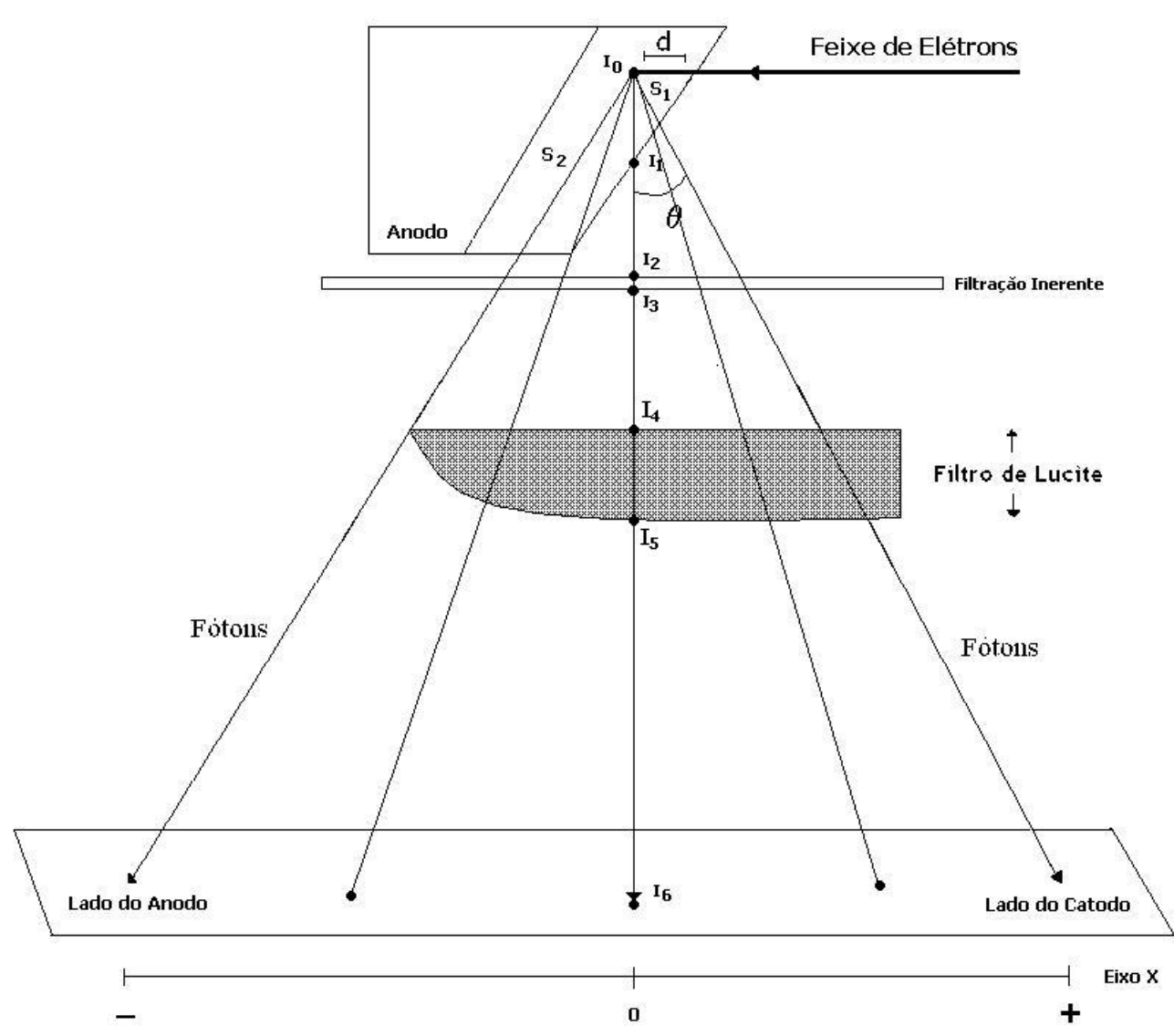

Figura 8.1. - Ilustração da geometria para o cálculo do filtro para uniformização do efeito "heel".

O procedimento para o cálculo da intensidade $I_{3}$, após o feixe ser atenuado pela filtração inerente, para qualquer ângulo de emissão, é exatamente o 
mesmo do programa de simulação da CSR. Para o novo algoritmo, calcula-se a intensidade $I_{4}$ utilizando-se a lei do inverso do quadrado da distância, considerando a distância em relação ao tubo de Raios-X, definida pelo usuário, a que o filtro de compensação deve ser colocado. A partir desses resultados, calcula-se inicialmente a intensidade final $\left(I_{6}\right)$ sem a colocação de nenhum filtro sob o feixe de Raios-X e levando-se em conta apenas a correção utilizada devido à distância do filtro ao campo.

Para a determinação do filtro de uniformização simula-se a colocação de um atenuador de espessura variável sob o feixe de Raios-X, conforme Figura 8.1, utilizando-se a mesma metodologia aplicada ao programa de simulação da CSR. Calcula-se, primeiramente, a intensidade da radiação nas diversas posições no campo, considerando a espessura inicial do filtro como sendo zero. As dimensões do campo e as posições onde o cálculo deve ser efetuado são definidas pelo usuário; assim, tem-se a variação de intensidade em função do posicionamento do objeto no plano imagem. A partir desses resultados, toma-se por base o menor valor para a intensidade encontrada no campo, geralmente na extremidade máxima no lado do anodo. Aumenta-se, então, gradativamente a espessura desse filtro em todas as outras posições até que a intensidade final resultante em cada uma delas seja exatamente igual à menor intensidade encontrada no campo, onde conseqüentemente a espessura calculada para o filtro será zero. Dessa forma, tem-se a espessura necessária do absorvedor em cada posição para que a intensidade ao longo de todo o campo mantenha-se uniforme.

Primeiramente, escolheu-se o alumínio como material para esse filtro, mas os resultados obtidos na simulação seriam dificilmente utilizados na prática. $\mathrm{O}$ filtro resultante para a uniformização da intensidade no campo, mesmo para aparelhos operando em $120 \mathrm{kVp}$, apresentavam variações de espessura muito pequenas de uma extremidade a outra, da ordem de $0,5 \mathrm{~mm}$, difícil de se construir na prática. Assim, optou-se por utilizar o Lucite $\left(\mathrm{C}_{5} \mathrm{H}_{8} \mathrm{O}_{2}\right)$ como material, por ser ele mais transparente aos Raios-X e de mais fácil manuseio do que o alumínio. Os resultados obtidos da simulação com o Lucite apresentaram valores maiores para a variação de espessura (entre 1 e $10 \mathrm{~cm}$ ), conforme esperado, o que torna a confecção do filtro muito mais fácil na prática. 
O programa calcula, a partir dos mesmos parâmetros de entrada do programa de simulação da CSR, as dimensões requeridas para o filtro de Lucite para a uniformização da intensidade do feixe ao longo de todo o campo. Além disso, o programa também fornece o valor da intensidade do feixe em diversas posições no campo, antes e depois da utilização do filtro. A Figura 8.2, a seguir, ilustra a tela do programa de simulação desenvolvido.

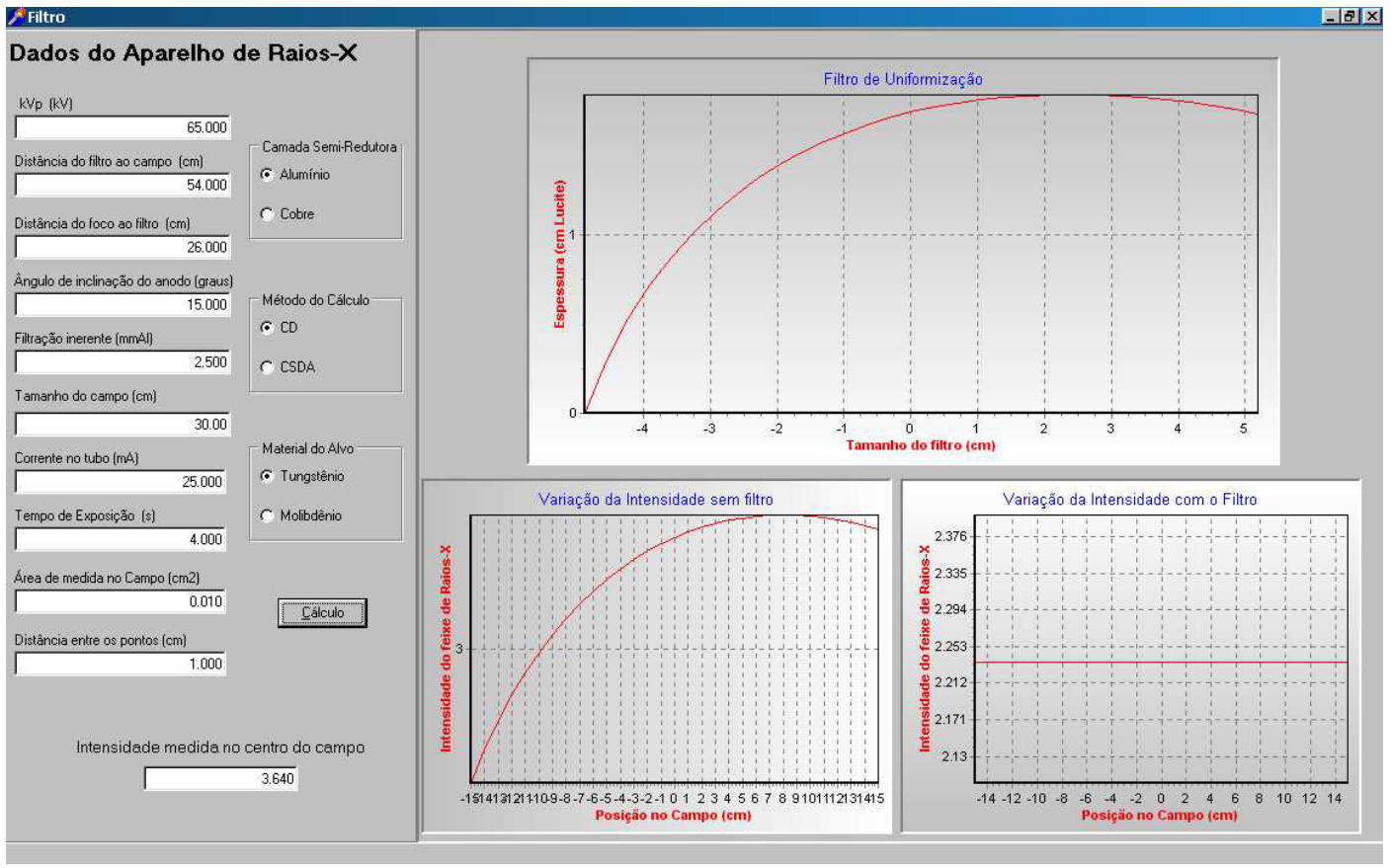

Figura 8.2. - Tela do programa de simulação de filtros para compensação do efeito "heel".

\subsection{Filtros para radiografia lateral da coluna cervical}

Conforme descrito no Capítulo 4, existem problemas relativos à visualização da transição cérvico-torácica em radiografias da coluna cervical, especificamente na posição lateral, devido à diferença brusca de espessura entre o pescoço e a região dos ombros do paciente, que proporciona uma absorção não uniforme dos Raios-X. A Figura 4.1 mostra um exemplo de radiografia onde o ajuste de tensão e corrente no tubo $(\mathrm{kVp}$ e $\mathrm{mAs})$ foram suficientes para produzir um contraste satisfatório na imagem da região do pescoço, mas insuficientes para a visualização da região dos ombros. Isto ocorre porque a transição cérvico-torácica 
(também conhecida como C7-T1, por representar a ligação entre a sétima vértebra cervical e a primeira vértebra torácica) fica mascarada pela massa muscular presente nos ombros, conforme ilustrado na Figura 8.3. Assim, quando o ajuste de kVp e mAs é suficiente para que os Raios-X atravessem toda a extensão muscular dos ombros (em perfil), torna-se excessivo para a região do pescoço, já que os fótons, nesse caso, atravessam uma espessura cerca de quatro vezes menor, o que impossibilita a visualização dessa região devido à ocorrência de saturação na imagem.

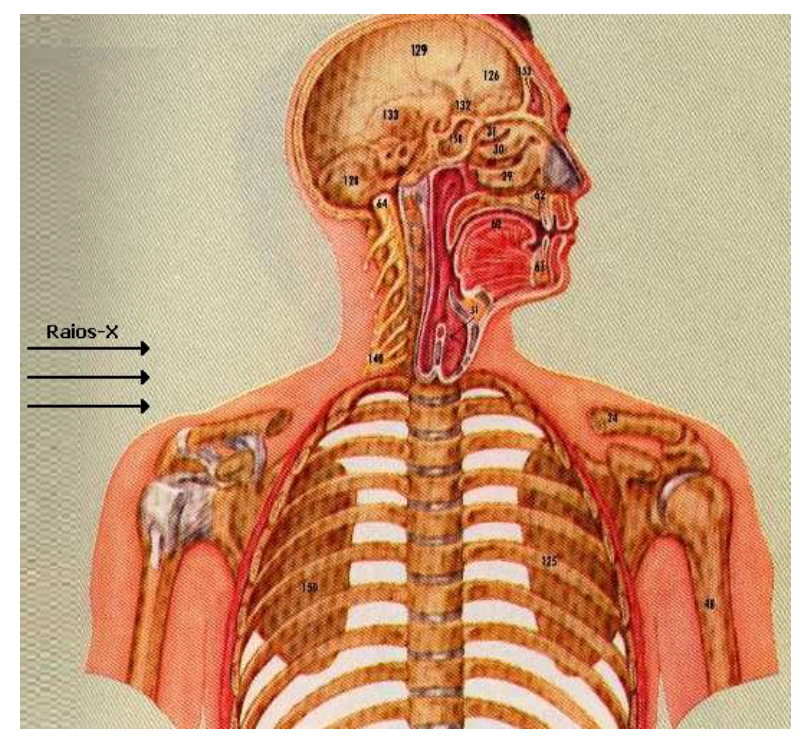

Figura 8.3. - Ossos da região superior do corpo humano; vista frontal ${ }^{11}$.

Assim, elaborou-se um programa de simulação computacional para o desenvolvimento de um filtro que compense essa diferença de absorção, para que um único ajuste nos parâmetros do aparelho radiográfico permita uma imagem de contraste satisfatório em ambas as regiões. Para que isso seja possível, torna-se necessário que o ajuste de $\mathrm{kVp}$ e mAs seja suficiente para a visualização da região mais espessa, pois assim o filtro torna uniforme o contraste na imagem, absorvendo o excesso de radiação que acaba irradiando a região do pescoço (menos espessa). O algoritmo calcula a espessura necessária de um determinado absorvedor (alumínio, lucite ou cobre) que seja capaz de filtrar a mesma quantidade de Raios-X que o

\footnotetext{
11 Temapédia: Medicina, Anatomia e Fisiologia. (1998) In: Nova Enciclopédia Barsa, São Paulo. Encyclopaedia Britannica do Brasil Publicações, p.330.
} 
excesso de massa muscular da região dos ombros do paciente, através de uma metodologia muito semelhante à utilizada nos algoritmos anteriores.

O programa calcula a intensidade da radiação $\left(I_{A}\right)$ no centro do campo a partir dos parâmetros de exposição ( $\mathrm{kVp}, \mathrm{mAs}$, distância, etc.), utilizando a mesma metodologia do algoritmo de simulação da CSR descrito no Capítulo 5. Com isso, determina-se a intensidade final resultante $\left(I_{B}\right)$ da absorção desse feixe por uma determinada espessura de músculo, definida através da largura do ombro do paciente, que é um dos parâmetros de entrada do programa. Essa filtração é efetuada pelo mesmo método utilizado nos outros algoritmos desenvolvidos, considerando os coeficientes de atenuação de massa $(\mu / \rho)$ para o músculo calculados por Johns \& Cunningham (JOHNS_83). Conhecendo-se essa intensidade, efetua-se o cálculo da absorção do mesmo feixe inicial $\left(I_{A}\right)$ por outro material atenuante (definido pelo usuário) de espessura variável. Aumenta-se gradativamente a espessura desse filtro até que a intensidade final resultante seja igual ao valor encontrado na filtração pelo músculo $\left(I_{B}\right)$. Assim, a espessura do filtro encontrada através dessa metodologia absorve a mesma quantidade de radiação que a massa muscular em excesso na região dos ombros do paciente absorveria e corresponde, portanto, à espessura do filtro necessária para compensar a variação na absorção de Raios-X que ocorre nos exames radiográficos da coluna cervical, já discutidos anteriormente.

A intensidade é calculada para o centro do campo, pois a região correspondente à transição entre o pescoço e os ombros do paciente deve ser colocada no centro do campo na técnica convencionalmente usada para tal exame. As diferenças de contraste derivadas do efeito "heel" podem ser minimizadas através do filtro projetado com o outro programa de simulação descrito no item 8.1.

\subsection{Resultados e discussões}

Confeccionou-se um filtro para compensação do efeito "heel" e um filtro para a utilização em radiografias laterais da transição cérvico-torácica para que fossem testados na prática em aparelhos radiográficos hospitalares, a fim de comprovar a validade dos algoritmos desenvolvidos. 
Primeiramente, projetou-se um filtro para compensar as variações de intensidade causadas pelo efeito "heel" no feixe radiográfico produzido pelo aparelho convencional de Raios-X do Hospital das Clínicas de Ribeirão Preto (Convencional B), considerando os parâmetros de entrada ilustrados pela Figura 8.2. Construiu-se, então, um filtro de Lucite (Figura 8.4) baseado nas características fornecidas pelo algoritmo de simulação proposto.

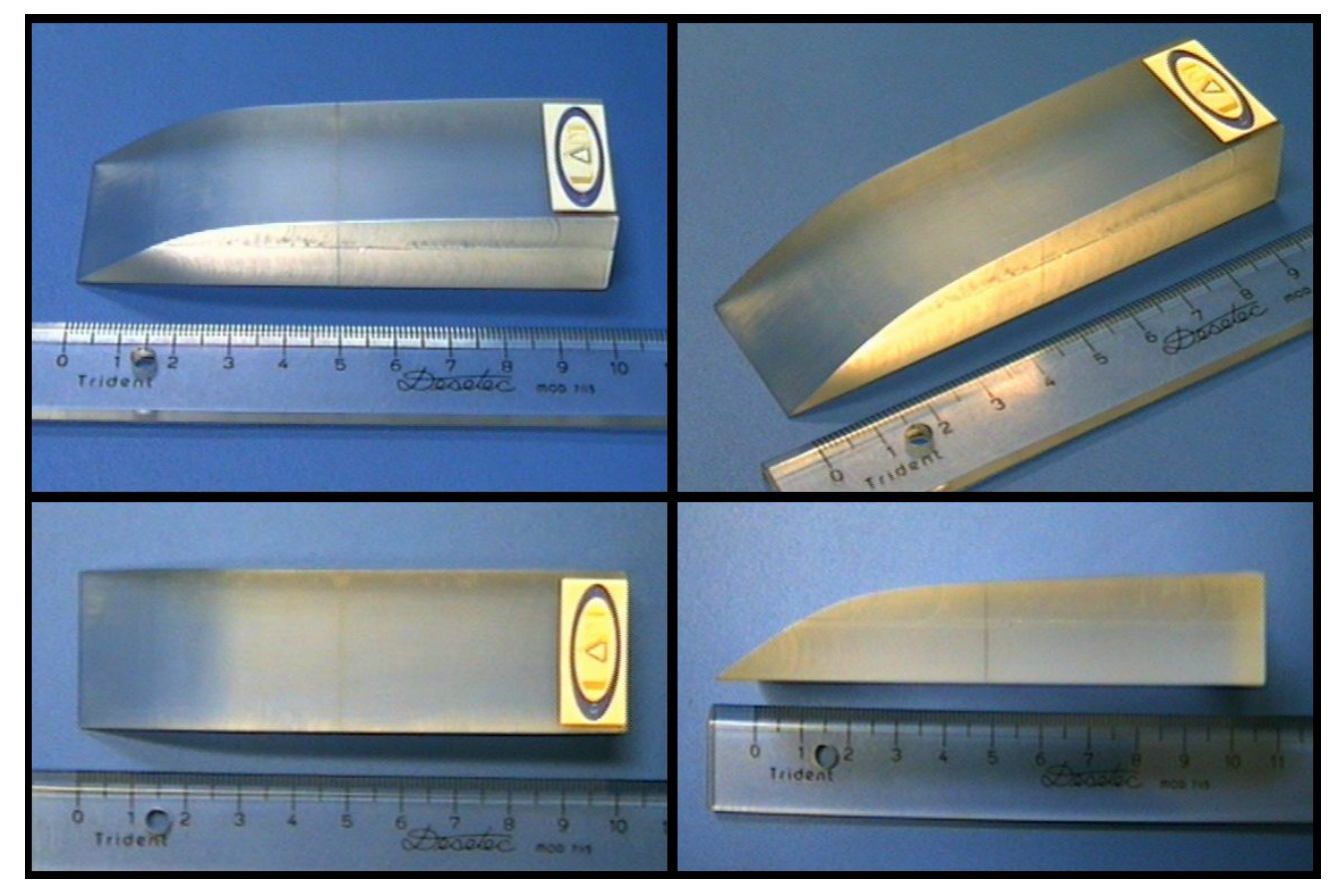

Figura 8.4. - Filtro de Lucite construído para uniformizar a intensidade da radiação no campo de exposição.

Para os testes com o filtro desenvolvido utilizou-se o aparelho eletrônico de medição (CURI_98) descrito no item 3.7, posicionando o sensor de silício sobre o mesmo suporte da cunha de alumínio utilizado para as medidas da CSR (ilustrada na Figura 3.16). Dessa forma, o sensor não sofre absorção pela cunha, pois está sobre o mesmo plano que ela, podendo ser deslocado de um extremo a outro no campo até o máximo de $12,4 \mathrm{~cm}$ durante uma única exposição aos Raios-X. Com o auxílio de um software de aquisição de dados desenvolvido por Curi (CURI_98) especialmente para medidas de efeito "heel", é possível prever as variações de intensidade no campo de exposição em toda sua extensão. 
O filtro ilustrado na Figura 8.4 foi projetado para uniformizar a intensidade num campo de exposição de $15 \mathrm{~cm}$. Primeiramente, foram obtidas as medidas para variação da intensidade do feixe entre o centro do campo e a extremidade do lado do anodo (até $7,2 \mathrm{~cm}$ ) e entre o centro e a extremidade do lado do catodo (até 7,8 cm), sem a utilização de nenhum filtro de compensação. A Figuras 8.5 e 8.6, a seguir, mostram os resultados obtidos nos testes com o aparelho. A intensidade medida no centro do campo correspondeu a uma leitura de $3,12 \mathrm{~V}$ pelo sistema de aquisição de sinal. O sensor registrou uma variação de $0,94 \mathrm{~V}$ entre a leitura no centro do campo e a 7,2cm de distância do centro (em direção ao lado correspondente ao anodo), ou seja, uma variação de 30,1\% na intensidade causada pelo efeito "heel" (Figura 8.5). Do mesmo modo, para o lado correspondente ao catodo, o sensor registrou uma variação de $0,14 \mathrm{~V}$ entre a leitora no centro e a $7,8 \mathrm{~cm}$ de distância, ou seja, 4,49\% de variação (Figura 8.6).

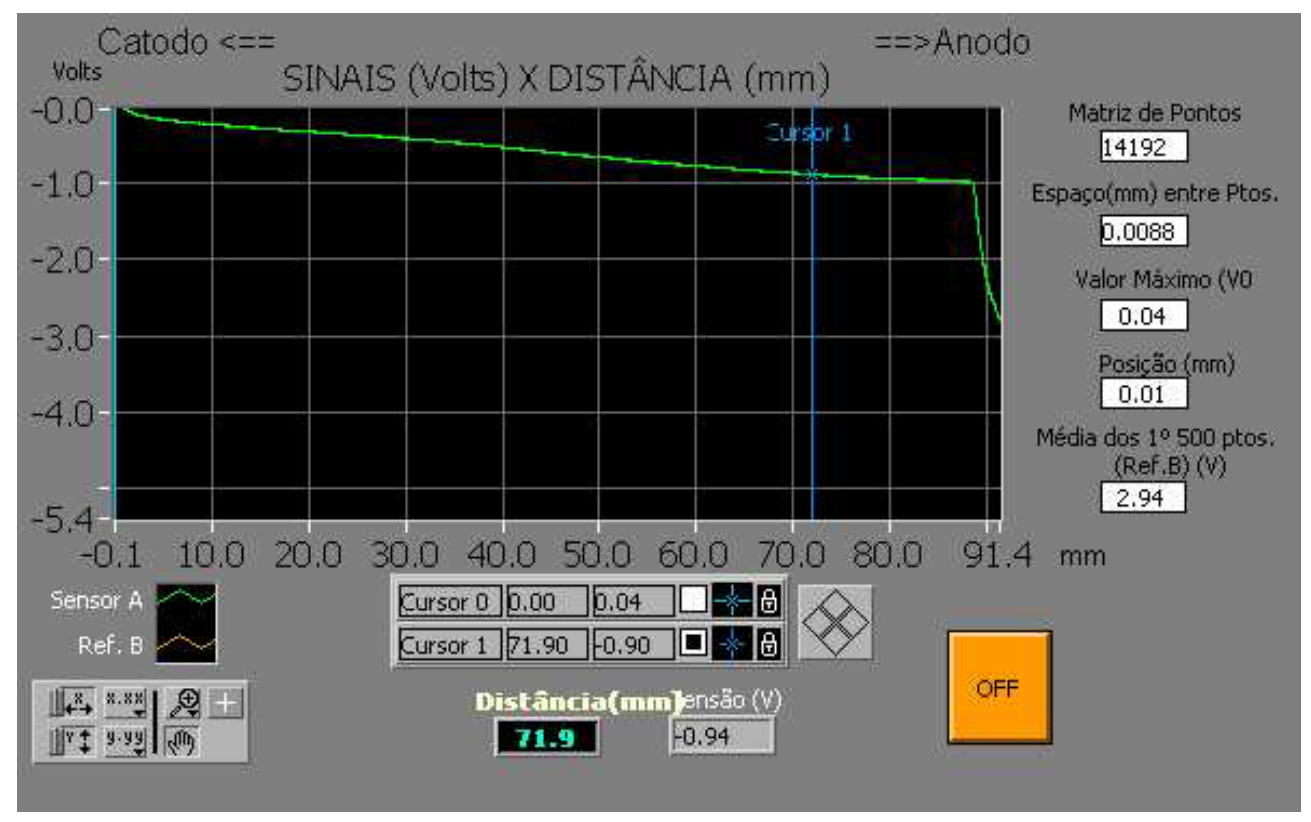

Figura 8.5. - Sinal proveniente do sensor em diversas posições no campo (lado do anodo), sem a utilização do filtro de compensação, mostrando a variação da intensidade do feixe causada pelo efeito "heel". 


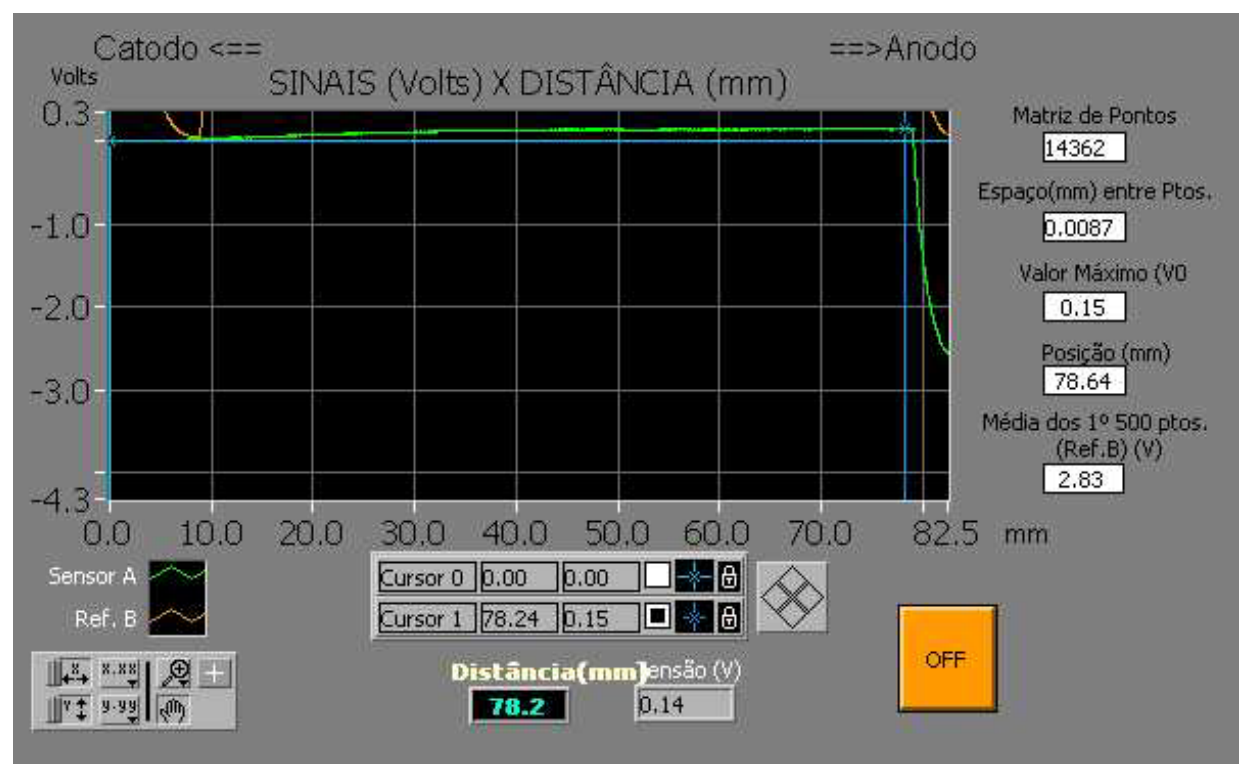

Figura 8.6. - Sinal proveniente do sensor em diversas posições no campo (lado do catodo), sem a utilização do filtro de compensação, mostrando a variação da intensidade do feixe causada pelo efeito "heel".

Utilizando-se o filtro de compensação para o efeito "heel" posicionado sob o feixe de Raios-X, na janela de saída do tubo, foram feitas medidas de variação de intensidade sob as mesmas condições do teste anterior. Os resultados obtidos com o sensor são mostrados nas Figuras 8.7. e 8.8.

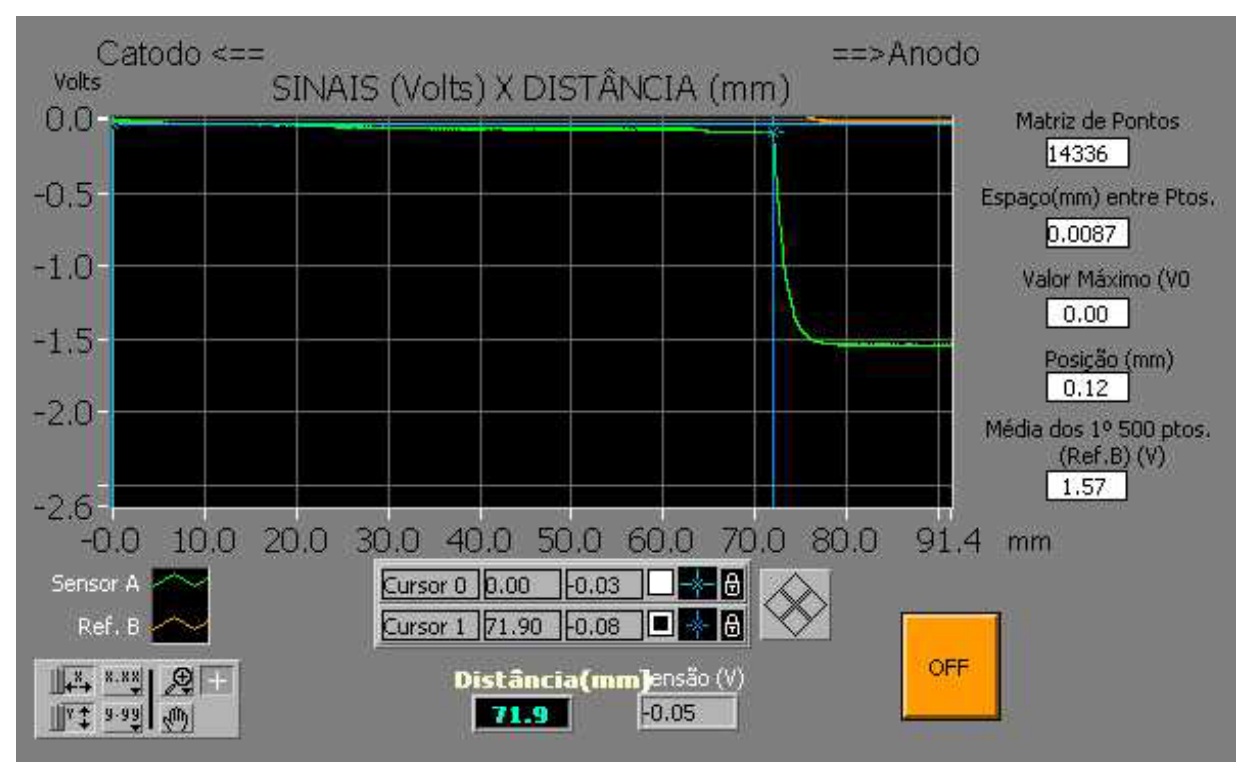

Figura 8.7. - Sinal proveniente do sensor em diversas posições no campo (lado do anodo) com o filtro de compensação posicionado sob o tubo de Raios-X. 


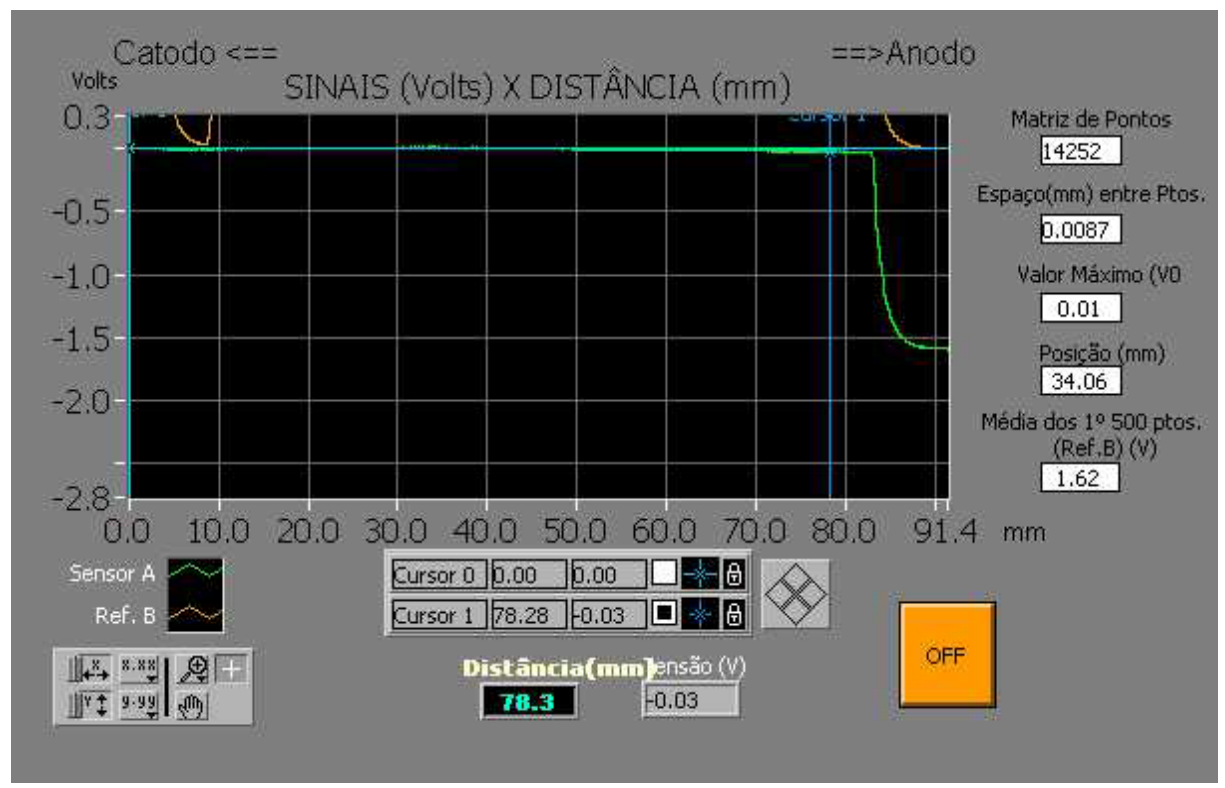

Figura 8.8. - Sinal proveniente do sensor em diversas posições no campo (lado do catodo) com o filtro de compensação posicionado sob o tubo de Raios-X.

Com a utilização do filtro de compensação, a leitura no centro do campo diminuiu para 2,06V em razão da absorção pelo filtro, já que foram utilizados os mesmos parâmetros do teste anterior. Assim, com a utilização do filtro desenvolvido, a variação na intensidade do feixe foi de apenas $2,43 \%$ entre a região central e a região distante $7,2 \mathrm{~cm}$ do centro, para o lado do campo correspondente ao anodo, e de 1,46\% para o lado do catodo, a 7,8cm do centro. Considerando-se toda a extensão do campo $(15 \mathrm{~cm})$, a variação total na intensidade do feixe de uma extremidade à outra do campo passou de 34,6\% sem a utilização do filtro de compensação para 3,88\% com a utilização do filtro de compensação, obtendo-se assim uma maior uniformidade do feixe ao longo do campo.

Para os testes de radiografia lateral da coluna cervical calculou-se a espessura de um filtro para compensar a diferença de espessura através do programa de simulação descrito no item 8.2. A tensão normalmente utilizada no tubo de Raios-X para esse exame, conforme apresentado no Capítulo 4, é $65 \mathrm{kVp}$. Para a utilização de um filtro de compensação é necessário que o feixe de radiação seja suficiente para apresentar um contraste satisfatório na imagem da região dos ombros, pois o filtro será posicionado de modo a filtrar apenas a parcela de radiação que irradia a região do pescoço do paciente. Portanto, utilizou-se uma tensão de $85 \mathrm{kVp}$ 
para o cálculo da espessura do filtro de compensação. A Figura 8.9, a seguir, mostra a tela do algoritmo de simulação utilizado para o cálculo daquela espessura.

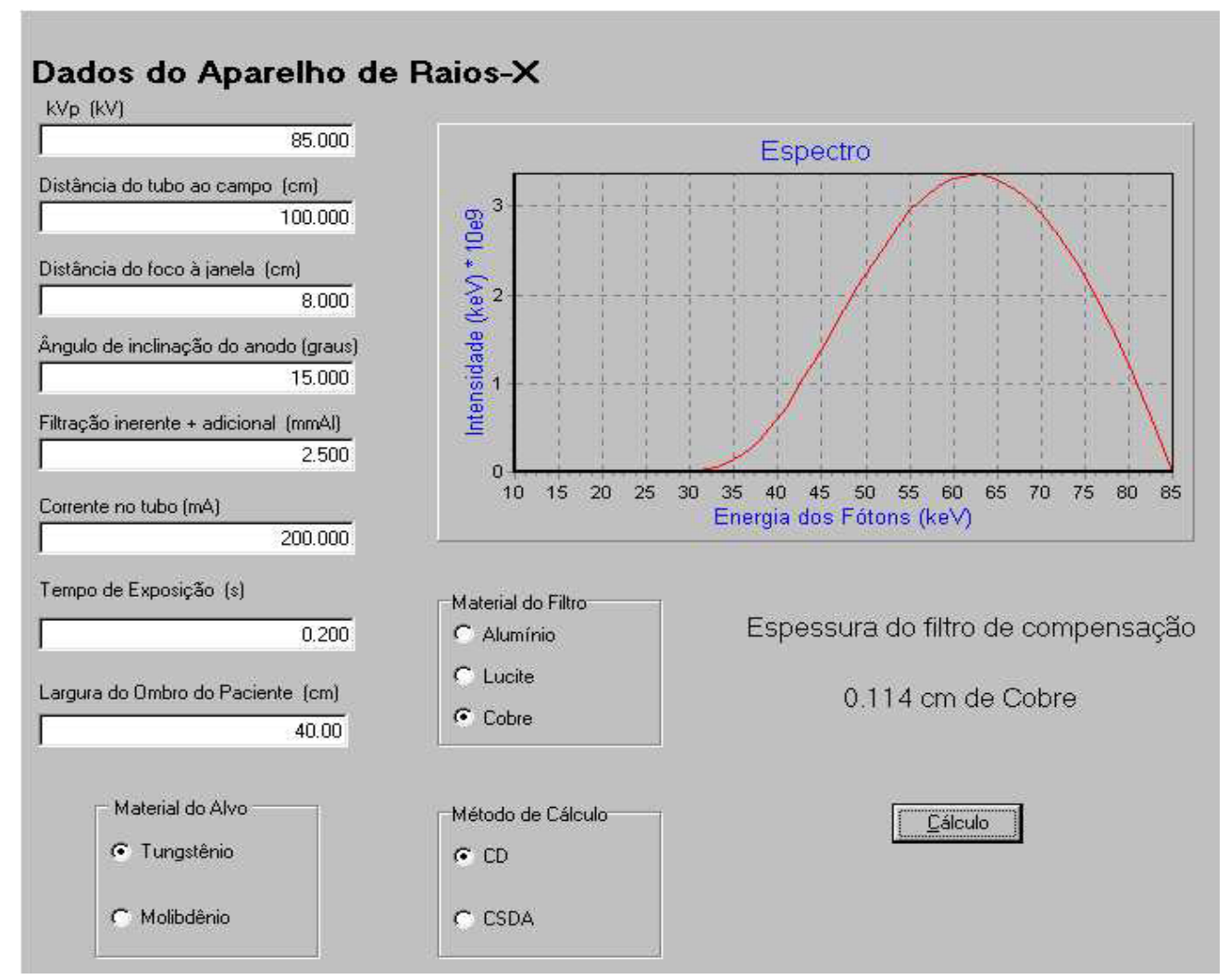

Figura 8.9. - Tela do programa de simulação do filtro de compensação para radiografia lateral da coluna cervical.

Portanto, confeccionou-se um filtro quadrado de cobre, de $4 \mathrm{~cm}$ de largura e $0,11 \mathrm{~mm}$ de espessura (Figura 8.10), que foi posicionado na saída do colimador do aparelho de Raios-X cobrindo apenas a metade do campo correspondente ao lado do anodo (Figura 8.11), para a realização dos testes. 


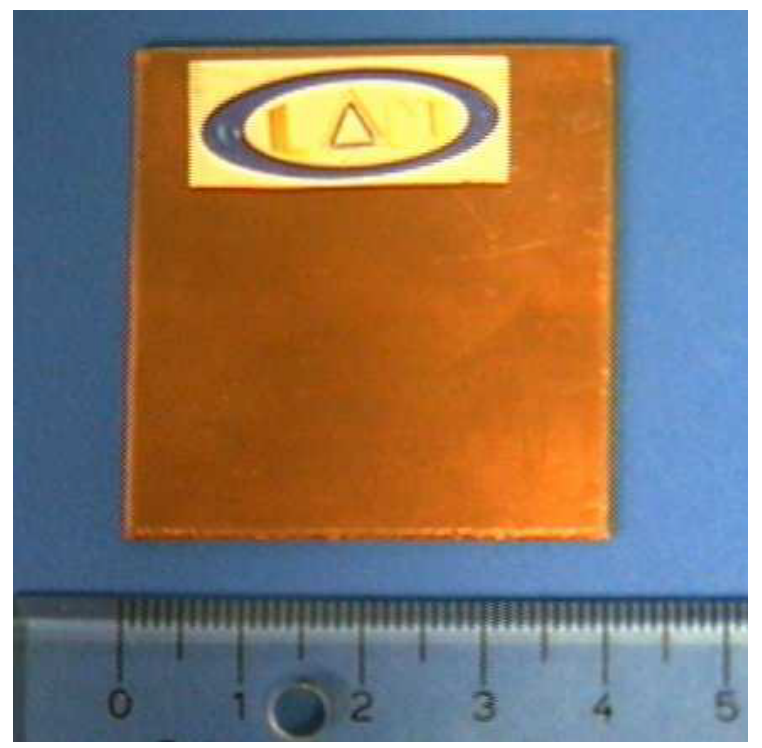

Figura 8.10. - Filtro desenvolvido para utilização em radiografia lateral da coluna cervical.

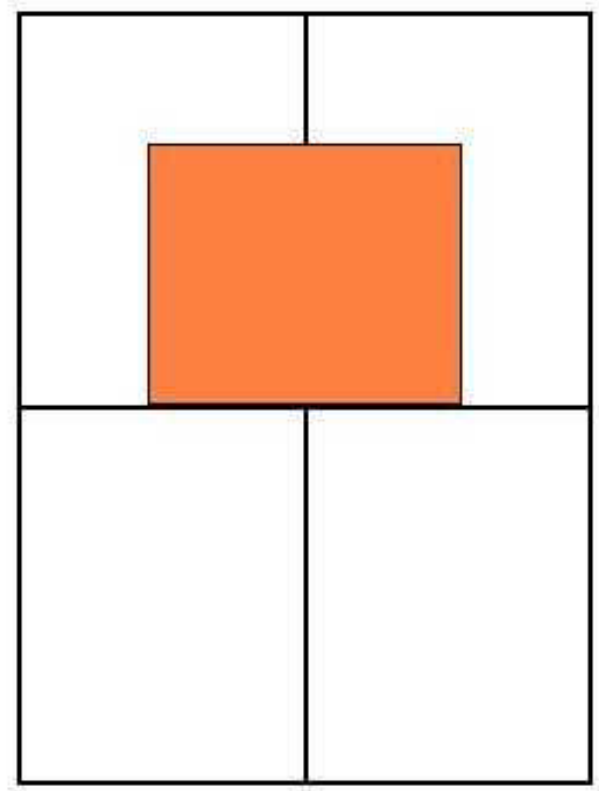

Figura 8.11. - Posicionamento do filtro de cobre na janela do colimador do aparelho de Raios-X utilizado nos testes.

Testes com esse filtro foram realizados no Hospital das Clínicas de Ribeirão Preto. Primeiramente, foi obtida uma imagem radiográfica lateral da transição cérvico-torácica de um paciente, utilizando-se uma tensão de $85 \mathrm{kVp}$, sem o filtro de compensação. Essa imagem é mostrada na Figura 8.12. 


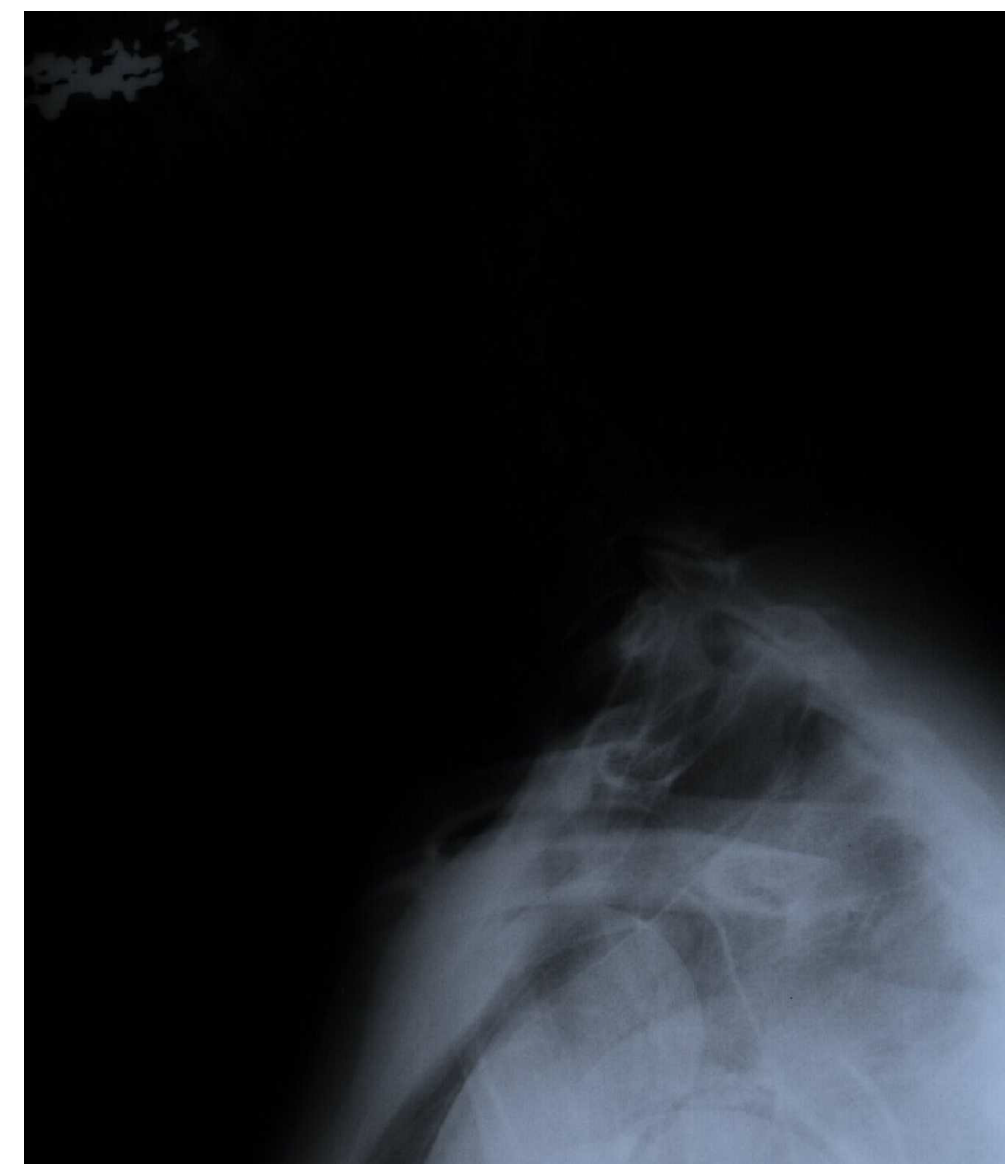

Figura 8.12. - Radiografia lateral da coluna cervical sem o filtro de compensação $(85 \mathrm{kVp}, 32 \mathrm{mAs})$.

Nota-se que a tensão utilizada foi suficiente para a visualização da região correspondente aos ombros do paciente, mas excessiva para a região do pescoço, onde a imagem apresentou saturação. Assim, realizou-se outra exposição sob as mesmas condições da anterior, posicionando-se o filtro de cobre na saída do colimador do tubo para que cobrisse apenas a metade do campo de exposição. Dessa forma, o paciente foi posicionado da maneira usual, mas de modo que a região correspondente ao pescoço ficasse na metade do campo coberta pelo filtro de cobre e a região dos ombros ficasse livre de filtração. A imagem obtida sob essas condições é mostrada pela Figura 8.13. 


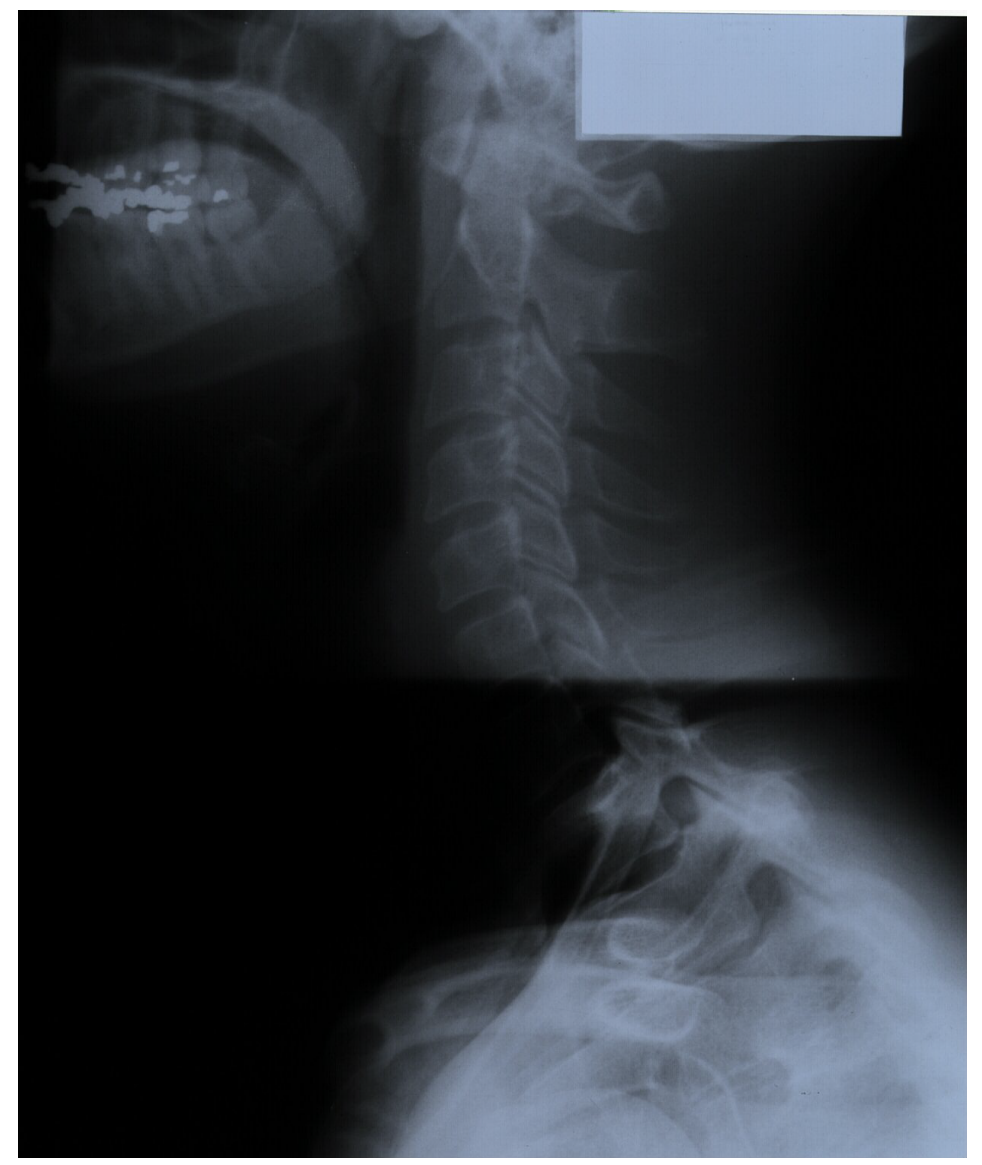

Figura 8.13. - Radiografia lateral da coluna cervical com o filtro de compensação posicionado na saída do colimador do tubo de Raios-X (85kVp, 32mAs).

Como efeito, percebe-se uma maior uniformidade no contraste entre as duas regiões irradiadas devida à absorção dos Raios-X pelo filtro de cobre na região do pescoço do paciente. É nítida também a melhora na visualização da região dos ombros em razão do aumento da tensão do tubo, o que tornou o feixe mais penetrante. Assim, com um melhor posicionamento desse filtro e testes com outros materiais é possível obter uma imagem de melhor qualidade da transição cérvicotorácica do que as imagens obtidas atualmente nos exames de rotina.

De qualquer modo, a utilização do filtro projetado nas novas condições operacionais propostas representa uma melhoria na qualidade desse tipo de imagem, melhorando, portanto, as condições para diagnósticos de fraturas na transição cérvico-torácica. Além disso, um outro aspecto importante é que sua utilização não implica em modificações significativas na técnica usual de exposição para esse tipo de exame. 


\section{CAPÍt́tulO 9}

\section{Conclusões}

Nesse capítulo são apresentadas as conclusões relativas à pesquisa realizada e algumas sugestões para trabalhos futuros que envolvam o mesmo assunto.

\subsection{Simulação computacional da camada semi-redutora}

O algoritmo de simulação apresentou resultados satisfatórios quando comparados às medidas efetuadas na prática. Sua utilização possibilita uma avaliação mais completa dos aparelhos de Raios-X, já que a simulação permite o conhecimento da sua CSR e da dose de radiação em toda a extensão do campo, sem a necessidade de medidas adicionais além das que já são recomendadas nos programas de garantia de qualidade em radiologia médica realizados atualmente.

O conhecimento do valor da CSR em toda a extensão do campo é importante, pois permite definir as regiões de melhor desempenho em termos energéticos em diferentes sistemas radiográficos. Assim, com o uso da simulação, pode-se definir rapidamente a posição no campo de exposição em que a imagem produzida deve apresentar a melhor qualidade, o que auxilia o diagnóstico médico.

Uma avaliação mais ampla, medindo-se a CSR em diversas outras posições no campo, é praticamente inviável atualmente como rotina nesses programas de controle de qualidade, pois os procedimentos experimentais para sua 
avaliação são muito longos e exaustivos, conforme verificado e descrito nesse trabalho. Para uma única medida da CSR devem ser feitas um mínimo de cinco a seis exposições com o tubo de Raios-X, já que os atenuadores são adicionados ao feixe gradativamente; além disso, cuidados com o posicionamento correto desses atenuadores sob o feixe e a utilização de espessuras diferentes de filtração a cada disparo acaba tornando até uma única medida da CSR muito demorada. Com a utilização do dispositivo eletrônico de medição descrito no item 3.7 , a medida da CSR torna-se mais rápida, já que pode ser determinada a partir de uma única exposição. Isso, porém, não resolve o problema se uma série de medidas em diferentes posições for necessária. A utilização da simulação proposta torna viável essa avaliação, dada a facilidade em se obter os resultados desejados.

O fator que melhor define a qualidade de um feixe de Raios-X não é sua intensidade, mas sim sua energia efetiva. Essa energia efetiva do feixe pode ser facilmente avaliada através do conhecimento da sua camada semi-redutora. Nos testes realizados no âmbito dessa pesquisa, percebe-se que a maioria dos aparelhos avaliados apresentaram maior valor para a CSR e menor valor para a dose de radiação quando medidas no lado do campo correspondente ao anodo. Dessa forma, permite-se concluir que esta é a região de melhor desempenho desses aparelhos, ou seja, as imagens de objetos posicionados nessa região apresentarão melhor qualidade, sob o ponto de vista da energia efetiva, mesmo considerando-se que a intensidade nessa região tende a ser cerca de $30 \%$ menor do que no outro extremo do campo. Além disso, é importante lembrar que a característica de campo (DOI_77) leva as imagens de objetos posicionados no lado do anodo a apresentar maior resolução devido ao menor tamanho efetivo do ponto focal nessa região.

Foi desenvolvido em pesquisa prévia, também em nosso laboratório, um dispositivo eletrônico de alinhamento (SCHIABEL_97b) capaz de posicionar, com precisão, o sensor do dispositivo eletrônico de medição (CURI_98) no centro do campo para que sejam efetuadas as medidas centrais da CSR e da dose. Interligandose o programa de simulação desenvolvido nessa pesquisa ao software de processamento de dados que é utilizado juntamente com os dispositivos eletrônicos de medição e alinhamento, a utilização conjunta dos três dispositivos torna possível, com uma única exposição, a medida da CSR e da dose em qualquer posição desejada 
no campo em aparelhos radiográficos hospitalares, de uma maneira mais simples e mais rápida do que com os métodos convencionais.

\subsection{Filtros de compensação para Raios-X}

O algoritmo de simulação dos filtros de compensação apresenta resultados satisfatórios na prática. O filtro desenvolvido para a uniformização da intensidade no campo é eficiente, pois consegue atribuir diferentes parcelas de filtração para cada região do feixe de Raios-X. Dessa forma, a parcela do feixe que sofre menos filtração pelo material do alvo (e irradia a região do campo correspondente ao lado do catodo) é mais absorvida pelo filtro de compensação desenvolvido do que as outras parcelas do feixe, uniformizando também a energia efetiva de todo o feixe de Raios-X. Assim, a utilização de um filtro de compensação para o efeito "heel" não só uniformiza a intensidade da radiação que irradia toda a extensão do campo, como permite que a energia efetiva, e conseqüentemente a qualidade do feixe radiográfico, seja aproximadamente a mesma para todas as regiões no plano imagem. Considerando que o sistema utilizado apresente imagens de resolução satisfatória em todas as regiões do campo modificadas pela característica de campo, isso ocorrerá também em relação ao contraste das estruturas radiografadas com o uso dos filtros propostos, independentemente da posição do objeto do campo.

O filtro projetado para a radiografia lateral da coluna cervical permitiu uma visualização completa da transição cérvico-torácica nessas imagens e pode ser facilmente utilizado na rotina em hospitais e em clínicas radiológicas. Da mesma forma, outros filtros podem ser desenvolvidos para melhorar as imagens de estruturas que apresentem variações de espessura, seguindo a mesma metodologia descrita no Capítulo 8. 


\subsection{Conclusões finais}

As comparações entre os resultados obtidos com o programa de simulação e os resultados experimentais confirmam a validade do algoritmo desenvolvido na determinação da CSR em qualquer posição do campo. A importância disso está no fato de que o uso das simulações torna mais fácil e prático a variação dos parâmetros desejados, obtendo-se rapidamente os resultados sem a necessidade de demorados testes experimentais. O conhecimento de um parâmetro que avalie a energia de um feixe de Raios-X, aliado ao conhecimento do seu comportamento em termos de resolução espacial em qualquer ponto do campo, permite melhor definir a sua qualidade para a formação de imagens radiográficas.

Além disso, com os algoritmos propostos também é possível a elaboração de filtros de compensação para a melhoria da qualidade da imagem de determinados exames, como os descritos nesse trabalho, o que poderá ser de muita ajuda ao diagnóstico médico se adequadamente aplicados.

\subsection{Sugestões para pesquisas futuras}

- Desenvolver um procedimento capaz de definir com precisão as regiões do campo com melhor desempenho em qualquer aparelho radiográfico, considerando-se todos o fatores que influenciam na qualidade da imagem, como intensidade, energia, filtração, resolução espacial, etc.

- Desenvolver filtros de compensação para utilização em outros exames radiográficos que envolvam também estruturas anatômicas de espessura variável, para melhorar a qualidade das imagens produzidas.

- Testar outros materiais para a confecção dos filtros de compensação e definir os que poderiam ser utilizados para produzir imagens de melhor contraste. Além disso, definir materiais que apresentem melhor relação custo/benefício, considerando não só a qualidade da imagem, mas a viabilidade de sua produção e sua utilização em exames de rotina. 


\section{CAPÍTULO 10}

\section{Referências Bibliográficas}

(BERGER_64)

BERGER, M.J.; SELTZER, S.M. (1964). Tables of Energy Losses and Ranges of Electrons and Positrons (microficha). Washington, U.S. Department of Commerce, National Bureau of Standards. (NASA. SP, 3012).

(BOONE_96)

BOONE, J.M.; CHAVEZ, A.E. (1996). Comparison of x-ray sections for diagnostic and therapeutic medical physics. Medical Physics, v.23, n.12, p.1997-2005.

(BURGESS_77)

BURGESS, A.E. (1977). Focal Spots: III Field characteristics. Investigative Radiology, v.12, n.1, p.54-61.

(CALDWELL_90)

CALDWELL, C.D.; YAFFE, M.J. (1990). Development of an anthropomorphic breast phantom. Medical Physics, v.17, p.273-280. 
(CURI_98)

CURI, N.S.M. (1998). Controle de qualidade em radiologia: um novo instrumento para avaliação do ponto focal e das características operacionais. São Carlos. 112p. Tese (Doutoramento) - Instituto de Física de São Carlos, Universidade de São Paulo.

\section{(CURRYIII_90)}

CURRY III, T.S.; DOWDEY, J.E.; MURRY, R.C. (1990). Christensen's Physics of Diagnostic Radiology. 4.ed. Philadelphia, Lea \& Febiger.

(DOI_77)

DOI, K. (1977). Field characteristics of geometric unsharpness due to X-ray tube focal spot. Medical Physics, v.4, n.1, p.15-20.

(FRITZ_82)

FRITZ, S.L.; LIVINGSTON, W.H. (1982). A comparison of computer and measured heel effect for various target angles. Medical Physics, v.9, n.2, p.216-219.

(FRITZ_85)

FRITZ, S.L.; LIVINGSTON, W.H. (1985). The effect of anode curvature on radiographic heel effect. Medical Physics, v.12, n.4, p.443-446.

(GREENSPAN_96)

GREENSPAN, A. (1996). Radiologia Ortopédica. 2.ed. New York, Raven Press.

(JOHNS_83)

JOHNS, H.E.; CUNNINGHAM, J.R. (1983). The Physics of Radiology. 4.ed. Illinois, Charles C. Thomas Publisher.

(KARILA_88)

KARILA, K.T.K. (1988). Quality control of mammographic equipment: a 5-year follow-up. The British Journal of Radiology, v.61, p.1155-1167. 
(KEMP_58)

KEMP, F.H.; NICHOLS, A.F. (1958). Focal Spot Sizes. The British Journal of Radiology, v.31, n.369, p.486-488.

(KRATZAT_88)

KRATZAT, M. (1988). Evaluating the importance of focal spot sizes in mammography. Medicamundi, v.33, p.74-80.

(KREEL_82)

KREEL, L. (1982). Posicionamento em Radiografia de Clark. 10.ed., Editora Manole, vol. 1.

(KUNTKE_57)

KUNTKE, A.H.G. (1957). On the determination of Roentgen Tube Focal Spot Sizes by Pin-Hole Camera Roentgenography. Acta Radiology, v.47, p.55-64.

(MARQUES_96)

MARQUES, M.A.; FRÈRE, A.F.; OLIVEIRA, H.J.Q.; SCHIABEL, H.; AZEVEDO MARQUES, P.M.; FERRARI, R.J.; PEREIRA, A.S. (1996). Computer simulation of the geometric unsharpness effect on radiologic images. In: SPIE OPTICAL SCIENCE, ENGINEERING AND INSTRUMENTATION. Proceedings, v.2847, p.609-617.

(MARQUES_98)

MARQUES, M.A. (1998). Simulação computacional de parâmetros importantes de sistemas radiológicos. São Carlos. 156p. Tese (Doutoramento) - Instituto de Física de São Carlos, Universidade de São Paulo.

(MESCHAN_75)

MESCHAN, I. (1975). An Atlas of Anatomy Basic to Radiology. Philadelphia, W.B. Saunders Co. p.535-543. 
(METZ_79)

METZ, C.E.; DOI, K. (1979). Transfer function analysis of radiographic imaging systems. Physics in Medicine \& Biology, v.24, p.1079-1106.

(MUNTZ_78)

MUNTZ, E.P. et al. (1978). Optimization of electrostatic imaging systems for minimum patient dose or minimum exposure in mammography. Radiology, v.127, p.517-523.

(NASCIMENTO_84)

NASCIMENTO, J. (1984). Temas de Técnica Radiológica. 2.ed. Rio de Janeiro, Editora de Publicações Médicas Ltda.

(OLIVEIRA_95)

OLIVEIRA, H.J.Q. (1995). Simulação computacional da nitidez de imagens radiológicas para controle de qualidade. São Carlos. 189p. Dissertação (Mestrado) Escola de Engenharia de São Carlos, Universidade de São Paulo.

(OLIVEIRA_96)

OLIVEIRA, H.J.Q.; FRÈRE, A.F.; SCHIABEL, H.; AZEVEDO MARQUES, P.M.; MARQUES, M.A.; PEREIRA, A.S. (1996). Evaluating the radiologic images quality by a simulation of objects sharpness. In: SPIE OPTICAL SCIENCE, ENGINEERING AND INSTRUMENTATION. Proceedings, v.2847, p.618-627.

(RAO_69)

RAO, U.V.G.; BATES, L.M. (1969). The Modulation Transfer Function of X-ray focal spots. Physics in Medicine \& Biology, v.14, p.93-106.

(RESNICK_88)

RESNICK, D.; NIWAYAMA, G. (1988). Diagnosis of Bone and Joint Disorders. 3.ed. Philadelphia, W.B. Saunders Co. p.513-521. 
(ROSSMANN_69)

ROSSMANN, K. (1969). Point Spread Function, Line Spread Function and Modulation Transfer Function. Radiology, v.93, p.257-272.

(SCAFF_79)

SCAFF, L.A.M. (1979). Bases Físicas da Radiologia: Diagnóstico e Terapia. São Paulo, Sarvier.

(SCHIABEL_93)

SCHIABEL, H.; FRÈRE, A.F.; AZEVEDO MARQUES, P. M. (1993). The need for investigating the optical transfer functions in several field orientations for nonisotropic radiographic systems. Medical Physics, v.20, p.999-1005.

(SCHIABEL_97a)

SCHIABEL, H.; CURI, N.S.M.; FRÈRE, A.F. (1997). Novo dispositivo para aferição de $\mathrm{kVp}$ e dose em equipamentos de radiodiagnóstico. Radiologia Brasileira, v.30, p.257-262.

(SCHIABEL_97b)

SCHIABEL, H.; SANTOS, L.H.E.; OLIVEIRA, H.J.Q.; AZEVEDO MARQUES, P.M.; FRÈRE, A.F. (1997). Alignment device for determining the center of X-ray beam in radiographic systems quality assurance. In: WORLD CONGRESS ON MEDICAL PHYSICS AND BIOMEDICAL ENGINEERING (NICE97). Proceedings. Nice, France. Sep. 14-19.

(SCHIABEL_98)

SCHIABEL, H.; SILVA, M.A.; OLIVEIRA, H.J.Q.; AZEVEDO MARQUES, P.M.; FRÈRE, A.F. (1998). A computer simulation technique to preview the influence of the recording system on the image sharpness in mammography. In: SPIE PHYSICS OF MEDICAL IMAGING. Proceedings, v.3336. 
(SILVA_97)

SILVA, M.A. (1997). Um Método de Avaliação da Nitidez de Imagens Radiográficas por Simulação Computacional do Sistema de Registro. São Carlos. Dissertação (Mestrado) - Escola de Engenharia de São Carlos, Universidade de São Paulo.

(SPIEGLER_72)

SPIEGLER, P.; BRECKINRIDGE, W.C. (1972). Imaging of focal spots by means of the star test pattern. Radiology, v.102, p.679-684.

(STANTON_84)

STANTON, L.; VILLAFANA, T.; DAY, J.L.; LIGHTFOOT, D.A. (1984). Dosage Evaluation in Mammography. Radiology, v.150, p.577-584.

(TROUT_60)

TROUT, E.D.; KELLEY, J.P.; LUCAS, A.C. (1960). Determination of Half-Value Layer. Am. J. Roentgen., v.84, p.729-740.

(TROUT_62)

TROUT, E.D.; KELLEY, J.P.; LUCAS, A.C. (1962). The Second Half-Value Layer and the Homogeneity Coefficient. Am. J. Roentgen., v.87, p.574-584.

(TUREK_91)

TUREK, S.L. (1991). Ortopedia: princípios e sua aplicação. Editora Manole, vol. 3, p.1516-1518.

(UNSWORTH_70)

UNSWORTH, M.H.; GREENING, J.R. (1970). Theoretical Continuous and LCharacteristic X-Ray Spectra for Tungsten Target Tubes Operated at 10 to $50 \mathrm{kV}$. Physics in Medicine \& Biology, v.15, n.4, p.621-630. 
(WAGNER_90)

WAGNER, L.K.; ARCHER, B.R.; CERRA, F. (1990). On the Measurement of HalfValue Layer in Film-Screen Mammography. Medical Physics, v.17, n.6, p.989-997, Nov./Dec.

(WILKS_87)

WILKS, R.J. (1987). Principles of Radiological Physics. New York, Churchill Livingstone.

(WOLBARST_93)

WOLBARST, A.B. (1993). Physics of Radiology. Norwalk, Appleton \& Lange. 